Rechtsmedizin 2021 · 31:336-394

https://doi.org/10.1007/s00194-021-00521-5

( ) Springer Medizin Verlag GmbH, ein Teil von

Springer Nature 2021

\section{Q}

DEUTSCHE GESELLSCHAFT

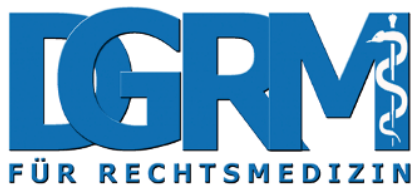

\section{Jahrestagung der Deutschen Gesellschaft für Rechtsmedizin}

\author{
München, 13.-16. September 2021
}

\title{
Inhaltsverzeichnis/Table of contents
}

\section{HISTORIE/HISTORY}

Historie V-H-1 bis V-H-3

\section{Vorträge/Lectures}

Klassische Rechtsmedizin V-RM-1 bis V-RM-12

Klinische Rechtsmedizin V-KI-1 bis V-KL-7

Toxikologie V-TX-1 bis V-TX-13

Forensische Molekularbiologie, Lehre V-FM-1 bis V-FM-10

Bildgebung, Identifikation V-BI-1 bis V-BI-9

Traumatologie Verkehr V-TR-1 bis V-TR-13

\section{Poster/Poster}

Klassische Rechtsmedizin P-RM-1 bis P-RM-42

Klinische Rechtsmedizin P-KL-1 bis P-KL-6

Toxikologie P-TX-1 bis P-TX-20

Forensische Molekularbiologie, Lehre P-FM-1 bis P-FM-7

Bildgebung, Identifikation P-BI-1 bis P-BI-5

Traumatologie Verkehr P-TR-1 bis P-TR-7 


\section{HISTORIE}

Historie - Vortragsprogramm

$\mathrm{V}-\mathrm{H}-1$ bis $\mathrm{V}-\mathrm{H}-3$

\section{$\mathrm{V}-\mathrm{H}-1$}

Von Meran bis München - Die Jahrestagungen der Deutschen Gesellschaft für gerichtliche Medizin/ Rechtsmedizin im Spiegel der Geschichte

K. Albrecht ${ }^{1,2}$, M. Windgassen ${ }^{3}$, S. Hartwig ${ }^{3}$

${ }^{1}$ Brandenburgisches Landesinstitut für Rechtsmedizin (BLR), Potsdam, Deutschland; ${ }^{2}$ Medizinische Hochschule Brandenburg (MHB), Neuruppin, Deutschland; ${ }^{3}$ Charité Universitätsmedizin Berlin, Institut für Rechtsmedizin, Berlin, Deutschland

Fragestellung: Die Ausrichtung von medizinischen Kongressen gehört zur guten Tradition wissenschaftlicher Fachgesellschaften, so auch der im Jahr 1904 gegründeten Deutschen Gesellschaft für gerichtliche Medizin/ Rechtsmedizin, welche ein Jahr später ihre erste Tagung in Meran abhielt. In diesem Beitrag sollen vor dem Hintergrund der Jubiläumstagung in München sowohl inhaltliche Aspekte als auch die spezifischen Probleme des Faches und die Tagungskultur bis zur 100. Tagung im Jahr 2021 erfragt werden.

Methode: Auf Grundlage von Tagungsberichten und Mitteilungen wurde eine Auswertung spezifischer Inhalte vorgenommen und die chronologische Entwicklung der Jahrestagungen der Fachgesellschaft von 1905 bis 2021 skizziert.

Ergebnisse: In seiner Geschichte erlebte das Fach insbesondere in Bezug auf seine Eigenständigkeit und freie Entfaltung, bereits vor Gründung der Fachgesellschaft Einschränkungen, da Fachgebiete wie die pathologische Anatomie als auch die öffentliche Gesundheitspflege ihre fachliche Stellung unterstrichen und zur eigenen Selbstständigkeit drängten. Die Jahrestagungen spiegeln die medizinische und wissenschaftliche Entwicklung von mehr als einhundert Jahren wider, welche insbesondere durch die politischen und gesellschaftlichen Strukturen des 20. Jahrhunderts, von bedeutenden medizinischen und technischen Fortschritten als auch von epochalen Katastrophen geprägt waren.

Diskussion: Seit Beginn des 20. Jahrhunderts mit Gründung der Fachgesellschaft und Ausrichtung der 1. Tagung entwickelte sich neben einer zunehmend breitgefächerten Versorgung insbesondere auch eine wissenschaftliche Struktur, welche zusammen mit integrierten Nachbardisziplinen die Grundlage zur Anerkennung und Etablierung eines eigenständigen Fachgebietes bildete.

Fazit: Der Vorsitzende der 1. Tagung, Fritz Strassmann aus Berlin, stellte im September 1905 fest: „Nichts aber wird mehr dazu dienen, unser Ansehen zu heben, der gerichtlichen Medizin die Achtung zu verschaffen, die ihr noch immer nicht gewährt wird, als die Steigerung unserer wissenschaftlichen Leistungen."

\section{$\mathrm{V}-\mathrm{H}-2$}

\section{Rechtsmedizin zwischen Deutschland Ost und West}

\section{Burkhard Madea}

Institut für Rechtsmedizin, Universitätsklinikum Bonn, Stiftsplatz 12, 53111 Bonn

Das Verhältnis zwischen Deutschland Ost und West war spätestens seit 1963 geprägt von „eisernem Vorhang und Mauer“. Aber offensichtlich waren die Grenzen für Rechtsmediziner volatiler als für die übrige Bevölkerung. Dies wird im Rahmen des hier nur begrenzt zu Verfügung stehenden

Bei den mit * gekennzeichneten Autoren handelt es sich um die präsentierenden Autoren.
Raumes dargestellt an drei Fällen, in denen ost- und westdeutsche Rechtsmediziner zusammenarbeiteten:

der Fall Hetzel, in dem es um die Frage ging: Todesursache Strangulation, speziell Drosseln oder handelte es sich bei allen Befunden um postmortale Artefakte.:

eine E605-Vergiftung, bei der aufgrund der Überlebenszeit von zwei Stunden von interessierter Seite eine homizidale Beibringung ausgeschlossen werden sollte.

ein Fall von venöser Luftembolie, in dem die vorbildlich erhobenen gasanalytischen Befunde zur Verifizierung der Diagnose zerredet wurden.

Die Zusammenarbeit verlief immer dann gut, wenn es neben finanziellen Aspekten, der Mehrung des eigenen Ruhms um die Schädigung von Kollegen ging. Ziel war nicht die möglichst lückenlose Aufklärung eines Sachverhaltes, sondern „ein dubium zu streuen“.

Im Fall Hetzel gelang dies deswegen, da der Gutachter im Grundverfahren entgegen dem schriftlichen Vorgutachten Aussagen getroffen hatte, die so nicht zu halten waren.

Der Fall Hetzel macht zudem deutlich, wie Wiederaufnahmeverfahren initiiert und unter welchem publizistischen Geleitschutz sie am Köcheln gehalten werden.

\section{$\mathrm{V}-\mathrm{H}-3$}

Die Tagungen der Gesellschaft für Gerichtliche Medizin der DDR zwischen 1967 und 1990 - Teil der deutschdeutschen Fachgeschichte?!

\section{J. Preuß-Wössner ${ }^{1}$, F. Zack², S. Hartwig ${ }^{3}$}

'Universitätsklinikum Schleswig-Holstein, Institut für Rechtsmedizin, Kiel, Deutschland; ${ }^{2}$ Universitätsmedizin Rostock, Institut für Rechtsmedizin, Rostock, Deutschland; ${ }^{3}$ Charité - Universitätsmedizin Berlin, Institut für Rechtsmedizin, Berlin, Deutschland

Einleitung/Fragestellung: Die Existenz zweier deutscher Staaten über 40 Jahre brachte nicht nur eine Teilung der Menschen und des Landes mit sich, sondern auch eine zumindest strukturelle Teilung der akademischen Welt und der Fachgesellschaften. Die Gesellschaft für Gerichtliche Medizin der DDR (GFGM) wurde 1967 gegründet und 1990 aufgelöst. Historisch führt die erst gesamt- und dann westdeutsche Fachgesellschaft (DGRM) nach der Wiedervereinigung die Tradition der 1905 in Meran gegründeten Deutschen Gesellschaft für gerichtliche Medizin fort. Zur 100. Jahrestagung der DGRM sollen auch die 10 Jahrestagungen der Fachgesellschaft der DDR gewürdigt werden.

Methode: Auf Grundlage von Tagungsberichten, Programmheften, Mitteilungen des Vorstandes der GFGM, publizierten Tagungsbeiträgen und Mitteilungen von Zeitzeugen wurden die Tagungen der GFGM in ihrer Chronologie erfasst und bezogen auf die Geschichte der beiden deutschen Fachgesellschaften und das gesellschaftliche Zeitgeschehen beleuchtet.

Ergebnisse: Nach ersten Symposien und Tagungen der Gerichtsmediziner der DDR ab 1957 fand die erste Tagung der Gesellschaft für Gerichtliche Medizin der DDR bereits im Gründungsjahr der GFGM 1967 statt. Bis 1990 wurden 10 Jahrestagungen und eine deutlich größere Zahl an Regionaltagungen und Arbeitstagungen der Arbeitsgemeinschaften der GFGM auch mit internationaler Beteiligung durchgeführt. Die Themen der teils mehrtägigen akademischen Austausche bezogen das gesamte Spektrum der gerichtlichen Medizin und der naturwissenschaftlichen Kriminalistik ein. Diskussion: Wenngleich gegenseitige Besuche der Tagungen in Ost- und Westdeutschland durch staatliche Vorgaben für beide Seiten erschwert waren, bestanden ein Austausch zwischen Vertretern beider Fachgesellschaften über die gesamte Zeit der Existenz der GFGM. Eine erwogene Neugründung einer gesamtdeutschen Fachgesellschaft scheiterte 1990 an formalen Gründen.

Fazit: Rückblickend resümierte Hansjürg Strauch (1940-2007) 2004:

„Die gerichtliche Medizin war in der DDR ein angesehenes Fach und zu keiner Zeit in ihrer Existenz gefährdet." 


\section{VORTRÄGE}

\author{
Klassische Rechtsmedizin - Vortragsprogramm \\ V-RM-1 bis V-RM-12
}

\section{V-RM-1 \\ Befunde der Spezialambulanz für plötzlichen Herztod und familiäre Arrhythmiesyndrome am Institut für Rechtsmedizin in Frankfurt am Main - das erste Jahr im Rückblick}

Britt M. Beckmann', Stefanie Scheiper-Welling ${ }^{1,6}$, Constanze Niess', Franziska Holz', Christoph G. Birngruber', Elise Gradhand ${ }^{2}$, Lars Bodammer ${ }^{3}$, Maria Gonzalez ${ }^{4}$, Cora Wunder', Robert Kopetschke ${ }^{7}$. Dirk Hillebrand ${ }^{8}$, Klaus Kettering ${ }^{5}$, Julia Erath-Honold ${ }^{5}$, Felix Operhalski ${ }^{5}$, Mattias Kettner', Tina Jenewein ${ }^{1,6}$, Marcel A. Verhoff', Silke Kauferstein ${ }^{1}$

'Institut für Rechtsmedizin, Universitätsklinikum Frankfurt, Goethe-Universität, Frankfurt am Main, Deutschland; ${ }^{2}$ Dr. Senckenbergisches Institut für Pathologie, Universitätsklinikum Frankfurt, Goethe-Universität, Frankfurt am Main, Deutschland; ${ }^{3}$ Praxis für Kardiologie Frankfurt-Sachsenhausen, Frankfurt am Main, Deutschland; ${ }^{4}$ Kinderherzzentrum und Zentrum für angeborene Herzfehler der Justus-Liebig-Universität, Universitätsklinikum Gießen, Gießen, Deutschland; ${ }^{5}$ Medizinsche Klinik III/Kardiologie, Universitätsklinikum Frankfurt, Goethe-Universität, Frankfurt am Main, Deutschland; ${ }^{6}$ DRK-Blutspendedienst Baden-Württemberg - Hessen, Abteilung Molekulare Diagnostik; ${ }^{7}$ Praxis für Kardiologie, Ahrensfelde, Deutschland; ${ }^{8}$ Praxis für Kinderkardiologie, Pinneberg, Deutschland

Einleitung: Bei plötzlichen ungeklärten Todesfällen in jungem Alter hat die Klärung der Todesursache eine erhebliche Bedeutung für die Prävention weiterer, möglicherweise vermeidbarer, plötzlicher Todesfälle. Wenn sich nach makroskopischem Obduktionsbefund sowie ergänzenden toxikologischen und histologischen Untersuchungen keine Todesursache ergibt, sollte überprüft werden, ob ein hereditäres kardiales Arrhythmiesyndrom ursächlich ist bzw. sich bestimmte Risikomarker oder -konstellationen für maligne Herzrhythmusstörungen erkennen lassen.

Methode: In unserer Ambulanz werden Ratsuchenden eine Beratung und Abklärung im Hinblick auf ein mögliches hereditäres Arrhythmiesyndrom angeboten. In diesem Rahmen wird bei Verstorbenen die Durchführung einer molekularen Autopsie ermöglicht und es werden medizinische Vorbefunde der Verstorbenen beurteilt, sofern diese vorhanden sind.

Ergebnisse: Unsere bisherigen Befunde sind heterogener als erwartet und bislang beschrieben. Insbesondere zeigten sich überraschenderweise bislang in unserem Kollektiv seltener verlängerte QT-Zeiten im EKG als kurze QT-Zeiten. Es ist möglich, dass es sich bei einer kurzen QT-Zeit um einen Risikomarker für maligne Arrhythmien handelt, selbst wenn die derzeitigen Diagnosekriterien für das Vorliegen eines Short-QT-Syndroms nicht vollständig erfüllt werden, ähnlich wie es sich bei einem verlängerten QT-Intervall um einen anerkannten Risikomarker handelt.

Diskussion: Bei früheren Daten, welche aus der Sicht einer der Kardiologie zugehörigen Spezialambulanz für Herzgenetik und familiäre Arrhythmiesyndrome am LMU-Klinikum erhoben wurden, zeigte sich ein deutlich höherer Anteil von Verstorbenen mit der Diagnose eines Long-QT-Syndroms oder einer katecholaminergen polymorphen ventrikulären Tachykardie. Dabei könnte es sich um eine andere Vorauswahl des Kollektives gehandelt haben.

Fazit: Bei unserer Arbeit zeigt sich die Bedeutung der Zusammenschau aller Befunde unter Berücksichtigung von Obduktionsbefunden, klinischen Vorbefunden und kardiologischer Untersuchung der Angehörigen in einem spezialisierten Team.
V-RM-2

Differential diagnosis of hemorrhage of traumatic origin, cerebral infarction of ischemic and hemorrhagic origin by diffuse tomography of fluctuations of linear dichroism

M. Garazdiuk, O. Pavliukovych, V. Bachynskyi, O. Garazdiuk

Higher State Educational Establishment of Ukraine, Forensic Medicine Department Chernivtsi, Ukraine

Introduction: One of the debatable issues in forensic traumatology is the differential diagnosis of hemorrhages in the human brain (HB) of traumatic and non-traumatic genesis. Differential diagnosis of the cause of death from ischemic cerebral infarction (ICl), hemorrhages of traumatic (HTG) and non-traumatic (HNG) genesis eliminates the violent nature of death Material and methods: native sections of brain taken from 105 in the case of: death from coronary heart disease- 25 native sections (group 1-control); HTG-30 sections (group 2), ICl-25 sections (group 3), HNG-25 sections (group 4). Measurement of the values of the distribution of coordinate parameters of polarization at the points of microscopic images was performed at the location of the standard Stokes polarimeter.

Results: Analysis of the topographic and statistical structure of polarization-reconstructed diffuse maps of fluctuations of linear dichroism (FLD) revealed:

clear differences in the topographic structure of all polarization-reproduced diffuse maps of FLD of optically anisotropic absorption by fibrillar networks of histological sections of HB from groups 1-4;

maximum differences in the value of the average (statistical moment 1 $\left.\left(S M_{1}\right)\right)$, scatter of random values of dispersion $\left(\mathrm{SM}_{2}\right)$, significant asymmetry $\left(\mathrm{SM}_{3}\right)$ and kurtosis $\left(\mathrm{SM}_{4}\right)$, which characterize the histograms of the distributions of the FLD of fibrillar networks of HB samples from control and experimental groups.

The detected data of diffuse tomography of polarization reproduction of maps of the magnitude of FLD show a statistically significant difference $\left(p_{i-1 ; 2 ; 3 ; 4}<0,05\right)$ between the average values of all statistical moments of 1-4 orders for differentiation between control and experimental groups. Conclusions:. The use of the technique of diffuse tomographic reproduction of maps of fluctuations of linear dichroism provided the following level of parameters of operational characteristics of force (sensitivity, specificity and balanced accuracy) of method:

good $\left(\mathrm{SM}_{1}\right.$ and $\mathrm{SM}_{2}-85-92 \%$ scatter of values of fluctuations of linear dichroism) and excellent (statistical moments of higher orders SM3; SM498-100\%) balanced differentiation of a set of representative samples of histological sections of the brain between groups 1-2,3,4;

excellent $\left(\mathrm{SM}_{3} ; \mathrm{SM}_{4}-95-97 \%\right)$ balanced accuracy between groups $2-3$, and also intergroup differentiation between groups 2-4;

$\operatorname{good}\left(\mathrm{SM}_{3} ; \mathrm{SM}_{4}-90-92 \%\right)$ balanced accuracy of intergroup differentiation of groups 3-4.

\section{V-RM-3}

Die Stärkung des Rechtsstaates in Mexiko - ein rechtsmedizinischer Beitrag

\section{CG Birngruber ${ }^{1}, \mathrm{M} \mathrm{Murck}^{2}, \mathrm{~F} \mathrm{Holz}^{1}$}

'Institut für Rechtsmedizin, Klinikum der Goethe-Universität, Frankfurt am Main/ Deutschland; ${ }^{2}$ Gesellschaft für Internationale Zusammenarbeit (GIZ), Projekt „Stärkung des Rechtsstaats in Mexiko", Mexiko Stadt/Mexiko

Hintergrund: Mexiko befindet sich in einer tiefgreifenden humanitären Krise und die Belastung des sozialen Friedens ist vergleichbar mit PostKonfliktgebieten. Mehr als 35.000 Tötungsdelikte jährlich belasten Gesellschaft, Rechtsstaat und rechtsmedizinische Institute. Darüber hinaus gelten aktuell 80.000 Personen als vermisst und 39.000 Leichen als nicht identifiziert. Es ist anzunehmen, dass sich zahlreiche verschwundene Personen unter den bisher nicht identifizierten Verstorbenen befinden. 
Projekt: Mexiko steht vor großen Herausforderungen bei der Organisation und Koordination seines Sicherheits- und Justizsystems. Das vom Auswärtigen Amt der Bundesrepublik Deutschland finanzierte GIZ-Projekt "Stärkung des Rechtsstaats in Mexiko" hat das Ziel, über die Identifizierung unbekannter Verstorbener zur Stärkung des Rechtsstaates in Mexiko beizutragen.

Rechtsmedizinische Arbeit: Von Oktober 2019 bis März 2020 waren die beiden rechtsmedizinischen Autoren in Mexiko für das Projekt tätig, um zusammen mit Kollegen vor Ort die Bearbeitung von Vermisstenfällen und den Identifizierungsprozess zu analysieren und Lösungsstrategien zu erarbeiten. Der Einsatz erfolgte in enger Abstimmung mit der Deutschen Botschaft und im Austausch mit (inter)nationalen, am Identifizierungsprozess beteiligten staatlichen und nicht-staatlichen Organisationen.

Ergebnisse: Die rechtsmedizinischen Institute vor Ort arbeiten am Rand ihrer Belastbarkeit. Die mexikanische Zivilgesellschaft ist traumatisiert und mit ihr leidet das Vertrauen in die Arbeit der Institute und Staatsanwaltschaften. Die Arbeitsbelastung, die Vielzahl von Akteuren bei der Bearbeitung von Vermisstenfällen und die komplizierte interinstitutionelle Zusammenarbeit erschweren die Umsetzung pragmatischer Lösungsansätze.

Fazit und Ausblick: Über die Identifizierung unbekannter Verstorbener den Angehörigen Gewissheit zu geben, zu einer sozialen Befriedung Mexikos und zur Stärkung des Vertrauens in den Rechtsstaat beizutragen sind überaus wichtige, jedoch nicht kurzfristig erreichbare Ziele. Um die Arbeit der Rechtsmedizin als Bestandteil eines funktionierenden Rechtsstaates weiter zu unterstützen, wird aktuell im Rahmen einer Kooperation zwischen der GIZ und dem DAAD der akademische Austausch zwischen Rechtsmedizinern in Mexiko und Deutschland gefördert.

\section{V-RM-4 \\ Retrospektive Auswertung stromassoziierter Todesfälle am Institut für Rechtsmedizin München von 1996 bis 2020}

\section{Eppler M, Prinz L, Pankratz H}

Institut für Rechtsmedizin der Universität München

Die Anzahl letaler Stromunfälle ist gemäß Daten des VDE in den letzten Dekaden, vor allem aufgrund der Verbesserungen in der Gebäudeinstallation (FI-Schalter), rückläufig gewesen. Verstorbene infolge Strombeibringung in suizidaler Absicht sind immer wieder im rechtsmedizinischen Sektionsportfolio vertreten, Homizide durch Applikation technischer Elektrizität gelten hingegen als Rarität.

Vor dem Hintergrund der einschlägigen Literatur werden die Ergebnisse einer aktuell laufenden Auswertung der Stromtodesfälle der letzten 25 Jahre aus dem Obduktionsgut des IRM München, vor allem im Hinblick auf die Fallkonstellation (Unfall, Suizid, Homizid) und die technischen Gegebenheiten der Spannungsübertragung (spannungsführender Gegenstand, Spannungsbereich) sowie den Stromweg, dargestellt und diskutiert.

\section{V-RM-5 \\ Welche Farbe hat Mekonium bei der Autopsie?}

Jan-Peter Sperhake ${ }^{1}$, Stefanie M. Hauck², Ann Sophie Schröder ${ }^{1}$, Johanna Preuß-Wössner ${ }^{3}$

${ }^{1}$ Institut für Rechtsmedizin, Universitätsklinikum Hamburg-Eppendorf; ${ }^{2}$ Abteilung Proteinanalytik, Helmholtz Zentrum München; ${ }^{3}$ Institut für Rechtsmedizin, Universitätsklinikum Schleswig-Holstein

Einleitung: Mekonium, auch Kindspech genannt, ist bei neugeborenen Kindern der übliche Inhalt des Dickdarmes, der nach der Geburt in den ersten zwei Lebenstagen als schwarz-grünliche, glänzende Masse ausgeschieden wird. Ob Mekonium auch eine andere Farbe aufweisen kann, ist bislang nicht hinreichend untersucht worden.
Falldarstellung: Eine Frau wurde vor dem Landgericht die Tötung ihres neugeborenen Kindes vorgeworfen. Die Schwangerschaft habe sie verheimlicht. Das Kind war fäulnisverändert in einer verschlossenen Tüte im Freien aufgefunden worden. Die Mutter machte nachvollziehbar eine Geburt 10 bis 11 Monate vor dem Auffinden geltend, wobei die Lagerungsbedingungen des Leichnams unklar blieben. Das Kind habe nach der Geburt keine Lebenszeichen gezeigt.

Bei Fäulnis war mit den zur Verfügung stehenden diagnostischen Methoden nicht mehr feststellbar, ob das Kind nach der Geburt gelebt hatte. Der Magen war bereits weitgehend durch Autolyse und Fäulnis zerstört und insofern nicht beurteilbar. Auffallend war, dass der gesamte Dickdarm mit voluminösem, goldgelbem Inhalt gefüllt war und kein typisches Mekonium enthielt. Die Obduzenten haben dies zunächst als Hinweis dafür gewertet, dass das Kind nach der Geburt bereits gefüttert worden sein müsste und das Mekonium bereits abgesetzt hatte. Diese Schlussfolgerung wurde in Zweifel gezogen und war Gegenstand einer Befragung und Erörterung vor dem Landgericht. Die Mutter wurde wegen Totschlags zu einer Haftstrafe verurteilt.

Diskussion: In der sehr alten rechtsmedizinischen Literatur (z. B. Krahmer, 1857) wird erwähnt, dass Mekonium bei Totgeborenen in den oberen Dickdarmabschnitten hellgelb bis gelbgrün sein kann. 1950 wird erstmalig von Ponsold in seinem Lehrbuch der Gerichtlichen Medizin erwähnt, dass sich die Farbe des Mekoniums bei Totgeborenen durch Fäulnis von schwarz-grün in goldgelb umwandeln kann, was von späteren Autoren übernommen worden ist. Vorgestellt werden 1) die Ergebnisse einer Literaturrecherche, 2) die Ergebnisse einer Recherche eigener Obduktionsfälle definitiv totgeborener Kinder im Hinblick auf den Dickdarminhalt und dessen Farbe, 3) das Resultat kontrollierten Faulenlassens von Kindspech/ Darminhalt/Darmpech (von Tieren) mit und ohne Darmumhüllung, sowie 4) die Ergebnisse einer vergleichenden Proteomanalyse aus Kindspech, Milchstuhl und einer Stuhlprobe des Kindes aus dem gegenständlichen Gerichtsfall.

\section{V-RM-6}

\section{Identitätsverschleierung durch Manipulation von Fingerkuppen - Untersuchungen zur Entfernung von Klebesubstanzen}

Ann Sophie Schröder', Bettina Böge', Angelika Lodwig², Klaus Püschel', Benjamin Ondruschka', Sven Anders'

1 Institut für Rechtsmedizin, Universitätsklinikum Hamburg-Eppendorf, Hamburg, Deutschland; ${ }^{2}$ Behörde für Inneres, Polizei Hamburg, LKA 145, Hamburg, Deutschland

Hintergrund und Fragestellung: Das Aufbringen von Klebesubstanzen auf die Fingerkuppen zur Identitätsverschleierung kam in jüngerer Vergangenheit, z. B. bei Umweltaktivisten, vor. Nachdem das Entfernen der Klebesubstanzen für die erkennungsdienstliche Behandlung innerhalb einer vertretbaren Zeit durch die Polizei wiederholt nicht gelungen war, wurden in Hamburg mehrfach Rechtsmediziner für die Durchführung dieser Maßnahme angefordert. Es stellte sich somit die Frage nach einem geeigneten, für den Probanden gesundheitlich vertretbaren und für die Polizei praktikabel anwendbaren Lösungsmittel und Reinigungsverfahren. Methode: Es wurden Versuchsreihen zur Entfernung verschiedener Klebesubstanzen, die nach Angaben der Polizei auch real zur Verschleierung der Identität auf den Fingerkuppen aufgebracht worden waren, durchgeführt und das Ergebnis mittels Fingerabdruckscanner überprüft. Das Verfahren wurde auf Anwendbarkeit für die Polizei bewertet.

Ergebnisse: Das Entfernen von Kraftkleber, Nagellack, Bitumen, Glitter Glue und Vulkanisierer gelang innerhalb weniger Minuten mittels Wasser mit Spülmittel und durch Abziehen oder Abreiben. Das Entfernen der nach Angaben der Polizei gebräuchlichsten Substanz Sekundenkleber gelang unter Verwendung eines handelsüblichen acetonhaltigen Nagellackentferners innerhalb von einigen Minuten. Das Verfahren zeigte sich als schmerzlos, Hautirritationen entstanden nicht. Die Geruchsentwicklung war vertretbar. 
Diskussion und Fazit: Es werden Versuche zur Entfernung von Klebesubstanzen auf den Fingerkuppen und die daraus abgeleiteten Reinigungshinweise vorgestellt. Einige Klebesubstanzen lassen sich durch einfaches Waschen und simple mechanische Manipulation entfernen. Das Entfernen von Sekundenkleber auf den Fingerkuppen kann durch acetonhaltigen Nagellackentferner erfolgen. Eine Gesundheitsgefährdung für Probanden und Anwender ist bei topischer Anwendung in einem durchlüfteten Raum nicht zu erwarten. Das Verfahren kann somit durch Polizeibeamte im Bedarfsfall zur Anwendung kommen.

\section{V-RM-7 \\ Nachweisbarkeit und Infektiosität von SARS-CoV-2 nach Exhumierung}

S. Plenzig', F. Holz', D. Bojkova'2, M. Kettner', J. Cinatl'2, M. A. Verhoff', C.G. Birngruber', S. Ciesek², H. F. Rabenau ${ }^{2}$

'Institute of Legal Medicine, Goethe University, University Hospital Frankfurt, Kennedyallee 104, 60596 Frankfurt am Main, Deutschland; ${ }^{2}$ Institute of Medical Virology, Goethe University, University Hospital Frankfurt, Paul-Ehrlich-Straße 40, 60596 Frankfurt am Main, Deutschland

Einleitung: Der Nachweis von SARS-CoV-2 nach Exhumierung eines Leichnams kann beispielsweise bei nachträglich angezeigtem Behandlungsfehlervorwurf Bedeutung erlangen. Weder über den möglichen Nachweiszeitraum viraler Nukleinsäure (z. B. per RT-qPCR) noch über die potenzielle Infektiosität des Virus nach Exhumierung existieren hinreichend Daten in der Literatur.

Kasuistiken: In zwei Fällen mit je etwa 4 Monaten zwischen Eintritt des Todes und Exhumierung und einem nahezu identischen Zeitpunkt des Todeseintritts wurden diese Parameter in der folgenden Studie untersucht. Der Nachweis per SARS-CoV-2-RT-qPCR in Abstrichen der Lungen und des Oropharynx war in beiden Fällen mit $C_{t}-$ Werten um 30 trotz mäßiggradigen Verwesungserscheinungen möglich. Proben der Haut um Mund und Nase sowie an der Innenseite der Leichensäcke, entnommen zur Abschätzung des Infektionsrisikos von an der Exhumierung Beteiligter, waren in der PCR negativ. Eine Infektiosität in der Zellkultur war weder bei den Lungen- noch den Oropharynxabstrichen feststellbar. In einem Fall lag ein positiver PCR-Befund eines Oropharynx-Abstrichs vom Todestag vor, der mit dem PCR-Ergebnis des postmortalen Oropharynx-Abstrichs verglichen werden konnte und nahezu identische $C_{\mathrm{t}}$-Werte zeigte.

Fazit: Dies belegt eindrücklich, wie stabil die virale RNA im intakten Leichnam ist. Allerdings waren die Temperaturverhältnisse über die Zeit im Erdgrab (Wintermonate in Mitteleuropa) günstig. Der Nachweis einer SARS-CoV-2-Infektion kann demzufolge an Verstorbenen nach Exhumierung sogar nach Monaten im Erdgrab noch gelingen.

\section{$\mathrm{V}-\mathrm{RM}-8$ \\ Secondary Cardiomyopathy: Wastebasket Diagnosis In Sudden Cardiac Death In Young Adults}

Siamionau V.V., Tsiatsiuyeu A. M.

Belarussian State Medical University, Minsk, Belarus

Introduction: Autopsy of sudden cardiac death $(\mathrm{SCD})$ in young adults often fails to reveal evident morphological substrate to estimate definite cause of death. In such cases some medico-legal experts may consider secondary cardiomyopathy as underline cause of death.

The aim of our study was to examine morphological changes of the hearts in cases of SCD in young adults when secondary cardiomyopathy was determined as a cause of death.

Methods: We have analyzed 207 cases of SCD of men in the age of 18-45 years $(\mathrm{Me}=39.7)$. Secondary cardiomyopathy was established as a cause of death in 52 cases.

The mean hearts measurement values were the following: weight $387 \pm 95 \mathrm{~g} \quad(\mathrm{Me}=360 \mathrm{~g})$; length $12,2 \pm 1,3 \mathrm{~cm} \quad(\mathrm{Me}=12 \mathrm{~cm})$; width
$10,3 \pm 1,2 \mathrm{~cm} \quad(M e=10 \mathrm{~cm})$; thickness $5,4 \pm 1,3 \mathrm{~cm} \quad(M e=5 \mathrm{~cm})$; free right ventricle wall $0,2 \pm 0,07 \mathrm{~cm} \quad(M e=0,2 \mathrm{~cm})$; free left ventricle wall $1,4 \pm 0,3 \mathrm{~cm} \quad(M e=1,5 \mathrm{~cm})$; interventricular septum $1,3 \pm 0,3 \mathrm{~cm}$ $(\mathrm{Me}=1,4 \mathrm{~cm})$. No pathological changes of coronary arteries were found. $\mathrm{H} \& \mathrm{E}$ and Lee's stains were used for histological examination.

Results: In all cases, a combination of foci of uneven cardiomyocytes hypertrophy and atrophy, mild or moderate edema of the myocardial stroma and perinuclear lipofuscinosis, stromal and perivascular lipomatosis, and mild focal perivascular sclerosis were revealed.

Discussion: Thus, after excluding the violent death and significant pathology of inner organs and organ systems the secondary cardiomyopathy seems a diagnosis of "rescue option". The only justification for diagnosis of secondary cardiomyopathy was the results of histological examination of non-mapped fragments of the myocardium and without conduction system examination. The revealed noncritical (nonfatal) morphological changes of the heart do not explain the cause of SCD and only in some cases they indicated to the arrhythmogenic thanatogenesis.

In our opinion SCD in the reviewed cases might be caused by polyetiologic syndrome of spontaneous electrical instability of the myocardium. The possible causes of this syndrome may be congenital pathology of conductive system, genetic channelopathies, myocardial contractile proteins structure changes on the background of excessive physical exertion, emotional stress, acute alcohol and/or drug intoxication, metabolic disorders and fluctuations in the hormonal background, leading to electrolyte changes in ionic balance and impaired coronary blood flow with the development of myocardial hypoxia.

Conclusion: An integrated approach to the medico-legal diagnostics of SCD requires including examination of medical records, family history and standardized autopsy with revealing or excluding the above mentioned possible causes of SCD in young adults.

\section{V-RM-9 \\ Autopsy Heart Dissection In Case Of Sudden Death In Young Adults}

Tsiatsiuyeu A. M., Siamionau V.V.

Belarussian State Medical University, Minsk, Belarus

Introduction: From $10 \%$ to $45 \%$ of sudden death in the young is autopsy-negative. When an autopsy is undertaken, not all postmortem examinations are equal. Published guidelines have been established in Europe, Australia, Korea. Yet, even with a standardized and thoughtful approach to the autopsy, almost half of sudden unexpected deaths are still without an identifiable cause. High workload for medico-legal experts in some countries, including Belarus, and predominant focus on violent death led to forensic medicine specialists have not given sudden unexpected death the attention it deserves. Basically, it is a paradigm "to exclude criminal death" but not to make a precise diagnosis. Banner J. et al. (2021) recognize important deficiencies in current autopsy practice in Europe including lack of training and expertise in cardiovascular pathology and a lack of knowledge, or failure of application, of anatomical guidelines for sudden cardiac death autopsies.

Methods: We have compared several guidelines and published suggestions for heart dissection technique in cases of sudden death in young adults. The aim of heart dissection is to reveal gross pathological changes or to make such a systematic and standardized heart examination which allows to reveal grossly non visible pathological changes.

The basic steps of heart dissection are the following:

Coronary arteries examination including searching for their anomalies; Transversal "slicing" the heart from the apex until the left anterior papillary muscle is visible;

Opening the right atrium preserving sinoatrial node region;

Opening the right ventricle on the posterior wall parallel to septum;

Opening the right ventricle outflow tract;

Opening the left atrium;

Opening the left ventricle by incision between the papillary muscles; 
Opening the left outflow tract continuing with incision through the commissure between the right and left cusps of the aortal valve;

Weighing of the heart;

Taking samples for histological examination (grossly abnormal areas of myocardium, valves and coronary arteries; mapped transmural blocks of the 4 regions of the left ventricle; right ventricle outflow and anterior free wall [a strip of myocardium, extending along the anterior wall of the RV from the pulmonary valve to the apex]; fragment of the left atrium with the SA node; fragment with the region of the AV node).

Discussion/Conclusion: In the diagnosis of inherited heart disease, molecular study may take primacy in achieving a final diagnosis. The described technique for heart sectioning is quite universal and provides a complete study of the coronary vessels, myocardium, valves, and the elements of the cardiac conduction system. After such a dissection it is easy to restore the anatomical relationships of the heart structures and perform a re-examination.

\section{V-RM-10}

\section{The involvement of CX3CR1 in stress-induced thymic atrophy}

T. Kondo, Y. Ishida, Y. Kuninaka, M. Nosaka, H. Yamamoto, E. Shimada, M. Kawaguchi, A. Kimura, F. Furukawa, N. Mukaida

Department of Forensic Medicine, Wakayama Medical University, Wakayama, Japan

Introduction: The thymus is a specialized primary lymphoid organ of the immune system. Within the thymus, T cells mature. T cells are critical to the adaptive immune system, where the body adapts specifically to foreign invaders. The thymus continues to grow between birth and puberty and then begins to atrophy, called thymic involution. The process accelerates after puberty, thymus decreases both in size and activity, and the tissue of the thymus is primarily replaced with adipose tissue. It was reported that thymus severely involuted in abused infants and children. However, the mechanism of thymic involution still remains investigated. In the present study, we examined the pathophysiological roles of CX3CR1, a chemokine receptor, in stress-induced thymic atrophy.

Materials and methods: Specific pathogen-free 8- to 10-week-old male $\mathrm{C} 57 \mathrm{BL} / 6$ and $\mathrm{C} \times 3 \mathrm{Cr}^{-1-}$ mice were used in the present study. Mice were immobilized individually in well-ventilated cylindrical wire mesh restrainers sized $12 \mathrm{~cm} \times 3 \mathrm{~cm}$ that were closed off at both ends. They were restrained for $1 \mathrm{~h}$ daily followed recovery, and this procedure were repeated the following 2 days. Subsequently, the thymus was taken and subjected to the following analyses.

Results and discussion: There was no significant difference in thymus weight between unrestrained WT and $\mathrm{C}_{3} \mathrm{Cr}^{-/-}$mice. When WT mice were restrained, the thymuses significantly involuted. However, in $\mathrm{C}_{3} \mathrm{Cr}^{-1-}$ mice treated with the same manner, the involution of thymus was significantly suppressed. In the next series, we examined apoptotic cells in the thymus of WT and $\mathrm{Cx}_{3} \mathrm{Cr}^{-1-}$ mice. Restrain stress significantly induced the apoptosis in the thymic cells of WT mice. On the contrary, the absence of CX3CR1 significantly suppressed apoptosis of thymic cells. These observations implied that the absence of CX3CR1 resisted stress-induced thymic atrophy. Thus, CX3CR1-mdiated signals would promote thymic involution induced by restrain stress. From the forensic aspects, CX3CR1would be a key molecule for diagnosing abuse in infants and children.
V-RM-11

\section{Unilateral tonsillitis as a cause of sudden and} unexpected death

\author{
J. Šidlo ${ }^{1,2}$, J. Šikuta ${ }^{1,2}$, L. Mikuláś ${ }^{1,2}$, H. Šidlová ${ }^{3,4}$ \\ 'Institute of Forensic Medicine, Faculty of Medicine, Comenius University in Bratislava, \\ Bratislava, Slovak republic; ${ }^{2}$ Institute of Forensic Medicine, Health Care Surveillance \\ Authority, Bratislava, Slovak republic; ${ }^{3}$ nnstitute of Pathology, Faculty of Medicine, Slovak \\ Medical University in Bratislava, Bratislava, Slovak republic; ${ }^{4}$ Institute of Pathology, St. \\ Elisabeth Cancer Institute, Bratislava, Slovak republic
}

Introduction: Tonsillitis is an infectious disease characterized primarily by inflammation of the tonsils. It is most often of viral or bacterial origin. Enlargement or infection of the tonsils, due to their location in the upper gastrointestinal tract, can be a source of several complications and can have a direct effect on the size of the airway lumen. At present, most acute tonsillitis is not associated with serious consequences, however, we can rarely encounter unexpected fatalities in forensic practice. Forensic analysis in such cases is necessary to determine the mechanism of death.

Case report: The authors present the case of a 47-year-old man with no history of health problems who suffocated after a short episode of respiratory distress. Autopsy revealed left-handed necrotizing tonsillitis, with an unaffected palate, with massive oedema and reactive inflammation of the uvula, laryngeal flap, and surrounding soft tissues causing significant airway narrowing and signs of suffocation. No other serious pathological changes were detected. Toxicological-chemical examination of biological materials did not reveal the presence of ethanol or other foreign toxicologically significant substances.

Conclusion: This is a very rare case of sudden death, which points to the need for thorough resection of Waldeyer ring tissues and deep neck structures to correctly determine the immediate cause and mechanism of death in cases of suspected death due to pathological changes in the throat.

\section{V-RM-12}

\section{Gekocht oder nicht gekocht? - Zum Nachweis einer Bestattung more teutonico über D-Asparaginsäure in Knochenprotein}

\section{Schröder', L. König' ${ }^{1}$ A. Reckert ${ }^{1}$, H. Fangerau' ${ }^{2}$, S. Ritz-Timme ${ }^{1}$}

'Institut für Rechtsmedizin, Universitätsklinikum Düsseldorf, Düsseldorf, Deutschland; ${ }^{2}$ Institut für Geschichte, Theorie und Ethik der Medizin, Heinrich-Heine-Universität, Düsseldorf, Deutschland

Einleitung: Mittelalterliche Quellen belegen, dass es um das 12./13. Jahrhundert eine Bestattung more teutonico (,auf deutsche Art") für hochgestellte Personen gab, die fern der Heimat verstorben waren und in ihrer Heimat bestattet werden sollten. Eine Überführung des Leichnams über hunderte Kilometer war - nicht zuletzt auch wegen der zunehmenden Leichenveränderungen - kaum möglich, sodass der Leichnam oftmals „in Kesseln gekocht" wurde „bis sich das Fleisch gelöst" habe. Die Knochen wurden anschließend zurück in die Heimat überführt. Über die genaue Methode des Kochens (Dauer, Hitze etc.) und mögliche weitere konservatorische Schritte ist wenig bekannt. Bada et al. (1989) wies in Knochen von Lothar I. D-Asparaginsäuregehalte nach, die deutlich über den Werten lagen, die in Knochen zweier anderer Individuen festgestellt wurden, die in derselben Zeit starben, aber sicher nicht erhitzt worden waren. Diese Befunde wurden als Beweis dafür interpretiert, dass die Knochen Lothars, erheblicher Hitze ausgesetzt waren, sein Körper also im Rahmen einer Bestattung more teutonico gekocht wurde. Aus Versuchen mit Tierknochen wurde weiter abgeleitet, dass Lothars Knochen $6 \mathrm{~h}+/-30$ min. gekocht worden seien; dabei stützen sich Bada et al. (1989) nicht auf eigene Untersuchungen. Der beschriebene Ansatz ist hochinteressant, wurde aber nicht weiter untersucht und nie wieder eingesetzt.

Methode: Anlässlich einer Anfrage eines Museums wurde dieser Ansatz zur Objektivierung einer Bestattung more teutonico durch systematische 
Untersuchungen überprüft. Unter Be-rücksichtigung mittelalterlicher Beschreibungen des Prozederes der Behandlung von Leichen wurden „Kochversuche" durchgeführt und die Kinetik der hitzebedingten D-Asparaginsäure-Akkumulation beschrieben. Nach Optimierung soll der Ansatz ggf. genutzt werden, um die Frage zu klären, ob auch Otto, Herzog von Schwaben und Bayern, dieser Prozedur unterworfen wurde; er starb am 31. Oktober 982 in Lucca und wurde später in der Aschaffenburger Stiftskirche beigesetzt.

\section{Klinische Rechtsmedizin - Vortragsprogramm VORTRÄGE V-KI-1 bis V-KI-7}

\section{V-KI-1 \\ Völkerstrafrecht: die rechtsmedizinische Bewertung der "Caesar-Files"}

Markus A. Rothschild', Martin Hellmich², Sibylle Banaschak'

'Institut für Rechtsmedizin, Medizinische Fakultät, Universität zu Köln; ${ }^{2}$ Institut für Medizinische Statistik und Bioinformatik, Medizinische Fakultät, Universität zu Köln

Fragestellung: Die Untersuchung Lebender zur Dokumentation und Interpretation von Verletzungen gehört von je her zur Rechtsmedizin, hat aber in den letzten rund 20 Jahren im deutschsprachigen Raum enorm an Bedeutung gewonnen. Dieser und die nachfolgenden Beiträge zeigen das vielfältige Spektrum der Klinischen Rechtsmedizin auf.

Caesar ist das Pseudonym eines Fotografen der syrischen Militärpolizei, der von 2011 bis 2013 an verschiedenen Gewahrsamsorten in Damaskus die Leichen von Zivilisten fotografierte. Er schmuggelte die Bilder aus Syrien und floh schließlich selbst. Die Bilder gelangten zur Generalbundesanwaltschaft, die eine rechtsmedizinische Auswertung der Bilder zur Frage systematischer Misshandlung erbat.

Methode: Die Fotos wurden von zwei Rechtsmedizinern an einem hoch auflösenden Bildschirm unabhängig voneinander ausgewertet und die Befunde in eine eigens entwickelte Datenbank mit vorgegebenen Auswertungsparametern eingegeben. Die Auswertung erfolgte mit SPSS Statistics.

Ergebnisse: 26.938 Bilder zeigen die Körper von 6821 Menschen, davon eine Frau. 88 \% der Körper mit sicheren Todeszeichen. 2 Drittel mit körperlichen Auffälligkeiten (unterernährt, verletzt, verdreckt). $10 \%$ mit Hinweisen auf Fesselungen. Wenn Gewalteinwirkungsfolgen vorlagen $(51,4 \%)$, dann handelte es sich in $90 \%$ um stumpfe Verletzungsfolgen. In mehr als der Hälfte der Fälle fanden sich die Verletzungen an den Beinen. In $14 \%$ konnte eine Todesursache hinreichend angenommen werden: Die häufigste angenommene Todesursache war hierunter ein Verhungern und in $18 \%$ eine tödliche Halskompression.

Diskussion: Die Auswertung wurde vor dem Hintergrund eines Völkerstrafgerichtsverfahrens vor dem OLG Koblenz beauftragt. Im Kern ging es um die Frage, ob die Bilder der Caesar-Files den Schluss zulassen, dass hier eine systematische Misshandlung/Tötung an der Zivilbevölkerung vorgenommen wurde. Die rechtsmedizinische Begutachtung lässt einen solchen Schluss zu. Das Gutachten wurde zur Grundlage der Anklage und schließlich der Urteilsfindung des Senats. Zugleich wurden die Grenzen einer rechtsmedizinischen Bewertung alleine anhand von Bildern und die Gefahr der Überinterpretation von Befunden deutlich.

Fazit: Die Methode der Auswertung von Bildern durch zwei Rechtsmediziner*innen unabhängig voneinander und anschließende gemeinsame Beurteilung der diskrepant bewerteten Fälle hat sich bewährt und ist eine unabdingbare Voraussetzung für derartige Gutachtenerstattungen. Es müssen Standards für die rechtsmedizinische Auswertung von Bildern Verstorbener entwickelt werden (sichere Todeszeichen; nicht mit dem Leben vereinbare Verletzungen etc.).
$\mathrm{V}-\mathrm{KI}-2$

10 Jahre Kinderschutzambulanz am Institut für Rechtsmedizin der $\mathrm{MHH}$ - Entwicklung und Perspektiven

\section{T. A. Engelmann, A.S. Debertin}

Institut für Rechtsmedizin, Medizinische Hochschule Hannover (MHH), Hannover, CarlNeuberg-Straße 1, 30625 Hannover, Deutschland

Einleitung: Seit Oktober 2010 bietet das Institut für Rechtsmedizin der Medizinischen Hochschule Hannover (MHH) niedergelassenen und klinisch tätigen Ärztinnen und Ärzten in Niedersachsen ein spezialisiertes niederschwelliges Angebot einer fachlich fundierten Beratung und qualifizierten medizinischen Diagnostik bei vermuteter körperlicher und/oder sexualisierter Gewalt gegen Kinder. Damit soll die Früherkennung von Kindesmisshandlung und -missbrauch sowie die Handlungssicherheit für Ärztinnen und Ärzte in dem komplexen und herausfordernden Arbeitsfeld verbessert werden. Eine unkomplizierte und flächendeckenden Bereitstellung rechtsmedizinischer Expertise im Kinderschutz mit Erhebung gerichtsfester belastender, aber auch entlastender Befunde bedient auch Aspekte der Strafverfolgung und kann das System entlasten.

Methode: In einer retrospektiven Auswertung wurden für den Zeitraum von Oktober 2010 bis Dezember 2020 sämtliche Fälle analysiert, in denen niederschwellig die Kinderschutzambulanz des Instituts für Rechtsmedizin der MHH kontaktiert wurde. Für die Auswertung wurden die Dokumentationen der körperlichen Untersuchungen, die Aufzeichnungen der Telefonberatungen sowie die Akten- und Telekonsile herangezogen. Unter anderem wurden der Vorstellungsgrund, das Alter sowie das Geschlecht, bei erfolgter Untersuchung der Ort dieser Untersuchung sowie die Fachrichtung der anfordernden Ärztinnen und Ärzte ausgewertet. Ferner wurde die Beziehung zwischen dem Tatverdächtigen und dem geschädigten Kind sowie die rechtsmedizinische Beurteilung der Befunde analysiert.

Ergebnisse/Diskussion: In den 10 Jahren des Bestehens konnten mit den verschiedenen Beratungsansätzen wie Tele- und Aktenkonsilen, Untersuchungen in der Kinderschutzambulanz, wohnortnahen Konsilen, Telefonberatungen sowie zahlreichen Fortbildungsveranstaltungen eine gute interdisziplinäre Zusammenarbeit etabliert und Lücken geschlossen werden. Die Kinderschutzambulanz hat sich zu einem kompetenten Adressaten - zum Schutz der Kinder und Stärkung der Rechtssicherheit - entwickelt und es konnten in zahlreichen Fällen, bei insgesamt stetig steigender Nachfrage, insbesondere Fragestellungen zu Interpretation von Befunden und Fallmanagement sowie rechtliche Unsicherheiten geklärt und beantwortet werden.

Fazit: Für eine weitere Verbesserung des Kinderschutzes wäre zukünftig z. B. eine SGB-übergreifenden Kooperation mit Ausweitung des beschriebenen Angebotsportfolios anzustreben, damit rechtsmedizinische Expertise zur schnellen Gefährdungseinschätzung auch für die Kinder- und Jugendhilfe verbindlich geregelt und finanziert wird.

\section{V-KI-3}

Entwicklung einer mobilen rechtsmedizinischen Kinderschutzambulanz am Institut für Rechtsmedizin Greifswald: Erste Erfahrungen.

\section{Martin Dokter, Klaus Peter Philipp und Britta Bockholdt}

Institut für Rechtsmedizin, Universitätsmedizin Greifswald, Greifswald, Deutschland

Die Begutachtung von Verletzungen bei Kindern ist seit jeher Aufgabe der Rechtsmedizin. Waren es bis in die 1990er-Jahre Untersuchungen von toten Leibesfrüchten und Kinderleichen, gewann die klinische Rechtsmedizin in den vergangenen Jahren zunehmend an Bedeutung. Insbesondere die gerichtsverwertbare Verletzungsdokumentation und fachgerechte Sicherung biologischer Spuren sind dabei rechtsmedizinische Kernkompetenzen, die im Rahmen der regulären ärztlichen Versorgung meistens nur ungenügend oder gar nicht erfolgen. Auch ist hinlänglich bekannt, 
dass das Erkennen von misshandlungsbedingten Verletzungen sowohl für klinisch tätige Ärzte*innen als auch Mitarbeiter*innen von Jugendämtern oft problematisch ist.

In Greifswald stieg die Zahl untersuchter Kinder seit der Eröffnung der Opferambulanz im Jahr 2010 kontinuierlich an (2012: 31; 2016: 63; 2019: 81). Die Zuweisung erfolgte zumeist über die Kliniken unsers Einzugsgebietes als Konsil, gefolgt von den entsprechenden Jugendämtern. Trotzdem blieb die Inanspruchnahme rechtsmedizinischer Expertise auch aufgrund finanzieller Aspekte und der oft weiten Entfernungen ausbaufähig.

Aus diesen Gründen und ausgelöst durch einen dramatischen Fall im Jahr 2019 erfolgten Verhandlungen zum Aufbau einer rechtsmedizinischen Kinderschutzambulanz mit dem Ministerium für Soziales, Integration und Gleichstellung MV (für die Konsile) und den Landkreisen Mecklenburgische Seenplatte, Vorpommern-Greifswald und Vorpommern-Rügen (Untersuchungen §8a SGB VIII und im Auftrag von Eltern) mit dem Ergebnis eines fallunabhängigen Finanzierungsmodells einer mobilen rechtsmedizinischen Kinderschutzambulanz seit dem 01.01.2020.

Der Anteil der im Auftrag der Jugendämter untersuchten Kinder stieg seitdem deutlich an (30\% in 2018, $53 \%$ in 2020). Hauptuntersuchungsanlass (ca. $75 \%$ ) ist nach wie vor der Verdacht der körperlichen Misshandlung.

Im Ergebnis der Untersuchungen wurden am häufigsten Folgen stumpfer Gewalt festgestellt, wobei auch Fälle von Halskompressionen und nicht-akzidentellen Schädelhirntraumata registriert wurden. Der Anstieg der zurückgelegten Kilometer pro Fall (2018: 64 km; 2020: 72 km) deutet auf eine Erweiterung unseres Aktionsradius in den flächenmäßig größten Landkreisen der BRD hin, deren flächendeckende Versorgung eine Herausforderung bleiben wird.

\section{$\mathrm{V}-\mathrm{KI}-4$ \\ GUIDE4YOU - Begleitung von Frauen nach häuslicher Gewalt nach rechtsmedizinischen Untersuchungen}

Kristina Wojtanowski, Prof. Dr. Kathrin Yen, Aysche Landmann

Institut für Rechts- und Verkehrsmedizin, Universitätsklinikum Heidelberg

Ausgangssituation: Die Gewaltambulanz des Instituts für Rechtsmedizin in Heidelberg bietet seit 2011 Betroffenen physischer Gewalt ein niederschwelliges Angebot, das auch Frauen nach häuslicher Gewalt die Möglichkeit bietet, ihre Verletzungen gerichtsverwertbar dokumentieren zu lassen - unabhängig davon, ob sie zu einem späteren Zeitpunkt noch eine Anzeige erstatten möchten.

Nach der Dokumentation der Befunde wurden betroffene Frauen über verfügbare Angebote von Beratungs- und Interventionsstellen informiert. Ob Betroffene dieses Angebot annahmen, die Stellen aufsuchten und/ oder Anzeige erstatteten, ob und aus welchen Gründen sie dies unterließen, konnte nicht nachvollzogen werden.

Vorgehensweise: Dies hat sich durch das von der EU kofinanzierte Modellprojekt "Guide4You" verändert. In Zusammenarbeit mit der Stadt Heidelberg, der SRH Hochschule und der Allgemeinen Psychiatrie hat die Gewaltambulanz des Instituts für Rechtsmedizin in Kooperation mit der Polizei und der Interventionsstellen für Frauen und Kinder ein Instrumentarium geschaffen, welches den Frauen niederschwellig sehr kurzfristig Unterstützung anbietet. Durch ein sogenanntes Lotsensystem erhalten betroffene Frauen im Anschluss an die klinisch-forensische Untersuchung das Angebot einer Beratung und Begleitung: Ob zu Gerichtsterminen, zur Polizei, zu einer weiteren Beratungsstelle oder zur Rechtsantragsstelle eine Lotsin unterstützt die Frauen nach ihrem individuellen Bedarf und begleitet sie persönlich zu den verschiedenen Stellen.

Ergebnisse: Die Versorgungslücke zwischen den Hilfssystemen konnte durch das Lotsensystem verkleinert werden. $80 \%$ der Frauen, die in der Gewaltambulanz seit Juli 2020 nach häuslicher Gewalt untersucht wurden, konnten in das Hilfssystem integriert werden. Vor allem die Mobilität des Lotsensystems hat sich dabei als hilfreich herausgestellt und an den neuralgischen Punkten, Polizei und Justiz, konnten durch eine enge Begleitung die Frauen im Hilfssystem verankert bleiben.
In der Präsentation des Projektes sollen die Struktur des Lotsensystems und anhand von Fallbeispielen die heterogenen Erfahrungen vorgestellt werden.

\section{V-KI-5}

FoKoGi - Forensisches Konsil Gießen 2016-2020

L. Malolepszy, C. Hochscheid, A. Weber, T. Wolter, E. Hoffmann, T. Ohlwärther, R. Dettmeyer

Institut für Rechtsmedizin, Justus-Liebig-Universität Gießen

Einleitung: Die klinische Rechtsmedizin hat in den letzten Jahren an Bedeutung gewonnen. Dies zeigen auch die Daten des Forensischen Konsils Gießen als niedrigschwelliges Angebot einer rechtsmedizinischen Gewaltopferuntersuchung, gefördert vom Hessischen Ministerium für Gesundheit und Soziales. Eine zeitnahe Untersuchung, Beschreibung, Dokumentation und ggf. Begutachtung drittverursachter Verletzungen wird Gewaltopfern auch ohne Information der Polizei angeboten, Kooperationen mit Partnerkliniken sind Bestandteil des FoKoGi.

Material: Die 2016 bis 2020 erfolgten rechtsmedizinisch-körperlichen Untersuchungen und Begutachtungen im Rahmen des FoKoGi wurden ausgewertet.

Ergebnisse: Es zeigte sich zunächst eine kontinuierliche Fallzahlensteigerung und zunehmende Akzeptanz des Projektes gerade bei Jugendämtern. Kliniken konnten als Kooperationspartner gewonnen werden. Gut die Hälfe der untersuchten mutmaßlichen Gewaltopfer waren minderjährig. Ein erheblicher Teil der Untersuchungsaufträge kam aber auch von der Polizei. Das Angebot regelmäßiger Fortbildungen durch die Rechtsmedizin wurde sehr positiv aufgenommen. Im Jahre 2020 zeigte sich jedoch bedingt durch die Corona-Pandemie ein deutlicher Rückgang der präsenzbezogenen Aktivitäten des FoKoGi bzw. ein Rückgang der Zahl der Untersuchungen. Die Ergebnisse werden im Detail präsentiert.

Fazit: Das Forensische Konsil Gießen (FoKoGi) wurde erfolgreich etabliert. Eine durch das Projekt angestrebte Sensibilisierung und Erweiterung der Zusammenarbeit der einzelnen medizinischen Disziplinen bzw. Kliniken und sozialen Institutionen wurde deutlich vertieft.

\section{V-KI-6}

\section{Partnerschaftsgewalt gegen Männer}

Sven Anders, Dragana Seifert, Xenia Wörmann, Sandra Wilmes

Universitätsklinikum Hamburg-Eppendorf, Institut für Rechtsmedizin, Deutschland

Fragestellung: Insbesondere im deutschsprachigen Raum liegen bislang nur wenige Untersuchungen über Männer als Opfer von Partnerschaftsgewalt vor. Ziel der vorliegenden Studie ist es, Häufigkeit und Fallcharakteristika körperlicher Partnerschaftsgewalt gegen männliche Personen zu charakterisieren, die in der klinisch-rechtsmedizinischen Untersuchungsstelle für Gewaltopfer in Hamburg über einen Zeitraum von 11 Jahren untersucht wurden.

Methode: Standardisierte Auswertung der Protokolle zu klinisch-rechtsmedizinischen körperlichen Untersuchungen der Jahre 2006-2016.

Ergebnisse: Männliche Opfer repräsentierten 6,2 \% der untersuchten Fälle von Partnerschaftsgewalt $(n=167)$. In $78,4 \%$ der Fälle lag zum Zeitpunkt der klinisch-rechtsmedizinischen Untersuchung eine polizeiliche Anzeigenerstattung vor. Häufigste:r Täter:in war die aktuelle Partnerperson $(60,5 \%)$ mit einer Dominanz weiblicher Täter, der Großteil der Fälle $(82,0 \%)$ ereignete sich im häuslichen Umfeld. In mehr als der Hälfte der Fälle $(57,5 \%)$ suchten die Opfer die rechtsmedizinische Untersuchungsstelle ohne vorherige Inanspruchnahme medizinischer Versorgung auf. Etwa ein Drittel der Opfer (31,7\%) berichtete auch über vorangegangene Partnerschaftsgewalt. Eine differenzierte Analyse zeigte zudem spezifische Risiken unterschiedlicher Fallgruppen auf, z. B. hinsichtlich der aktuellen Wohn- und Partnerschaftskonstellation. 
Diskussion: Die Ergebnisse weisen auf die Relevanz von Männern als Opfer von Partnerschaftsgewalt, fallgruppenspezifische Risikofaktoren und verletzungsabhängiges Verhalten in Bezug auf die Inanspruchnahme von Gesundheitsleistungen hin.

Fazit: Die Daten unterstreichen die Notwendigkeit der Etablierung bzw. Stärkung von spezialisierten Unterstützungsangeboten für betroffene Männer und die Bedeutung der klinischen Rechtsmedizin bei der Dokumentation und Beurteilung von gewaltbedingten Verletzungen.

\section{V-KI-7}

\section{Frakturen und Hautläsionen bei misshandlungsbedingtem Kopftrauma: eine multizentrische Studie}

Katharina Feld', Tim Ricken², Dustin Feld ${ }^{3}$, Janine Helmus ${ }^{4}$, Maria Hahnemann ${ }^{5}$, Sebastian Schenk $\left.\right|^{6}$, Holger Muggenthaler ${ }^{6}$, Heidi Pfeiffer ${ }^{2}$, Sibylle Banaschak', Bernd Karger ${ }^{2}$, Daniel Wittschieber ${ }^{6}$

${ }^{1}$ Institut für Rechtsmedizin, Universitätsklinikum Köln, Köln; ${ }^{2}$ Institut für Rechtsmedizin Universitätsklinikum Münster, Münster; ${ }^{3}$ adiutaByte $\mathrm{GmbH}$, Business Campus, Sankt Augustin; ${ }^{4}$ Institut für Rechtsmedizin, Universitätsklinikum Essen, Essen; ${ }^{5}$ Abteilung für Radiologie, Arztpraxis, Jena; ${ }^{6}$ Institut für Rechtsmedizin, Universitätsklinikum Jena, Jena

Einleitung: Das misshandlunsgbedingte Kopftrauma (engl.: abusive head trauma, AHT) bei Säuglingen und Kleinkindern und seine häufigste Variante, das Schütteltrauma-Syndrom (engl.: shaken baby syndrome, SBS), sind überwiegend durch ZNS-assoziierte Läsionen gekennzeichnet. Über den Stellenwert von Skelett- und Hautverletzungen für die Diagnose des SBS/AHT liegen vergleichsweise wenige Daten vor.

Methode: In der vorliegenden Studie wurden daher retrospektiv 72 Fälle untersucht, bei denen im Rahmen rechtsmedizinischer Lebendbegutachtungen an drei Universitätsinstituten ein SBS diagnostiziert wurde.

Ergebnisse: In 15 Fällen wurde die Diagnose eines SBS unabhängig von der Befundlage durch Tatgeständnisse untermauert. Der Vergleich mit den 57 Fällen ohne Tatgeständnis ergab keine signifikanten Unterschiede bezüglich der Häufigkeiten feststellbarer Haut- oder Skelettläsionen. Ein Skelettscreening mittels konventioneller Röntgenuntersuchungen wurde lediglich in $78 \%$ der Fälle durchgeführt. Frakturen wurden in $32 \%$ der Fälle gefunden. Schädel (43\%) und Rippen ( $48 \%$ ) waren am häufigsten betroffen und nur in $8 \%$ der Fälle waren klassische metaphysäre Läsionen (CML) nachweisbar. In $48 \%$ der Fälle waren ältere, in Abheilung befindliche Frakturen vorhanden. Hautläsionen (Hämatome und Abschürfungen) wurden in $53 \%$ der Fälle gefunden, wobei Gesicht (76\%), behaarte Kopfhaut ( $26 \%)$ und Rumpf ( $50 \%)$ die am häufigsten betroffenen Körperregionen waren. In $48 \%$ der Fälle wurden zudem ältere, in Abheilung befindliche Hautläsionen beobachtet. Nahezu 80 \% der Fälle mit Frakturen wiesen ebenfalls Hautläsionen auf.

Diskussion/Fazit: Die Daten belegen, dass SBS bzw. AHT häufig von anderen Formen der körperlichen Misshandlung begleitet wird. Daher ist ein Skelettscreening unverzichtbar und sollte bei Verdacht auf Kindesmisshandlung immer vollständig und gemäß den bestehenden Bildgebungsrichtlinien durchgeführt werden.

\section{Toxikologie - Vortragsprogramm V-TX-1 bis V-TX-13}

\section{V-TX-1 \\ Toxikologische Charakterisierung der Fälle aus der Frankfurter Suizidstudie (FraPPE)}

Cora Wunder, Franziska Holz, Sarah C. Koelzer, Silvana Petzel-Witt, Stefan W. Toennes

Institut für Rechtsmedizin, Frankfurt am Main
Fragestellung: Im Rahmen des „Frankfurter Projekt zur Prävention von Suiziden mittels Evidenz-basierter Maßnahmen (FraPPE)“ wurden die Prävalenz und Charakteristiken von Suiziden in einem definierten Kollektiv (Frankfurt/Main Stadt) im Zeitraum 07/2018-12/2020 systematisch untersucht.

Methode: Die toxikologischen Untersuchungen umfassten aktuell aufgenommene Wirkstoffe (Alkohol, Rauschdrogen, Arzneimittel, sonstige Giftstoffe) in Blut, Urin, Mageninhalt sowie Marker chronischer Aufnahme (Ethylglucuronid, Rauschdrogen, Psychopharmaka) in Haaren. In Fällen ohne Obduktion konnten Auffindesituation und nähere Angaben ausgewertet werden.

Ergebnisse: Von den 229 Studienfällen wurden 106 obduziert. Von insgesamt 56 Intoxikationen (24,5\%; Median 53 [IQR 35-71,25] Jahre; 57,1\% Männer) waren 26 nicht toxikologisch untersucht. Die sehr heterogenen Fälle können grob klassifiziert werden in 30 Medikamentenvergiftungen (53,6\%, davon 4 Fälle mit Insulinbeteiligung), 10 Opioidintoxikationen (17,9\%, 4×Fentanylbeteiligung, $3 \times$ Heroin/Opium), 8 Fälle von Gasvergiftungen ( $5 \times \mathrm{CO}, 2 \times \mathrm{CO} 2$, Propangas), 3 Stimulanzienüberdosierungen, 2 Cyanid- (gemeinsamer Suizid) und 2 Chloroquinvergiftungen sowie eine Alkoholvergiftung. Toxikologisch relevante Begleitbefunde fanden sich in zusätzlich 19 der untersuchten Fälle (17,9\%): 13×Sedativa (4×Alkohol, $6 \times$ Benzodiazepine/Z-Substanzen) und $3 \times$ Helium- und $1 \times$ Stickstoffinhalation.

Von den obduzierten Suizidenten waren 79,8\% nicht alkoholisiert, bei $11,7 \%$ lag eine BAK $>1,1 \%$ vor. Bei $18,4 \%$ der Fälle spricht der Haar-EtGWert für einen übermäßigen Alkoholkonsum, bei $28,1 \%$ sprechen die Befunde für Drogenkonsum (Cannabis, Stimulanzien, Opiate) und bei 23,6\% für die Aufnahme von Opiaten/Opioiden. Bei 70,4\% der Fälle wurde eine Aufnahme von Psychopharmaka nachgewiesen (Antidepressiva, Antipsychotika, Antiepileptika, Sedativa, Antihistaminika), bei 50,9\% bis zu 4 Antidepressiva und bei $39,6 \%$ von bis zu 4 Antipsychotika. 49 Suizidenten $(46,2 \%)$ hatten aktuell Antidepressiva oder Antipsychotika eingenommen.

Diskussion/Fazit: Etwa die Hälfte der Suizidenten stand unter Medikation, bei fast jedem fünften Suizid spielten Arzneistoffe eine Rolle, meist Sedativa. Eine letale Intoxikation findet sich in einem Viertel der Suizide, vornehmlich mit Arzneistoffen.

\section{V-TX-2}

\section{Nachweis der Übertragung von Methadon und EDDP durch Schweiß auf zuvor unbelastetes Kinderhaar}

Katharina Feld', Patrick Dahm', Tobias Kieliba', Axel Klee², Markus A. Rothschild', Hilke Andresen-Streichert', Justus Beike ${ }^{3}$

${ }^{1}$ Uniklinik Köln, Institut für Rechtsmedizin, Köln; ${ }^{2}$ LVR-Klinik Bonn, Abteilung für Abhängigkeitserkrankungen und Psychotherapie, Bonn; ${ }^{3}$ Universitätsklinikum Münster, Institut für Rechtsmedizin, Münster

Fragestellung: Zur Klärung der Frage, ob Kinder mit Drogen in Kontakt gekommen sind, werden häufig deren Kopfhaare untersucht. Bei positivem Nachweis von Drogen stellt sich dann die Frage, auf welchem Weg die nachgewiesenen Stoffe einschließlich deren Metaboliten in das Kinderhaar gelangten. Handelte es sich um eine Aufnahme von Drogen durch das Kind, z. B. durch orale Einnahme oder Inhalation, oder um eine äußere Kontamination der Haare, z. B. durch Stäube oder den Kontakt mit dem Schweiß von Drogenkonsumenten.

Methode: In dieser Studie wurde die Möglichkeit der Übertragung von Methadon und dessen Metabolit EDDP durch Kontakt mit Personen in einer Opiat-Substitutionstherapie mit Methadon auf zuvor unbelastetes Kinderhaar untersucht. Dazu wurde der enge Hautkontakt durch die Anbringung von unbelastetem Kinderhaar (je 5 Haarsträhnen) mit einem Netzgürtel auf der Haut (Rücken oder Bauch) von Substitutionspatienten $(n=15)$ über einen Zeitraum von 5 Tagen simuliert. Zusätzlich wurden Schweiß-Sammelpflaster auf der Haut der Probanden angebracht. Von jedem Probanden wurden täglich eine Haarsträhne und ein Schweiß-Sam- 
melpflaster entnommen. Die Analysen erfolgten mittels GC-MS/MS (Haare) und LC-MS/MS (Schweiß-Sammelpflaster).

Ergebnisse: Nach 4 Tagen Hautkontakt war bei allen 15 Patienten Methadon in den zuvor drogenfreien Haarsträhnen nachweisbar. EDDP konnte in 34 der insgesamt 75 Haarproben nachgewiesen werden, wobei nach 5 Tagen des Hautkontakts die maximale Anzahl der positiven EDDV-Ergebnisse (11 von 15) vorlag.

Diskussion: Diese Ergebnisse zeigen, dass die Übertragung von Methadon und EDDP auf zuvor drogenfreies Haar durch engen Hautkontakt mit Substitutionspatienten möglich ist. Eine Korrelation zwischen Schweißkonzentrationen und Substanzkonzentrationen in den Haarsträhnen konnte nicht nachgewiesen werden, jedoch ist eine Tendenz zu höheren Konzentrationen nach längerer Kontaktzeit deutlich erkennbar.

Fazit: Der Nachweis des Metaboliten EDDP im Kinderhaar ist nicht beweisend für die Körperpassage von Methadon bei dem betreffenden Kind.

\section{V-TX-3 \\ Einzelhaaranalytik auf zentral wirksame Substanzen - Methodenentwicklung und Anwendungen \\ C. Wiedfeld, G. Skopp, F. Musshoff \\ Forensisch Toxikologisches Centrum, München}

Fragestellung: Bei forensisch-toxikologischen Haaranalysen zum retrospektiven Nachweis einer Aufnahme von Fremdsubstanzen werden routinemäßig Abschnitte von mehreren cm Länge analysiert; auch segmentale Analysen zur Überprüfung der Änderung eines Konsumverhaltens sind etabliert. Hierdurch sind jedoch eine hohe zeitliche Auflösung und Aussagen zur Häufigkeit einer Substanzaufnahme nicht möglich. Diese Limitierungen werden durch eine Analyse von Einzelhaaren bei Mikrosegmentierung, ermöglicht durch eine immer sensitivere Analysentechnik, umgangen. Vorliegend wurde ein umfangreiches Screeningverfahren erarbeitet; seine erfolgreiche Anwendung bei einem Missbrauchsfall wird vorgestellt.

Methode: Jedes Einzelhaar wurde unter einer Lupe in $2 \mathrm{~mm}$ Segmente geteilt. Nach methanolischer Extraktion erfolgte die Analyse mittels LC-MS/MS (1290 Infinity LC System (Agilent, Waldbronn), Sciex QTRAP 6500 (Sciex, Darmstadt)). In das Screeningverfahren wurden 156 vorwiegend zentral wirksame Substanzen aufgenommen. Nach erfolgreicher Validierung konnten authentische Fälle bearbeitet werden; zur Anwendung in der Fallarbeit gelangten 10 Einzelhaare.

Ergebnisse und Diskussion: Die Sensitivität der Methode ist ausreichend, um für eine Vielzahl von Substanzen auch eine einmalige Aufnahme zu belegen. Die graphische Darstellung der Einzelergebnisse (pg/Segment vs. Segmentlänge) ergibt bei einmaliger/mehrmaliger Substanzaufnahme ein charakteristisches Konzentrationsprofil mit hoher zeitlicher Auflösung.

Exemplarisch gelang der Nachweis einer Beibringung von K. o.-Mitteln bei einem 11jährigen Kind. Das Kind war nach dem letzten Vorfall zwar stationär behandelt worden, das Krankenhausasservat war zu dem Zeitpunkt der Verdachtsschöpfung jedoch nicht mehr verfügbar. Durch die hohe zeitliche Auflösung der Einzelhaaranalyse konnte dann belegt werden, dass sogar eine dreimalige Gabe zu bestimmten Zeitpunkten erfolgte, was den Fall in ein anderes Licht rückte.

Fazit: Eine Einzelhaaranalyse kann bei bestimmten Fragestellungen zusätzliche Informationen über Häufigkeiten und Zeitpunkte einer Fremdstoffaufnahme liefern.

\section{V-TX-4}

Prävalenz nicht überprüfter Medikation oder nicht entdeckten Missbrauchs bei Abstinenzkontrollen durch Haarproben im Rahmen der Fahreignungsdiagnostik

C. Wiedfeld, T. Franz, G. Skopp, F. Musshoff

Forensisch Toxikologisches Centrum, München
Fragestellung: In den vergangenen Jahren ist ein deutlicher Anstieg der Verschreibungszahlen von Opioiden und Z-Substanzen festzustellen. Laut einer Studie der OECD ist in Deutschland die Anzahl Opioid-bedingter Todesfälle geringer als in den USA (Opioid-Krise), allerdings werden vergleichsweise viele Schmerzmittel verschrieben und eingenommen. ZSubstanzen (Zolpidem, Zopiclon) gelten als scheinbar nebenwirkungsärmere Alternativen zu Benzodiazepinen, zeigen jedoch ein ähnlich hohes Abhängigkeitspotenzial.

Im polytoxikologischen Standard-Screening bei Analysen im Rahmen der Fahreignungsdiagnostik werden diese Opioide und Z-Substanzen jedoch nicht erfasst. Lediglich bei einem Verdacht auf eine vorangegangene Opioid-Aufnahme soll das Screening um bestimmte Opioide erweitert werden. Es stellt sich die Frage, ob Analysen für diese Substanzgruppen angemessen beauftragt werden oder eine relevante Dunkelziffer vorhanden ist.

Methode: Die Analysendaten von ca. 15.000 Haarproben, welche in den Jahren 2018/19 im Rahmen eines polytoxikologischen Screenings zur Fahreignungsdiagnostik untersucht wurden, wurden anonymisiert auf die Anwesenheit der nicht im Standardscreening erfassten Opioide (Buprenorphin, Tilidin, Tramadol, Oxycodon und Fentanyl) bzw. Z-Substanzen (Zolpidem und Zopiclon) retrospektiv ausgewertet. Neben der generellen Erhebung der Prävalenz wurde bei den positiven Fällen anhand der Angaben aus den Anträgen auch berücksichtigt, ob eine Einnahme bekannt war oder vermutet wurde und ob eine zusätzliche Untersuchung überhaupt beauftragt war.

Ergebnisse und Diskussion: Die Ergebnisse für die Opioide weisen darauf hin, dass die Prävalenz im Vergleich zur Positivrate standardmäßig getesteter Substanzen (10,8\%) mit 4,1\% durchaus relevant ist. Kritisch erscheint, dass nur in $17 \%$ der positiven Fälle ein erweitertes Screening auf Opioide tatsächlich angefordert wurde.

Die Ergebnisse für die Z-Substanzen weisen darauf hin, dass die Prävalenz gering ist $(0,9 \%)$, jedoch deutlich höher liegt als bei den durch das Routinescreening erfassten Benzodiazepinen (0,2\%). Ein um Z-Substanzen erweiterter Untersuchungsauftrag lag nur in den wenigstens Fällen vor, auch nicht bei bekannter Einnahme und insbesondere auch dann nicht, wenn eine ehemalige Einnahme ggf. auch von anderen Sedativa/ Hypnotika bekannt war.

Fazit: Die Ergebnisse dieser Erhebung legen nahe, den künftigen Untersuchungsumfang bei Kontrollen im Rahmen der Fahreignungsdiagnostik zu erweitern, um die Verkehrssicherheit zu erhöhen.

\section{V-TX-5}

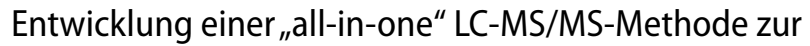
toxikologischen Analytik im Rahmen der Diagnostik des irreversiblen Hirnfunktionsausfalls

Sven Baumann', Carolin Zosel ${ }^{2}$, Heiner Trauer', Lars Wünsch², Jens Meiler', Jan Dreßler ${ }^{1}$

'Institut für Rechtsmedizin; ${ }^{2}$ Institut für Wirkstoffentwicklung, Medizinische Fakultät der Universität Leipzig, Deutschland

Fragestellung: Hirntodfeststellungen sind routinemäßige interdisziplinäre klinische Entscheidungen (Konsil). Die Diagnostik eines irreversiblen Hirnfunktionsausfalls (IHA) bedarf des Ausschlusses reversibler Ursachen. Aus toxikologischer Sicht sind hierbei vor allem Einflüsse durch zentral dämpfende Medikamente relevant. In den Empfehlungen der GTFCh wurde diesbezüglich ein Anforderungskatalog hinsichtlich der Leistungsfähigkeit analytischer Methoden chemisch-toxikologischer Analysen aufgestellt.

Methode: Ziel war die Entwicklung und Validierung einer Methode zur quantitativen Bestimmung aller derzeitig in der GTFCh-Empfehlung enthaltenen Analyten auf einer analytischen Plattform. Hierzu wurde eine zielgerichtete LC-MS/MS-Methode zur Quantifizierung mittels Multiple Reaction Monitoring (MRM) entwickelt und optimiert. Für die Probenvor- 
bereitung wurde eine einfache und schnelle Proteinpräzipitation angewendet.

Ergebnisse: Die aktuelle Methode umfasst die Analyse aller in der GTFChEmpfehlung empfohlenen Substanzen aus dem Bereich der allgemeinen Narkotika, Barbiturate, Opioide sowie Benzodiazepine aus Blutproben. Die empfohlenen Konzentrationen hinsichtlich Nachweis- und Bestimmungsgrenze werden dabei für alle Substanzen erfüllt. Zur vollständigen Analyse werden zwei chromatographische Läufe mit variierten lonisierungsbedingungen (positiv ESI-MS/MS sowie negativ APCI-MS/MS) verwendet. Derzeit wird die vorliegende Methode gemäß den Richtlinien der GTFCh validiert. Daten hierzu werden zur Jahrestagung der DGRM vorliegen und ebenfalls vorgestellt.

Diskussion: Im forensisch-toxikologischen Routinebetrieb war die Analyse von zentral dämpfenden Medikamenten im Rahmen der IHA-Diagnostik bislang auf verschiedene Instrumente verteilt. Ziel war daher die Entwicklung einer umfassenden Methode zur Verringerung des Labor- und Messaufwands. Aufgrund der unterschiedlichen physikochemischen Eigenschaften der zu bestimmenden Substanzen und der Anforderung hinsichtlich ihrer Nachweisempfindlichkeit sind pro Probe zwei Analysenläufe mit veränderten Konditionen nötig.

Fazit: Es konnte eine „all-in-one“ LC-MS/MS-Methode zur klinisch-toxikologischen Analytik im Rahmen der IHA-Diagnostik etabliert werden, die bei derartigen Fragestellungen nunmehr gezielt eingesetzt werden kann.

\section{V-TX-6 \\ K.-o.-Verdachtsfälle aus dem Institut für Rechtsmedizin Hamburg - Untersuchung mit einer sensitiven LC-MS/ MS Methode}

Anne Szewczyk', Alexander Müller ${ }^{1}$, Nadine Aboutara', Hilke Jungen', Stefanie Iwersen-Bergmann', Hilke Andresen-Streichert ${ }^{2}$

${ }^{1}$ Institut für Rechtsmedizin, Hamburg; ${ }^{2}$ Institut für Rechtsmedizin, Köln

Fragestellung: Unter dem Begriff "K.-o.-Mittel“ werden zentral wirksame Drogen und Medikamente verstanden, die bei Sexualstraftaten oder Raubdelikten beigebracht werden. Häufig melden sich die Geschädigten erst mit Zeitverzug, so dass es notwendig erscheint, mit der größtmöglichen Messempfindlichkeit die Nachweisdauer aufgenommener Substanzen zu erhöhen. Mit einer Methode, die 143 Analyten (Muttersubstanzen und/oder ihre Metabolite) mit Nachweisgrenzen von $5 \mu \mathrm{g} / \mathrm{L}$ erfasst, sollte untersucht werden, welche Substanzen in Hamburg Anwendung als K.o.-Mittel finden.

Methode: 237 K.-o.-Verdachtsfälle, die von Januar 2017 bis Mai 2021 im Institut für Rechtsmedizin Hamburg mit Auftrag zur Untersuchung eingingen, wurden in die Studie eingeschlossen. Die Urinproben wurden nach Glucuronidspaltung mittels Festphase extrahiert und mit LC-MS/MS analysiert.

Ergebnisse: Es fanden sich in $73 \%$ der Fälle $(n=173)$ eine oder mehrere Substanzen und/oder Alkohol. In 91 Fällen (38\%) wurde mindestens ein illegales Betäubungsmittel detektiert: Cannabis $(n=48)$, Cocain $(n=47)$, MDMA $(n=17)$ und Amphetamin $(n=15)$. Der Nachweis von Alkohol erfolgte in $33 \%$ aller Fälle $(n=78)$ (BAK $0,23-3,19 \%$; UAK 0,12-3,52\%o). Mit der LC-MS/MS Methode fanden sich darüber hinaus Benzodiazepine $(n=18)$, Morphin und Cetirizin (je $n=15)$, Codein $(n=6)$, Dextromethorphan $(n=3)$, Ketamin $(n=4)$, Diphenhydramin $(n=3)$, Citalopram und Pipamperon (je $n=6$ ), Promethazin und Fluoxetin (je $n=5$ ), Quetiapin $(n=4)$, Pregabalin $(n=3)$ und weitere. GHB wurde in 1,5\% aller Fälle $(n=4)$ nachgewiesen.

Diskussion: Die Prävalenz für Alkohol und illegale Betäubungsmittel war hoch. Im Hinblick auf sedierende Medikamente wurde eine Vielzahl von Wirkstoffen, meist Benzodiazepine, nachgewiesen. Es erscheint sinnvoll bei fraglichen K.-o.-Mittel Fällen analytisch sehr breit aufgestellt und sensitiv zu untersuchen.

Fazit: Es ist zu berücksichtigen, dass auch die eigene Medikation und ein aktiver Substanzkonsum der Geschädigten analytisch erfasst werden. Ein
Nachweis jeglicher Substanzen sollte daher stets kritisch beurteilt werden (ausführliche Anamnese).

\section{V-TX-7}

\section{Aktuelles zu neuen psychoaktiven Substanzen und deren Nachweis in verschiedenen Matrices}

Helena Fels, Gisela Skopp, Frank Musshoff

Forensisch Toxikologisches Centrum (FTC) München, München

Einleitung: Zwar hat sich in den vergangenen Jahren die Anzahl der erstmals aufgetretenen neuen psychoaktiven Substanzen (NPS) stabilisiert, dennoch werden jedes Jahr mehr als 50 neue Stoffe über das EU-Frühwarnsystem gemeldet. Darüber hinaus werden jährlich etwa 400 der insgesamt rund 790 überwachten NPS auf dem europäischen Drogenmarkt registriert. Neben der Vielzahl und Vielfalt der verfügbaren Substanzen stellt vor allem das rasche Auftreten von neuen Verbindungen eine große Herausforderung für die forensische Toxikologie dar. Für den Nachweis von NPS in biologischen Matrices und Stoffproben sind umfangreiche und empfindliche Screeningmethoden notwendig, die kontinuierlich aktualisiert werden müssen. Unter Verwendung verschiedener Analysenverfahren werden aktuelle Fallbeispiele, bei denen NPS in unterschiedlichen Untersuchungsmaterialien identifiziert wurden, vorgestellt.

Methode: Die Analyse auf Designerstimulanzien erfolgte mittels Flüssigkeitschromatographie-Quadrupol-Flugzeitmassenspektrometrie (LCQTOF-MS, Sciex TripleTOF 5600). Für die Bestimmung von synthetischen Cannabinoiden bzw. deren Metaboliten wurde die Flüssigkeitschromatographie-Tandem-Massenspektrometrie (LC-MS/MS, Sciex Triple Quad $6500+)$ verwendet; Blut- und Urinproben wurden zusätzlich mit Hilfe einer LC-QTOF-MS-Methode untersucht. Diese Methode wurde auch für die Analyse von Kräutermischungen herangezogen.

Ergebnisse: In einer Blutprobe, welche im September 2019 entnommen wurde, konnte mittels LC-QTOF-MS das Methaqualon-Derivat SL-164 identifiziert werden. Bei der Untersuchung einer im März 2021 abgegebenen Urinprobe auf Stoffwechselprodukte von synthetischen Cannabinoiden wurden bei der zusätzlichen Analyse mittels LC-QTOF-MS ein Hydroxysowie der Defluorierungsmetabolit von 5F-EDMB-PICA detektiert, welche durch die LC-MS/MS-Methode zunächst nicht erfasst wurden. In einer Haarprobe, die im Februar 2021 entnommen und im Rahmen der Fahreignungsdiagnostik auf synthetische Cannabinoide untersucht werden sollte, wurden JWH-018 und JWH-210 mittels LC-MS/MS nachgewiesen. Beide Substanzen wurden bereits im Jahr 2008 bzw. 2010 registriert. Bei der Analyse einer Kräutermischung, die im September 2020 eingesandt wurde, konnte mittels LC-QTOF-MS das synthetische Cannabinoid Cumyl-BC-

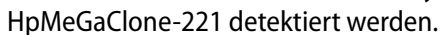

Schlussfolgerung: Die vorangegangenen Fallbeispiele machen deutlich, dass neben kürzlich auf dem Markt erschienenen NPS immer wieder auch Stoffe nachgewiesen werden können, die bereits vor einigen Jahren aufgetreten sind. Aus diesem Grund müssen Screeningmethoden nicht nur stets aktuell gehalten werden, sondern sollten auch möglichst umfangreich sein.

\section{V-TX-8}

Forensische Entomotoxikologie - Erste Ergebnisse der Prävalidierungsphase für den Nachweis von Benzodiazepinen und BenzodiazepinStoffwechselprodukten in Maden nekrophager Insekten

Rahaus, S, Graw, M, Mußhoff, F, Zinka, B, Groth, 0

IRM München

Fragestellung: Aktuell beschränken sich Untersuchungen von Leichenmaterial regelhaft auf Methoden, die für Matrices wie Blut und Urin erarbeitet wurden. Aufgrund unterschiedlicher Zersetzungsgrade eines 
Leichnams stellt sich eine Validierung von postmortalem Material oft als schwierig dar. Trotz ihrer fettigen Matrix sind Maden nekrophager Insekten wahrscheinlich geeigneter für einen postmortalen qualitativen Nachweis von Substanzen, insbesondere als alternative Matrix bei Leichen mit fortgeschrittener Zersetzung.

Ziel dieser Arbeit war, eine Methode zu entwickeln, mit der es möglich ist an Maden den indirekten Nachweis von zu Lebzeiten aufgenommenen Substanzen am Beispiel von Benzodiazepinen zu erbringen.

Methode: Die Prävalidierungsphase beinhaltete die Entwicklung einer geeigneten Extraktionsmethode. Hierfür wurden für mehrere Benzodiazepine und Benzodiazepin-Stoffwechselprodukte Proteinfällungsextraktionen (PE) mit Acetonitril, eine Flüssig-Flüssig-Extraktion (LLE) mit Diethylether und Festphasenextraktionen (SPE) mit kommerziell erhältlichen Säulen durchgeführt und im Anschluss mittels LC-MS/MS analysiert.

Ergebnisse: Die nach der "post-extraction-addition“ Methode durchgeführten Untersuchungen der Matrixeffekte und der Ausbeute haben gezeigt, dass die PE zwar die beste Extraktionseffizienz aufweist, gleichzeitig jedoch auch die stärksten Matrixeffekte. Ausgewogenere Ergebnisse konnten mit LLE erzielt werden. Somit wurden Madenproben eines Realfalles mittels der entwickelten LLE-Methode aufgearbeitet und untersucht. Die erhobenen Befunde wurden mit den Ergebnissen der Leichenmaterialien verglichen.

Diskussion: Die Ergebnisse der Untersuchungen haben ergeben, dass die Extraktion der Substanzen mit der Proteinfällung die besten Resultate aufzeigt, die PE allerdings nicht geeignet ist, die Fette ausreichend aus der Matrix zu entfernen. Die SPE ergab im Vergleich mit der LLE schlechtere Ergebnisse bei der Extraktionseffizienz, aufgrund der besseren Handhabung der SPE sollte jedoch über eine Optimierung der Methode nachgedacht werden.

Fazit: Im Anschluss werden die Validierungsphase und Untersuchungen mit Maden, die mit einem Benzodiazepin versetzten Nährmedium gefüttert wurden, folgen, um mögliche pharmakokinetische Vorgänge der ausgewählten Substanzen in den Maden zu überprüfen. Maden von weiteren realen rechtsmedizinischen Obduktionsfällen sollen untersucht und mit den Ergebnissen der entsprechenden Humanproben verglichen werden.

\section{V-TX-9 \\ Neuartige Phospholipid-Biomarker - Nachweis eines zurückliegenden Konsums von gamma- Hydroxybuttersäure oder Propanol/Isopropanol}

\section{T.R. Sundermann 1,2, J. Thimm', V. Hofmann' ', G. Schmitt', M. Bartel'}

'Institut für Rechts- und Verkehrsmedizin, Universitätsklinikum Heidelberg; ${ }^{2}$ Institut für Pharmazie und Molekulare Biotechnologie, Universität Heidelberg

Fragestellung: Phospholipide stellen eine aussichtsreiche Verbindungsklasse für die Suche nach neuen Biomarkern dar, die neben Ethanol auch einen zurückliegenden Konsum anderer Alkohole, wie Propanol und Isopropanol, aber auch von gamma-Hydroxybuttersäure (GHB) oder beta-Hydroxybuttersäure (BHB) ermöglichen. Vergiftungen durch Propanol- und Isopropanol-haltige Lösungsmittel (z.B. Desinfektionsmittel), aber auch durch GHB (Vergewaltigungsdroge) können zum Gegenstand forensischtoxikologischer Untersuchungen werden, wobei sich insbesondere die GHB aufgrund der raschen Elimination im Körper einem eindeutigen forensischen Nachweis entziehen kann.

Methode: Aufgrund der komplexen Zusammensetzung der Phospholipide sind analytische Referenzsubstanzen für eine eindeutige Identifizierung und Quantifizierung erforderlich. Da modifizierte Phospholipide bisher nur begrenzt kommerziell erhältlich sind, sollten die PhospholipidHomologe 16:0/18:1 des Isopropanols, der GHB und der BHB mittels organisch-chemischer Synthese hergestellt und anschließend instrumentellanalytisch untersucht werden.

Ergebnisse: In Kooperation mit dem Institut für Pharmazie und Molekulare Biotechnologie wurden die drei Zielverbindungen erfolgreich synthetisiert und analytisch charakterisiert (Kernspinresonanzspektroskopie,
Massenspektrometrie). Zudem wurde eine Methode mittels Hochleistungsflüssigkeitschromatographie mit tandemmassenspektrometrischer Detektion entwickelt. Alle drei Phospholipide konnten basisliniengetrennt chromatographisch aufgetrennt und massenspektrometrisch nachgewiesen sowie in gespikten Vollblutproben eindeutig identifiziert werden. Des Weiteren konnten in-vitro Untersuchungen eine Bildung der Substanzen durch die Phospholipase D belegen.

Diskussion/Fazit: Die bisherigen Möglichkeiten zum Nachweis von GHB sind hinsichtlich ihrer Sensitivität, Spezifität und dem kurzem Detektionsfenster begrenzt. Ob die hier dargestellten Biomarker für einen zurückliegenden Konsum von GHB oder Propanol/Isopropanol für die forensisch-toxikologische Beurteilung geeignet sind, muss noch durch weiterführende Studien mit authentischem Probenmaterial geklärt werden.

\section{$\mathrm{V}-\mathrm{TX}-10$}

Untersuchungen zum Alkoholkonsumverhalten bei einem Kollektiv obdachloser Probanden in Hamburg - Die Alkoholkonsummarker PEth, CDT und MCV im Vergleich

Nadine Aboutara, Hilke Jungen, Anne Szewczyk, Alexander Müller, Victoria van Rüth, Fabian Heinrich, Stefanie Iwersen-Bergmann

Universitätsklinikum Hamburg-Eppendorf, Institut für Rechtsmedizin, Hamburg

Fragestellung: In einem Kollektiv mit vermutet hohem Alkoholkonsum wurde untersucht, welche Konzentrationen an spezifischen (Carbohydratdeficient-Transferrin (CDT), Phosphatidylethanol (PEth)) und unspezifischen (mittleres korpuskulares Volumen (MCV)) Alkoholmarkern messbar sind und welche diagnostische Performance diese im Kollektiv zeigen. Methode: Bei 147 obdachlosen Personen wurde neben Fragen zum subjektiven Alkoholkonsumverhalten eine körperliche Untersuchung mit Blutentnahme durchgeführt. In den Blutproben wurden die Blutalkoholkonzentration (BAK), PEth, CDT und MCV laborchemisch bestimmt.

Ergebnisse: In 39 Blutproben wurde eine BAK oberhalb von 0,1\%o bestimmt (0,1-2,5\%o, Mittelwert (MW) 1,0\%o). Alle diese Proben waren ebenfalls PEth positiv $(>10 \mathrm{ng} / \mathrm{ml}), 31$ Proben CDT positiv $(>2,4 \%)$ und $30 \mathrm{MCV}$ positiv. Insgesamt lag CDT bei 52 Proben über dem Cut-off (2,5-22,1\%, MW 6,9\%). In 104 Proben wurde PEth nachgewiesen (11$5687 \mathrm{ng} / \mathrm{ml}$, MW $1049 \mathrm{ng} / \mathrm{ml}$ ). Die durchschnittliche PEth-Konzentration war bei Proben, die auch CDT positiv waren, signifikant höher als bei ausschließlich PEth-positiven Fällen $(p=0,004)$. CDT- und PEth-Konzentrationen zeigten eine signifikant positive Korrelation (Spearmans-Korrelationskoeffizient $\rho=0,68)$. MCV war bei 58 Probanden erhöht (>95fl). Die Korrelation zu PEth $(\rho=0,58)$ war besser als die zu CDT $(\rho=0,47)$. 62 Probanden machten Angaben zu ihrem Alkoholkonsumverhalten, dabei gaben $16 \%$ an, nie und $19 \%$ gelegentlich Alkohol zu trinken. Einen regelmäBigen moderaten Konsum gaben $39 \%$ an, einen regelmäßig hohen $26 \%$.

PEth zeigte mit $88 \%$ die beste Sensitivität für die Angaben eines Alkoholkonsums, die Sensitivität für CDT lag bei $67 \%$ und für MCV bei $60 \%$. Spezifitäten lagen für PEth bei $50 \%$, CDT bei $90 \%$ und MCV bei $88 \%$.

Diskussion: In dem untersuchten Kollektiv fanden sich ungewöhnlich hohe Konzentrationen der Alkoholkonsummarker PEth und CDT, welche so im klinischen Setting kaum auftreten. Bezogen auf die geäußerten Trinkangaben war die Sensitivität von PEth sehr gut, die Spezifität jedoch für einen direkten Alkoholmarker unerwartet schlecht. Die Glaubhaftigkeit der Angaben einiger Probanden hinsichtlich ihres Alkoholkonsums muss daher kritisch hinterfragt werden.

Fazit: Die sehr hohen PEth-Konzentrationen korrelierten gut mit den außergewöhnlich hohen CDT-Werten. Im Hinblick auf die Sensitivität ist PEth dem CDT deutlich überlegen. PEth erweist sich auch in dem besonderen Kollektiv zur Feststellung eines Alkoholkonsums und zur Einschätzung des Trinkverhaltens als geeignet. 
V-TX-11

\section{Das kommt nur von Corona - Atemalkoholkonzentrationen nach Desinfektion?}

Dankwart Stiller, Marko Weber, Rüdiger Lessig, Martin Küster

Institut für Rechtsmedizin, Universitätsklinikum Halle (Saale)

Fragestellung: In Widerspruchsverfahren gegen Strafbefehle wegen § 24 StVG (Fahren unter Alkoholeinfluss) kam es wiederholt zur Inanspruchnahme von Gutachtern, weil vorgetragen wurde, dass die gemessene Atemalkoholkonzentration Folge einer wiederholten Händedesinfektion gewesen sei. Dabei wurde anwaltlicherseits auf Publikationen der Universität Greifswald hingewiesen.

Methode: Nach erfolgter Literaturrecherche ergaben sich Hinweise im nicht-rechtsmedizinischen Schrifttum, dass die Möglichkeit einer dermalen Resorption als Ursache einer relevanten Blutalkoholkonzentration beschrieben wurde. Die Untersuchungen und deren Wertungen erfolgten aus arbeitsmedizinischen Betrachtungen.

Mittels Messgerät Dräger Alcotest Evidential 9510 erfolgte die Prüfung der Möglichkeit der Generierung von messbaren Atemalkoholkonzentrationen u.a. nach einmaliger und mehrfacher normaler Händedesinfektion, Anwendung von Desinfektionsgel und "chirurgischer

Händedesinfektion" (15 min, reiner Alkohol).

Ergebnisse: Rechtlich relevante Atemalkoholwerte waren bei keinem der - teilweise auch bei Nichteinhaltung der DIN VDE 0405-1 durchgeführten - Versuche messbar. Dafür wurden verschiedene Fehlermeldungen des verwendeten Messgerätes angezeigt.

Diskussion/Fazit: Die eigenen Ergebnisse werden vor dem Hintergrund der Literatur diskutiert, wobei die Autoren davon ausgehen, dass in jedem Fall einer gemäß DIN VDE 0405 durchgeführten Messung der angezeigte Atemalkoholwert nicht durch dermale Resorption nach Desinfektion entstanden sein kann.

\section{V-TX-12}

\section{Auswirkungen von Alkoholeinfluss auf die Fahrsicherheit von E-Scooter-Fahrenden}

Katharina Zube, Thomas Daldrup, Michael Lau, Rüdiger Maatz, Anne Tank, Irina Steiner, Holger Schwender, Benno Hartung

Institut für Rechtsmedizin Düsseldorf

Fragestellung: Derzeit wird bei E-Scooter-Fahrenden von einer "absoluten Fahrunsicherheit" ab einer Blutalkoholkonzentration (BAK) von $1,10 \%$ zum Fahrtzeitpunkt ausgegangen. Um diesen Beweisgrenzwert zu prüfen, wurden praktische Fahrversuche sowie begleitende ärztliche Untersuchungen bei unterschiedlichen BAKen durchgeführt.

Methode: An den Untersuchungen nahmen 57 Alkohol konsumierende Probandlnnen $(28 \mathrm{w}, 29 \mathrm{~m})$ sowie 6 durchgängig nüchterne Probandlnnen $(3 \mathrm{w}, 3 \mathrm{~m})$, die als Kontrollkollektiv dienten, teil. Es wurde ein festes Trinkschema vorgegeben, welches im Vorfeld individuell mit der Widmark-Formel berechnet wurde. Es erfolgten wiederholte Fahrten durch einen festgelegten Parcour.

Im Anschluss an jede Fahrt erfolgte eine Blutprobe zur BAK-Bestimmung und es wurde die psychophysische Konstitution durch Tests ärztlich untersucht.

Ergebnisse: Bereits im Bereich um 0,30\%o (0,21-0,40\%) zeigte sich eine signifikante Verschlechterung der Fahrleistung auf ca. $60 \%$ des Ausgangsniveaus.

Bei unterschiedlichen Hindernissen, insbesondere bei der sich verjüngenden Fahrspur, den Tordurchfahrten und den Kreisfahrten, wurden verschiedene BAK-Bereiche für die Verkehrssicherheit relevant.

Bei der Untersuchung des Romberg-Tests und Unterberger-Tretversuchs konnte eine starke Signifikanz von Stand-und Gangunsicherheit zur Höhe der BAK und der Fahrleistung belegt werden.
Einen die Ergebnisse beeinflussenden Lerneffekt durch das wiederholte Durchfahren des Parcours ergab der Vergleich mit dem Kontrollkollektiv nicht.

Geschlechtsspezifische Unterschiede konnten nicht festgestellt werden.

Diskussion: Die schon bei niedrigen BAKen deutliche Verschlechterung im Vergleich zur nüchternen Fahrleistung bestätigt ein besonderes $\mathrm{Ge}$ fährdungspotential durch Alkoholisierung bei Benutzung von E-Scootern und dürfte vermehrt zur Annahme „relativer Fahrunsicherheit" führen. Darüber hinaus geben die Ergebnisse der Studie Anlass zu diskutieren, ob der gegenwärtige Beweisgrenzwert "absoluter Fahrunsicherheit" im Zusammenhang mit der Benutzung von E-Scootern herabgesetzt werden muss.

Der Romberg- und Unterberger-Test sind aufgrund ihrer Prüfung von Stand- und Gangunsicherheit als ergänzende Untersuchungsmethode zur Prüfung der Fahrsicherheit in Betracht zu ziehen.

Fazit: Da schon bei niedrigen BAKen eine deutliche Verschlechterung im Vergleich zur nüchternen Fahrleistung vorlag, könnte von juristischer Seite eine Herabsetzung dieser Grenze diskutiert werden.

\section{V-TX-13}

\section{Beurteilung einer (tödlichen?) Alkoholkonzentration in Obduktionsblutproben - eine Kasuistik}

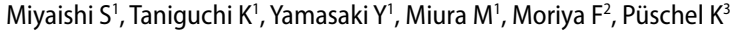

'Institut für Rechtsmedizin, Universität Okayama, Okayama, Japan; ${ }^{2}$ Fachbereich Pflegewissenschaft, Kawasaki Universität für Medizinisches Wohlergehen, Kurashiki, Japan; ${ }^{3}$ Institut für Rechtsmedizin, Universitätsklinikum Hamburg-Eppendorf, Hamburg, Deutschland

Einleitung: Bei der Beurteilung der Alkoholkonzentration (AK) im Leichenblut muss man die Möglichkeit postmortaler Veränderungen berücksichtigen. Wir berichten über einen Fall, in dem die AK im Herzblut (HB) im Zusammenhang mit einer Aspiration von Mageninhalt (MI) das tödliche Niveau erreichte.

Falldarstellung: An einem Tag im Januar wurden zwei Männer (Opfer A und B) in einem vier Tage unbeachteten Auto tot aufgefunden. Die Verstorbenen waren 33 und 34 Jahre alt und saßen auf dem Fahrer- respektive Beifahrersitz. Flaschen für alkoholische Getränke waren geöffnet (AK $9 \%$, die vermutlich eingenommene Menge lag bei total 1000 bis $1500 \mathrm{ml}$ ), daneben lagen verbrannte Grill-Briketts.

Obduktionsbefunde: Opfer A: $87 \mathrm{~kg}$ Körpergewicht bei $180 \mathrm{~cm}$ Körperlänge. Hellrote Totenflecke. $370 \mathrm{ml}$ wässriger MI mit deutlichem Alkoholgeruch. Luftwege frei. CO-Sättigung im HB: $75 \%$. AK (mg/g): 0,72 und 0,27 im HB links und rechts; 0,13 und 0,12 im Femoralblut (FB) links und rechts; 27,40 im MI. Todesursache (TU): CO-Vergiftung. Postmortales Intervall (PMI): 5 Tage.

Opfer B: 84 kg Körpergewicht bei $175 \mathrm{~cm}$ Körperlänge. Hellrote Totenflecke. $80 \mathrm{ml}$ blutig-wässriger MI mit deutlichem Alkoholgeruch. Aspiration des Mls bis in die tiefen Atemwege. CO-Sättigung im HB: $75 \%$. AK (mg/g): 5,27 und 1,09 im HB links und rechts; 0,23 und 0,11 im FB links und rechts; 0,16 im Urin; 27,41 im MI. TU: CO-Vergiftung. PMl: 5 Tage.

Diskussion: Die Todesursache sowie das postmortale Intervall der beiden männlichen Opfer waren gleich. Alter, Körperbau und Körperhaltung waren ähnlich. Nur Opfer B aspirierte den MI bis in die tiefen Atemwege. Die AK im HB zwischen den beiden Verstorbenen war deutlich unterschiedlich, obwohl die AK in sonstigen Obduktionsmaterialien unauffällig waren. Die AK im linken HB des Opfers B $(5,27)$ erreichte ein tödliches Niveau. Es ist davon auszugehen, dass die Diffusion des Alkohols vom aspirierten $M I$ in der Lunge mit extrem hoher AK $(27,41)$ die AK im linken HB des Opfers erhöhte. Die höhere AK im rechten HB des Opfers $B(1,09)$ im Vergleich mit Opfer $A(0,27)$ könnte von der Diffusion des Alkohols direkt vom Luftweg und über das linksseitige $\mathrm{HB}$ resultieren. Die relativ höhere $A K$ im $\mathrm{HB}$ $(0,72$ und 0,27$)$ als im FB $(0,13$ und 0,12$)$ des Opfers A könnte als Diffusion von $\mathrm{Ml}$ oder postmortale Alkoholproduktion interpretiert werden. 
Forensische Molekularbiologie und Lehre

V-FM-1 bis V-FM-10

\section{V-FM-1}

\section{Von der Entdeckung des genetischen Fingerabdrucks zur forensischen DNA-Phänotypisierung: Die rasante Entwicklung eines Fachgebiets}

Walter Bär ${ }^{1}$, Katja Anslinger ${ }^{2}$

IInstitut für Rechtsmedizin, Zürich, Schweiz; ${ }^{2}$ Institut für Rechtsmedizin, LMU, München, Deutschland

Nicht einmal vier Jahrzehnte ist es her, als der britische Genetiker Alec Jeffreys den genetischen Fingerabdruck entdeckte und die Methode in kürzester Zeit so weiterentwickelte, dass sie zuerst zur gerichtlichen Klärung von Abstammungs- und Einwanderungsfällen, etwas später dann auch für die individualisierende Untersuchung von Spuren eingesetzt werden konnte. Eine Entdeckung, die als Meilenstein in der Geschichte der forensischen Genetik gilt und das Fundament für die bemerkenswerte Entwicklung dieses Fachgebiets darstellt.

Vor allem der Erfindung der PCR durch Kery Mullis ist es zu verdanken, dass im Laufe der Zeit immer sensitivere Analysemethoden entwickelt werden konnten. Wurden anfangs noch große Mengen hochmolekularer DNA für eine erfolgreiche Analyse benötigt, ist heute die Erstellung eines Identifizierungsmusters aus geringsten DNA-Mengen, ja sogar einer einzelnen Zelle, möglich. Kein anderer Bereich der rechtsmedizinischen Forschung hat die Strafverfolgung in den letzten Jahrzehnten mehr beeinflusst.

Schon längst beschäftigt sich die Wissenschaft nicht mehr ausschließlich nur mit der Erstellung von Identifizierungsmustern zum Zwecke der Abstammungsbegutachtung und Spurenanalyse. Gesetzesänderungen in vielen Ländern erlauben heute auch Untersuchungen zur Vorhersage äuBerlich sichtbarer Merkmale, der biogeographischen Herkunft sowie des Alters eines unbekannten Spurenverursachers.

Der Vortrag blickt zurück auf die Arbeit der Pioniere des Fachs, erinnert an die wichtigsten Entwicklungen und Neuerungen auf dem Weg in die moderne forensische Molekularbiologie und gibt einen Überblick über die aktuellen Schwerpunkte der Forschung.

\section{V-FM-2 \\ Die Vermessung der Zeit: Die DNA-Methylierung als Biomarker für die forensische Altersschätzung}

\section{Jana Naue}

Institut für Rechtsmedizin, Universitätsklinikum Freiburg, Medizinische Fakultät, AlbertLudwigs-Universität, Freiburg, Deutschland

Übersichtsreferat: In den Bereichen Altersforschung und Epigenetik wurden in den letzten Jahren viele neue Erkenntnisse gewonnen, welche auch Fortschritte für die Möglichkeiten der forensischen Altersschätzung gebracht haben. Die DNA-Methylierung ist eine von mehreren epigenetischen Regulatoren, welche für die forensische Molekularbiologie besonders interessant ist, da sie an bestimmten Positionen im Genom eine altersabhängige Zu- oder Abnahme zeigt. Diese Veränderungen sind mit modernen molekularbiologischen Methoden messbar und die benötigte DNA wird für die klassische STR-Analyse ohnehin extrahiert, sodass eine parallele Analyse erleichtert wird. Mit der Erweiterung des $\S 81 \mathrm{e}$ der StPO wurde überdies die rechtliche Grundlage für die Anwendung in der Fallarbeit geschaffen. Mittlerweile wurden verschiedenste Methoden und Modelle, welche altersabhängige DNA-Methylierungsmarker nutzen, entwickelt. Dadurch kann das chronologische Alter eines unbekannten Spurenlegers oder Verstorbenen, sowie von lebenden Individuen geschätzt werden. Die Erfolge der Methodik basieren insbesondere auf der interdisziplinären Forschung in den verschiedensten Fachbereichen wie der Medizin, Molekularbiologie, Bioinformatik und Mathematik und deren praktische Implementierung. Wie bei allen, insbesondere ,jungen" Methoden, gibt es auch kritische Aspekte, die bei der Anwendung bedacht werden müssen bzw. die noch weiterer Forschung bedürfen, um das volle Potenzial der Methodik auszunutzen.

Der Vortrag wird neben einer Einführung in die interdisziplinären Grundlagen einen Überblick über die Entwicklungen von der Identifizierung der Biomarker, der Etablierung von Methoden zur Detektion bis zur Erstellung und Etablierung von Vorhersagemodellen geben. Dabei sollen Möglichkeiten und Limitierungen aufgezeigt werden. Neben der Altersschätzung auf Basis der DNA-Methylierung wird auch kurz auf andere molekulare Biomarker eingegangen, welche im Fokus der aktuellen Forschung und (potenziellen) Anwendung stehen.

\section{V-FM-3}

Forensische Lebensaltersschätzung auf Basis der DNA-Methylierung: Signifikant veränderte DNA-Methylierungsmuster bei Kindern mit Wachstumsstörungen sind zu berücksichtigen

J. Becker', T. Gündüz', J. Blum ', F. Mayer', B. E. Koop', W. Wagner², S. Eickhoff ${ }^{3 ;}$, P. Böhme', S. Ritz-Timme'

'Institut für Rechtsmedizin, Universitätsklinikum Düsseldorf, Moorenstr. 5, 40225 Düsseldorf; ${ }^{2}$ Helmholtz Institute for Biomedical Engineering, Stem Cell Biology and Cellular Engineering, RWTH Aachen University Medical School, 52074 Aachen; ${ }^{3}$ nstitut für Systemische Neurowissenschaften, Universitätsklinikum Düsseldorf, Düsseldorf; ${ }^{4}$ Institut für Neurowissenschaften und Medizin, Gehirn und Verhalten (INM-7), Forschungszentrum Jülich, 52428 Jülich

Einleitung: Die Lebensaltersschätzung auf Basis der Methylierung von DNA (DNAm) gewinnt zunehmend an Bedeutung in der forensischen Praxis. Hinsichtlich des Einflusses endo- sowie exogener Faktoren auf die DNA-Methylierung besteht nach wie vor Forschungsbedarf, um entsprechende Fehlermöglichkeiten zu kennen und zu adressieren.

Methode: Vor diesem Hintergrund wurde die DNA-Methylierung an fünf Genorten (PDE4C, DDO, EDARADD, ELOVL2, RPA2) in Mundschleimhautabrieben von 104 Kindern mit Wachstumsstörungen (1-17 Jahre) mittels Pyrosequenzierung untersucht. Als Vergleichskollektiv diente eine Gruppe von unauffälligen Individuen derselben Altersgruppe (0,08-20 Jahre). Unterschiede zwischen den beiden Kollektiven wurden mittels ANCOVA getestet. Zudem wurde das Alter der Kinder mit Wachstumsstörungen über ein Modell geschätzt, das auf Basis der Analyse der genannten Marker in Mundschleimhautabrieben von 368 unauffälligen Probanden über einen Random Forest Ansatz und unter Optimierung für die Altersgruppe bis 20 Jahren entwickelt wurde.

Ergebnisse/Diskussion: Es ergaben sich signifikante Unterschiede zwischen den Kindern mit Wachstumsstörungen und den unauffälligen Kindern in den Markersystemen PDE4C, DDO und insbesondere RPA2. Diese Unterschiede führten zu systematischen und erheblichen Abweichungen der für die Kinder mit Wachstumsstörungen über das etablierte Modell geschätzten Lebensalter. Die grundlagenwissenschaftliche Interpretation der Befunde steht noch aus. Hier erscheint insbesondere das RPA2-Gen interessant; Replication Protein A (RPA) ist ein multifunktionales Protein, das u. a. essentiell für DNA-Replikation und Zellzyklus-Progression ist und bereits in Zusammenhang mit Wachstums- und Entwicklungsstörungen diskutiert wurde.

Fazit: Im Blick auf die forensische molekulare Lebensaltersschätzung belegen die erhobenen Daten, dass bei Kindern mit entsprechenden Störungen große Vorsicht geboten ist. 


\section{V-FM-4}

\section{Pushing the boundaries: forensic phenotyping challenged by single-cell sequencing}

\author{
Marta Diepenbroek, Birgit Bayer, Katja Anslinger \\ Institut für Rechtsmedizin der Ludwig-Maximilians-Universität, München, Germany
}

Question: A single human cell contains around $6 \mathrm{pg}$ of DNA consisting of about $2 \times 3.3$ billion base pairs. Sequencing of this amount of genomic data became possible thanks to the rapid development of the Next Generation Sequencing. The meaning of the single cell sequencing in medicine cannot be overestimated but in forensics this branch is not commonly used. The main motivation behind introducing this technology into forensics is the potential to improve the mixture deconvolution. If a trace is a mixture of different biological materials (like for an example blood and epithelium) there are methods to separate cell pools and to investigate them separately. Problems arise when the mixed trace consists of the same cell type. Several studies, including our own, presented that it is possible to deconvolute such a mixture by separating single cells and obtaining from them a CE-based STR profile. The results suggest the potential in other forensic applications, like the forensic phenotyping. In principal, it is not recommended to use mixed stains to analyse the externally visible characteristics. Therefore, we evaluated a possibility of performing a reliable prediction of a mixture contributors' phenotypes.

Methods: For this study we collected autopsy blood from which the white cells were first stained and later separated with the DEPArray ${ }^{\mathrm{TM}}$ NxT System. Pools of 20, 10 and 5 cells as well as 20 single cells were collected and submitted for DNA extraction. All the extracts were amplified with our custom assay, Ion AmpliSeq ${ }^{\text {TM }}$ PhenoTrivium Panel, which includes both phenotype and ancestry associated SNV-markers. Prior to sequencing, half of the single-cell based libraries were additionally amplified and purified in order to improve the libraries concentrations.

Results and Discussion: Ancestry and phenotype analysis resulted in nearly full consensus profiles and correct predictions obtained for the cells groups. The re-amplification of single-cell based libraries resulted in $400 \%$ higher average total coverage and increase of genotyping rate from mean $26 \%$ to $78 \%$. A nearly full consensus profile and correct predictions were obtained also for the single cells.

Conclusion: Our results suggest that single-cell sequencing can be a promising tool used to deconvolute mixed traces submitted for the forensic phenotyping.

\section{V-FM-5 \\ FORMics: Forensic Microbiome and Metabolome Analysis for Body Fluid Identification}

\author{
Meghna Swayambhu' ${ }^{1}$, Tom Schneider ${ }^{1}$, Cordula Haas ${ }^{1}$, Andrea Steuer ${ }^{1}$, \\ Thomas Krämer ${ }^{1}$, Rolf Kümmerli², Natasha Arora ${ }^{1}$ \\ 'Institut für Rechtsmedizin Zürich, Universität Zurich, Winterthurerstraße 190/52, \\ CH-8057, Zürich, Switzerland; '2Department of Quantitative Biomedicine, University of \\ Zurich, Winterthurerstraße 190, CH-8057 Zurich, Switzerland
}

Research question: In a forensic investigation, body fluid identification plays an important role in the reconstruction of criminal activity and selection of samples for downstream analyses. Microbiome composition as well as metabolites have been posited as promising novel methods but their potential has not yet been fully investigated. In our project, we investigate the reliability of microbiome data as well as the utility of metabolites for body fluid identification from biological evidence.

Methods: In this study, we examined 7 forensically relevant body fluid categories namely: saliva, semen, urine, feces, vaginal fluid, menstrual blood and blood. We carried out targeted amplification of bacterial $16 \mathrm{~S}$ rRNA gene regions to analyse the microbial signatures of control samples along with mixtures and samples deposited on substrates. The DNA sequence data was then analysed using open source bioinformatic tools (DADA2) and PCA plots were generated using R. To study the metabolic signatures, control samples were analysed using a high resolution Liquid Chromatography-Quadrupole Time Of Flight Mass Spectrometer (LC-QTOF-MS, Sciex 6600). The metabolic data was then analysed using Progenesis QI and statistical analysis was done using metaboanalyst 5.0.

Results: Overall, the PCA/PCoA for both types of data showed that samples group according to their bodily origin. We also found microbial DNA data recovered from aged samples and samples deposited on substrates to be a reliable indicator of body fluid. For some body fluids, metabolite markers were more informative due to the challenges posed by low microbial content or taxonomic distinction.

Discussion: Our results indicate that data from bacterial communities may also be useful when samples are recovered from substrates, which is a setting characteristic of forensic scenarios. To our knowledge, this is the first study examining metabolic signatures across a wide range of body fluid categories and donors. Our analyses show that metabolites too yield a clear distinction among body sites. Thus, we demonstrate the potential of a novel and accurate method for body fluid identification using both microbial and metabolic signatures.

Conclusion: Our pilot studies show body fluids can be distinguished with microbial and metabolic

signatures. Thus, we aim to combine these two methods in our future studies to increase the prediction accuracies for forensic body fluid identification.

\section{V-FM-6 iNOS Expression in postmortalen humanen Infarktherzen zum Nachweis von oxidativem Stress}

Wilmes $V^{1}$, Niess $C^{1}$, Gradhand $E^{2}$, Verhoff $M A^{1}$, Kauferstein $S$

'Institut für Rechtsmedizin, Universitätsklinikum Frankfurt, Goethe-Universität, Frankfurt am Main, Deutschland; ${ }^{2}$ Senckenbergisches Institut für Pathologie, Universitätsklinikum Frankfurt, Goethe-Universität, Frankfurt am Main, Deutschland

Fragestellung: Der Myokardinfarkt zählt zu den häufigsten Todesursachen in Deutschland. Der Erforschung der zugrundeliegenden molekularen Vorgänge kommt somit eine entscheidende Rolle zu.

Die Bildung von oxidativ wirksamen Molekülen verursacht oxidativen Stress und kann zu zellulären Veränderungen führen. Oxidativer Stress könnte somit einen wichtigen Faktor im Rahmen eines Myokardinfarkts darstellen. Die induzierbare Stickoxidsynthase (iNOS) stellt hier einen wichtigen Marker dar. iNOS katalysiert die Entstehung von Stickoxid, kann aber auch die Entstehung von radikalem Sauerstoff katalysieren, was Gewebeschädigung und Zelltod zur Folge hat. In dieser Studie sollte ein Beitrag zur Aufklärung der Rolle der iNOS bei Myokardinfarkt geleistet werden.

Methode: Es wurden die mRNA-Expression mittels q-RT-PCR, sowie das Zellexpressionsmuster der iNOS mittels immunhistochemischer Färbungen im infarzierten und nicht infarzierten Myokard untersucht und mit gesunden Kontrollen verglichen. Dazu wurden CD68- und iNOS-Färbungen angewendet.

Ergebnisse: In den infarzierten Regionen zeigte sich iNOS signifikant hochreguliert im Vergleich zu gesunden Kontrollen, während die iNOS Proteinexpression hauptsächlich in den Makrophagen sichtbar war. Zudem zeigte sich ein deutlicher Anstieg der iNOS Proteinexpression in den infarzierten Herzen.

Diskussion: Unsere Ergebnisse sind ein Hinweis auf erhöhten oxidativen Stress bei Myokardinfarkt. Die durch oxidativen Stress ausgelösten Zellschädigungen könnten in Zusammenhang mit dem Schweregrad des Infarktes stehen. Des Weiteren deuten die Ergebnisse auf eine komplexere Regulation der iNOS Expression hin, die mit der Makrophagenpolarisierung und dem Infarktalter zusammenhängen könnte.

Fazit: iNOS stellt somit einen wichtigen Marker zur Untersuchung einer kardialen Erkrankung bei Verstorbenen durch oxidativen Stress auf molekularer Ebene dar. 


\section{V-FM-7}

\section{Hebelwerkzeuge als Spurenträger}

\section{David Hollenbach', Sabine Cappel ${ }^{2}$, Darius Makuch ${ }^{1}$, Peter Schmidt ${ }^{2}$}

${ }^{1}$ Landespolizeipräsidium Saarland, Dezernat LPP 242 - Kriminaltechnik; ${ }^{2}$ Universität des Saarlandes, Inst. f. Rechtsmedizin, Geb. 49.1, 66421 Homburg (Saar)

Fragestellung: Werkzeuge als Spurenträger gewinnen zunehmendes Interesse in der forensischen DNA-Analyse. Im Untersuchungsgut des Homburger Instituts ist eine deutliche Zunahme von Hebelspuren zu verzeichnen. Deswegen verfolgt die vorliegende Studie das Ziel, systematisch den DNA-Gehalt entsprechender Spuren zu ermitteln und damit ein rational begründetes Konzept für die Tatortarbeit zu entwickeln.

Methode: 2 Versuchspersonen setzten mit 6 verschiedenen Hebelwerkzeugen (4 Schraubendreher, 2 Nageleisen) an 3 Fenstern verschiedener Materialart (Holz, Aluminium, Kunststoff) in jeweils 24 definierten Arealen Hebelspuren. Die Spurenlegereigenschaft der Probanden wurde initial durch Analyse an Gegenständen des täglichen Gebrauchs (Handy) überprüft. Fenster und Werkzeuge wurden mit Microbac forte, bzw. DNA Exitus gereinigt. Anschließend wurden die Werkzeuge 3-mal täglich, an 3 aufeinanderfolgenden Tagen durch mittelkräftiges 10-mal Händereiben kontaminiert. Die Abriebe wurden standardisiert analysiert (DNA-Extraktion mit EZ1 DNA-Investigator Kit, Investigator Lyse/Spin-Basket Kit der Firma Quiagen; Quantifizierung mittels Real-Time PCR, Investigator Quantiplex Pro Kit der Firma Quiagen, Multiplex-PCR mit PowerPlex ${ }^{\circledast}$ ESX 17 Kit der Firma Promega und Kapillarelektrophorese mittels 3500 Genetic Analyzer von Applied Biosystems und Gene Mapper ID-X Software). Die Analyse erfolgte in Doppelbestimmungen.

Ergebnisse: Insgesamt wurden 144 Bestimmungen an 72 Spuren durchgeführt. Lediglich an einer Spur wurde DNA in einer Konzentration von $22 \mathrm{pg} / \mu \mathrm{l}$ nachgewiesen und ein auswertbares Profil generiert. Dieses Experiment betraf die Versuchsperson mit der besten Spurenlegereigenschaft, einen Schraubendreher als Werkzeug und ein Kunststofffenster.

Diskussion: Auch wenn der positive Befund zunächst den Rückschluss auf einen Nutzwert bei der polizeilichen Fallarbeit legitimiert, sind bei der Bewertung die Spurenlegung unter Laborbedingungen mit extremem DNA-Abgabeverhalten sowie bei der Übertragung auf den realen Fall die Möglichkeit von vorbestehenden Kontaminationen mit Fremd-DNA zu bedenken.

Fazit: Bei einer "Erfolgsaussicht" von größenordnungsmäßig $1 \%$ obliegt die abschließende Bewertung der polizeilichen Einschätzung der jeweiligen Ermittlungslage.

\section{V-FM-8}

\section{Generationenwandel in der Rechtsmedizin - Konfliktpotential oder Chance?}

\section{Anna Heger, Stefanie Ritz-Timme}

Institut für Rechtsmedizin, Universitätsklinikum Düsseldorf, Düsseldorf, Deutschland

Fragestellung: Im Berufsleben treffen inzwischen mind. drei Generationen aufeinander: ,Babyboomer" (GenB, Jahrgänge <1965) , ,Generation X" (GenX, 1965-1980) und "Generation Y" (GenY, 1981-1995). Inwiefern der Generati-onenwandel Auswirkungen auf den Arbeitsalltag in der Rechtsmedizin hat und welches Konfliktpotential daraus resultiert, wurde bisher noch nicht untersucht.

Methoden: Im Sept. 2019 wurde eine Online-Umfrage an 436 rechtsmedizinisch tätige ÄrztInnen verschickt. Der Frage-bogen enthielt u.a. Fragen zur Zusammenarbeit mit anderen Generationen und daraus resultierenden Konfliktsituationen. Im Sept. 2020 wurden zwei Fokusgruppeninterviews (mit 5 FachärztInnen der GenX \& GenB bzw. 4 AssistenzärztInnen der GenY) durchgeführt, um die Thematik vertiefend zu erörtern. Es erfolgte eine quantitatiV-deskriptive Auswertung, wo sinnvoll, sowie eine qualitative Inhaltsanalyse der Fragebögen und der transkribierten Interviews.
Ergebnisse: 48,6 \% der 181 Umfrage-TeilnehmerInnen gehören der GenY an, $36,5 \%$ der GenX und $14,4 \%$ der GenB. $72,9 \%$ der ÄrztInnen gaben an, bei der Zusammenarbeit mit anderen Generationen Konfliktsituationen zu kennen (keine sign. Unterschiede zwischen den Generationen). Die meisten Konflikte drehen sich um die Themen Arbeitszeit \& WorkLife-Balance. WeiterbildungsassistentInnen (WBA) nannten zudem u.a. eine mangelnde Wissensvermittlung, eine ungerechte Aufgabenverteilung, das Ansetzen unterschiedlicher Maßstäbe und eine mangelnde Diskussionsbereitschaft seitens erfahrener FachärztInnen als Problemfelder. FachärztInnen nannten als Probleme u.a. eine mangelnde Eigeninitiative hinsichtlich WB, Routine und Wissenschaft, Selbstüberschätzung und mangelnde Kollegialität seitens der WBA.

Diskussion: Generationenunterschiede sind für die meisten RechtsmedizinerInnen spürbar. Obwohl die unterschiedlichen Prioritäten/Sichtweisen teilweise bekannt sind, resultieren im Alltag Konflikte. Eine erschwerte Anpassung alter Strukturen an veränderte Anforderungen und gegenseitige Missverständnisse dürften dazu maßgeblich beitragen. Offene Kommunikation, Veränderungs- und Kompromissbereitschaft sind erforderlich, um das gegenseitige Verständnis und die Qualität der (Zusammen-)Arbeit zu steigern und um zur Berufszufriedenheit und Weiterentwicklung unseres Faches beizutragen.

Fazit: Der Generationenwandel ist auch aus dem rechtsmedizinischen Alltag nicht mehr wegzudiskutieren. Es bedarf gemeinsamer Anstrengungen, um potenzielle Konfliktfelder zu reduzieren.

\section{V-FM-9}

\section{Umsetzung und Erweiterung des Lehrangebotes des Institutes für Rechtsmedizin in Mainz in Zeiten der Corona-Pandemie}

\section{U.-D. Immel, T. Germerott, K. Elsner \\ Institut für Rechtsmedizin der Universitätsmedizin Mainz}

Fragestellung: Im Zusammenhang mit der Corona-Pandemie wurde eine Umstellung des Lehrangebotes der Johannes-Gutenberg-Universität in Mainz erforderlich.

Methoden: Das bisher bestehende Lehrangebot für die rechtsmedizinische Ausbildung bestand aus einem Praktikum mit sechs Doppelstunden theoretischem Unterricht sowie zwei Einzelstunden Leichenschaukurs als praktische Einheiten. Ergänzt wurden diese Pflichtveranstaltungen durch zwei freiwillige Vorlesungseinheiten pro Woche zu verschiedenen ausbildungsrelevanten rechtsmedizinischen Themen, die mittels eines webbasierten Video-Content-Management-Systems für die Studierenden aufgezeichnet wurden. Die Videos wurden über die zentrale Lehrplattform "Moodle" der Universität Mainz verlinkt und den Studenten zugänglich gemacht. Weiterhin mussten die Studierenden Hausaufgaben zu spezifischen Themen, wie u. a. „Leichenschau/Totenschein ausstellen“ bearbeiten und diese einreichen. Da der Leichenschaukurs im ersten Semester (Sommersemester 2020) auf Grund der Hygienevorschriften der hiesigen Universität nicht stattfinden durfte, wurden gemeinsam mit der Rudolf Frey Lernklinik der Universitätsmedizin Mainz mehrere Lehrvideos gedreht. Diese beinhalteten zum einen eine vollständige Leichenschau und zum anderen eine Obduktion. Als weiteres Tool wurde anfangs die Lernsoftware „Inmedea“ (Telemed CompuGroup Medical Deutschland AG) zur Verfügung gestellt, in der die Studierende Fälle zu bearbeiten hatten.

Im Verlauf der Semester wurden weitere virtuelle Lehrangebote (u.a. Seminare zu speziellen Themen wie Klinische Rechtsmedizin und zur Todesbescheinigung) aus den vorangegangenen Erfahrungen entwickelt und den Studierenden angeboten.

An den Semesterenden wurden alle Studierenden zum aktuellen Lehrangebot in eine Befragung eingeschlossenen, um das bereitgestellte Lehrangebeot zu evaluieren und vor allem innovativ weiterzuentwickeln. Ergebnisse und Diskussion: Wir stellen unsere Erfahrungen mit den von uns erarbeiteten Alternativen des Lehrangebotes, die Auswertung der Be- 
fragung und das Feedback der Studierenden zur Umsetzung unserer Lehrangebotes vor und diskutieren die verschiedenen Punkte.

Fazit: Zudem gehen wir auf weitere Planungen für die kommenden Semester ein.

\section{V-FM-10 \\ Wie hat die Corona-Pandemie die Gestaltung der rechtsmedizinischen Lehre beeinflusst?}

\author{
Britta Bockholdt, Martin Dokter und Klaus-Peter Philipp \\ Institut für Rechtsmedizin Universitätsmedizin Greifswald, Greifswald, Deutschland
}

Fragestellung: Die Approbationsordnung (ÄAppO) stellt die Grundlage der ärztlichen Ausbildung dar; die Studien- und Prüfungsordnung regelt auf der Grundlage der Approbationsordnung für Ärzte in der jeweils gültigen Fassung den Inhalt und den Aufbau des Medizinstudiums an der Universität Greifswald. Das Fach Rechtsmedizin wird an der Universität Greifswald im 10. Semester gelehrt; das Curriculum besteht aus $23 \mathrm{~h}$ Vorlesungen, $6 \mathrm{~h}$ Praktika und $8 \mathrm{~h}$ Seminaren. Das Semester ist für die Seminare in 8 Gruppen geteilt. Am zeitintensivsten waren immer die Praktika, da diese in Kleingruppen (je 6-8 Studierende) absolviert wurden. Im Sommersemester 2020 war aufgrund der Corona-Pandemie die Durchführung dieser regulären Lehrveranstaltungen in Präsenz nicht möglich.

Methode: Es mussten sehr schnell alternative Lehrformate gefunden werden. Sehr unkompliziert wurden die Vorlesungen digitalisiert und den Studierenden über das E-Learning-Portal des Studiendekanates online zur Verfügung gestellt. Die Seminare konnten in gekürzter Form ebenfalls digital abgehalten werden. Das Leichenschaupraktikum wurde von uns selbst als Lehrfilm erstellt und den Studierenden online zum Selbststudium bereitgestellt. Zusätzlich entwickelten wir einen Vorlesungsteil über die Problemfelder der ärztlichen Leichenschau.

Ergebnisse: Diese Lehrformate wurden im Sommersemester 2020 von den Studierenden sehr gut angenommen. Da erkennbar war, dass auch im Sommersemester 2021 keine Präsenzlehre in klassischer Form möglich sein wird und das Studiendekanat entsprechende Ausstattungen bereitgestellt hatte, war es möglich, erneut die Vorlesungen digital anzubieten und die Seminare in vollem Umfang digital abzuhalten. Einen erheblichen Qualitätssprung erreichten wir im praktischen Teil, mit Unterstützung von professionellen Kameraleuten wurde ein Lehrfilm über die ärztliche Leichenschau in höchster Qualität erstellt.

Diskussion: Die Evaluation dieser Lehrveranstaltungen aber auch eine fakultätsinterne Umfrage zur digitalen Lehre erbrachte neben Ergebnissen, die wir erwartet haben, auch Unerwartetes. Beispielsweise evaluierten die Studierenden die digital bereitgestellten Vorlesungen als sehr gut; ein Aspekt, den wir so nicht erwartet hätten, insofern wird es wahrscheinlich in Greifswald keine Rückkehr zum klassischen Vorlesungsformat in Präsenz geben.

Fazit: Nach den aufgrund der Pandemie erzwungenen Änderungen in den Lehrformaten und den Evaluationsergebnissen sind digitale Vorlesungen und Seminare als geeignete Alternative zum Präsenzunterricht zu bewerten.
Bildgebung/ldentifikation - Vortragsprogramm $\mathrm{V}-\mathrm{BI}-1$ bis V-BI-9

\section{V-BI-1 \\ Multispektrale 3D Ganzkörper-Photogrammetrie zur Detektion und Dokumentation von latenten Spuren und Verletzungen}

Sören Kottner ${ }^{1}$, Martin M. Schulz ${ }^{2}$, Florian Berger ${ }^{1}$, Michael J. Thali ${ }^{1}$, Dominic Gascho

${ }^{1}$ Institut für Rechtsmedizin, Universität Zürich, Winterthurerstraße 190/52, 8057 Zürich, Schweiz; ${ }^{2}$ Institut für Rechtsmedizin, Ludwig-Maximilians-Universität München, Nussbaumstraße 26, 80336 München, Deutschland

Fragestellung: Mit Hilfe von Photogrammetrie lässt sich aus einer Serie von überlappenden Einzelfotos ein dreidimensionales (3D) Farb- und Oberflächenmodel des gesamten Körpers eines Verstorbenen rekonstruieren. Diese Methode wurde bislang mit gewöhnlichen Fotoaufnahmen im sichtbaren Bereich des elektromagnetischen Spektrums durchgeführt. Durch den Einsatz von multispektraler Photographie lässt sich die reine Dokumentation um die Detektion von nicht sichtbaren (latenten) Spuren erweitern. Zu diesem Zweck wurde im Rahmen dieser Studie eine Methode zur multispektralen 3D Ganzkörper-Photogrammetrie entwickelt und evaluiert.

Methode: Ein Multikamerasystem basierend auf vier modifizierten Spiegelreflexkameras, ultraviolett (UV) und infrarot (IR) Lichtquellen, sowie zusätzlichen Objektivfiltern wurde auf einem angefertigten Holzrahmen montiert und in Kombination mit einem medizinischen Computertomographen (CT) verwendet. Der automatische Tischvorschub des CTs wurde für die sequenzielle Erfassung der einzelnen Körperabschnitte genutzt. Im Anschluss wurde ein Ganzkörper CT Scan ohne Positionsänderung des Körpers durgeführt.

Ergebnisse: Texturierte 3D Modelle basierend auf multispektralen Datensätzen von vier Beispielfällen konnten berechnet und rekonstruiert werden. Die Qualität und Detailgenauigkeit der Polygonmodelle war abhängig davon, in welchem Spektralbereich der photogrammetrische Datensatz aufgenommen wurde. Die Dauer einer Ganzkörper-Dokumentation betrug bei UV-Beleuchtung durchschnittlich $5 \mathrm{~min}$. und bei Weisslicht bzw. IR-Beleuchtung ca. 3 min.

Diskussion: Das multispektrale Kamerasystem ermöglicht innerhalb weniger Minuten eine 3D Erfassung des gesamten Körpers im erweiterten elektromagnetischen Spektrum. Die multispektralen Ganzkörperaufnahmen in Kombination mit CT Scans erlauben eine Zusammenführung und Befundung der äusseren und inneren Körperdokumentation.

Fazit: Eine multispektrale 3D Dokumentation erweitert die forensische Dokumentation von Verstorbenen und ermöglicht nicht sichtbare Spuren und Verletzungen zu detektieren und dokumentieren.

\section{V-BI-2}

\section{Quantitative optimization of the FLAIR sequence in post} mortem magnetic resonance imaging

\footnotetext{
C. Berger ${ }^{1,2}$, M. Bauer ${ }^{1,2}$, E. Scheurer ${ }^{1,2}$, C. Lenz ${ }^{1,2}$

'Institute of Forensic Medicine, Department of Biomedical Engineering, University of Basel, Basel, Switzerland; ' Institute of Forensic Medicine, Health Department Basel-Stadt, Basel, Switzerland

In magnetic resonance imaging (MRI), the fluid attenuated inversion recovery (FLAIR) sequence suppresses the cerebrospinal fluid (CSF) signal by acquiring images at CSFs null point inversion time $\left(\mathrm{TI}_{\text {null }}\right){ }^{1}$ The latter indicates the time point at which the longitudinal magnetization $\left(T_{1}\right)$ of CSF is zero. ${ }^{1}$ Furthermore, it is known that $\mathrm{T}_{1}$ and subsequently $\mathrm{TI}_{\text {null }}$ decreases with a decreasing brain temperature, therefore it is crucial to correct $\mathrm{TI}_{\text {nul }}$ for temperature in order to suppress CSF signal in post mortem FLAIR se-
} 
Fig. $1<$ Plot of $\mathrm{TI}_{\text {wll }}$ as a function of the brain temperature and fitted by a linear model (red) with its confidence interval (red shaded area)

quence due to the passive cooling of the deceased. ${ }^{2,3}$ However, these studies examined the temperature dependence of brain CSFs $\mathrm{TI}_{\text {null }}$ using the core temperature, although the brain and core temperature reveal different temperature cooling rates. ${ }^{4}$ Thus, the goal of this study is to determine the brain temperature effect on post mortem $\mathrm{TI}_{\text {null }}$ in order to suppress CSF signal using FLAIR in in situ post mortem MRI.

For this purpose, 8 deceased subjects $\left(\mathrm{T}_{\text {brain }}=4.9-14.9^{\circ} \mathrm{C}\right)$ underwent an in situ MRI brain examination on a 3T scanner. $\mathrm{TI}_{\text {null }}$ of CSF was determined quantitatively using a FLAIR sequence [TR/TE: $15,000 / 81 \mathrm{~ms}$, Tls: $800-2800 \mathrm{~ms}$ ] by automatic segmentation of CSF using FSL and fitting an exponential model voxelwise to the signal intensity of CSF and the inversion time. ${ }^{5}$ The brain temperature was determined transethmoidally prior to the MRI scan in order to determine the temperature dependency of CSFs $\mathrm{TI}_{\text {null. }}$.

A significant positive linear relation $(, p<0.05, r=0.78)$ was found between $\mathrm{TI}_{\text {null }}$ of CSF and the brain temperature (see $\bullet$ Fig. 1).

The results reveal a linear temperature dependency of $\mathrm{TI}_{\text {null }}$. Further, the found linear relation between $\mathrm{TI}_{\text {null }}$ and the brain temperature allows the correction of $\mathrm{TI}_{\text {null }}$ for the brain temperature of the deceased in the FLAIR sequence post mortem. This allows an optimal suppression of CSF signal in post mortem FLAIR MR image.

\section{References}

1. Hajnal et al., JCAT, 1992

2. Tofts et al., MRM, 2008

3. Abe $K$ et al., MRMS, 2015

4. Bartgis et al., JTB, 2016

5. Zhang, Y. et al., T-MI, 2001

\section{V-BI-3}

Realitätsnahe dreidimensionale Darstellung von Verletzungen in der Rechtsmedizin - umfragebasierter Methodenvergleich von CRT und VRT

\section{G. M. Bruch'1, S. Grabherr ${ }^{1,2}$, K. Engel ${ }^{3}$, P. Glemser ${ }^{4,5}$ \\ 'Centre Universitaire Romand de Medecine Legale, Centre Hospitalier Universitaire Vaudois, Chemin de la Vulliette 4, CH - 1000 Lausanne 25, Schweiz; ${ }^{2}$ Centre Universitaire Romand de Medecine Legale, Hopitaux Universitaires de Geneve, Rue Michel-Servet 1 , $\mathrm{CH}-1211$ Geneve 4, Schweiz; ${ }^{3}$ Medical Imaging Technologies, Siemens Healthcare Technology Center, Erlangen, Deutschland, ${ }^{4}$ Department of Radiology, German Cancer Research Center (DKFZ), Heidelberg, Deutschland, ${ }^{5}$ Radiologie Franken-Hohenlohe, Hohenloher Str. 1, Neckarsulm, Deutschland}

Einleitung: Forensisches Bildmaterial aus postmortalen Computertomographien (PMCT) und postmortale CT-Angiographien (PMCTA) im Auftrag von Polizei und Staatsanwaltschaft sind ein zunehmender Bestandteil rechtsmedizinischer Gutachten. Diese müssen die detektierten Befunde (wie z. B. komplexe Frakturen, Blutungsquellen etc.) für Juristen und Polizisten "laienverständlich“ darstellen. Hierfür hat sich, zusätzlich zu der Darstellung in 2D, eine dreidimensionale Visualisierung mittels Volume Rendering Technique (VRT) etabliert. Seit kurzem ist eine neuartige 3DVisualisierungsmöglichkeit basierend auf Techniken aus dem Animationsfilm mit speziellen Kamera- und Lichteffekten verfügbar, die als Cinematic Rendering (CRT; Siemens Frontier, Siemens Healthineers, Erlangen) be-

zeichnet wird. Diese Software könnte die Verständlichkeit und Nachvollziehbarkeit von Gutachten für die Auftraggeber weiter verbessern. Methode: Um einen möglichen Nutzen der neuen CRT-Software, im Vergleich zu der etablierten VRTSoftware zu untersuchen, wurden insgesamt 14 PMCTA-Fälle mit beiden Visualisierungstechniken aus der jeweils selben Ansicht rekonstruiert. Die erstellten Rekonstruktionen wurden hinsichtlich verschiedener quantitativer und qualitativer Parameter wie z. B. „Anzahl ersichtlicher Knochenverletzungen“, „Vorstellung der Lage einer Pathologie" und "Beurteilung der Lebensbedrohlichkeit" sowohl von Rechtsmedizinern als auch von medizinischen Laien (Juristen \& Polizisten) mittels eines Online-Fragebogens getrennt beurteilt.

Ergebnisse: Erste Ergebnisse zeigen hinsichtlich der „Beurteilung der Lebensbedrohlichkeit" keine relevanten Unterschiede zwischen CRT und VRT. Bezüglich der "Vorstellung der Lage einer Pathologie" zeigte sich CRT gegenüber VRT in den ersten Ergebnissen überlegen.

Durch eine möglichst realitätsgetreue Darstellung von Verletzungen in 3D Visualisierungen kann sich eine grössere Verständlichkeit eines Fachgutachtens für Strafverfolgungsbehörden ergeben. Somit würde sich auch die interdisziplinäre Kommunikation der verschiedenen, an einem Fall beteiligten Fachgruppen verbessern. Die Ergebnisse der Studie werden im Rahmen des Kongresses präsentiert.

\section{V-BI-4}

\section{Radiologische Zeichen des letalen Status epilepticus}

\section{A. Albers' ${ }^{1}$ T. A. Engelmann'1, S. Heinze², M. Klintschar ${ }^{1}$}

'Institut für Rechtsmedizin, Medizinische Hochschule Hannover (MHH), Hannover, CarlNeuberg-Straße 1, 30625 Hannover, Deutschland; ${ }^{2}$ Institut für Rechts- und Verkehrsmedizin, Universitätsklinikum Heidelberg, Heidelberg, Voßstraße 2, 69115 Heidelberg

Die Todesursachenfeststellung als eine der zentralen Fragestellungen bei der rechtsmedizinischen Leichenöffnung ist insbesondere bei todesursächlichen Erkrankungen bzw. Zustandsbildern ohne fassbares morphologisches Korrelat mit besonderen Schwierigkeiten verbunden. Ein ebensolches Zustandsbild stellt u. a. der letale Status epilepticus dar. Zwar sind in der einschlägigen Fachliteratur typische Befunde beschrieben, die jedoch allenfalls als hinweisgebend zu bewerten sind, sodass durch zusätzliche radiologische Zeichen eine gesteigerte Diagnosesicherheit erreicht werden dürfte.

Ein 41-jähriger Mann verstirbt 10 Monate nach einer längere Zeit unentdeckt gebliebenen Methylquecksilberintoxikation in einem durch medizinisches Personal beobachteten und letztlich therapierefraktären Status epilepticus. Bei einer postmortalen CT-Untersuchung imponiert eine bilaterale anteriore Kiefergelenkluxation. Im Rahmen der Obduktion zeigen sich als wesentliche Befunde eine augenscheinlich frischere Bisswunde in der Mundschleimhaut sowie eine Hirnatrophie mit Zeichen akuter ischämischer und hämorrhagischer Veränderungen sowie einem umschriebenen Erweichungsherd im linken Hinterhauptlappen.

Ein 74-jähriger Mann stürzt unbeobachtet von einem Schlafsofa und wird nicht ansprechbar und krampfend von seinen Angehörigen aufgefunden Er verstirbt im stationären Behandlungsverlauf. Im Rahmen der klinischerseits durchgeführten radiologischen Diagnostik kommen Brüche der Oberarmköpfe und beider Oberschenkelhälse zur Darstellung, die nicht durch ein einfaches Sturzgeschehen bzw. Transport- und Bergungsmaßnahmen erklärlich sind. Diese Befunde bestätigen sich intra obductionem.

In der aktuellen Literatur finden sich einzelne Darstellungen denkbar krampfbedingter Knochenbrüche, jedoch keine Beschreibung einer bilateralen Kiefergelenkluxation als postmortales Zeichen des Status epilepticus. Im Rahmen des Vortrages sollen zwei Fallbeispiele vorgestellt und typische Knochenbrüche sowie Luxationen als mögliche postmortale Diagnosekriterien sowie die Bedeutung der postmortalen bildgebenden Verfahren in diesem Zusammenhang diskutiert werden. 


\section{V-BI-5 \\ Histopathologische Befunde ultraschallgestützter Organpunktionen bei SARS-CoV-2 Sterbefällen}

Julia Schädler ${ }^{1}$, Antonia Fitzek1 , Dustin Möbius', Inga Kniep ${ }^{1}$, Alexandra Ron¹, Axel Heinemann', Stefan Steurer ${ }^{2}$, Benjamin Ondruschka

${ }^{1}$ Institut für Rechtsmedizin, Hamburg-Eppendorf, Deutschland; ${ }^{2}$ Institut für Pathologie, Hamburg-Eppendorf, Deutschland

Fragestellung: Die ultraschallgestützte minimal invasive Autopsie (usMIA) offenbart sich als leicht zugängliches und kosteneffizientes Verfahren mit hoher diagnostischer Leistung. Neben der Frage nach der Durchführbarkeit der usMIA und Treffsicherheit der Punktionen sollte beantwortet werden, ob dieses Verfahren zur Klärung der Todesursache geeignet ist und ob die untersuchten Personen mit oder an COVID-19 verstorben sind.

Methode und Ergebnisse: Die usMIA kombiniert eine Ultraschalluntersuchung des Thorax und Abdomens mit ultraschall-gestützten Organbiopsien und anschließender histologischer Untersuchung. Der Untersuchungszeitraum für diese am Institut für Rechtsmedizin des UKE durchgeführte Studie erstreckte sich über 8 Monate. Am Beispiel von 37 SARS-CoV-2 assoziierten Todesfällen werden die Ultraschall- und Histologiebefunde anhand repräsentativer Beispiele vorgestellt.

Diskussion: Durch die rasche und mobile Verfügbarkeit der usMIA kann ein kurzes postmortales Intervall bis zur Organpunktion eingehalten werden, welches eine gute Qualität der histologischen Schnitte erlaubt. Die usMIA stellt eine adäquate Alternative zur konventionellen Obduktion dar, vor allem, wenn Angehörige im Zwiespalt stehen zwischen dem Wunsch, das Wissen über die abschließende Todesursache zu erlangen, aber die Invasivität einer konventionellen Autopsie aus unterschiedlichen Gründen ablehnen. Dies spiegelt sich in einer hohen Zustimmungsquote für diese Untersuchungsmethode wider.

\section{V-BI-6}

\section{Evaluation der Repräsentativität von Gebiss- \& Zahnstatus bei zahnärztlicher-forensischer Befundung}

Wieser $\mathrm{M}^{1}$, Abriani $\mathrm{A}^{2}$, Kunz $\mathrm{SN}^{1,3}$

'Universität Ulm; ${ }^{2}$ VITAL Zahnärzte Augsburg GmbH; ${ }^{3}$ Institut für Rechtsmedizin Ulm

Hintergrund: Bei unbekannten Verstorbenen gilt die Identifizierung mittels Gebissstatus als juristisch anerkannte und bewährte Methode. Die postmortal odontologische Befunderhebung und der darauffolgende Abgleich mit dem ante mortem zahnärztlichen Befund erweist sich jedoch im klinischen Alltag als erschwert. Der Repräsentativität des klinischen Gebissbefundes zur Identifizierung von unbekannten Leichnamen geht diese Studie nach.

Material und Methoden: Postmortal wurde im Rahmen der Sektion ein klinischer Befund/Gebiss-/Zahnstatus erhoben. Von der Studie ausgeschlossen wurden Verstorbene mit fehlenden dentalen Überresten, Unbekannte mit zahnlosem Befund oder mit Milchgebiss. Untersucht wurde die Anzahl, Position und der Zustand vorhandener Zähne, die Anzahl, Position und Art von Restaurationen, anatomische Anomalien, sowie das Vorhandensein von Implantaten. Ermittelt wurde die individuelle Diskrepanz zwischen ante- und post mortem Befund bezüglich der genannten Parameter. Zudem werden die zeitliche Diskrepanz beider und das Vorhandensein einer prämortalen röntgenologischen Bildgebung im Sinne einer Panoramaschichtaufnahme (PSA) ermittelt.

Ergebnisse: Aufgrund der noch geringen Ergebnisse ist eine vollständige, repräsentative Schlussfolgerung noch nicht darzulegen. Die vorläufigen Ergebnisse zeigen, dass bei vorliegenden Vergleichsdaten die Identifizierung mittels Abgleich des rein klinisch post mortem erhobenen Befundes mit dem dokumentierten Zahnstatus beim Hauszahnarzt grundsätzlich möglich und gerichtsverwertbar durchzuführen ist.

Limitierend ist bei dieser Art der Identifizierung die Qualität der hauszahnärztlichen Dokumentation.
V-BI-7

Identifizierung eines Skeletts durch ein Zahnimplantat: Falldarstellung:

Jung Harald ${ }^{1}$, Simion Simina Petra ${ }^{1}$, Kurt Trübner², Sorin Popsor ${ }^{3}$

Institut für Rechtsmedizin Targu Mures, Rumänien; ${ }^{2}$ Institut für Rechtsmedizin, Universitätsklinikum Essen, Deutschland; ${ }^{3}$ Lehrstuhl für Zahnprothetik, Universität für Medizin und Pharmazie Targu Mures, Rumänien

Die Feststellung der Identität eines Verstorbenen nach längerer Liegezeit, insbesondere beim Fehlen von Weichteilen kann oft nur in Zusammenarbeit zwischen Rechtsmediziner, Polizei, Zahnarzt, Radiologen und forensischer Genetik gelingen.

Kasuistik: Ein fast vollständiges menschliches Skelett wurde zufällig im Wald von einem Jäger aufgefunden. Die Untersuchung des Schädels ergab zwei glatt umrandete Löcher im Os frontale, die auf eine frühere neurochirurgische Operation hindeuteten und ein überkrontes Zahnimplantat in Position 11. Die anderen Zähne waren vollständig vorhanden mit Zahnfüllungen der Zähne 36 und 38. Die Analyse relevanter anthropologischer Merkmale und des Obliterationsgrades von Schädelnähten deuteten auf eine männliche Leiche im Alter von ungefähr 40 Jahren hin. Für die Beschreibung des Zahnimplantates wurde ein dentoalveoläres Röntgenbildangefertigt. Das Implantat wies folgende Merkmale auf: 10-11 mm langes Implantat mit Innenverbindung, aufgestelltem Kopf, konischem Körper und abgerundeten Gewinde. Die Untersuchung der anderen Skelettteile ergab ein kleines Metallfragment(abgebrochene Messerspitze) in der Spina scapulae, sowie Knochenscharten in den Wirbeln und Rippen durch mehrere Messerstiche. Aufgrund von Informationen aus Zahnarztpraxen in unserer Region, die Implantate einsetzen, konnte die Identität der Person festgestellt werden. Als Todesursache wurden Stichverletzungen vermutet. Dies wurde schließlich durch den festgenommenen Täter bestätigt und eine Liegezeit von anderthalb Jahren konnte bestimmt werden.

Diskussion und Fazit: Die Charakteristika der Zahnimplantate können für die forensische Identifizierung wichtige Informationen geben, z.B. Hersteller und Lieferungszeitintervall. Jedoch können die Implantate nicht eindeutig einer Person zugeordnet werden, denn sie haben keine indviduelle Seriennummer. Ein Landesregister für Zahnimplantate sollte eingeführt werden, das auch für forensische Zwecke genutzt werden könnte.

V-BI-8

Euthanasie im Nationalsozialismus - Untersuchungen an drei Skeletten der Kriegsgräberstätte Idstein-Kalmenhof (Hessen)

F Holz', K Mückenberger ${ }^{2}$, F Kántor ${ }^{2}$, JE Schulte ${ }^{3}$, V Krause ${ }^{4}$, J Kozlowski ${ }^{5}$, CG Birngruber', C Wunder', R Zehner', W Betz ${ }^{6}$, S Fischer ${ }^{7}$, MA Verhoff'

Institut für Rechtsmedizin, Universitätsklinikum Frankfurt, Goethe-Universität, Frankfurt am Main; ${ }^{2}$ Landesamt für Denkmalpflege Hessen, hessenARCHÄOLOGIE, Wiesbaden; ${ }^{3}$ Landeswohlfahrtsverband Hessen, Fachbereich Archiv, Gedenkstätten, Historische Sammlungen, Hadamar; ${ }^{4}$ Volksbund Deutsche Kriegsgräberfürsorge e.V., Landesverband Hessen, Frankfurt am Main; ${ }^{5}$ Volksbund Deutsche Kriegsgräberfürsorge e. V., Landesverband Brandenburg, Halbe; ${ }^{6}$ Institut für Diagnostische und Interventionelle Radiologie, Universitätsklinikum Frankfurt, Goethe-Universität, Frankfurt am Main; ${ }^{7}$ Zentrum der Zahn-, Mund- und Kieferheilkunde, Carolinum Zahnärztliches Universitäts-Institut $\mathrm{gGmbH}$, Frankfurt am Main

Hintergrund: Der Kalmenhof wurde 1888 vom „Verein für die Idiotenanstalt zu Idstein" gegründet. Ursprüngliches Ziel war es, geistig behinderten Menschen eine Unterbringung und das Nachgehen einer sinnvollen Tätigkeit zu ermöglichen. Durch das NS-Regime wurde die Einrichtung praktisch verstaatlicht, in der "Kinderfachabteilung" wurden hunderte Kinder und Jugendliche von Ärzten ermordet und an unterschiedlichen Orten in Idstein begraben.

Material und Methoden: Zur Feststellung der Grenzen des zur Kriegsgräberstätte erklärten „Anstaltsfriedhofs“ wurden im Sommer 2020 Grabun- 
gen durchgeführt. Die knöchernen Überreste von drei unbekannten Individuen wurden exhumiert und untersucht. Von den Langknochen und den rekonstruierten Kiefern wurden Röntgenaufnahmen gefertigt, ferner erfolgten chemisch-toxikologische und molekulargenetische Untersuchungen.

Ergebnisse: In einer Bodentiefe zwischen 100 und $122 \mathrm{~cm}$ wurde in einer $160 \times 65 \mathrm{~cm}$ großen Grube eine Mehrfachbestattung mit drei Individuen aufgefunden. Die Knochen lagerten teils übereinander, die Ausrichtung der Skelette unterschied sich voneinander. Zwei Individuen waren männlich, Sterbealter etwa 2,0 bis 2,25 Jahre bzw. 2,5 Jahre. Das dritte Individuum war eine jugendliche weibliche Person, mit makroskopischen und radiologischen Hinweisen auf wiederholte und längere Zeit vorherrschende Phasen mit unzureichender Nährstoffversorgung. An keinem der Knochen waren Hinweise auf eine körperliche Behinderung festzustellen, prä- oder perimortale Verletzungen fanden sich nicht. Die chemisch-toxikologischen Untersuchungen verliefen negativ. Bei den kindlichen Individuen konnte jeweils ein vollständiges STR-Profil, bei dem jugendlichen Individuum ein STR-Teilprofil erstellt werden.

Diskussion: Die Untersuchungsergebnisse stehen in Einklang mit historischen Angaben, wonach es zu Mehrfachbelegungen von Gräbern kam. Eine ursprünglich angenommene Unterteilung des Friedhofes nach dem Sterbealter war nicht nachvollziehbar. Dank der guten interdisziplinären Zusammenarbeit konnten Erkenntnisse gewonnen werden, anhand derer nun ein konkreter Identitätsverdacht erarbeitet werden soll. Die knöchernen Überreste wurden am Volkstrauertag 2020 im Rahmen einer Gedenkveranstaltung wieder beigesetzt.

\section{V-BI-9}

\section{Case-Report über Fund einer weitgehend skelettierten Leiche im Wald - Charakterisierung der Schädelfrakturen}

\section{Schweitzer W, Thali M, Bolliger S, Roidou M}

Institut für Rechtsmedizin der Universität Zürich, Schweiz

Fall: eine weitgehend skelettierte Leiche, die in einem Wald gefunden wurde, wurde später über DNA-Vergleich als 45-jähriger Mann identifiziert. Auffallend war eine relativ hochgradige Fragmentierung des Schädels im Gegensatz zum übrigen, intakte Knochen aufweisenden Skelett.

Methode und Ergebnisse: die Bruchmorphologie wurde mit Fällen mit stumpfer Gewalt gegen den Kopf sowie mit Fällen nach Kopfschuss verglichen. Aufgrund der Vergleiche, deren Einzelheiten im Tagungsbeitrag dargestellt werden, kamen wir zum Schluss, dass eine Sprengwirkung oder Schuss im Vordergrund stehen dürfte. Insbesondere war neben der Orientierung der Bruchlinien die Kantenmorphologie hierfür ausschlaggebend. Im Rahmen dieser Auswertungen kam in diesem Fall als Ergebnis außerdem hinzu, dass der 45 Jahre alte Mann über Ausbildung und Erfahrungen mit Sprengmitteln verfügte.

Diskussion: die Auswertung der Bruchmorphologie bei der Abgrenzung von stumpfer Gewalt gegenüber rascher eintretender Gewalt wie bei Schuss oder Explosion könnte durch einen vertieften Einbezug der Kantenveränderungen gewinnen. Auf diese Möglichkeit hatten indessen bereits Passalacqua und Rainwater (Skeletal Trauma Analysis, Wiley, 2015) hingewiesen.

Traumatologie Verkehr

V-TR-1 bis V-TR-13

\section{V-TR-1 \\ Traumatomechanik - Wesen, Geschichte und Ausblick als Teilgebiet der Rechtsmedizin}

Felix Walz, Zürich; Steffen Peldschus

München. Deutschland
Die Traumatomechanik, auch als Trauma-Biomechanik, Verletzungs(bio) mechanik und forensische Biomechanik bezeichnet, umfasst die Betrachtung mechanisch induzierter Entstehung von Verletzungen. Darin werden insbesondere externe Vorgänge über die physikalischen Zusammenhänge zu Kräften und Bewegungen mit den Strukturen des menschlichen Körpers verbunden und verletzungsrelevante mechanische Belastungen der Gewebe adressiert. Es kommen dabei eine Vielzahl von Verletzungsmechanismen, welche verschiedene Verletzungen mit möglichen Belastungen in einen kausalen Zusammenhang stellen, in Frage. Die Erforschung und Anwendung des Wissens dieses Teilgebiets der Rechtsmedizin erfordert Kenntnisse in sehr unterschiedlichen Bereichen wie z. B. der Anatomie, Physiologie und Mechanik.

Die genannten Zusammenhänge werden in der Forschung am häufigsten im Zusammenhang mit Unfällen im Straßenverkehr analysiert, was u. a. an der Häufigkeit des Auftretens und, insbesondere im Falle von betroffenen Fahrzeuginsassen, an einer natürlichen Gruppierung im Sinne von Lasteinträgen liegt. Ein bedeutendes Beispiel dafür ist die Heckkollision mit möglichen Verletzungsfolgen an der Halswirbelsäule.

In diesem Vortragsblock wird abschließend ein Blick in Zukunft geworfen und die Frage adressiert, inwiefern computergestützte Methoden die Arbeit im interdisziplinären Feld der Verletzungsmechanik unterstützen können. Zunächst sind hier Mehrkörpersysteme zu betrachten, die sich für die Analyse von Anstoßvorgängen und kinematischen Antworten des menschlichen Körpers etabliert haben. Daneben halten in der Forschung zunehmend Modelle auf Basis der Methode der Finiten Elemente Einzug, mit denen sich bei Vorliegen entsprechender experimenteller Grundlagen Belastungen in den menschlichen Geweben analysieren lassen. Im Vergleich zur Bearbeitung von Fragestellungen der Prävention sind im forensischen Kontext der Verletzungsmechanik die individuellen Charakteristika des Körpers von größter Bedeutung. In diesem Zusammenhang stellt die Individualisierung von numerischen Modellen, z. B. auf Basis medizinischer Schnittbilder oder Oberflächenscans, eine besondere Herausforderung dar.

\section{V-TR-2}

\section{Außergewöhnlicher Fall einer inkompletten Dekapitation mit vollständiger Enthirnung nach} Überrollen

Vanessa Thoma', Dominik Schuldis' ${ }^{1}$, Andreas Lickert ${ }^{2}$, Anette Thierauf-Emberger ${ }^{1}$

${ }^{1}$ Institut für Rechtsmedizin, Freiburg/Deutschland; ${ }^{2}$ DEKRA Automobil GmbH, Freiburg/ Deutschland

Einleitung: Der Tod infolge einer Enthauptung, also der gewaltsamen Abtrennung des Kopfes vom Rumpf, ist im Allgemeinen ein eher seltenes Ereignis im rechtsmedizinischen Untersuchungsgut. Dekapitationen werden vorwiegend im Rahmen von Suizidhandlungen ( $<1 \%$ aller Suizide) etwa nach Schienenfahrzeugüberfahrungen, seltener auch nach Stürzen aus großer Höhe in eine meist unelastische Schlinge bei Erhängungsfällen, beobachtet. Eine weitere Kategorie stellen Hochrasanzunfälle dar, die in $<0,01 \%$ der Fälle mit einer Dekapitation einhergehen. Speziell im Hinblick auf verunfallte Kraftradfahrer finden sich in der vorhandenen Literatur lediglich einzelne Fallbeispiele einer (Teil-)Dekapitation. Neben einem direkten Trauma durch Aufprall mit einem Hindernis kann auch eine massenträgheitsbedingte Hyperextension des Nackens, teilweise unter zusätzlicher Einwirkung des Kinnriemens des getragenen Schutzhelmes, ursächlich für die Kopfabtrennung sein. Eine (Teil)Enthauptung (von motorisierten Zweiradfahrern) nach Überrollen wurde (nach derzeitigem Kenntnisstand) bisher noch nicht beschrieben und ist deshalb - auch unter Berücksichtigung der Unfallrekonstruktion - von forensischer Bedeutung.

Kasuistik: Ein 69 Jahre alter, behelmter Rollerfahrer $\left(125 \mathrm{~cm}^{3}\right)$ befuhr die in die rechte Fahrspur übergehende Auffahrt zu einer Bundesstraße. Zeitgleich habe ein Sattelzug von der linken auf den rechten Fahrstreifen ge- 
wechselt und hierbei den bevorrechtigen, bereits den rechten Fahrstreifen befahrenden Rollerfahrer übersehen. Der Rollerfahrer habe noch versucht auszuweichen und sei in der Folge auf einem angrenzenden Grünstreifen in Pendelbewegung gekommen, habe die Leitplanke touchiert und sei gestürzt. Nach Spurenlage sei er zwischen Zugmaschine und Auflieger auf der Fahrbahn zu Liegen gekommen. Anschließend sei der Rollerfahrer im Bereich des Kopfes von der rechten Radseite des Sattelzuges überrollt worden. Der Sattelzug habe Fahrerflucht begangen. Der Rollerfahrer verstarb unmittelbar an der Unfallstelle. Hauptbefundlich imponierte eine inkomplette Enthauptung mit vollständiger Enthirnung. Unfallhergang und Verletzungsmuster werden unter Berücksichtigung des technischen Sachverständigengutachtens vorgestellt und diskutiert.

\section{V-TR-3 \\ Was ist härter? Augustiner vs. Coca Cola vs. Weinbau Geyer}

Hurzlmeier $\mathrm{C}^{1}$, Nentwig $\mathrm{C}^{1}$, Adamec $\mathrm{J}^{2}$, Kunz SN ${ }^{1,2}$

'Universität Ulm; ${ }^{2}$ Institut für Rechtsmedizin, Ludwig-Maximilians Universität Ulm; ${ }^{3}$ Institut für Rechtsmedizin Universitätsklinikum Ulm

Hintergrund: Die klinische Begutachtung von Kopfverletzungen durch Schläge mit Glasflaschen sowie die Einschätzung deren Verletzungspotential ist ein wichtiges Thema rechtsmedizinischer Expertise. Im Rahmen der juristischen Aufarbeitung eines entsprechenden Sachverhalts stellen sich die Fragen nach der tatsächlich erfolgten Tathandlung und der akuten sowie potenziellen Lebensgefahr einer getroffenen Person.

Material und Methoden: Leere Glasflaschen der Augustiner Brauerei München, der Coca-Cola GmbH sowie des Weinhandels Geyer wurden hinsichtlich ihrer maximalen Schlagkraft und des damit einhergehenden Verletzungspotentials bei Schlägen auf den Schädel untersucht. Manuell wurden die Glasflaschen auf einen Dummy-Kopf aus Aluminium geschlagen, welcher mit Kunsthaut aus Acryl oder mit Schweineschwarte überzogen und auf einer Kistler Kraftmessplatte fixiert war.

Ergebnisse: Die Wahrscheinlichkeit durch einen Schlag mit einer leeren Glasflasche lebensbedrohliche Verletzungen des Gesicht- und/oder Gehirnschädels hervorzurufen ist abhängig von der Form, Dicke und Beschaffenheit des Tatwerkzeuges.

Bei Kontakt der untersuchten Glasflaschen im Gesichtsbereich sind Knochenverletzungen grundsätzlich möglich.

Durch einen Glasflaschenschlag gegen den Schädel lebensgefährliche Verletzungen hervorzurufen konnte im vorliegenden Vergleich mit absteigender Wahrscheinlichkeit von Coca Cola > Augustiner > Weinbau Geyer bewertet werden.

\section{V-TR-4}

\section{Biomechanische Analyse von Schlägen durch kampfsporterfahrene Personen}

Peter Hofer ${ }^{1}$, Jutta Schöpfer ${ }^{2}$, Matthias Graw², Fabio Monticelli ${ }^{1}$ Stefan Pittner ${ }^{1}$, Jiri Adamec ${ }^{2}$

'IFFB Gerichtsmedizin und Forensische Neuropsychiatrie, Paris-Lodron-Universität Salzburg, Österreich; ${ }^{2}$ nstitut für Rechtsmedizin München, Ludwig-Maximilians-Universität München, Deutschland

Fragestellung: Die Beurteilung von Schlägen hinsichtlich ihrer Gefährlichkeit ist eine wesentliche Anforderung an rechtsmedizinische Sachverständige. Schon in vorangegangenen Publikationen konnten wesentliche biomechanische Grundlagen unterschiedlicher Schlagtechniken dargelegt werden. In unseren früheren Untersuchungen wurden spezifisch trainierte Personen (Kampfsportler*innen) ausgeschlossen, da wir einen starken Einfluss auf die Schlagparameter erwartet haben. In der gegenständlichen Arbeit erfolgt ein Vergleich zwischen Probandengruppen mit und ohne eine Kampfsporterfahrung.
Methode: Es erfolgte die Messung wesentlicher Schlagparameter von zehn erfahrenen Kampfsportler*innen. Diese mussten seit mindestens zwei Jahren regelmäßig (mindestens 2x/Woche) unterschiedliche Kampfportarten betreiben. Zum Vergleich wurden die Ergebnisse von Messungen derselben Schlagtechniken, ausgeführt von untrainierten Personen, herangezogen. Die Schläge wurden an einer Kraftmessplatte durchgeführt, welche die Kraftübertragung mit einer Frequenz von $10 \mathrm{kHz}$ registrierte. Die Schlaggeschwindigkeit wurde mittels Hochgeschwindigkeitskamera gemessen.

Ergebnisse: Es konnte bei systematischem Vergleich dieser zwei Gruppen die bereits vermuteten, teils deutlichen Unterschiede in der Höhe des Kraftstoßes festgestellt und quantifiziert werden. Ausschlaggebend waren hierfür nicht alleinig (wie eventuell anzunehmen) Unterschiede biometrischer Parameter. Die durch Training verbesserte Schlagtechnik ist als Ursache für die höhere erzielte Schlagintensität zu sehen.

Diskussion: Es muss diskutiert werden, ob durch kampfsporterprobte Personen ausgeführte Schläge in ihrer Gefährlichkeit strenger beurteilt und eingestuft werden müssen. In der gegenständlichen Arbeit wurden Unterschiede einzelner Kampfsportarten zueinander nicht berücksichtigt, dies soll Ziel weiterführender Arbeiten sein.

Fazit: Rückschlüsse über die Gefährlichkeit von Schlägen sollten nicht alleinig aufgrund etwa der Statur oder Geschlecht von Beschuldigten erfolgen. Auch Kampfsporterfahrungen und die Frage nach regelmäßigem Training müssen hierzu stets miteinfließen.

\section{V-TR-5}

\section{Tin ear syndrome revisited}

\author{
J. Adamec ${ }^{1 *}$, P. Hofer ${ }^{2 *}$, J. Schöpfer ${ }^{1}$, S. Pittner ${ }^{2}$, F. Monticelli ${ }^{2}$, M. Graw ${ }^{1}$ \\ ${ }^{1}$ Institut für Rechtsmedizin der Universität München, Deutschland; ${ }^{2}$ Gerichtsmedizin \\ und Forensische Neuropsychiatrie, Paris Lodron Universität Salzburg, Österreich
}

Fragestellung: Als Folge körperlicher Misshandlung von Kindern wurde im Fachschrifttum das so genannte "Tin ear syndrome“ beschrieben - die Kombination einer einseitigen Verletzung der Ohrmuschel (Hämatom), des radiologischen Nachweises einer ipsilateralen Hirnschwellung und retinalen Blutungen. Als Ursache wird eine Ohrfeige, bzw. ein direkt gegen das Ohr geführter Schlag mit der flachen Hand und die daraus resultierende ruckartige Kopfbewegung mit einer wesentlichen Drehkomponente angenommen. Henigan et al. führten zur Eingrenzung der Krafteinwirkung einer Ohrfeige bzw. zur Frage, ob die oben genannte Krafteinwirkung durch einen Schlag mit der flachen Hand erreicht werden kann, eine Kraftmessung durch. Die präsentierten Messergebnisse waren jedoch aus unserer Sicht auffällig.

Methode: Im Zuge eines großen Forschungsvorhabens haben wir Kraftmessungen mit dem Ziel durchgeführt, Vergleichsdaten mit der o.g. Studie zu generieren. Mit der flachen Hand wurde auf eine Kraftmessplatte direkt sowie auf ein auf ihr fixiertes Polster - geschlagen.

Ergebnisse: Die aus unseren Messungen resultierenden Kraft-Zeit-Kurven wichen in mehreren wesentlichen Merkmalen, trotz identischer Vorgehensweise (Schläge auf eine fixierte Kraftmessplatte), stark von den durch Henigan et al. präsentierten Daten ab.

Diskussion: Die festgestellten Unterschiede lassen sich nicht durch die Messmethode, das Messequipment oder die Schlagausführung erklären, vielmehr muss von einer fehlerhaften Darstellung der Zeitachse ausgegangen werden. Kritisch zu bewerten ist ferner das Verhältnis zwischen durch solche Schläge zu erreichender Stoßintensität (Kraftstoß bzw. Kraft) und den im Fachschrifttum zu findenden Toleranzwerten für das "Tin ear syndrome". Im Beitrag werden die Zusammenhänge zwischen Messungen und realen Vorgängen mit der Verletzungsentstehung im Allgemeinen erörtert.

Fazit: Biomechanische Messdaten stellen eine wichtige und objektive Bewertungsgrundlage dar. Bei ihrer Erhebung, Darstellung und Interpretation ist jedoch stets große Vorsicht geboten, denn eine einfache Korrespondenz zwischen einer Labormessung und einem realen (Verletzungs-)Vorgang ist selten gegeben. 


\section{V-TR-6}

Numerische Simulation oberflächennaher Weichgewebsdeformation bei Belastung durch nichtletale Wirkmittel

Felicitas Lanzl', Günther Löwisch², Steffen Peldschus ${ }^{1}$

${ }^{1}$ Abteilung für Biomechanik und Unfallforschung, Institut für Rechtsmedizin, LudwigMaximilians-Universität München; ${ }^{2}$ Fakultät für Maschinenbau, Universität der Bundeswehr München

Schlagwörter: Stumpfe Gewalteinwirkung, Materialmodell, Finite Elemente, Weichgewebe, Nicht-letale Wirkmittel

Fragestellung: Die Gewebe des Weichteilmantels - Haut, subkutanes Fettgewebe und Muskelgewebe - spielen für die Bewertung von Verletzungen infolge stumpfer Gewalteinwirkung eine große Rolle. Da sie die äußersten Schichten des menschlichen Körpers bilden, stehen zunächst abhängig von der Belastungsart Verletzungsrisiken in diesen Geweben selbst im Raum. Daneben beeinflussen sie die Spannungen und Dehnungen, die auf die unterliegenden Strukturen, wie innere Organe oder Knochen, übertragen werden und somit auch deren Verletzungsrisiko.

Methode: Im Rahmen dieser Studie wurde ein dehnratenabhängiges Materialmodell der oberflächlichen Weichgewebe zur Simulation dynamischer Anprallvorgänge in der Simulationsumgebung LS-DYNA entwickelt. Versuchsaufbauten der Belastung von Schweinegewebe mit einem halbkugelförmigen Impaktor wurden als Finite-Elemente-Modell abgebildet. Mit dem FE-Modell eines Arms wurden Versuche an Probanden nachgestellt.

Diskussion: Die Simulationsergebnisse stimmten mit den Ergebnissen aus der Belastung von Schweinegewebe mit einem halbkugelförmigen Impaktor bei unterschiedlichen Geschwindigkeiten gut überein. Mit dem Modell konnten anschließend die Freiwilligenversuche simuliert werden, bei denen der Oberarm der Probanden unter ähnlichen Bedingungen sowohl im entspannten als auch im angespannten Zustand impaktiert wurde.

Diskussion: Die Modellierung der oberflächennahen Weichgewebe stellt eine Herausforderung dar, da sie nichtlineares Verhalten aufweisen, welches von der Belastungsgeschwindigkeit abhängt. Das hier entwickelte Modell kann beispielsweise Anwendung finden, um das Verletzungsrisiko einzelner Knochen oder Organe bei Beschuss mit nicht-letalen Wirkmitteln oder Trauma hinter ballistischem Körperschutz zu untersuchen.

\section{V-TR-7 \\ Die Schreckschussmunition 9 mm P. A. K. Rubber - Das kann ins Auge gehen.}

Marcus Schwarz'1, Jan Dreßler', Ronny Bayer', Benjamin Ondruschka²

'Institut für Rechtmedizin, Medizinische Fakultät, Universität Leipzig, Deutschland; ${ }^{2}$ Institut für Rechtsmedizin, Universitätsklinikum Hamburg-Eppendorf, Deutschland

Fragestellung: In mehreren Fällen, kam es zum Schusswaffengebrauch mit Schreckschusswaffen unter Einsatz eines bisher in der Literatur wenig beachteten Waffensystems. Dadurch wird das Gefahrenpotential, das in der Regel von diesen Waffen ausgeht, massiv erhöht, da eine Hartgummikugel mit sehr hoher Geschwindigkeit abgeschossen wird. Dieses System und erste Ergebnisse der Datenerhebung sollen vorgestellt werden.

Methode: Ergebnisse der rechtsmedizinischen körperlichen Untersuchungen wurden ausgewertet um anschließend Rekonstruktionen mit ballistischer Gelatine und Knochensurrogat durchzuführen. Es wurden erste ballistische Daten ermittelt und das Verletzungspotential eingeschätzt.

Ergebnisse: Die maximale Anfangsgeschwindigkeit der Projektile (Durchmesser $9 \mathrm{~mm}$ ) wurde mit bis zu $545 \mathrm{~m} / \mathrm{s}$ gemessen. Bei einem Geschossgewicht von ca. 0,65 g ergibt sich eine Anfangsenergie von $96 \mathrm{~J}$. Die hohe Geschwindigkeit wird dadurch erreicht, dass die Schreckschusswaffe nicht über eine Laufsperre, sondern über einen auf $6 \mathrm{~mm}$ verengten Lauf verfügt, durch den das, sich durch den Gasdruck verformende Projektil, ge- presst wird. Dies führt zu Durchschüssen von $5 \mathrm{~mm}$ starken Platten aus Knochensurrogat auf bis zu $5 \mathrm{~m}$ Entfernung. Ballistische Gelatine wird hinter den Knochenplatten noch bis zu Tiefen von $4 \mathrm{~cm}$ penetriert. Bei einem mit Gelatine gefüllten Schädelreplikat findet sich das Projektil in $3,5 \mathrm{~cm}$ Tiefe. Die Ein- und Ausschüsse sind im Vergleich zu Geschossen aus Metall größer, da sich beim Auftreffen das Hartgummiprojektil zuerst elastisch verformt, bis die Grenzenergie des Surrogats überschritten wird.

Diskussion: Anders als bei vergleichbaren, teils modifizierten Schreckschusswaffen, bei denen eine Gummi- oder Plastikkugel in den Lauf einer Waffe vor eine Schreckschusspatrone vorgeladen wird, handelt es sich bei der $9 \mathrm{~mm}$ P. A. K. Rubber um eine im Internet gehandelte Munition. Hierzu passende Schreckschusswaffen sind in unterschiedlichen Ausführungen, angepasst nach den jeweiligen Waffengesetzen der Mitgliedsstaaten, auch in der EU erhältlich. Das Verletzungspotential übersteigt deutlich das von bisher beschriebenen Hartgummi- und Plastikgeschossen.

Fazit: Die $9 \mathrm{~mm}$ P.A.K. Rubber kann auch bei deutlichem Überschreiten des Nahschussabstandes lebensgefährliche und potenziell tödliche Verletzungen erzeugen und wird daher eingehender auf ihr Verletzungspotential untersucht werden. Bei den Waffen handelt es sich im Sinne des Waffengesetzes um Schusswaffen und nicht um Schreckschusswaffen.

\section{V-TR-8}

\section{Tödliche Schussverletzungen im Polizeieinsatz nach Einführung des neuen Polizeigesetzes in NRW}

Trübner, Kurt; Freislederer, Andreas

Institut für Rechtsmedizin, Universitätsklinikum Essen, Deutschland

Einführung: Führen staatliche Institutionen auf gesetzlicher Grundlage freiheitsentziehende Maßnahmen durch, geht die Verpflichtung, das Recht auf Leben und körperliche Unversehrtheit zu schützen, unmittelbar auf den Staat über. Todesfälle im Gefängnis, im Gewahrsam oder während eines Polizeieinsatzes erregen immer öffentliches Interesse und führen nicht selten zu Spekulationen über Brutalität der Polizei oder unzureichende Haftbedingungen. Umfassende polizeiliche Ermittlungen, Obduktionen und Zusatzuntersuchungen sind nötig, um eventuellen späteren Vorwürfen gegenüber der Polizei oder des Personals der Haftanstalten entgegenzutreten zu können, aber auch, um Präventionsmöglichkeiten herauszuarbeiten.

Seit Einführung des neuen Polizeigesetzes in NRW im Jahr 2018 kann die Polizei einschreiten, wenn eine „drohende Gefahr" aufgrund des individuellen Verhaltens einer Person bevorsteht. Diese Definition ermöglicht der Polizei, den Zeitpunkt festzulegen, ab dem sie ihre Maßnahmen einsetzt, sowie um wie viel der Zeitpunkt konkreter Gefahren und Straftaten vorverlagert wird.

Methode: Unter der Annahme, dass der Schusswaffengebrauch der Polizei seit 2018 zugenommen hat, wurden Sektionsprotokolle des Instituts für Rechtsmedizin aus den Jahren 2015-2021 hinsichtlich der Todesfälle während eines Polizeieinsatzes ausgewertet.

Ergebnisse: Insgesamt gab es 54 Todesfälle durch Schussverletzungen in diesem Zeitraum, von denen sich 9 während eines Polizeieinsatzes ereigneten. Bei 8 Verstorbenen handelte es sich um die Personen, die den Polizeieinsatz verursacht hatten und in einem Fall wurde ein Beamter des SEK getötet.

Die Fälle werden vorgestellt und deren juristische Konsequenzen erläutert, denn es muss immer die Frage beantwortet werden, inwieweit der Einsatz der Schusswaffe bezüglich einer Notwehr oder einer Nothilfe entsprechend $\S 32$ StGB gerechtfertigt ist.

Diskussion und Fazit: Im Obduktionsgut des Instituts für Rechtsmedizin waren Schussverletzungen während eines Polizeieinsatzes vor dem Jahr 2017 eine ausgesprochene Rarität. Der dramatische Anstieg seit Einführung des neuen Polizeigesetzes 2018 ist auffällig und sollte weiter beobachtet und ggf. juristisch in Bezug auf die Verpflichtung, das Recht auf Leben und körperliche Unversehrtheit zu schützen, hinterfragt werden. 


\section{V-TR-9}

\section{Splitterbildung nach Schüssen durch Verbundglas}

Constantin Lux ${ }^{1}$, Alexander Krutzek², Tobias Reich ${ }^{3}$, Stephan Welkerling ${ }^{3}$, Hannes Gruber', Patrick Sauer ${ }^{1}$, Natascha Kern' ${ }^{1}$, Marcel Verhoff', Mattias Kettner

'Institute of Forensic Medicine, Goethe University Frankfurt/M., Kennedyallee 104, D-60596 Frankfurt/Main, Deutschland; ${ }^{2}$ Meadow Bridge Training Center, Außerhalb 3, D-65468 Trebur, Deutschland; ${ }^{3}$ Hessisches Landeskriminalamt, Hölderlinstr. 1-5, D-65187 Wiesbaden, Deutschland

Im Rahmen einer experimentellen Studie wurde die Ausbildung von rundlichen, ca. $1 \mathrm{~cm}$ durchmessenden Verbundglassplittern nach Schüssen durch eine Windschutzscheibe untersucht.

Verwendet wurden eine Pistole im Kaliber 9 mm (HK P30) und zwei verschiedene Patronen mit (a) einem Vollmantelprojektil und (b) einem Deformationsgeschoss. Anhand von 42 Schüssen wurden Morphologie, Auftreffwinkel und Zielballistik entstandener Verbundglassplitter untersucht.

Die Ergebnisse zeigen, dass die Morphologie der Verbundglassplitter Rückschlüsse auf die Art des verwendeten Projektils zulässt. Die Splitter waren in der Lage, rundliche Textildefekte in Baumwolle zu erzeugen und hiernach bis zu $2,4 \mathrm{~cm}$ tief in ballistische Gelatine $\left(10 \%, 4{ }^{\circ} \mathrm{C}\right)$ einzudringen.

In Abhängigkeit des verwendeten Projektils wiesen sie unterschiedliche, reproduzierbare Auftreffwinkel auf, durch die sie sich deutlich von der allgemein bekannten Splitterkegelbildung nach Glasdurchschüssen unterschieden. Die Erkenntnisse können dabei helfen, atypische Befundkonstellationen zu erklären und einer etwaigen Fehlinterpretation bei der Rekonstruktion eines Tatherganges nach Schusswaffengebrauch vorzubeugen.

\section{V-TR-10}

\section{Singuläre Stichverletzungen am Rumpf: Suizid oder Fremdbeibringung?}

\section{Edler, A. Ron, B. Ondruschka, K. Püschel, S. Anders}

Institut für Rechtsmedizin Hamburg

Fragestellung: Die Differenzierung von selbst- und fremdbeigebrachten Verletzungen ist eine klassische Fragestellung bei rechtsmedizinischen Begutachtungen. Die Unterscheidung erfolgt zum einen durch die Untersuchungsbefunde, zum anderen durch die Vorgeschichte und die Gegebenheiten am Tat-/Fundort. Ziel der Studie war eine zusammenfassende Darstellung der Sektionsfälle mit singulären Stichverletzungen am Rumpf sowie die Identifizierung von richtungsweisenden Befunden bzw. Fallumständen im Vergleich mit der Literatur.

Material und Methode: Es erfolgte eine retrospektive Auswertung aller Sektionsfälle aus dem Hamburger Institut für Rechtsmedizin mit singulären Stichverletzungen am Rumpf von 1996 bis 2020 mittels elektronischer Datenbanksuche. Dabei wurden verschiedene Parameter wie die Stichlokalisation, der Stichkanalverlauf, Begleitverletzungen sowie Angaben aus der Vorgeschichte erfasst.

Ergebnisse: In dem Untersuchungszeitraum wurden insgesamt 56 solcher Fälle obduziert (49 männlich, 7 weiblich), mit einem singulären Bauchstich in 12 sowie einem isolierten Bruststich in 44 Fällen. Im Ergebnis konnten etwas mehr als die Hälfte als Fremdbeibringung und etwa ein Fünftel als Suizide gewertet. In Hinblick auf das Alter der Verstorbenen sowie die Anzahl und Art der Begleitverletzungen ergaben sich deutliche Unterschiede zwischen diesen beiden Fallgruppen. Andere relevante Parameter, wie Kleidungsdefekte, knöcherne Verletzungen oder Stichkanalverläufe, ergaben keine wegweisende Differenzierungsmöglichkeit.

Diskussion: Eine Unterscheidung zwischen Homizid und Suizid gelingt allein rechtsmedizinisch nicht in jedem dieser Fälle. Daher sollten stets Sektionsbefunde, die Tat-/Fundortgegebenheiten sowie die polizeilichen Ermittlungsergebnisse gemeinsam interpretiert werden. Bei Einlassungen zum Tatgeschehen, wie z. B. einem Hineinlaufen in ein Tatwerkzeug, soll- ten im interdisziplinären Ansatz Plausibilitätsprüfungen durch rekonstruktive Experimente und biomechanische Tests erfolgen.

\section{V-TR-11 \\ Ungewöhnlicher Suizid - Werkzeug-Bits als Geschosse}

N.Mann, K. Elsner, C. Brockmann, I. Schulz, T. Germerott

Institut für Rechtsmedizin/Mainz

Fragestellung: Im Jahr 2019 erfolgten in Deutschland insgesamt 666 Selbsttötungen mittels Schusswaffen. Dabei kommen auch manipulierte Schusswaffen zum Einsatz. Es wird der Fall eines 82 jährigen Mannes berichtet, der sich mittels einer manipulierten Schreckschusswaffe und Werkzeug-Bits als Munition suizidierte.

Fallbericht: Der Mann wurde leblos in seinem Wohnzimmer aufgefunden und zur weiteren Versorgung in eine neurochirurgische Fachabteilung eingeliefert. In der kranialen Computertomographie zeigte sich ein ca. $2,5 \mathrm{~cm} \times 0,5 \mathrm{~cm}$ messender, strahlendichter Fremdkörper im linken Hinterhauptslappen. Der Mann verstarb bei infauster Prognose kurze Zeit nach Krankenhauseinlieferung.

Bei der gerichtlichen Obduktion stellte sich in der rechten Schläfenpartie ein ca. 0,8 cm durchmessender Substanzdefekt mit bei Präparation abgrenzbaren schwarzen Kleinstpartikeln dar. Die umgebende Haut zeigte zudem rot-schwärzliche Verfärbungen. Im rechten Schläfenbein zeigte sich korrespondierend ein sich trichterförmig nach innen erweiternder, $0,5 \mathrm{~cm}$ messender Defekt. Neben einer subduralen und -arachnoidalen Blutung war eine ausgeprägte Zerstörung vom rechten Schläfen- bis in den linken Hinterhauptslappen vorliegend. Der radiologisch beschriebene Fremdkörper konnte anlässlich der Obduktion als Werkzeug-Bit identifiziert werden. Todesursächlich war somit ein schussbedingtes SchädelHirn-Trauma.

Im Zuge der weiteren Ermittlungen konnte als Tatwaffe ein Schreckschussrevolver vorgefunden werden. Der Lauf des Revolvers verfügte über ein innenliegendes Gewinde für die Benutzung eines Abschussbechers, in das ein passendes, mit einem Außengewinde versehenes Rohr geschraubt war. Aufgrund des Innendurchmessers von 7,2 mm war dieser auch für die Aufnahme von Werkzeug-Bits passend. Weiterführende kriminaltechnische Untersuchungen ergaben, dass die für den Schreckschussrevolver zugelassene Kartuschenmunition als Treibladung, für den händisch ins das aufgeschraubte Rohr eingelegten Werkzeug-Bit, diente. Die beim Schuss einer $9 \mathrm{~mm}$ Revolver-Kartuschenmuniton erzeugte Druckwelle kann dabei eine Geschwindigkeit von bis zu $1500 \mathrm{~m} / \mathrm{s}$ sowie einen Mündungsdruck von bis zu 200 mbar erreichen.

Fazit: Der Erwerb von Schreckschuss- und Signalwaffenwaffen ist in Deutschland nicht mit dem Besitz eines Waffenscheins oder einer Tauglichkeitsüberprüfung verbunden. Der präsentierte Fall zeigt jedoch erneut auf, dass mittels einfachster Manipulationen dieser Waffen auch Geschosse abgefeuert werden können.

\section{V-TR-12}

\section{Comparison of the motor vehicle collision injuries between pregnant and non-pregnant women: a national} crash data-based study

Masahito Hitosugi, Arisa Takeda, Marin Takaso

Department of Legal Medicine, Shiga University of Medical Science, Tsukinowa, Seta, Otsu, Shiga 520-2192, Japan

Objective: Safety promotion for vehicle users is recommended to decrease moderate to severe motor vehicle collision (MVC) injuries. The objectives are first, to compare the detail characteristics of the MVCs and outcome between pregnant and non-pregnant women. Then, effective interventions for both pregnant women and non-pregnant women are proposed. 
Method: This is an observational and retrospective study using the data of National Automotive Sampling System/Crashworthiness Data System. After excluding cases without any anatomical injuries, two data sets as pregnant women and nonpregnant women vehicle passengers were created. Collision characteristics, injury severities and outcomes of the women were compared between the two groups.

Result: Among the vehicle passengers registered from 2001 to 2015, the 736 pregnant women and 21,874 non-pregnant women of child bearing age with abbreviated injury scale (AIS) score of 1 or more were collected. At the comparison of collision characteristics, pregnant women had suffered from less severe collisions, less suffer from airbag deployment and pretensioner acting, than non-pregnant women. For the outcome, the fatality was significant higher, the prevalence of admission was significantly smaller and that of outpatient was significantly higher in non-pregnant women than in pregnant women. Regarding the injuries, the values of maximum AIS were significantly higher in non-pregnant women than in pregnant women. Only for the abdomen, the rate of having AIS2+ injuries was higher in pregnant women, but in other body regions, rates were higher in non-pregnant women. Conclusion: Pregnant women had suffered from less severe injuries and lower fatality late than non-pregnant women. Among each body region, the rate of having AIS2+ injuries was higher in pregnant women only in the abdomen. For preventing moderate to severe injuries of vehicle passengers, interventions for pregnant women are more simple and effective than for non-pregnant women because the improvement of influencing factors would be achieved by education from health professionals to the pregnant women.

\section{V-TR-13}

Der Torkelbogen: ein geeigneter Indikator für verkehrsrelevante Ausfallserscheinungen und konkrete Fahrfehler bei Cannabispatienten?

\author{
B. Stöttner ${ }^{1,2}$, M. Bartel ${ }^{2}$, P. Strohbeck-Kühner ${ }^{2}$ \\ ${ }^{1}$ Institut für Rechtsmedizin, Ludwig-Maximilians-Universität München, München; ${ }^{2}$ Insti- \\ tut für Rechts- und Verkehrsmedizin, Universitätsklinikum Heidelberg, Heidelberg
}

Fragestellung: Seit der im März 2017 in Kraft getretenen Gesetzesänderung ist eine Teilnahme am Straßenverkehr unter dem Einfluss von medizinisch verordnetem Cannabis gestattet, sofern keine Beeinträchtigung der Fahrsicherheit vorliegt. Ob und in wie weit die im Rahmen polizeilich angeordneter Blutentnahmen durchgeführte psycho-physiologischen Tests („Torkelbogen“) als Indikator für den Konsum von medizinischem Cannabis geeignet sind und ob eine Korrelation zum THC-Spiegel im Blut und konkreten Fahrfehlern besteht, soll untersucht werden.

Methode: Im Rahmen einer kontrollierten Studie am Institut für Rechtsund Verkehrsmedizin des Universitätsklinikums Heidelberg wurden 32 Cannabispatienten sowie eine hinsichtlich Alter und Geschlecht vergleichbare Kontrollgruppe einer ärztlichen Untersuchung, entsprechend der Untersuchung bei polizeilich angeordneten Blutentnahmen, unterzogen. Mit Hilfe halb-strukturierter Interviews wurden verkehrsmedizinisch relevante Erkrankungen, die Medikation sowie die Vorerfahrung mit Cannabis erfasst. Danach wurde mit den Cannabispatienten eine standardisierte Fahrverhaltensbeobachtung im Realverkehr durchgeführt. Im Anschluss daran erfolgte eine Blut- und Urinentnahme, unter anderem zur Bestimmung des THC-Spiegels im Serum.

Ergebnisse: Die Ergebnisse der Studie zeigen, dass trotz teilweise sehr hoher THC-Konzentrationen zumeist nur geringe medikationsassoziierte Ausfallserscheinungen und physiologische Auffälligkeiten festgestellt werden konnten. Dargestellt werden weiterhin die Zusammenhänge zwischen den Befunden der ärztlichen Untersuchung, den THC-Spiegeln, der Vorerfahrung mit Cannabis sowie den konkreten Fahrfehlern.

Diskussion und Fazit: Die Ergebnisse der Studie lassen erkennen, dass den einzelnen, bei der ärztlichen Untersuchung erhobenen Indikatoren nur eine begrenzte Aussagekraft im Hinblick auf verkehrsrelevante Ausfallserscheinungen bei Cannabispatienten zukommt, was mögli- cherweise auf die Heterogenität der medizinischen Diagnosen sowie die unterschiedliche Dosierung und die unterschiedlichen Gewöhnung zurückgeführt werden kann.

\section{POSTER}

Klassische Rechtsmedizin

P-RM-1 bis P-RM-42

\section{P-RM-1 \\ Erdrosseln mittels Kabelbinder als seltene Suizidmethode}

\author{
Seßler $M^{1}$, Bormann C ${ }^{1}$, Mußhoff F ${ }^{2}$, Helmreich C ${ }^{1}$ \\ ${ }^{1}$ Institut für Rechtsmedizin der Universität München; ${ }^{2}$ Forensisch Toxikologisches \\ Centrum München
}

Deutschlandweit suizidieren sich jährlich etwa 9000 bis 10.000 Menschen. Im Institut für Rechtsmedizin der Universität München werden pro Jahr mehr als 200 Sektionen mit der Fragestellung Suizid durchgeführt. Häufigste Methode der Selbsttötung ist dabei die Strangulation, meist in Form von Erhängen.

Ein suizidales Erdrosseln ist dagegen laut gängiger Literatur eher selten. Für ein suizidales Erdrosseln muss das zirkulär um den Hals gelegte Drosselwerkzeug durch eigene Hand zugezogen werden und der Druck auch nach Eintritt der Bewusstlosigkeit erhalten bleiben. Kommt es durch die Drosselung zu einer hämodynamisch wirksamen, inkompletten Kompression der Halsgefäße, ergeben sich als Obduktionsbefunde oft deutliche Zeichen der venösen Stauung mit Petechien der Hals- und Gesichtshaut oberhalb der Drosselmarke, insbesondere in den Augenlid- und -bindehäuten, der Mundvorhofschleimhäute sowie der Ohr- und Hinterohrregionen. Auch eine Zyanose und Dunsung des Gesichts sowie Blutaustritte aus Mund und Nase sind zu beobachten. Daneben sind Muskelunterblutungen im Halsbereich und Verletzungen des Kehlkopfes möglich.

Fragestellung: Es soll die Häufigkeit von Suiziden mittels Erdrosseln durch eigene Hand im Münchner Obduktionskollektiv ermittelt werden, zur Klärung der Frage, ob es ich hierbei tatsächlich um eine selten angewandte Suizidmethode handelt.

Methode: In den Jahren 2011 bis Mai 2021 fanden sich im Sektionsgut des Instituts für Rechtsmedizin der Universität München einzelne Fälle von Selbsterdrosselung mittels Kabelbinder. Diese wurden unter Zuhilfenahme der Sektionsprotokolle, der staatsanwaltschaftlichen Ermittlungsakten und der zusätzlich beauftragten Untersuchungen (z. B. chemischtoxikologische Untersuchung) ausgewertet.

Ergebnisse: Insgesamt fanden sich im Obduktionskollektiv 9 Fälle von Selbsttötungen mittels Erdrosseln durch einen Kabelbinder, insgesamt 2 Frauen und 7 Männer im Alter von 48 bis 87 Jahren.

Diskussion:/Fazit: Die Fälle sollen im Weiteren, insbesondere in Bezug auf die Stauungssymptomatik, die Kehlkopfbefunde und unter Berücksichtigung der chemisch-toxikologischen Untersuchungsergebnisse, näher dargestellt und erörtert werden.

\section{P-RM-2}

Trends in suicides due to the prolonged COVID-19 pandemic in Japan: A comparison to trends during the increase in suicides about 25 years ago

Ken Inoue ${ }^{1}$, Tatsushige Fukunaga ${ }^{2}$

'Research and Education Faculty, Medical Sciences Cluster, Health Service Center, Kochi University, Kochi, Japan; ${ }^{2}$ National Research Institute of Police Science, Chiba, Japan

Objective: Over a year has passed since the COVID-19 pandemic struck Japan and the rest of the world. These circumstances have greatly fatigued 
the Japanese people. The pandemic is the major impact on the economy, work, and life. Japan was shaken by a societal problem, an increase in suicides and consistently numbers of suicides, in the late 1990s. Therefore, this study has compared trends during the increase in suicides in Japan about 25 years ago and suicide trends right now, over a year since the COVID-19 pandemic began.

Methods: Numerical data on suicide trends in Japan by a report of the National Police Agency were researched in detail. Suicide trends were divided into 2 periods: the first period from 1994-1998 showed a subsequent increase in suicides after 1994; the second period from 2019-2020 showed increasing numbers of suicides. We compared their trends in the 2 periods.

Results: Whether the slight increase in the number of suicides in 2020 was due to the COVID-19 pandemic is unclear, but "females" and "age 20s" were key contributors to the increase in suicides in the second period. The cause of/motive for suicide in 2019 and 2020 revealed no marked changes. The percentage of suicides by males increased in 1998 in the first period. "Economic and life problems" accounted for a larger proportion of suicides, and there were more suicides by all age groups.

Discussion: Given the suicide trends in Japan from 1994-1998, suicides due to "economic and life problems" are likely to increase after 2021. The entities that can promptly ascertain detailed trends in suicides in Japan and that can apprise society of those findings are the police and forensic medicine. Suicide trends need to be analyzed from deep and broad perspective of forensic medicine.

Conclusion: Police, medical personnel such as forensic medicine, government agencies, economic and labor fields, and organizations involved in suicide prevention need to discuss together as necessary to address various aspects of the ongoing COVID-19 pandemic such as economic and life hardships in order to prevent an abrupt increase in suicides.

\section{P-RM-3}

\section{Forensic examination of complex suicide cases}

A. Ishigami, M. Tanaka, Y. Hashizume, J. Matsuki, Y. Ishida, M. Nosaka, H. Yamamoto, Y. Kuninaka, E. Shimada, M. Kawaguchi, A. Kimura, F. Furukawa, T. Kondo

Department of Forensic Medicine, Wakayama Medical University, Wakayama, Japan

Introduction: Most cases of suicide use one method. Moreover, cases using multiple methods are sometimes seen, which is called 'complex suicide'. These methods are used simultaneously or consecutively. So, suspicion of the involvement by other persons often makes difficult to distinguish between suicide and homicide. Establishing methods and causes of complex suicide and eliminating the involvement of other persons are important for forensic scientists and investigators.

Methods: Based on the criteria, we examined cases of complex suicide that were autopsied at Wakayama Medical University from 2003 to 2020 and compared them with overseas reports.

Results: 24 cases were complex suicide ( $2.8 \%$ ) in the 856 suicide cases. The most common cause of death was drowning (16 cases). The most common method used was the use of sharp weapon on the neck, wrists, and abdomen (18 cases). The most common combination of methods was the use of sharp weapon and entering in the water (11 cases). On the other hand, use of a gun which was often taken place in overseas was not observed. It is difficult to interpret the situation of complex suicide cases. Elucidating the whole picture of complex suicide is one of the important assignments for forensic scientists.

Discussion: In particular, the distinction between suicide and homicide is always a challenge and an obligation. Complex suicides sometimes mimic homicide and suspect the involvement of other persons. In order to exclude homicide, it is important to collect detailed information such as investigation of the discovered place, medical history, the antemortem action of the victim and testimony of the persons concerned, and to perform forensic autopsy thoroughly.

\section{P-RM-4}

\section{An insight into complex suicides}

Zija Ismaili', Bledar Xhemali', Mirnela Koçibelli' ${ }^{1}$, Admir Sinamati ${ }^{11}$, Elton Serani1), Gentian Vyshka ${ }^{2)}$

'Institute of Legal Medicine, Ministry of Justice in Tirana, Albania; ${ }^{2}$ Faculty of Medicine, University of Medicine in Tirana, Albania

Introduction: Suicide presents a major challenge to forensic medicine, psychiatry and public health in general, with continuous scientific attempts to identify early signs and approaches that might help drafting preventive measures. As such, complex suicide is an even more intricate occurrence, whose rarity deserves a detailed study case after case.

Methodology: Four cases of complex suicide that came to our attention during the last two years, along with respective images of forensic value, will be showcased.

Results: The first case of complex suicide deals with a fall from height accompanied with intoxication with poison from the family of insecticides. The second case deals a rope hanging suicide combined with previous immediate self-inflicted gunshot wound. The third case was a complex suicide accompanied with attempted electrocution. The fourth case of complex suicide was a rope hanging one, with the victim consuming few minutes before the attempt a high dose of rodenticide poison. Blood samples and stomach contents were analyzed in all cases through liquid gas chromatography. Pyrethroids were detected in the first case, and phostoxin in the fourth case; no poisonous content was detected in the two other cases.

Conclusions: In the present time when the complexity of suicides has become rampant, with people using more than a single method, the value of toxicology remains crucial; especially when the mechanism of death remains unclear or when the evidence is not convincing about the lethality of the first and visible used method of suicide (such as self-inflicted gunshot wound, incomplete hanging etc).

\section{P-RM-5}

\section{Ein Fall von suizidalem Erstickungstod mit nachweißlichen Befunden einer Selbsterdrosslung}

loana Diaconescu, Sorin Hostiuc

Institut für Rechtsmedizin Bukarest, Medizinische und Pharmazeutische Universität Carol Davila Bukarest, Rumänien

Fragestellung: Die Differenzialdiagnose zwischen dem Selbstmord und der Fremdtötung stellt im rechtsmedizinischen Bereich eine große Herausforderung dar.

Methode: Wir berichten wir über einen Fall von einer Erstickungstod, bei der sowohl Befunde einer Erstickung, als auch einer Erdrosslung gefunden wurden.

Ergebnisse: Anlässlich der Obduktion wurden die folgenden besonderen Befunde betätigt: Einblutung der vorderen Halsmuskeln, komplette Fraktur des linken großen Zungenbeinhorn, Intimaeinrisse Halsschlagader bilateral, sowie Stauungssyndrom mit Hirnödem, subpleurale petechialen Stauungsblutungen und Hyperämie der inneren Organe.

Diskussion: Die Leiche eines 34 Jahre alten Manns wurde in seiner Wohnung desselbigen von seinen Eltern vorgefunden, der Kopf von einem Plastikbeutel bedeckt und zudem ein Plastikbeutel mit vorderem Knoten, zirkulär submental angebracht, der wahrscheinlich als Strangwerkzeug Verwendung fand. Auf dem Schlafzimmertisch wurde eine Xanax-Verpackung vorgefunden, was den Aussagen seines Vaters entsprechen würde, dass er unter einer psychischen Erkrankung litt, jedoch wies die toxikologische Untersuchung keine medikamentöse oder alkoholische Beeinflussung auf. Laut der kriminalistischen Ermittlung war die Wohnung von innen verriegelt, jedoch waren die Fenster des Balkons geöffnet, sodass unter diesen Umständen ein Mord nicht komplett auszuschliessen ist. 
Fazit: Ob der starke Druck des weichen Strangwerkzeugs als Hauptuhrsache dieser beträchtlichen Verletzung des Zungenbeins samt Halsschlagader gilt, muss ohnehin kritisch bewertet werden. Angesichts dieser außergewöhnlichen Merkmale stellen wir im vorliegenden Fall den komplexen Mechanismus des Erstickungstodes in den Vordergrund

\section{P-RM-6}

Frankfurter Projekt zur Prävention von Suiziden mittels Evidenz-basierter Maßnahmen (FraPPE) Deskriptiv-statistische Analyse des rechtsmedizinischen Fallkollektivs

\author{
Sarah C. Koelzer, Mattias Kettner, Marcel A. Verhoff, Stefan W. Toennes, \\ Cora Wunder, Franziska Holz \\ Institut für Rechtsmedizin, Universitätsklinikum Frankfurt, Goethe-Universität, Frankfurt
} am Main, Deutschland

Fragestellung: Die Prävalenz und Charakteristiken von Suiziden wurden in einem definierten Kollektiv (Stadtgebiet Frankfurt am Main) im Zeitraum 07/2018-12/2020 in der prospektiv angelegten FraPPE-Studie systematisch untersucht.

Methode: Die Datenerhebung des rechtsmedizinischen Fallkollektivs erfolgte in Zusammenarbeit mit dem Gesundheitsamt der Stadt und der Kriminalpolizei durch Fundortbegehungen, Befragung von Angehörigen, kriminalpolizeiliche Ermittlungsergebnisse, Sektionsergebnisse und chemisch-toxikologische Untersuchungen. Die Daten wurden deskriptiv-statistisch ausgewertet.

Ergebnisse:Von den 229 Suizidenten waren $65 \%$ männlich und $35 \%$ weiblich. Bei den Männern war der größte Anteil in der Altersgruppe der 50- bis 59-Jährigen ( $23 \%$ ), bei den Frauen bei den 70- bis 79-Jährigen (18,5\%) zu verzeichnen, wobei die Suizidrate pro 100.000 Einwohner der betreffenden Altersgruppe bei beiden Geschlechtern in der Gruppe der 80- bis 89-Jährigen am größten war (männlich 63,3; weiblich 24,9). Männer suizidierten sich am häufigsten durch einen Sturz/Sprung aus großer Höhe $(23,6 \%)$, gefolgt von Erhängen/Ersticken (23\%) und Intoxikationen (19,6\%). Jeweils $27,2 \%$ der Frauen wählten eine der drei aufgeführten Suizidmethoden. Bezogen auf die in Frankfurt gemeldeten Personen lag die Suizidrate pro 100.000 Einwohner bei den deutschen Staatsbürgern mit 14,3 mehr als doppelt so hoch wie bei den nicht-deutschen EU-Bürgern $(6,0)$ und fast doppelt so hoch wie bei den Nicht-EU-Bürgern $(7,3)$. Ein Anstieg der Suizidrate während der Corona-Pandemie wurde nicht festgestellt.

Diskussion: Die Studienergebnisse hinsichtlich der Geschlechter- und Altersverteilung Frankfurter Suizidenten decken sich mit denen in der Literatur. Demgegenüber zeigten die FraPPE-Ergebnisse nicht, dass Männer tendenziell "härtere" Suizidmethoden als Frauen wählen. Die Suizidrate bezogen auf die Nationalität steht im Widerspruch zu anderen Studien, die einen höheren Ausländeranteil unter den Suizidenten feststellten. Die im Rahmen des rechtsmedizinischen Anteils der Studie erhobenen Ergebnisse dienen dem aktuell in Auswertung befindlichen primären Ziel einer Überprüfung des Erfolgs suizidpräventiver Maßnahmen.

\section{P-RM-7}

Differentiation of formation of hemorrhages of traumatic genesis, cerebral infarction of ischemic and hemorrhagic genesis by azimuthally invariant Mullermatrix images of optical activity of histological sections of the brain

\section{Garazdiuk, V. Bachynskyi, O. Garazdiuk, N. Pavliukovych}

Higher State Educational Establishment of Ukraine, Forensic Medicine Department, Chernivtsi, Ukraine

Introduction: It is important for a forensic expert to make a differential diagnosis of hemorrhage into the human brain (HB) of traumatic and non- traumatic origin, as there are cases when in the absence of external injuries in the internal examination hemorrhages in the brain revealed.

Materials and methods: In study were used native histological sections of HB from 95 corpses in the case of: death from coronary heart disease-25 native sections (group 1-control); hemorrhage of traumatic genesis-20 sections (group 2), ischemic cerebral infarction-20 sections (group 3), hemorrhage of non-traumatic genesis-20 sections (group 4). Measuring the coordinate allocation of Muller-matrix invariants (MMI) of microscopic images was carried out at the location of the standard Stokes polarimeter.

Results: In work results of statistical analysis of layer-by-layer maps of MMI distributions obtained by "phase scan" and digital holographic reproduction of distributions of complex amplitudes of a laser field transformed into an optically anisotropic medium of section of HB are present. Phase scanning provides the possibility of algorithmic selection and recovery on this basis of cross-sections of polarization manifestations of the properties of the object with different scattering multiplicity-from minimum to maximum. The minimum phase corresponds to almost a single scattering-an analogue of the optically thin layer of biological tissue; maximum-multiple scattering in the volume of the real test sample.

From the analysis of the obtained 3D Mueller-matrix mapping data for $\boldsymbol{\delta}=\mathbf{0 , 4 r a d}$ (almost single scattering) the individual topographic structure of all MMI maps was established. Histograms, which characterize the distributions of the optical activity of brain samples from all groups, are characterized by significant mean values and variance of dispersion values, large asymmetry and kurtosis. Comparative analysis of the obtained data revealed the maximum intergroup differences in the magnitude of the set of statistical moments of the $1 \mathrm{st}-4$ th orders and the statistical significance of the differentiation ( $\mathrm{pi}-1 ; 2 ; 3 ; 4<0,05$ ) between the cases of all groups. Conclusions: The maximum level of balanced accuracy of intergroup differentiation of histological sections of the brain that were astablished is: between the control and experimental groups-difference accuracy (95-96\%); between groups 2 and 3-good accuracy (92-93\%); between groups 3 and $4-$ satisfactory accuracy (85-86\%).

\section{P-RM-8}

\section{Histological and wet-dry weight analysis for post mortem assessment of brain edema}

Melanie Bauer ${ }^{1,2}$, Nikolaus Deigendesch ${ }^{3}$, Holger Wittig ${ }^{1,2}$, Eva Scheurer ${ }^{1,2}$, Claudia Lenz ${ }^{1,2}$

'Institute of Forensic Medicine, Department of Biomedical Engineering, University of Basel, Basel, Switzerland; ' 2 Institute of Forensic Medicine, Health Department Basel-Stadt, Basel, Switzerland; ${ }^{3}$ Institute of Medical Genetics and Pathology, University Hospital Basel, University of Basel, Basel, Switzerland

Post mortem evaluation of brain edema is routinely performed by pathologists based on macroscopic signs visible at autopsy [1]. Although this method is subjective, it represents the gold standard for the classification of brain edema in forensic medicine [2]. As we showed in our recent publication [3], histology and wet-dry weight measurements of tissue samples have limited benefits for the assessment of brain edema. In this work, both methods were correlated with the gold standard and the interrater correlation of the histological raters was calculated for every examined region separately in order to determine if a specific region is reliable for the edema evaluation.

Tissue samples from six different regions (subcortical white matter, capsula interna, cortex, thalamus, cerebellum and brain stem) of 34 brains were collected during autopsy. A neuropathologist and a forensic pathologist rated the histological slides, stained with a standard hematoxylin and eosin stain, independently of each other and without information about the gold standard evaluation. For the determination of the water content, the wet and the dry weight of each sample were set in relation.

The best interrater agreement for the histological raters was found for the cortex (Cohen's kappa $=0.65)$ where it is substantial $(\boldsymbol{\bullet}$ Tab. 1). A significant but low correlation ( $p$-value $=0.03$; correlation coefficient $r=0.39$ ) 


\begin{tabular}{|l|l|l|l|l|l|l|}
\hline Table 1 & Interrater agreement (Cohen's kappa) for the two histology raters for every examined region \\
\hline Region & $\begin{array}{l}\text { WM } \\
\text { subcortical }\end{array}$ & $\begin{array}{l}\text { Capsula } \\
\text { interna }\end{array}$ & Cortex & Thalamus & Cerebellum & $\begin{array}{l}\text { Brain } \\
\text { stem }\end{array}$ \\
\hline Kappa & 0.49 & 0.38 & 0.65 & 0.00 & 0.28 & 0.35 \\
\hline
\end{tabular}

Table 2 P-values and correlation coefficients $r$ of all regions of histology and wet-dry weight analysis compared to the gold standard

\begin{tabular}{|c|c|c|c|c|c|c|c|c|c|c|c|c|}
\hline \multirow{2}{*}{$\begin{array}{l}\text { Region } \\
\text { Gold } \\
\text { standard } \\
\text { correlated } \\
\text { with }\end{array}$} & \multicolumn{2}{|c|}{$\begin{array}{l}\text { WM } \\
\text { subcortical }\end{array}$} & \multicolumn{2}{|l|}{$\begin{array}{l}\text { Capsula } \\
\text { interna }\end{array}$} & \multicolumn{2}{|l|}{ Cortex } & \multicolumn{2}{|c|}{ Thalamus } & \multicolumn{2}{|c|}{ Cerebellum } & \multicolumn{2}{|l|}{$\begin{array}{l}\text { Brain } \\
\text { stem }\end{array}$} \\
\hline & p-value & $\mathbf{r}$ & p-value & $\mathbf{r}$ & p-value & $\mathbf{r}$ & p-value & $\mathbf{r}$ & p-value & $\mathbf{r}$ & p-value & $\mathbf{r}$ \\
\hline $\begin{array}{l}\text { Wet dry } \\
\text { weight }\end{array}$ & 0.18 & 0.24 & 0.53 & 0.14 & 0.03 & 0.39 & 0.38 & 0.16 & 0.97 & 0.01 & 0.66 & 0.03 \\
\hline $\begin{array}{l}\text { Histology } \\
\text { rater } 1\end{array}$ & 0.93 & 0.00 & 0.77 & 0.04 & 0.71 & 0.15 & 0.45 & 0.12 & 0.77 & 0.13 & 0.54 & 0.12 \\
\hline $\begin{array}{l}\text { Histology } \\
\text { rater } 2\end{array}$ & 0.20 & 0.24 & 0.16 & 0.24 & 0.66 & 0.11 & 0.26 & 0.24 & 0.97 & 0.03 & 0.71 & 0.08 \\
\hline
\end{tabular}

exists between the wet-dry weight values of cortex samples and the gold standard (- Tab. 2). The further regions of the wet-dry weight method as well as the histology evaluations of both raters were not significant.

Beside the analysis of these two methods in general [3], also the regional analyses show limited benefits for the assessment of brain edema. Therefore, we suggest to apply the objective normalized cerebral weight method, which was introduced by Bauer et al. [4], for the assessment of brain edema as it was proved to be in good agreement with the gold standard.

\section{References}

1. Hausmann et al., IJML, 2006, 120.

2. Radojevic et al., JFLM, 2017, 45.

3. Bauer et al., FSI, 2021, 323.

4. Bauer et al., FSI, 2020,308.

\section{P-RM-9}

Giant intracranial arteriovenous malformation in a drowned cadaver as the focus of epileptic seizures

Shin-ichi Kubo, Masayuki Kashiwagi, Kenji Hara, Aya Matsusue, and Brian Waters

Department of Forensic Medicine, Faculty of Medicine, Fukuoka University

A large vascular lesion on the brain was found in forensic autopsy case of a drowned cadaver. We report the histopathological findings of the cerebral vascular lesion, and the causal relationship between this vascular lesion and drowning.

Case report: An unemployed male in his late 50 s had been complaining of headaches and dizziness for 25 years. He also had repeated bouts of unconsciousness at least once a week, but had not sought treatment because of financial hardship. Main autopsy findings: Small white bubbles, foam, and watery liquid leaked from the nose and mouth. Pleural effusions were present in the left and right thoracic cavities at volumes of $40 \mathrm{~mL}$ and $80 \mathrm{~mL}$, respectively. The trachea and bronchi contained a somewhat large amount of liquid, white fine bubbles, and foam. The lungs were swollen, with the left lung weighing $753 \mathrm{~g}$ and the right lung weighing $929 \mathrm{~g}$. They were edematous, and leaked a large amount of liquid and foam. Alcohol analysis: No ethanol was detected in the blood. Urinary ethanol was $0.021 \mathrm{mg} / \mathrm{g}$. Toxicological screening: GC-MS and LC-MS/MS screening tests did not detect any drugs in the blood or urine. Diatom ex- amination: Diatoms found in the water where the body was recovered was also detected in his lungs, liver, and kidneys.

Intracranial vascular lesion: In the brain, the veins on the lateral groove, the bottom of the frontal lobe, and the anterior pole of the temporal lobe, each on the right cerebral hemisphere, were distended. A vascular lesion with a diameter of $5 \mathrm{~cm}$ and a length of $8 \mathrm{~cm}$ was found on the bottom of the right frontal lobe, and was located between the right middle cerebral artery and those veins. This vascular lesion extended to the brain parenchyma, and the basal ganglia of the right cerebrum was displaced outward and upward. Histopathological examination: The vascular lesions in the brain showed various sized veins, arteries, and cavernous vessels, and some of the vessel walls were thickened.

Discussion: His cause of death was diagnosed as drowning. The vascular lesion on the right frontal lobe was diagnosed as an arteriovenous malformation (AVM). According to the police investigation, the place where his body was found was a place he often came for fishing and walking. He was suffering from family and financial troubles before his death, so the possibility of suicide cannot be ruled out. Moreover, it was considered that his AVM may have rendered him unconscious, causing him to fall into the sea.

\section{P-RM-10}

\section{Autopsy Case Report of a Sudden Death from Idiopathic Giant Cell Myocarditis}

\section{S. Bisharyan, K. A.Arsenyan, P.S. Khachatryan., A. A.Tonoyan}

Scientific-practical center of forensic medicine of the Ministry of Health of the Republic of Armenia, Department of forensic medicine of Yerevan State Medical University after M. Heratsi

Question: Idiopathic giant-cell myocarditis (GCM) is a rare rapidly progressing and usually fatal autoimmune disorder, which predominantly affects middle-aged people. Usually is as associated with other autoimmune disorders such as Chron's disease, rheumatoid arthritis, ulcerative colitis, myasthenia gravis etc. We report an autopsy case of GCM in a 38-year-old woman who died suddenly at home. There was no any clinical data or history of the disease. On autopsy grossly the heart was enlarged, with motley appearance on sections, more prominent on the posterior-lateral wall of the left ventricle, where interchange of whitish-grey and reddish-brown dark and light areas was found. Microscopically abundant inflammatory infiltrates consisted of lymphocytes and leukocytes, as well as numerous multinucleated giant cells were revealed both in clusters and separately. 
Methods: Different staining methods and immunohistochemical examination was performed to establish the diagnosis of GCM, as well as to make differential diagnosis. Staining methods such as $\mathrm{H} \& \mathrm{E}$, van Gieson and method by Lie were used to reveal microscopical changes. Immunohistochemical staining for detection of CD 8-positive T lymphocytes and CD68 positive protein to reveal the origin of multinucleated giant cells was used.

Results: Different staining methods hepled to establish the diagnosis of GCM and to make the differential diagnosis between GCM and other types of myocarditis accompanied by presence of giant cells. Morerover, staining method by van Gieson helped to reveal severe fibrotic changes in the affected myocardial tissue and method by Lie- to reveal hypoxic damage of cardiomyocytes.

Discussion: In cases of unexpected death caused by GCM, for the final diagnosis and establishment of the cause of death, during histological examination of the autopsy material, we suggest besides the routine staining methods such as H\&E, also additional methods such as van Gieson, method by Lie, as well as, immunohistocemical analysis of myocardial tissue specimens for differential diagnosis between GCM and other forms of myocarditis.

Conclusion: In cases of sudden death from acute myocarditis, in suspected cases during microscopical examination of autopsy material it is important to make correct differential diagnosis between rarely occurred GCM and other types of myocarditis. Microscopical diagnosis by the usage of different staining methods and immunohistochemical examination may confirm the diagnosis of GCM.

\section{P-RM-11}

\section{Forensic significance of intracardiac heme oxygenase-1 expression in acute myocardial ischemia}

Yuko Ishida', Yumi Kuninaka', Mizuho Nosaka', Akiko Ishigami', Akira Taruya², Emi Shimada', Akihiko Kimura', Hiroki Yamamoto', Mitsunori Ozaki', Fukumi Furukawa'1,4, Jumpei Matsuki', Mariko Kawaguchi', Toshikazu Kondo'

'Department of Forensic Medicine, Wakayama Medical University, 811-1 Kimiidera, 6418509 Wakayama, Japan; ${ }^{2}$ Department of Cardiovascular Medicine, Wakayama Medical University, 811-1 Kimiidera, 641-8509 Wakayama, Japan; ${ }^{3}$ Department of Neurological Surgery, Wakayama Medical University, 811-1 Kimiidera, 641-8509 Wakayama, Japan; ${ }^{4}$ Takatsuki Red Cross Hospital, 1-1-1 Abuno, Takatsuki-shi, Osaka 569-1096, Japan

Objective: Ischemic heart disease is the leading cause of death in the worldwide and is the most common cause of sudden cardiac death (SCD). In the cases of SCD, the postmortem diagnosis of acute myocardial ischemia is an important issue for both clinical physicians and forensic pathologists if death occurs within a short period of time after the onset of ischemic heart attack. Heme oxygenase-1 (HO-1), an inducible stress-response protein, exerts anti-oxidant and anti-apoptotic effects. However, its significance in forensic diagnosis of acute ischemic heart diseases (AIHD) such as myocardial infarction (MI) is still unknown.

Method: A total of 56 human forensic autopsy cases with a postmortem interval (PMI) of less than $96 \mathrm{~h}$ were selected based on autopsy documents. Cases were divided into two groups as follows: 23 acute ischemic heart disease with advanced sclerosis and/or stenosis in coronary artery and 33 others. Heart samples were fixed in $4 \%$ formaldehyde buffered with PBS and then embedded with paraffin. Immunohistochemical analysis was performed using anti-HO-1, -MPO, -Macrophage Marker, or -myoglobin Abs. Morphometrical analysis was performed with immunohistochemical findings. Cases in which HO-1-positive cells were uniformly observed in myocardial samples were defined as $\mathrm{HO}-1^{+}$cases.

Result: HO-1 positive signals in cardiomyocyte nuclear were detected in $78.2 \%$ of AlHD cases, however, that were detected in only $24.2 \%$ control cases with statistical difference between AIHD and non-AIHD groups. In contrast to HO-1 protein expression, there was no significant difference in the appearance of myoglobin pallor regions and leukocyte infiltration in the hearts between AIHD and non-AIHD groups.
Discussion and Conclusion: We proposed a useful marker HO-1 in the forensic diagnosis of acute myocardial ischemia. However, no single immunohistochemical reaction is ideal for diagnosis early myocardial ischemia, but the combination of immunoreaction of $\mathrm{HO}-1$ and existence of contraction bands, can improve the ability of forensic pathologists to detect AIHD when macroscopic or microscopic evidence is insufficient.

\section{P-RM-12}

\section{Aufbau eines Registers von plötzlichen Herztodesfällen in jungen Jahren}

Jenewein $T^{1}$, Scheiper-Welling $S^{1}$, Beckmann BM'1, Constanze Niess', Storf $H^{2}$,

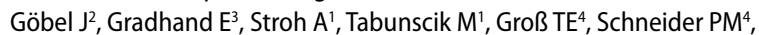
Rothschild $M A^{4}$, Verhoff $M A^{1}$, Kauferstein $\mathrm{S}^{1}$

${ }^{1}$ Institut für Rechtsmedizin, Universitätsklinikum Frankfurt, Goethe-Universität, Frankfurt am Main, Deutschland; ${ }^{2}$ Medical Informatics Group, Universitätsklinikum Frankfurt, Goethe-Universität, Frankfurt am Main, Deutschland; ${ }^{3}$ Dr. Senckenbergisches Institut für Pathologie, Universitätsklinikum Frankfurt, Goethe-Universität, Frankfurt am Main, Deutschland; ${ }^{4}$ Institut für Rechtsmedizin, Universitätsklinikum Köln, Universität zu Köln, Köln, Deutschland

Hintergrund: Der unerwartete Tod eines scheinbar gesunden Kindes oder jungen Erwachsenen ist ein seltenes und tragisches Ereignis, dessen Ursache nicht immer von vornherein geklärt werden kann. Bei einer selektiven Recherche wurden weltweit 15 Register für plötzliche Herztodesfälle ermittelt (Paratz et al. 2020). Es zeigte sich hierbei eine uneinheitliche Datengrundlage innerhalb der Register, was die Auswertung der vorhandenen Daten in diesen Registern erheblich erschwert. Dies begründet sich zum Beispiel durch Spezialisierungen der einzelnen Register auf Teilbereiche, die einen Vergleich der global vorliegenden Daten einschränken. Allein 8 der weltweit 15 Register für plötzliche Herztodesfälle sind lediglich auf spezifische Untergruppen von plötzlichen Herztodesfällen ausgerichtet. Auch das bisher einzige deutsche Register erfasst ausschließlich plötzliche Todesfälle im Sport. Primär sind drei Herausforderungen bei der Erstellung eines Registers von Bedeutung. Zum einen muss die Vorgehensweise bei der Datenerfassung allgemein verständlich und einheitlich sein. Zum anderen sollte eine qualitativ hochwertige Zusammenstellung von Daten einen praktischen Nutzen des Forschungsgrundes für die Bevölkerung ermöglichen. Letztlich sollte eine globale Erfassung plötzlicher Herztodesfälle mit dem Ziel, Ursachen und Auslöser des plötzlichen Herztodes besser zu verstehen, angestrebt werden. Diesen drei Herausforderungen stellt sich das in Frankfurt entstandene Register für plötzliche Herztodesfälle in jungen Jahren.

Methoden und Ergebnisse: In Zusammenarbeit mit der Medical Informatics Group (MIG) am Universitätsklinikum Frankfurt wurde basierend auf einer Open Source Software (OSSE-Open-Source-Registersystem für Seltene Erkrankungen) das Register für plötzliche Herztodesfälle in jungen Jahren erstellt. Auf Grundlage spezifizierter Fragestellungen wurden Erfassungsbögen ausgearbeitet, mit denen Daten aus Sektionsberichten sowie zusätzlichen histologischen und chemisch-toxikologischen Befundberichten der Obduktionsfälle der Institute für Rechtsmedizin in Köln und Frankfurt erfasst wurden.

Fazit: Eine erste, retrospektive Auswertung des neuen Registers zur Erfassung von plötzlichen Herztodesfällen in jungen Jahren in Deutschland, bestätigt die Ergebnisse anderer internationaler Studien im Hinblick auf z. B. Todesumstände. Unsere Auswertung zeigt ebenso, wie wichtig die Bedeutung einer einheitlichen Datengrundlage zur Todesursachenklärung, aber auch zur Erkennung von Risikofaktoren ist. Dieses erste deutsche Register für plötzliche Herztodesfälle in jungen Jahren stellt eine wichtige Basis zur validen Ausarbeitung von Risikofaktoren bzw. familiären Prädispositionen in diesen Fällen dar. 
P-RM-13

\section{Sudden Cardiac Death (SCD): Plötzlicher Tod eines 26-jährigen Mannes mit Arrhythmogener Rechtsventrikulärer Cardiomyopathie (ARVCM)}

\section{T. Wolter, R. Dettmeyer}

Institut für Rechtsmedizin, Justus-Liebig-Universität Gießen, Universitätsklinikum Gießen \& Marburg

Einleitung: Bei einer geschätzten Inzidenz von 1:1000 bis 1:10.000 stellen Arrhythmogene Rechtsventrikuläre Cardiomyopathien (ARVCM) eine gehäuft bei Männern auftretende, genetisch bedingte Form der Kardiomyopathie dar. Bei Genträgern soll die Inzidenz eines plötzlichen Todes bei 1:200 zu liegen. Die ARVCM soll Ursache für bis zu $25 \%$ aller plötzlichen Todesfälle bei jungen Menschen sein.

Fallbericht. Leichnam eines 26 Jahre alt gewordenen Mannes, der leblos in seinem Bett vorgefunden wurde. Anamnestisch habe es wenige Monate zuvor einen grippalen Infekt gegeben, sonst keine ernsten Vorerkrankungen. Im Leichenschauschein sei der Verdacht auf einen epileptischen Anfall als Todesursache angegeben worden.

Obduktion: Makroskopisch normgewichtiger Leichnam $(78 \mathrm{~kg}, 172 \mathrm{~cm}$ Körperlänge). Akute Stauungshyperämie der inneren Organe, Hirn- und Lungenödem, Lebergewicht $1562 \mathrm{~g}$, Milzgewicht $286 \mathrm{~g}$. Herzgewicht 368 g: erweichtes, blass-orange-farbenes Herzmuskelgewebe. Rechter Herzvorhof und rechte Herzkammer dilatiert, rechtsventrikulär verwaschene Fett-Muskel-Grenze. Flüssiges Leichenblut.

Histologie: Fettzellnester bis unmittelbar subendokardial. Im rechtsventrikulären Myokard fokal eine irreguläre Textur von Myokardfasern, perivaskuläre Fibrosen, partiell prominente Zellkerne in Endothelzellen. Fokale, kleinherdige, lymphozytäre intramyokardiale Infiltrate. Teils akute, teils chronische Stauungshyperämie der Leber mit Wandfibrose der Zentralvenen im Sinne einer beginnenden Cirrhose cardiaque. Teils akute, teils chronische Stauungshyperämie der Milz.

Fazit:. Bei einem plötzlichen und unerwarteten Tod junger Menschen ohne konkurrierende Todesursache und Verdacht auf einen plötzlichen rhythmogenen Herztod sollte an einen Todeseintritt als Erstmanifestation einer ARVCM gedacht werden. Histopathologisch kann diese makroskopische Verdachtsdiagnose mit großer Sicherheit bestätigt oder ausgeschlossen werden. Gegebenenfalls sind genetische Untersuchungen erforderlich.

\section{P-RM-14 \\ Relation between sudden death during bathing and age-related changes in the heart}

Fumiko Satoh, Wataru Irie, Chizuko Sasaki, Eriko Ochiai, Hinako Inoue, Junichiro Saito, Maho Kondo, Naomi Nakamaru, Momoko Sakamoto, Junpei Nagato

Department of Legal Medicine, Kitasato University School of Medicine, Kanagawa, Japan

Objective: We evaluated findings of age-related decline in heart function in those cases and compared them to findings from medico-legal autopsy cases as controls to clarify whether decreased heart function is related to the cause of sudden death during bathing.

Method: Of the 72 sudden deaths during bathing that were autopsied through the 10-year period at our university, the study examined 40 cases. A total of 110 autopsy cases aged 20-99 years was included as control cases. Using the microscopic examination of specimens stained with $\mathrm{HE}$ and Masson-trichrome, lipofuscin deposition, basophilic degeneration, perivascular fibrosis, anisocytosis of the nucleus of myocardial cells, and amyloid deposition were investigated. Heart specimens were observed in 20 fields at $40 \times$ using the microscope, and were categorized as $0,1+$ $(<25 \%), 2+(25-50 \%)$, and $3+(>50 \%)$. The $\times 2$ test was applied to ascertain whether a significant difference can be inferred between the frequen- cies of age-related changes in the heart of patients who died suddenly versus control cases.

Result: The average age at sudden death during bathing was $76.4 \pm 11.9$ years. Among the 40 autopsy cases of sudden death during bathing, 12 (30\%) had cardiac hypertrophy. The average weight of the heart among cases of sudden deaths during bathing was $383.6 \pm 78.6 \mathrm{~g}$. Regarding lipofuscin deposition, 31 cases were categorized as $1+, 8$ cases as $2+$, and 1 case as $3+$. Basophilic degeneration was $1+$ in 8 cases and $2+$ in 1 case. There were 18 cases of $1+$ anisocytosis of the nucleus of myocardial cells. Perivascular fibrosis (1+) was observed in 13 cases. Only one case of aortic valve calcification was found. Regarding control cases, in the hearts of persons aged 70 years or older, the frequency of myocardial nucleus size difference, perivascular fibrosis, intramyocardial lipofuscin deposition, and basophilic degeneration increased with age. From comparison of sudden deaths during bathing with cases aged 60 years or older, no significant difference was found in histological age-related cardiac changes.

Discussion and Conclusion: The frequencies of cardiac findings were compared between those of elderly people aged 60 years or older who died suddenly and controls of similar age. No significant differences were found. Sudden cardiac death during bathing is frequently associated with age-related changes in the heart, but at a similar frequency as in control cases aged 60 years or older. Sudden death during bathing can occur in anyone, even elderly people. Preventive measures against sudden death must be taken during bathing. Elderly people should not bathe alone.

\section{P-RM-15 \\ Immunohistochemical analysis of Sstr4 Expression in mouse thymus after chronic stress treatment}

Yuki Abe', Takehiko Murase', Hiromi Yamashita ${ }^{2}$, Keita Shinghu', Yoriko Shinba', Masahide Mitsuma', Takahiro Umehara', Takuma Yamamoto', Kazuya Ikematsu

'Department of Forensic Pathology and Science, Unit of Social Medicine, Nagasaki University Graduate School of Biomedical Sciences, Nagasaki, Japan.; ${ }^{2}$ Department of Forensic Dental Science, Unit of Social Medicine, Nagasaki University Graduate School of Biomedical Sciences, Nagasaki, Japan.

Objective: Recently, long-term abuse, e. g., domestic violence, elder abuse and so on, have been a very serious social problem in Japan. Unfortunately, forensic pathologists do not have useful tools or markers to confidently diagnose the chronic stress, especially in adult. We demonstrated the Somatostatin receptor 4(Sstr4) mRNA expression changed in chronic stress mouse. Additionally, we revealed that the elevation of the mRNA in thymus.

So, in this study, we investigated its protein expression in thymus. Material and methods: 8-week old male mice were employed. They were divided into 3 groups. One group was stressed by restricted once a day for 1 week as chronic stress. The other group was stressed only once as single stress. And no restriction mice were employed as control group. Following euthanasia at $60 \mathrm{~min}$ after the final treatment, thymus was collected. The thymus was fixed in formalin, and processed into FFPE blocks. IHC was performed with the monoclonal Sstr4 antibody. The Histofine ${ }^{\circledast}$ fast red II substrate kit was used as a color developer. We obtained images with a BZ-9000 and expression of Sstr4 were examined by ImageJ analysis. Tukey-Kramer test was employed as statistical analysis.

Result: Significant decreases in Sstr4 expression in the chronic stress groups compared to the control groups were observed. On the contrary, no significant changes were observed in the chronic stress group compared to the single stress group.

Discussion: In this study, we revealed that the expression of Sstr4 protein significantly decreased in the mouse thymus after chronic stress.

Somatostatin (sst1-sst5) regulates stress-related behavior and it is altered in mood disorders. Moreover, a recent study reported that Sstr4 is involved in anxiolytic and depression-like behaviors (Scheich et al. 2015).

So, we infer that the evaluation of Sstr4 in thymus might be a useful marker for chronic stress. However, there is no significant changes of Sstr4 
with the single stress group and chronic stress group. Therefore, further study will be needed about Sstr4 protein expression.

We previously reported that expression of Sstr4 mRNA were different among the thymus, pituitary gland, and lang. Hence, we will investigate Sstr4 protein expression in each organ to clarify Sstr4 protein kinetics.

\section{P-RM-16 \\ Forensic pathological study on temporal appearance of dendritic cells in skin wounds}

Yumi Kuninaka', Yuko Ishida', Mizuho Nosaka', Akiko Ishigami', Emi Shimada', Akihiko Kimura', Mitsunori Ozaki², Hiroki Yamamoto', Fukumi Furukawa ${ }^{3}$, Jumpei Matsuki', Mariko Kawaguchi', Wolfgang Eisenmenger ${ }^{4}$, Toshikazu Kondo

'Department of Forensic Medicine, Wakayama Medical University, 811-1 Kimiidera, 641-8509 Wakayama, Japan; '2Department of Neurological Surgery, Wakayama Medical University, 811-1 Kimiidera,; 641-8509 Wakayama, Japan; ${ }^{3}$ Takatsuki Red Cross Hospital, 1-1-1 Abuno, Takatsuki-shi, Osaka 569-1096, Japan; ${ }^{4}$ Institute of Legal Medicine, University of Munich, Nußbaumstraße 26, 80336 Munich, Germany

Objective: Observation of cutaneous wounds is a basic and important issues in forensic autopsy. When a wound (or wounds) is found, the determination of wound age including wound vitality is always required. Dendritic cells (DCs) are mononuclear and antigen-presenting immune cells. It still remains investigated in the role of human DCs in inflammatory responses after injury. Herewith, we examined temporal expression of CD11 $\mathrm{C}^{+} \mathrm{HLA}-$ $\mathrm{DR}^{+} \mathrm{DC}$ s in human skin wounds, and discussed their forensic significances in wound age determination.

Method: Fifty-three human skin wounds with various wound ages were obtained from forensic autopsies cases with the postmortem interval of $<3$ days. Deparaffinized sections were incubated with a pair of anti-CD11c and anti-HLA-DRa antibodies. After incubation with fluorochrome-conjugated secondary Abs, the sections were observed by a fluorescent microscopy. Five high-power microscopic fields were randomly chosen in each section, and the number of $\mathrm{CD} 11 \mathrm{c}^{+} \mathrm{HLA}-\mathrm{DRa} \mathrm{a}^{+} \mathrm{DCs}$ was counted, and the average number was evaluated in each wound specimen. The means of $\mathrm{CD} 11 \mathrm{c}^{+} \mathrm{HLA}-\mathrm{DRa}^{+} \mathrm{DC}$ numbers and the standard error were calculated.

Result: In all of uninured skin samples and skin wounds aged 2 days or less, CD11 $\mathrm{c}^{+} \mathrm{HLA}-\mathrm{DRa^{+ }} \mathrm{DC}$ s were not observed. $\mathrm{CD} 11 \mathrm{c}^{+} \mathrm{HLA}-\mathrm{DRa^{+ }} \mathrm{DC}$ s were first noted in skin wound samples with a postinfliction interval of 3 days. Subsequently, the number of CD11 $\mathrm{c}^{+} \mathrm{HLA}-\mathrm{DRa} \mathrm{C}^{+} \mathrm{DC}$ increased progressively, with the aging of skin wounds. Morphometrical analysis revealed the distribution of the numbers of $C D 11 c^{+} H L A-D R a^{+} D C s$ in connection with wound ages.

Discussion and Conclusion: Forensic pathologists often want a specific marker to evaluate wound vitality or wound age. However, the examination of only a single marker cannot provide high reliability and objectivity in wound age determination. As it is quite challenging to distinguish wounds aged 4 to 7 days from ones in the age range of 9 to 14 days using the extent of $\mathrm{CD} 11 \mathrm{c}^{+} \mathrm{HLA}-\mathrm{DRa^{+ }} \mathrm{DCs}$ counts alone, combined evaluation with other markers is recommended for the determination of wound age.

\section{P-RM-17 \\ Wound Age Estimation based on Expression of Chitinase like 1 Protein}

Takehiko Murase', Masahide Mitsuma', Yoriko Shinba', Keita Shingu', Yuki Abe', Hiromi Yamashita², Takahiro Umehara', Kazuya Ikematsu'

'Department of Forensic Pathology and Science, ${ }_{i}{ }^{2}$ Department of Forensic Dental Science, Graduate School of Biomedical Sciences, Nagasaki University, Nagasaki, Japan

Introduction: Wound age estimation is one of the important topics in forensic practice. While we generally estimate a timing of injury with observations of wound, such as macroscopic or histopathological findings, even now, estimating it precisely and scientifically still remains difficult. Once, we focused on chronological expression changes of the Chitinase like protein family in mouse injured skin, and found that Chitinase like 1 (CHIL1) mRNA and protein increased early after injury. Following this examination, we measured CHIL1 protein expression in human injured skin by immunohistochemistry. Here, we report the result and the usefulness of CHIL1 detection for wound age estimation.

Materials and Methods: CHIL1 was visualized by immunohistochemistry with paraffin-embedded sections of human wounded skin collected at autopsy (134 samples). We employed only the specimens whose timings of injuries were correctly identified with the judicial investigations. We classified them into 4 groups, A: $0-1$ day, B: 2-3 days, C: $4-6$ days, and D: 7 days or longer after injuries. The ratios of the number of CHIL1-positive cells to the total number of cells in the microscopic fields ( $x 400)$ was calculated as the positive rate. The mean values of 10 fields were statistically analyzed by Tukey's multiple comparison test. (Nagasaki University Ethics Committee Approval Number: 15011660)

Results and Discussion: The means of CHIL1 positive rate in each group were 0.082 (Group A), 1.008 (B), 5.626 (C), and 1.268 (D), respectively. The value of the group $C$ was statistically significant compared to that of the others. This suggests that the positive rate of CHIL 1 in human skin injuries could indicate the wounds 4- 6 days after those injuries with high accuracy. While CHIL1 is regarded as the protein which involved in inflammation, the particular functions have not yet been revealed. From the result of this study, it is considered that it might play some role from the late-inflammatory to the proliferative period of wound healing.

Conclusion: The detection of CHIL1 in wounded skin might be useful to estimate wound age.

\section{P-RM-18 Exploration von Nebenschilddrüsen: Lust oder Frust?}

Manhart J', Reichenbach $\mathrm{K}^{2}$, Derani $\mathrm{H}^{3}$, Schafmayer $\mathrm{C}^{2}$, Büttner A', Philipp $\mathrm{M}^{2}$

1 Institut für Rechtsmedizin, Universitätsmedizin Rostock, Rostock; ${ }^{2}$ Klinik und Poliklinik für Allgemein-, Viszeral-, Gefäß- und Transplantationschirurgie, Zentrum für operative Medizin, Universitätsmedizin Rostock, Rostock; ${ }^{3}$ Institut für Pathologie, Universitätsmedizin Rostock, Rostock

Fragestellung: Plötzliche (atraumatische) Todesfälle im Zusammenhang mit einem primärem Hyperparathyreoidismus (pHPT) stellen eine Rarität dar. Ein Bezug zu suizidal motivierten Handlungen oder psychischer Alteration wird vermutet. Die autoptische Darstellung von Nebenschilddrüsen ist kein etablierter Standard. Da eine postmortale Parathormon-Bestimmung nicht sinnvoll ist und medizinische Informationen zu Vorerkrankungen bei plötzlichen Todesfällen zumeist fehlen, stellt die makroskopische und histologische Beurteilung der Nebenschilddrüsen einen möglichen Anhaltspunkt dar. In einer Autopsiestudie wurden die Nebenschilddrüsen gezielt exploriert und histologisch untersucht.

Methode: Mit positivem Ethikkommissionsvotum wurden klinische und gerichtliche Sektionsfälle mit dem Fokus auf psychiatrischen Vorerkrankungen und/oder suizidal motivierten Handlungen sowie plötzlichen Todesfällen selektiert. Die zervikale Exploration erfolgte interdisziplinär chirurgisch-rechtsmedizinisch via Kocher' schem Kragenschnitt und klassischer zervikaler Exploration der Nebenschilddrüsen. Vergleichend wurde an rechtsmedizinisch-sektionstechnisch gewonnen Halspaketen $\mathrm{Ne}$ benschilddrüsen exploriert. Alle Befunde wurden histologisch gesichert. Ergebnisse: 12 Sterbefälle $(8 \mathrm{~m} ; 4 \mathrm{f})$ wurden untersucht. Altersmittelwert 54 (12-88) Jahre, BMI-Spannbreite $18-42 \mathrm{~kg} / \mathrm{m}^{2}$. Postmortem-Intervall 1 bis $>12$ Tage. Dauer der Halsorgan-Explorationen zwischen 10 und 60 min. (Mittelwert $35 \mathrm{~min}$ ). Todesursachenspektrum: Ertrinken, Polytrauma, Kopfschuss, Verbluten, Erhängen und plötzlicher natürlicher Tod. Von 48 möglichen Nebenschilddrüsen wurden 41 makroskopisch identifiziert (18 craniale; 23 caudale) und 28 histologisch gesichert. In einem Fall konnte ein makroskopisch auffälliger Befund histologisch als Adenom klassifiziert werden.

Diskussion:, Fazit: Trotz klinischer Relevanz des pHPT ist schon die intravitale operative Darstellung von Nebenschilddrüsen nicht trivial. Techni- 


\begin{tabular}{|c|c|c|c|c|c|c|c|c|c|}
\hline nb & sex & age & вMI & cause of death & procedure & $\begin{array}{l}\text { exploration- } \\
\text { time }\end{array}$ & $\begin{array}{c}P G / \\
\text { autopsy }\end{array}$ & $\begin{array}{c}\text { PG I } \\
\text { histology }\end{array}$ & resutt \\
\hline 1 & m & 39 & 24 & sudden carcliac death & Kocher incision & 60 & $\begin{array}{l}x / x \\
x / x\end{array}$ & $\begin{array}{l}x / x \\
x / x\end{array}$ & $4 / 4$ \\
\hline 2 & $\mathrm{~m}$ & 62 & 23,8 & drowning & Kocher incision & 45 & $\begin{array}{c}(x) /(x) \\
x / x\end{array}$ & $\begin{array}{l}x / 2 \\
-/ x\end{array}$ & $2 / 4$ \\
\hline 3 & $t$ & 60 & 17,9 & alc intoxication & Kocher incision & 45 & $\begin{array}{l}(x) / x \\
x /(x) \\
\end{array}$ & $\begin{array}{l}x / x \\
\text { LN. }\end{array}$ & $2 / 4$ \\
\hline 6 & $\mathrm{~m}$ & 77 & 19,9 & bleeding & Kocher incision & 45 & $\begin{array}{c}-/ x \\
x^{\prime /(x)}\end{array}$ & $\begin{array}{r}-1 x \\
x / x \\
\end{array}$ & $3 / 4$ \\
\hline 8 & t & 35 & 18,4 & intoxication & Kocher incision & 45 & $\begin{array}{c}(x) /(x) \\
x / x\end{array}$ & $\begin{array}{r}x / . \\
x / L N\end{array}$ & $2 / 4$ \\
\hline 9 & m & 12 & - & hanging & Kocher incision & 30 & $\begin{array}{l}-1 /(x) \\
(x) / x\end{array}$ & $\begin{array}{l}-1 x \\
x / .\end{array}$ & $2 / 4$ \\
\hline 4 & $t$ & 79 & 29,3 & myocardial in farction & forensic & 30 & $\begin{array}{l}(\mathrm{x}) /(\mathrm{x}) \\
(\mathrm{x}) /(\mathrm{x})\end{array}$ & $\begin{array}{l}x / . \\
-1 .\end{array}$ & $1 / 4$ \\
\hline 5 & m & 66 & 26,3 & bleeding & forensic & 30 & $\begin{array}{l}-1 /(x) \\
x / 2\end{array}$ & $\begin{array}{l}-1 x \\
-1 .\end{array}$ & $1 / 4$ \\
\hline 7 & $\mathrm{~m}$ & 88 & 23,2 & drowning & forensic & 30 & $\begin{array}{l}-/ x \\
x / x \\
\end{array}$ & $\begin{array}{r}-1 / L N \\
\times / x \\
\end{array}$ & $2 / 4$ \\
\hline 10 & $t$ & 60 & 24,7 & electricty & forensic & 30 & $\begin{array}{r}-1 x \\
x / x \\
\end{array}$ & $\frac{-1 .}{x / x}$ & $2 / 4$ \\
\hline 11 & m & 42 & 26,6 & poyytrauma & forensic & 15 & $\begin{array}{l}-1 x \\
x / x\end{array}$ & $\begin{array}{l}-1 x \\
x / x\end{array}$ & $3 / 4$ \\
\hline 12 & m & 23 & 43,8 & polytrauma & forensic & 10 & $\begin{array}{l}x / x \\
x / x\end{array}$ & $\begin{array}{l}x / x \\
x / x\end{array}$ & $4 / 4$ \\
\hline & $\begin{array}{l}m: f \\
8: 4\end{array}$ & 54 & 25 & . & - & & - & - & $58 \%$ \\
\hline
\end{tabular}

$\Delta m$ male, $f$ female, $P G$ parathyroid gland, $x$ detected, $(x)$ suspicios, - none, LN lymph node

sche Hilfsmittel hierzu sind in Erprobungsstadien. Die autoptische Exploration wird aufgrund zahlreicher topographischer Variationen zusätzlich erschwert. Eine Darstellung am rechtsmedizinisch exenterierten Halspaket ist, eingeschränkt, möglich. Makroskopisch auffällige Befunde sollten den Obduzenten an die Möglichkeit eines pHPT denken lassen.

\section{P-RM-19}

\section{Absence of CCR5/CCL5 axis exaggerates thrombus formation through reduced $\mathrm{UPA}$, tPA and VEGF expression in murine DVT model}

Mizuho Nosaka', Yuko Ishida', Akiko Ishigami', Yumi Kuninaka', Emi Shimada', Yumiko Hashizume' ', Hiroki Yamamoto', Akihiko Kimura', Fukumi Furukawa', Naofumi Mukaida ${ }^{2}$, Toshikazu Kondo' ${ }^{1}$

'Department of Forensic Medicine, Wakayama Medical University, Wakayama, Japan.; ${ }^{2}$ Division of Molecular Bioregulation, Cancer Research Institute, Kanazawa University, Kanazawa, Japan.

Objective: Pulmonary thromboembolism (PTE) is a major health problem in not only clinically but also forensic aspects. The incidence of pulmonary thromboembolism has been increasing in recent years. In this study, we attempted to elucidate the pathophysiological role of the CCR5 axis in the formation and dissolution of deep vein thrombi using C57BL/6 (WT) and $\mathrm{Ccr5}^{-/-}(\mathrm{KO})$ mice.

Methods: Inferior vena cava (IVC) of mice were ligated with silk sutures under anesthesia and kept alive for 1 to 21 days, and then thrombi were collected for immunohistochemical staining and gene expression analysis of the factors involved in thrombolysis.

Results: The weight of the thrombi were larger in KO mice than in WT mice, and the blood flow rates of the IVCs were recovered in WT mice in a shorter period than in $\mathrm{KO}$ mice. Immunohistochemical staining showed that CCR5-positive cells were observed in the thrombus of WT mice throughout the observation period and increased with time after ligation. The gene expression of $\mathrm{Ccr} 5$ was also observed in the thrombus. On the other hand, the gene expression of Plat, Plau, and Vegf in the thrombus was significantly decreased in KO mice than in WT mice. In addition, when the intraperitoneal macrophages-derived from WT mice were stimulated with recombinant $\mathrm{CCL} 5$, the gene expression of Plau, Vegf, and Plat was increased, but when the intraperitoneal macrophages-derive from $\mathrm{KO}$ mice were stimulated, the expression of these genes were not increased.

Conclusion: These results suggested that absence of the CCL5/CCR5 axis inhibits thrombolysis by suppressing UPA, VEGF, and tPA expression, re- spectively, and that the CCR5 system may be a useful molecular target for DVT therapy. In addition, the results of this study may help to clarify the molecular pathology of the thrombi in autopsy cases.

\section{P-RM-20}

D-dimer values are not adequate for discriminating the blood obtained within a couple of hours of cardiopulmonary arrest from the antemortem blood

Misa Tojo, Mami Nakamura, Kohei Takashima, Masahito Hitosugi

Department of Legal Medicine, Shiga University of Medical Science, SetaTsukinowa-cho, Otsu, Shiga, 520-2192, Japan

Objective: D-dimer is a specific cross-linked fibrin derivative that is a product of the endogenous fibrinolytic degradation of fibrin. In forensic medicine, values of D-dimer in the blood have been used for discriminating postmortem blood from antemortem blood, however, the changes of Ddimer levels in the blood shortly after death have not been understood. The purposes of this study were first to clarify the relationship between the time after cardiopulmonary arrest and the values of D-dimer in the blood, next, to consider the adequacy of this method for discriminating the blood soon after death from antemortem blood.

Method: From forensic autopsies performed at Shiga University of Medical Science between January 2018 and December 2020, the cases in which the victim had been transported to a hospital and examined D-dimer in the peripheral blood were selected. The relationship between values and time after cardiopulmonary arrest (CPA) was examined. Furthermore, the values were compared according to any conditions.

Results and Discussion: For the D-dimer values obtained from 46 victims (32 males and 14 females), they increased exponentially with a marked increas after $120 \mathrm{~min}$. No significant differences of D-dimer values were found between those obtained within $120 \mathrm{~min}$ of CPA and those drawn from alive patients. When comparing the values between victims with haemorrhages and not, they were significantly higher in haemorrhage group than those of non-haemorrhage group $(p<0.05)$. Also, the values were significantly higher in victims without return of spontaneous circulation (ROSC) than with because the duration after CPA was significantly longer in victims without ROSC.

Conclusion: The discrimination of postmortem blood from antemortem blood by evaluating $\mathrm{D}$-dimer value is difficult when postmortem duration is short as a couple of hours. Further studies are required for establishing the cut-off values of D-dimer for ideal discrimination.

\section{P-RM-21}

\section{Gastromalacia and acute gastric mucosal lesions in forensic autopsy cases}

Tatsuya Hirokawa ${ }^{1,2}$, Tomoya Ikeda ${ }^{1,2}$, Naoto Tani ${ }^{1,2}$, Shida Alissa ${ }^{1}$, Yayoi Aoki ${ }^{1}$, Kei Ikeda', Fumiya Morioka', Takaki Ishikawa',2

'Department of Legal Medicine, Osaka City University Medical School, Asahi-machi 1-4-3, Abeno, 545-8585 Osaka, Japan; ${ }^{2}$ Forensic Autopsy Section, Medico-legal Consultation and Postmortem Investigation Support Center (MLCPI-SC), c/o Osaka City University Medical School, Asahi-machi 1-4-3, Abeno, 545-8585 Osaka, Japan

Objective: In forensic pathology, postmortem autolytic rupture of the stomach is referred to as gastromalacia because of a lack of inflammation at the perforation site. The present study reviewed gastric mucosal changes including gastromalacia and acute gastric mucosal lesions (AGMLs; e. g., erosion/petechial hemorrhages and gastric acute ulcers) in forensic autopsy cases and examined their causal relationships.

Methods: Forensic autopsy cases $(n=973)$ at our institute over about a 6-year-period (2009-2014) were reviewed. Cases for which the stomach could not be examined because of total gastrectomy or advanced postmortem changes were excluded. 
Results: Gastromalacia was found in 27 cases $(2.8 \%)$, and was often associated with intracranial lesions (10 cases) and hyperthermia- and heart stroke-related disorders (eight cases). Histological examination revealed no inflammatory cell infiltration in the gastric lesions associated with gastromalacia. Gastric erosion/hemorrhages during the agony period were detected in about half of the cases (51.2\%). The incidence was high in acute deaths from heart and aortic disease $(53.1 \%)$ and cerebrovascular disease $(60.0 \%)$. Acute gastric ulcers were detected in $3.4 \%$ of cases, mostly in intracranial pathologies, cold exposure, fire fatalities, and malnutrition. No correlation was found between gastric changes when comparing the frequency of gastromalacia with AGMLs and gastric acute ulcers by cause of death. A literature review revealed 11 reported cases of gastromalacia in the past 64 years, and those studies suggested an association between gastromalacia and intracranial pathologies, which was also found in other causes of death. In one clinical report, the cause of death was gastromalacia itself, and histopathological examination showed no inflammation.

Discussion: Gastromalacia was more common in intracranial pathologies, as previous reported, but was also observed in other causes of death. Some clinical reports have suggested that distinguishing between prenatal and postmortem changes based on the presence or absence of inflammatory findings at the perforation site could lead to misinterpretation.

Conclusion: Gastromalacia was associated with not only intracranial pathologies, but also hyperthermia and heart stroke-related disorders. The incidence differed from AGMLs and gastric acute ulcers, which suggests that the underlying mechanism could be different from that for other gastric mucous changes.

\section{P-RM-22}

\section{Three cases of bacterial meningitis}

Takehiko Murase', Masahide Mitsuma', Yoriko Shinba', Keita Shingu', Yuki Abe', Hiromi Yamashita², Takahiro Umehara', Kazuya Ikematsu'

${ }^{1}$ Department of Forensic Pathology and Science, ${ }^{2}$ Department of Forensic Dental Science, Graduate School of Biomedical Sciences, Nagasaki University, Nagasaki, Japan

Introduction: Bacterial meningitis is a fatal disease and requires urgent intervention. The mortality rate without any treatment reaches as high as $70 \%$. Here, we report three autopsy cases of bacterial meningitis.

Cases: 1: A 64-year-old woman. Yellow-brown turbid fluid was pooled in subarachnoid space. The brain was edematous and weighed $1501.0 \mathrm{~g}$. The soft tissue around the left elbow was edematous, and yellowish purulent fluid was collected in the joint cavity. A large amount of chicken fat clots was repleted in the heart and great vessels. Only Streptococcus pneumoniae was detected from both of the joint fluid and the cerebrospinal fluid by culture. Diagnosis: left elbow arthritis and meningitis by S. pneumoniae.

2: A 60-year-old man. Yellowish brown purulent fluid was stored in subarachnoid space. The brain was edematous and weighed $1314.0 \mathrm{~g}$. A lot of chicken fat clots filled the heart and great vessels. The liver was covered with coarse nodular. The mucosa of bladder was dark red and foamy. The urine was dark brown and turbid. Klebsiella pneumoniae was detected from both of the urine and the cerebrospinal fluid by culture. Diagnosis: emphysematous cystitis and meningitis by K. pneumoniae.

3: A 63-year-old man. Yellowish viscous fluid was collected in subarachnoid space. The brain was edematous and weighed $1406.0 \mathrm{~g}$. Many chicken fat clots were stored in the heart and great vessels. The right lung was softened and weighed $1008 \mathrm{~g}$. The lower lobe was filled by a plenty of dark reddish turbid viscous fluid. The liver was covered with coarse nodular. Klebsiella pneumoniae was detected from both of the right lung pus and the cerebrospinal fluid by culture. Diagnosis: pyothorax and meningitis by K. pneumoniae.

Discussions: Although it is suspected that many people might have been dead from bacterial meningitis at various places and have been transported to forensic department, in some cases, no clear diagnosis might be decided. Even if cadavers were not involved in crimes, report the causes of death following determination of the causative microbes, by autopsy or intracranial puncture, would contribute to public health.

\section{P-RM-23 \\ A case of necrotizing fasciitis following intra-articular injections-iatrogenic or spontaneous?}

J. Matsuki, A. Ishigami, Y. Ishida, M. Nosaka, Y. Kuninaka, H. Yamamoto, E. Shimada, Y. Hashizume, A. Kimura, F. Furukawa, T. Kondo

Department of Forensic Medicine, Wakayama Medical University, Wakayama, Japan

Introduction: Necrotizing fasciitis is one of the severe soft-tissue infectious diseases with high morbidity. It is classified into 4 types based on its pathogens: type 1: mixed flora of aerobes and anaerobes, type 2: monomicrobial mainly due to Gram-positive coccus like group A Streptococcus or Staphylococcus aureus, type 3: monomicrobial due to Gram-negative microorganism such as Vibrio vulnificus, and type 4: fungal. Group A Streptococci secret lots of virulent factors, some of which contribute to the pathogenesis of necrotizing fasciitis and subsequent streptococcal toxic shock syndrome (STSS). A significant increase in the severe group A streptococcal infection has been reported since the late $1980 \mathrm{~s}$ with a fatality of $30 \%$, and skin injuries seem one of the major causal factors. Intra-articular injection (IA injection) of hyaluronic acid (HA) is widely employed for the supportive treatment of osteoarthritis. Especially, IA injection of HA has significantly lower odds of infections and infestations in comparison with placebo. However, there is only one report case of necrotizing fasciitis following IA injection of HA in a patient under chemotherapy after the resection of breast cancer.

Case Report: Here, we report a case of necrotizing fasciitis after intra-articular injection of hyaluronic acid. Here, we report a case of necrotizing fasciitis following intra-articular injection of hyaluronic acid. A 72-year-old female received intra-articular injections of hyaluronic acid due to arthralgia at the left shoulder and knee, and was found dead in her living room at one day. At the forensic autopsy, injection marks with bullae and erythema were found at the left shoulder and knee and liquefactive necrosis of muscle tissues was observed in the left but not right extremities. Histopathological examinations of the left upper arm and thigh revealed severe rhabdomyolysis with lots of bacterial clusters. Bacteriological examinations detected group A Streptococcus from intracardiac blood and affected muscle tissues. Postmortem biochemical analysis of blood showed escalated blood urea nitrogen $(133.8 \mathrm{mg} / \mathrm{dL})$, creatinine $(4.57 \mathrm{mg} / \mathrm{dL})$ and C-reactive protein $(45.0 \mathrm{mg} / \mathrm{dL})$. The cause of her death was diagnosed as streptococcal toxic shock syndrome (STSS). Moreover, it was suggested that the injection was inappropriately conducted and served as a portal of bacterial entry.

\section{P-RM-24}

\section{Progression of fatty liver and blood leptin level-a preliminary study}

Yayoi Aoki', Tomoya Ikeda ${ }^{1,2}$, Naoto Tani ${ }^{1,2}$, Tatsuya Hirokawa ${ }^{1,2}$, Fumiya Morioka', Kei Ikeda', Alissa Shida', Takaki Ishikawa ${ }^{1,2}$

${ }^{1}$ Department of Legal Medicine, Osaka City University Medical School, Osaka, Japan; ${ }^{2}$ Forensic autopsy section, Medico-legal Consultation and Postmortem Investigation Support Center (MLCPI-SC), Osaka, Japan

Objective: In recent years, the prevalence of obesity has been increasing because of excessive nutritional intake. Fatty liver, representing fat accumulation in the liver due to overnutrition, has not been regarded as a serious disease. However, more attention has recently been paid to the dangers of fatty liver disease, as progression can lead to cirrhosis and liver cancer, and in the worst-case scenario, death due to liver dysfunction. To understand the progression of obesity and fatty liver/cirrhosis, this study examined the relationship with leptin, produced by adipose tissue as an indicator of obesity. 
Method: We examined the results of 81 adult autopsies performed in our laboratory (58 males, 23 females). Leptin levels in blood were quantified using Enzyme-Linked Immuno-Sorbent Assay. Histopathological examination of the liver samples was performed to evaluate progression of fatty liver and cirrhosis using the Steatosis, Activity and Fibrosis score, and subcutaneous and visceral fat were calculated from Computed Tomography images. From these results, relationships between each value were examined.

Result: Comparing blood leptin levels for each stage of fatty liver and cirrhosis, leptin levels increased significantly as the stage of fatty liver progressed, but flattened out after reaching a certain stage. Since a significant difference was seen between males and females, we examined leptin levels separately by sex, and found a similar tendency in male cases. However, no significant changes were observed in female patients. Subcutaneous and visceral fat masses both correlated with leptin levels.

Discussion: Since leptin increased with the progression of fatty liver stage, we considered that a strong relationship existed between increased body fat and fat accumulation in the liver. Differences were observed between males and females. Investigations are needed into the influence of sex hormones, which are strongly related to obesity and sexual differences. Leptin levels correlated strongly with the amount of visceral and subcutaneous fat, but types of obesity, such as visceral and subcutaneous, also need to be considered in future studies.

Conclusion: The progression of fatty liver correlated closely with the increase in fat mass. Since progression of fatty liver can lead to death, continued focus on the risks of fatty liver disease is warranted. Investigations need to examine possible risk factors, and potential markers for assessment of disease stage.

\section{P-RM-25 Handlungsfähigkeit nach tiefgreifendem Halsschnitt - Ein Fallbericht}

\section{A. Albers' ${ }^{1}$, T. A. Engelmann' , A. Fieguth', S. Schulz², M. Klintschar ${ }^{1}$ \\ 'Institut für Rechtsmedizin, Medizinische Hochschule Hannover (MHH), Hannover, Deutschland; ${ }^{2}$ Polizeiinspektion Celle, Celle, Deutschland}

Einleitung: Die Beurteilung der Handlungsfähigkeit, das heißt u. a. die Fähigkeit zur Ausführung von zielgerichteten Abwehrhandlungen aber auch Fluchtbewegungen, nach Verletzungen ist unter kriminalistischen Gesichtspunkten insbesondere bei voneinander abweichender Lokalisation des Tat- und des Fundortes, aber auch bei divergenten Einlassungen von Beteiligten und Zeugen eines Geschehens von eminenter Bedeutung für die polizeilichen Ermittlungen und stellt den rechtsmedizinischen Sachverständigen gleichermaßen vor besondere Herausforderungen.

Kasuistik: Ein 28-jähriger Mann wird nach vorne gebeugt auf einem Hocker sitzend aufgefunden. Auf Ansprache von Zeugen gibt er röchelnde Geräusche von sich und rennt los. Nach 20 Metern bricht er leblos zusammen. Auf einer Ablage in Griffweite des Hockers wird ein Messer vorgefunden.

Bei der Obduktion gelangt eine weitklaffende, glattrandige Schnittverletzung an der Halsvorderseite mit Durchsetzung der Halshaut und der -muskulatur zur Darstellung. Korrespondierend zeigen sich die vollständige Durchtrennung der rechten Halsvene bei unvollständiger Durchtrennung der rechten Halsschlagader und die komplette Absetzung des Kehldeckels sowie des rechten Kehlkopfoberhornes. Als weitere wesentliche Obduktionsbefunde sind eine positive Luftembolieprobe und Zeichen des Verblutens mit Blutarmut der inneren Organe, Entspeicherung der Milz und Unterblutungen des Herzinnenfells zu nennen.

Fazit: Derartige Fälle finden sich zwar in der einschlägigen Fachliteratur; gleichwohl ist die überwundene Wegstrecke, insbesondere vor dem Hintergrund der nicht unerheblichen Verletzung von größeren (auch arteriellen) Halsgefäßen, als beachtlich einzuordnen. Vor diesem Hintergrund soll die Falldarstellung eine weitere Entscheidungshilfe bei der Beurteilung der Handlungsfähigkeit nach tiefgreifenden Halsverletzungen liefern.
P-RM-26

Death due to a blow received during boxing sparring: an autopsy case report

Yayoi Aoki ${ }^{1}$, Tomoya Ikeda ${ }^{1,2}$, Naoto Tani ${ }^{1,2}$, Tatsuya Hirokawa ${ }^{1,2}$, Fumiya Morioka', Kei Ikeda', Alissa Shida', Takaki Ishikawa ${ }^{1,2}$

'Department of Legal Medicine, Osaka City University Medical School, Osaka, Japan; ${ }^{2}$ Forensic autopsy section, Medico-legal Consultation and Postmortem Investigation Support Center (MLCPI-SC), Osaka, Japan

Objective: In recent years, increasing numbers of people have chosen boxing as an activity to improve their health issues, such as being overweight and suffering from a lack of exercise, and this has been accompanied by increases in the variety of information available about boxing, which allows participants to select the exercise content that best suits their physical level. Here, we report an autopsy case of a sudden death caused by a blow to the left jaw during boxing sparring while wearing protective equipment.

Method: An autopsy was performed on a man who died after being struck on the left jaw by his opponent during sparring while wearing protective equipment, including headgear and gloves, within approximately $9 \mathrm{~h}$ after confirmation of death. Various samples such as body fluids and tissues were collected during the autopsy and examined.

Result: Regarding the autopsy findings, the case was an adult male (height: $170 \mathrm{~cm}$; weight: $52.7 \mathrm{~kg}$; body mass index: $18.2 \mathrm{~kg} / \mathrm{m}^{2}$ ). He had very mild facial congestion and subcutaneous hemorrhage in the left mandibular base. The heart $(290 \mathrm{~g})$ contained dark-red-colored liquid blood, as well as some soft and pig fat-like clots. The brain (1500 g) was markedly swollen, with subdural and diffuse subarachnoid hemorrhages on the surface. In addition, the bridging veins in the frontal lobe were torn, and contusions were apparent on the right frontal and temporal poles.

Discussion: Based on the autopsy results, we determined the cause of the death to be traumatic brain swelling due to a blow to the left jaw during boxing sparring, and considered intraventricular hemorrhage, subdural hematoma, and cerebral contusion as possible aggravating factors. We assumed that the rupture of the bridging vein and the brain contusion resulted from elongation of the bridging vein caused by the external rotational force due to the blow to the head.

Conclusion: With increasing numbers of participants, boxing is increasingly classified as a type of exercise rather than a combat sport. However, in boxing sparring, depending on the body position and direction of the force, death can still occur, even while wearing protective equipment. This case highlights the importance of reminding participants of the dangers involved in combat sports and the need to be careful at all times while participating in boxing activities.

\section{P-RM-27}

\section{Zigarettenbrandverletzungen vs. Dermatopathie - ein} Fallbericht

Hoffmann EHA, Dettmeyer R, Malolepszy L

Institut für Rechtsmedizin, Justus-Liebig-Universität Gießen

Einleitung: Dermatologen weisen gelegentlich darauf hin, Zigarettenbrandverletzungen als Kindesmisshandlung würden vorschnell diagnostiziert. Tatsächlich zeigt der vorliegende Fall, dass Zurückhaltung angebracht ist.

Vorgeschichte: Bei einem 11-jährigen Mädchen stellte der Hausarzt am Körper Wunden fest, die an eine Kindesmisshandlung durch Ausdrücken von Zigaretten auf der Haut denken ließen. Das Mädchen habe seit ca. 4 Jahren Anfälle von Juckreiz und kratze sich häufig, es seien die Matratze sowie mehrfach Wasch- und Pflegeprodukte gewechselt worden. Bei Stress trete die Symptomatik nicht vermehrt auf, multiple Therapieansätze seien ohne Erfolg gewesen. Die Mutter, ihr Lebensgefährte sowie der Kindsvater seien Nichtraucher. 
Befunde: An den Beinen und am rechten Arm rund-ovale, narbige Läsionen von bis $1 \mathrm{~cm}$ Durchmesser, randständig leicht erhaben. An beiden Unterschenkeln, rechtsbetont, mehrere frisch imponierende, rund-ovale, zentral erosive bzw. mit Schorf bedeckte, ca. $1 \mathrm{~cm}$ messende Läsionen, leicht erhaben erscheinend, narbig wirkender Randsaum.

Beurteilung: Aus rechtsmedizinischer Sicht ließen die Befunde zunächst an eine wiederholte Misshandlung mittels Zigarettenverbrennung denken. Wegen der Vorgeschichte stellte sich differentialdiagnostisch die Frage einer dermatologischen Erkrankung. Konsiliarisch hinzugezogene Dermatologen stellten die Differentialdiagnosen rezidivierende Impetigo contagiosa, Follikulitis, oder Ekthymata. Die Impetigo ist die häufigste Verdachtsdiagnose, jedoch heilt diese ohne Narbenbildung ab, ebenso (meistens) die Follikulitis, auch sind im vorgestellten Fall die Läsionen dafür zu groß. Somit kämen am ehesten Ekthymata in Betracht. Diese werden von $\mathrm{S}$. aureus aber auch gramnegativen Keimen, wie Pseudomonaden, verursacht und durch unzureichende Hygiene oder Hauterkrankungen, wie atopisches Ekzem, begünstigt.

Fazit: Bei Befunden wie im vorgestellten Fall wird nicht selten eine Misshandlung durch Zigarettenverbrennung vermutet. Dennoch sind dermatologische Erkrankungen als Ursache nicht selten (oftmals Impetigo contagiosa). Zweifelhafte Hautbefunde sollten deshalb immer dermatologisch-konsilisarisch beurteilt werden.

\section{P-RM-28}

Neonatizide im Untersuchungsgut des Instituts für Rechtsmedizin Greifswald vor und nach der politischen Wende 1990 - Umstände, Befunde, Besonderheiten

Jacob Ott, Martin Dokter, Klaus-Peter Philipp und Britta Bockholdt, Institut für Rechtsmedizin, Universitätsmedizin Greifswald, Greifswald, Deutschland

Einleitung: Als Neonatizid wird das sehr seltene Phänomen der Tötung eines Neugeborenen durch die eigene Mutter innerhalb von $24 \mathrm{~h}$ nach der Geburt bezeichnet (vgl. Häßler, F., Kindstod und Kindstötung, S. 189).

Fragestellung: In dieser Studie sollten die Neonatizide, die im Institut für Rechtsmedizin der Universitätsmedizin Greifswald untersucht wurden systematisch ausgewertet werden.

Material und Methoden: Dazu wurden aus dem Untersuchungsgut des Instituts aus den Jahren 1965 bis 2019 aus den insgesamt 9076 gerichtlichen Obduktionen 32 Fälle von Neonatiziden (entspricht 0,35\%) ermittelt.

Ergebnisse: 23 Fälle lagen zeitlich $(71,8 \%)$ vor der politischen Wende. Die Inzidenz in diesem Zeitraum betrug 6,4 Tötungen/100.000 Geburten. Nach der Wiedervereinigung konnten 9 Fälle $(28,13 \%)$ ermittelt werden. Dies entspricht einer Inzidenz von 5,39 Tötungen/100.000 Geburten. Weiterhin zeigte sich, dass alle untersuchten Geburten alleine und die meisten in der Häuslichkeit stattfanden. Die Opfer waren zu zwei Drittel Mädchen und die häufigste Todesursache war der Tod durch Ersticken. Die Hälfte der Leichname wurde bereits im Laufe eines Tages aufgefunden, $78 \%$ innerhalb von zwei Wochen nach der Tat. Die Täterinnen waren größtenteils zwischen 20 und 30 Jahren alt. Zu DDR-Zeiten hatten sie in der Mehrzahl der Fälle bereits mehrere Kinder und waren öfter verheiratet als die Täterinnen in der Zeit nach der Wiedervereinigung. Keine der Frauen hatte Abitur, eine war bereits vorbestraft. Ein klassisches Motiv konnte nicht herausgearbeitet werden, vielmehr zeigte sich, dass das Verdrängen der Schwangerschaft und das Einnehmen einer passiven Verhaltensweise eine wichtige Rolle spielte. In der DDR wurden die Täterinnen wegen Totschlages durchschnittlich zu einer Freiheitsstrafe von 4 Jahren und 5 Monaten verurteilt, wobei $49,57 \%$ der Strafe vollstreckt werden musste. Nach der Wiedervereinigung erfolgte die Verurteilung in der Mehrzahl ebenfalls wegen Totschlages mit einem Strafmaß von 4 Jahren und 11 Monaten Freiheitsstrafe. Die Vollstreckung war hier mit 62,83\% erkennbar länger. Diskussion: Neonatizide sind im Einzugsgebiet des Institutes für Rechtsmedizin Greifswald, einem ländlich geprägten Gebiet eher seltene Ereig- nisse. Vergleicht man die Inzidenz mit internationalen Untersuchungen liegt die Inzidenz unseres Einzugsgebietes im mittleren Bereich.

\section{P-RM-29 \\ Intra- und intermuskuläre Unterschiede des postmortalen Proteinabbaus zur Todeszeitschätzung}

Stefan Pittner ${ }^{1}$, Walther Gotsmy ${ }^{1}$, Angela Zissler², Bianca Ehrenfellner², Dominik Baumgartner ${ }^{2}$, Anna Schrüfer ${ }^{2}$, Peter Steinbacher ${ }^{2}$, Fabio Monticelli ${ }^{1}$

${ }^{\prime}$ IFFB Gerichtsmedizin und forensische Neuro Psychiatrie, Paris-Lodron Universität Salzburg, Salzburg; ${ }^{2}$ FB Biowissenschaften, Paris-Lodron Universität Salzburg, Salzburg

Hintergrund: Gerade in den letzten Jahren wurde die Untersuchung des postmortalen Abbaus von Biomolekülen zur Todeszeitschätzung zunehmend interessanter. Als besonders geeignet hat sich die Analyse des Abbaus verschiedener Proteine der Skelettmuskulatur herausgestellt. Nicht zuletzt aufgrund der Tatsache, dass es sich dabei um das größte homogene Kompartiment des menschlichen Körpers handelt und daher meist selbst bei schwersten Verletzungen, davon unbeeinflusste Proben gesammelt und untersucht werden könnten. Um dieses Potenzial ausnutzen zu können muss allerdings untersucht werden, ob der postmortale Proteinabbau in allen Bereichen des Körpers gleichmäßig (gleichzeitig) abläuft, oder es hierbei Unterschiede gibt.

Methode: In dieser Studie wurden drei Obduktionsfälle mit unterschiedlicher Leichenliegezeit untersucht. Es wurden jeweils (i) drei Proben aus unterschiedlichen Stellen des selben Muskels, (ii) drei verschiedene Skelettmuskeln, sowie (iii) jeweils eine Probe aus der Skelettmuskulatur, der glatten - und Herzmuskulatur gesammelt, mittels SDS-PAGE und Western blot untersucht und die postmortalen Proteinabbauprofile miteinander verglichen.

Ergebnisse: (i) Intramuskuläre Unterschiede waren minimal, bzw. gar nicht vorhanden und sind entsprechend von untergeordneter Bedeutung für die Analytik. (ii) Obwohl jeweils gut anwendbare Proteinabbaumuster festgestellt werden konnten unterschieden sich diese in den verschiedenen Skelettmuskeln mitunter voneinander. (iii) Herzmuskulatur zeigte qualitativ ähnliche Proteinabbaumuster, allerdings ebenfalls mit Unterschieden zu den verschiedenen Skeletmuskeln. Die verwendete glatte Muskulatur (Pylorus) zeigte hochgradig inkonsistente Ergebnisse zum Proteinabbau.

Diskussion: Mit dieser Studie konnte gezeigt werden, dass intramuskuläre Unterschiede bei der Analyse des postmortalen Proteinabbaus vernachlässigt werden können. Sowohl Skelett- als auch Herzmuskulatur zeigen Abbaumuster die sich qualitativ gut für die Todeszeitschätzung eignen. Der Proteinabbau läuft allerdings in den verschiedenen Muskeln unterschiedlich schnell ab. Das bedeutet zwar, dass es nicht gleichgültig ist welcher Muskel für die Untersuchungen herangezogen wird, bietet aber interessante Möglichkeiten die Todeszeitschätzung durch Muskelproteine zu präzisieren. Ist z. B. Protein X in Muskel A und B noch vorhanden, in C und D aber nicht (mehr) kann das entscheidende Hinweise liefern. Der Proteinabbau in der glatten Muskulatur des Pylorus unterliegt neben der Liegezeit zusätzlichen Abbaufaktoren (z. B. durch Verdauungssäfte und -enzyme) und eignet sich demnach nicht zur Eingrenzung des PMI.

\section{P-RM-30 \\ A case in which postmortem interval was estimated by diapause of the warm-season flies}

Kiyoshi Saigusa' ${ }^{1}$ Masataka Takamiya², Sachiko Fujita², Yasuhiro Aoki ${ }^{3}$

${ }^{1}$ Department of Biology, Center for Liberal Arts and Sciences, Iwate Medical University, Iwate, Japan; ${ }^{2}$ Division of Legal Medicine, Department of Forensic Science, School of Medicine, Iwate Medical University, Iwate, Japan; ${ }^{3}$ Department of Forensic Medicine, Nagoya City University Graduate School of Medical Sciences, Nagoya, Japan

Introduction: Iwate Prefecture located in the northern part of Japan's main island (Honshu), is covered with snow in winter, and insects that 
are dominantly active in the warm season, diapause and overwinter. Diapause of forensically important flies is induced in adult females experiencing certain photoperiods and temperatures.

Case Report: We report a case in which the postmortem interval of a corpse found indoors in spring was indicated more accurately by entomological evidence than by the police investigation. In mid-May of a certain year, a corpse in an advanced state of decomposition was found in a room after a large number of adult flies perched on the inside of the window drew attention. At the time of the forensic autopsy, information provided by the Iwate Prefectural Police stated that the victim was last confirmed alive in late March of the same year, so the estimated postmortem interval was about 1.5 months. However, the dried dermis of the corpse was colored amber to dark reddish brown, and the thoracic and abdominal organs were missing except for the both lungs and the right kidney. Moreover, the entomological evidence recovered from the body at autopsy, namely dead green bottle flies (Lucilia sericata) and dark reddish brown flesh fly pupae about $12 \mathrm{~mm}$ in length, were flies that are dominant in the warm season. No necrophagous beetles were found on the corpse.

Discussion: These findings strongly suggested that the flies had already colonized in the body no later than the warm/cold boundary season of the previous year. Therefore, from both the autopsy findings and entomological evidence, it was concluded that information provided by the police investigation on when the victim was last confirmed alive was likely incorrect. In fact, a subsequent police investigation found that it was over 6 months since the victim had last been confirmed alive. Although some studies have been conducted on the conditions inducing diapause in insects, the conditions for breaking diapause are unclear. Once the conditions for resuming activity have been elucidated, it would be possible to predict pupation and emergence of adults after diapause, which would contribute to the forensic entomological estimation of the postmortem interval.

\section{P-RM-31}

\section{Tödliche Lungenhypoplasie als Folge einer beidseitigen kongenitalen Zwerchfellhernie}

\section{Roeber I, Zindler K, Grellner W}

Abteilung Rechtsmedizin, Universitätsmedizin Göttingen, Robert-Koch-Str. 40, 37075 Göttingen, Deutschland

Einleitung: Kongenitale Zwerchfellhernien machen ca. $8 \%$ aller angeborenen Fehlbildungen aus und betreffen etwa 1 von 2000-3000 Neugeborenen. Sie sind in 80-90\% der Fälle linksseitig lokalisiert, bilaterale Hernien sind mit $2 \%$ selten. Mit dieser Fehlbildung gehen i.d. R. eine Verlagerung der jeweiligen Bauchorgane in den Thoraxraum sowie eine ipsilaterale Lungenhypoplasie einher.

Falldarstellung: Vorgeschichte: Im vorliegenden Fall wurde eine 35-jährige Erstgebärende in der 41. + 1. SSW aufgrund vaginaler Blutungen stationär aufgenommen. Bei auffälligem CTG entschloss man sich zu einer Not-Sectio. Das Kind zeigte sich nach der Entbindung avital und wurde reanimiert. Nach Intubation ließen sich kaum Atemgeräusche feststellen, ein 30-minütiger Wiederbelebungsversuch verlief frustran.

Obduktionsbefunde: Es zeigte sich eine bilaterale Zwerchfellhernie (links $4,5 \mathrm{~cm}$, rechts $3,5 \mathrm{~cm}$ ) mit Verlagerung von Magen, Milz, Leberanteilen sowie Dünndarm in die linke und teilweiser Verlagerung des rechten Leberlappens in die rechte Brusthöhle. Ferner ließ sich eine massive beidseitige Lungenhypoplasie mit einem gemeinsamen Lungengewicht von $5 \mathrm{~g}$ (entsprechend ca. der 19.-20. SSW) feststellen. Im Übrigen zeigte sich das Kind zeitgerecht entwickelt, auffällig war lediglich eine vermehrte Körperbehaarung.

Todesursache: Beidseitige Lungenhypoplasie bei bilateraler kongenitaler Zwerchfellhernie.

Diskussion: Es bestand zunächst der Verdacht auf eine medizinische Fehlbehandlung im Rahmen des Geburtsvorgangs des verstorbenen Kindes. Die Obduktion erbrachte jedoch den Nachweis einer ausgeprägten bilateralen kongenitalen Zwerchfellhernie mit konsekutiver beidseitiger Lun- genhypoplasie. Es bestand somit zum Zeitpunkt der Geburt keine Überlebensfähigkeit des ansonsten zeitgerecht entwickelten Säuglings. Die festgestellte Hypertrichose lässt an die Möglichkeit einer syndromalen $\mathrm{Er}$ krankung denken. Inwieweit die gravierende Fehlbildung im Rahmen vorgeburtlicher Untersuchungen hätte erkannt und ggf. behandelt werden können/müssen, ist gegenwärtig nicht bekannt.

Fazit: Im vorliegenden Fall konnte die rechtsmedizinische Obduktion den im Raum stehenden Vorwurf eines Behandlungsfehlers entkräften. Dies unterstreicht deren Relevanz in Fällen unerwarteter Säuglingstode.

\section{P-RM-32 \\ Tod in Kopftieflage zwischen Silageballen - ungewöhnlicher Ausgang eines Vermisstenfalles}

Clara-Sophie Schwarz, Tanja Germerott, Thomas Riepert

Institut für Rechtsmedizin der Johannes Gutenberg-Universität Mainz

Hintergrund: Todesfälle durch Kopftieflagen sind seltene Ereignisse; die Diagnose erfordert die kritische Würdigung sämtlicher Fallumstände.

Falldarstellung: Ein Jugendlicher äußert, sein Handy holen zu wollen und verlässt das Elternhaus. Er trägt einen Greifarm bei sich. Nachdem er nicht zurückkommt, wird er noch am selben Tag vermisst gemeldet. Fünf Monate später entdeckt ein Bauer in einem engen Spalt zwischen seinen in zwei Reihen gestapelten, mit glatter Folie umwickelten Silageballen einen Leichnam mit dem Kopf am Boden und den Füßen in der Höhe. Am Leichnam werden ein Greifarm und ein Handy gefunden.

Der noch $18 \mathrm{~kg}$ schwere Leichnam mit fortgeschrittenen Fäulnisveränderungen wird bei der Bergung in Abwesenheit eines Rechtsmediziners erheblich beschädigt. Am vollständig erhaltenen Skelett lassen sich bei der Obduktion keine Verletzungen erkennen. Mittels Gebissabgleich wird der Leichnam als derjenige des Vermissten identifiziert. Das laut Polizei am Leichnam belassene Handy ist zunächst nicht auffindbar, sodass eine Computertomografie angeschlossen wird. Das Handy wird zwischen verklebten Textillagen gesichtet und kann sichergestellt werden.

Todesursache: Die Umstände legen nahe, dass der Jugendliche beim Versuch, sein Handy aufzuheben, kopfüber zwischen die Ballen geriet und sich nicht befreien konnte. Der Tod trat infolge der ungünstigen Körperposition ein.

Einerseits ist eine Fixierung des Brustkorbes in Expirationsstellung mit der Folge einer lagebedingten Asphyxie denkbar, andererseits ist bei Kopftieflage ein „Versacken“ von Blut in der oberen Körperhälfte mit druckbedingter Störung des venösen Rückflusses zum Herzen in Betracht zu ziehen. Bei Aufliegen des Kopfes dürften eine fixierte Hyperextension oder -flexion der Halswirbelsäule und das den Brustkorb an angrenzende Gegenstände drückende Körpergewicht die Atemexkursionen zusätzlich beeinträchtigt haben. Auch Rückatmung kann eine Rolle gespielt haben. Fazit: Im vorliegenden Fall war die Auffindesituation ausschlaggebend für die Diagnose der Todesursache. Eine exakte Dokumentation hätte eine genauere Rekonstruktion der pathophysiologischen ermöglichen können. Außerdem wurde das Auffinden von Gegenständen an der Leiche durch das Vorgehen am Fundort erschwert. Der vorgestellte Fall zeigt, dass eine rechtsmedizinische Inaugenscheinnahme vor Ort bei ungewöhnlicher Auffindesituation und schwieriger Bergung grundsätzlich angestrebt werden sollte.

\section{P-RM-33}

\section{Ertrinkungsdiagnostik durch Diatomeen - Quantitative Analyse verschiedener Lungenpositionen}

Dominik Hagen ${ }^{1}$, Astrid Obermayer ${ }^{1}$, Walter Stoiber', Walther Gotsmy ${ }^{2}$ Fabio Monticelli², Stefan Pittner ${ }^{2}$

${ }^{1}$ FB Biowissenschaften, Universität Salzburg, AT; ${ }^{2}$ IFFB Gerichtsmedizin und forensische Neuropsychiatrie, Universität Salzburg, AT 
Hintergrund: Laut der Weltgesundheitsorganisation (WHO) ist „Ertrinken“ die dritthäufigste unbeabsichtigte Todesursache weltweit. Die Diagnostik des Ertrinkungstodes ist eine Ausschlussdiagnose und zählt bis heute zu einer der schwierigsten Aufgaben der forensischen Routine, unter anderem da sogenannte klassische Ertrinkungszeichen wie Paltauf-Flecken, Schaumpilz oder Wydler-Zeichen oft nur schwach ausgeprägt oder sogar gänzlich fehlen können. Neben feingeweblichen Untersuchungen, kann auch eine quantitative Diatomeen-Analyse als unterstützende Beweiskraft herangezogen werden.

Hierbei wird die Diatomeen-Konzentration aus $1 \mathrm{~g}$ Lungengewebe mit der aus $1 \mathrm{ml}$ Ertrinkungsmedium verglichen und daraus ein Quotient (L/DWert) berechnet. Ein L/D-Wert $>2$ entspricht demnach einer mehr als doppelt so hohen Diatomeendichte im Lungengewebe als im Ertrinkungsmedium, und gilt damit als klares Indiz für einen Ertrinkungsvorgang.

Methode: Nach Etablierung dieser Methode an unserem Institut wurden Lungengewebsproben bisher aus dem Bereich mit dem geringsten Inhalationsdruck, der linken Lungenspitze, entnommen. Unklar blieb jedoch, ob sich Diatomeen in der Lunge konsistent verteilen und andere Positionen ähnliche Ergebnisse erzielen würden. Um etwaige positionelle Unterschiede aufzudecken, wurden von $\mathrm{x}$ weiteren bestätigten Ertrinkungsfällen sieben verschiedene Lungenbereiche auf die jeweilige Diatomeen-Verteilung überprüft.

Es wurden Gewebeproben aus den oberen, mittleren und unteren Lungenlappen, sowie dem Bereich des rechten und linken Hauptbronchus entnommen und diese anschließend mit einer Kombinationslösung aus Salpetersäure und Wasserstoffperoxid chemisch aufgeschlossen, auf eine säurebeständige Membran filtriert und die verbleibenden Silicatschalen der Diatomeen elektronenmikroskopisch quantifiziert.

Ergebnisse: Die verschiedenen Stellen der Lunge zeigten unterschiedlich hohe Diatomeendichten mit charakteristischen Verteilungen. Unterschiede traten vor allem zwischen dem rechten und linken Lungenflügel auf. Außerdem konnte eine deutlich höhere Konzentration im Bereich der Hauptbronchien festgestellt werden.

Diskussion und Fazit: Die im Zuge des „Ertrinkens“ in die Lunge aufgenommenen Diatomeen verteilen sich heterogen. Dies kann teilweise mit Druckunterschieden bzw. physiologischen Vorgängen erklärt werden. Es bedarf jedoch weiterer Forschung, um fallspezifische Ursachen der ungleichmäßigen Verteilung, sowie die erhöhte Konzentration im Bereich der Hauptbronchien zu erklären und um eine zuverlässige Ertrinkungsdiagnose anhand der Diatomeendichte gewährleisten zu können.

\section{P-RM-34 \\ Application of polarization tomography of biological tissues for differential diagnosis of causes of death from alcohol and carbon monoxide poisoning in forensic medical practice}

\section{Ivaskevich, O. Vanchuliak, Y. Sarkisova \\ Higher State Educational Establishment of Ukraine, Forensic Medicine Department, Chernivtsi, Ukraine}

Introduction: Currently known diagnostic signs of death from acute alcohol and carbon monoxide poisoning are relatively probative, and sometimes allow for the possibility of subjective interpretation, which encourages the search for new diagnostic methods to differentiate the cause of death from poisoning in forensic medical practice.

Materials and methods: The object of the study were histological sections of the adrenal glands, myocardium and polycrystalline blood films selected from 155 corpses died from coronary heart disease (control group 1), due to ethanol poisoning (group 2) and carbon monoxide (CM) poisoning (group 3). The research methodology is based on the implementation of polarization reconstruction of the distributions of the average values of the birefringence of the polycrystalline component of samples of histological sections of biological tissues in cases of such poisoning.
Results: By applying the method of polarization tomography of the polycrystalline component of histological sections of the myocardium, adrenal glands and polycrystalline blood films revealed a number of characteristic features that have not been described before, and allow to objectively differentiate the cause of death in case of both poisonings. The best results were obtained in the study of samples of human adrenal glands: in alcohol poisoning, the value of $A s-2.04 \pm 0.038$ and $E k-2.42 \pm 0.056$; in CM poisoning $A s-2.21 \pm 0.073$ and $E k-2.58 \pm 0.061$. Information analysis of the results of statistical processing of polarization-reproduced coordinate distributions of the linear birefringence of polycrystalline networks of histological sections of the adrenal glands ( $A s, E k \rightarrow 93-96 \%)$ and myocardium $(A s, E k \rightarrow 92-93 \%)$ revealed an excellent level of accuracy, polycrystalline blood films-good level of accuracy (As, Ek $\rightarrow$ 82-86\%) in differential diagnosis of alcohol and $\mathrm{CM}$ poisoning.

Conclusions: The statistically significant efficiency $(\rho 1 ; \rho 2 ; \rho 1 ; p 2<0.05)$ of the forensic differentiation of cases of alcohol and carbon monoxide poisoning was demonstrated by calculating the central statistical moments that characterize the polarization-reproducible distributions of average of the linear birefringence values of histological sections of the myocardium, adrenal glands and polycrystalline blood films. An excellent level $(92-96 \%)$ of operational characteristics of the diagnostic power of the method in the study of samples of the adrenal glands and myocardium was revealed.

\section{P-RM-35}

Primär unbekannte Plasmozytomniere als Todesursache: Postmortaler Nachweis und Bedeutung

\section{Mahlke NS ${ }^{1}$, Tank $A^{1}$, Seidl $M^{2}$, Ritz-Timme $S^{1}$}

'Institut für Rechtsmedizin, Universitätsklinikum Düsseldorf, Düsseldorf/Deutschland; 'Institut für Pathologie, Universitätsklinikum Düsseldorf, Düsseldorf/Deutschland

Kasuistik: Eine 42 Jahre alt gewordene Frau wurde in ihrer Wohnung tot aufgefunden. Erste Ermittlungen erbrachten, dass die Frau seit 14 Jahren heroinabhängig gewesen sei und „immer mal wieder" an einem Methadonprogramm teilgenommen habe. An Vorerkrankungen seien eine Hypothyreose und schizoide Persönlichkeitsstörung bekannt gewesen.

Ergebnisse: Die Obduktion erbrachte als Hauptbefunde Hinweise auf einen Atemwegsinfekt und eine fraglich bereits länger bestandene Nierenschädigung. Die Nieren waren makroskopisch auffallend blass und weißlich-gelblich.

In den feingeweblichen Untersuchungen fand sich das typische Bild einer sog. Cast-Nephropathie, die pathognomonisch für ein Plasmozytom ist. In klinisch-chemischen Untersuchungen konnte die Vermehrung der Leichtketten nachgewiesen werden.

Diskussion: Das histologische Bild aus scholligen Zylindern in den Nierenkanälchen in Verbindung mit mehrkernigen Riesenzellen gilt als beweisend für eine Plasmozytomniere. Bei einer Cast-Nephropathie handelt es sich um eine Akutkomplikation und die häufigste Nierenbeteiligung eines Plasmozytoms. Die Diagnose eines Plasmozytoms kann dann durch den immunhistochemischen Nachweis von Leichtkettenprotein im Nierengewebe, durch klinisch-chemischen Nachweis von Leichtketten in Serum und/oder Urin und durch Knochenmarkhistologie bestätigt werden. Fazit: Das Auftreten eines Plasmozytoms im mittleren Alter ist eher ungewöhnlich und kann ein Hinweis auf eine genetische Disposition sein und hat daher eine hohe Relevanz für etwaige noch lebende Angehörige.

\section{P-RM-36 \\ Posteriores Reversibles Encephalopathie Syndrom (PRES) - ein Fallbericht}

\section{T. A. Engelmann', C. Hartmann², A. Fieguth', M. Klintschar'}

'Institut für Rechtsmedizin, Medizinische Hochschule Hannover (MHH), Hannover, Deutschland; ${ }^{2}$ Abteilung Neuropathologie, Institut für Pathologie, Medizinische Hochschule Hannover (MHH), Hannover, Deutschland 
Enleitung: Das Posteriore Reversible Encephalopathie Syndrom (PRES) ist ein heterogenes klinisch-radiologisches Syndrom, welches mutmaßlich Folge einer endothelialen Dysfunktion sowie Störung der zerebralen vaskulären Autoregulation ist. Dies führt zumeist in dem parieto-okzipitalen Bereich zu einem vasogenen Ödem mit teils schweren Komplikationen wie Vigilanzstörungen, Krampfanfällen, Infarkten und flächigen Blutungen. Obwohl dieses zumeist reversible Syndrom relativ häufig ist, ist über dessen Neuropathologie wenig bekannt.

Kasuistik: Eine 59-jährige Frau verstarb nach klinischer und radiologischer Besserung eines zirka zwei Monate zuvor diagnostizierten PRES unerwartet. Das PRES sei zuvor klinischerseits am ehesten als Folge einer Rituximab-Therapie bei einem T-Zell-reichen B-Zell-Lymphom bei zudem bekanntem M. Hodgkin interpretiert worden und stellte sich klinisch initial mit einem Grand mal Anfall und einer Somnolenz dar. Die Hinterbliebenen vermuteten einen Behandlungsfehler seitens der Onkologen und zeigten den Todesfall an.

Ergebnisse: Als wesentliche Obduktionsbefunde ergaben sich ein kleines, ödematös geschwollen imponierendes Gehirn, eine Arteriosklerose der Herzkranzschlagadern mit Ausbildung kleiner Thromben sowie ein histologisch bestätigter frischer Herzinfarkt. Die neuropathologischen Untersuchungen zeigten vorrangig eine Mikroangiopathie im Stromgebiet beider Aa. cerebri posteriores, multiple ältere perivaskuläre Mikroblutungen, ein perivasales Ödem und lokalisierte diffuse axonale Transportschäden. Da der todesursächliche Herzinfarkt unabhängig von dem PRES eintrat und ferner das PRES eine typische Komplikation der indizierten Behandlung mit einem monoklonalen Antikörper darstellt, konnte kein todesursächliches ärztliches Fehlverhalten nachgewiesen werden.

Fazit: Wir präsentieren hiermit die sehr seltene neuropathologische Studie eines zwei Monate lang überlebten PRES und beschreiben, trotz der typischen Reversibilität der klinischen Befunde, signifikante Auffälligkeiten. Ferner ist dies die bislang erste Diskussion der Bedeutung des PRES im rechtsmedizinischen Sektionsgut.

\section{P-RM-37 \\ Evaluation of postmortem serum parathyroid hormone levels in relation to cause of death in forensic autopsy cases}

Naoto Tani1,2, Tomoya Ikeda ${ }^{1,2}$, Tatsuya Hirokawa ${ }^{1,2}$, Yayoi Aoki', Kei Ikeda', Takaki Ishikawa ${ }^{1,2}$

'Department of Legal Medicine, Osaka City University Medical School, Osaka, Japan; ${ }^{2}$ Forensic Autopsy Section, Medico-legal Consultation and Postmortem Investigation Support Center (MLCPI-SC), Osaka, Japan

Objective: Parathyroid hormone (PTH) is secreted in the parathyroid gland, which is located in the neck near the thyroid gland. PTH may be released by physical neck compression; however, no studies have specifically examined the relationship between neck compression and intact PTH and whole PTH. In the present study, we investigated postmortem serum PTH levels in relation to neck compression and the pathophysiological significance of intact- and whole-PTH measurements.

Method: This study analyzed 209 serial forensic autopsy cases (157 men and 52 women; median age at death: 64 years; age range: $1-98$ years) at $96 \mathrm{~h}$ postmortem. The following causes of death were examined: sharp instrument injury ( $n=16)$, blunt injury ( $n=42$; head injury: $n=23$, other injury: $n=19)$, asphyxia ( $n=31$; hanging: $n=7$, strangulation: $n=9$, other: $n=15)$, drowning $(n=16)$, intoxication $(n=25)$, fire fatality $(n=58)$, and acute cardiac death $(n=21)$. Blood samples were collected from the left and right heart chambers and the external iliac vein, and serum intactand whole-PTH levels were measured.

Result: The results revealed no relationships at any sampling site between intact and whole PTH and the postmortem period, medical treatment, or use of hypertensive agents. No differences were found between cause of death in intact and whole PTH or between classifications of asphyxiation. In addition, both intact and whole PTH increased with increasing survival time. On the other hand, intact PTH and whole PTH were not correlated with blood urea nitrogen or creatine levels.

Discussion: The results of this study revealed no differences between cause of death and intact and whole PTH, and confirmed that they were not indicators of neck compression. In addition, the findings revealed that both intact- and whole-PTH levels were relatively stable in the postmortem period and increased with survival time, suggesting that intact- and whole-PTH levels may be increased by severe systemic hypoxia. Therefore, postmortem intact- and whole-PTH levels are not indicators of cervical compression. On the other hand, they may be used to assess the severity of systemic hypoxia.

\section{P-RM-38}

\section{Unusual Cause Of Death In A Patient With Covid-19}

Natasha Davceva ${ }^{1}$, Ana Ivceva ${ }^{2}$, Katerina Tosevska-Trajkovska ${ }^{3}$, Jasar Dzengis ${ }^{4}$

'Institute of Forensic medicine and criminalistcs, Faculty of medicine, University „ISs Cyril and Methodius" Skopje; Faculty of medical sciences, University Goce Delcev Stip, North Macedonia; Faculty of medicine, University of Maribor, Republic of Slovenia.; ${ }^{2}$ Institute of Forensic medicine and criminalistcs, Faculty of medicine, University, Ss Cyril and Methodius" Skopje, North Macedonia; ${ }^{\prime}$ Institute of medical and experimental biochemistry, Faculty of medicine, University "Ss Cyril and Methodius“ "Skopje, North Macedonia;; ${ }^{4}$ Acibadem Sistina hospital Skopje; Faculty of medical sciences, University Goce Delcev Stip, North Macedonia.

Case Report: This paper is a casuistic case presentation of a patient with confirmed coronavirus disease (COVID-19) who ended his life by violent death i.e. committing suicide by hanging. In this clinical-pathological analysis are presented the clinical history of the disease COVID-19, a clinical feature, the onset of the psychiatric symptoms and finally the pathological feature seen at autopsy.

The main aim has been to perceive, in which phase of the disease occurred the psychiatric symptoms and eventually their connection with some morphological feature of the brain caused by the primary COVID-19 disease. Other aims include: to evaluate the changes of the primary disease to the internal organs and finally, the ethical aspect i. e. how are these patients protected by the health care system.

Results: patient committed suicide on the 12th of the COVID-19 disease and around the 21st day after the infection, looking by the serum antibodies. On lungs dominated the picture of acute restrictive pulmonary disease and ARDS with strong inflammatory answer. A psychiatric disorder occurred just after receiving the positive result for molecular SARS CoV-2 testing and has been worsening during the last four days of the disease, with the epilog of double suicide attempt, of which the second one came to be successful.

\section{P-RM-39}

Distribution and infectivity of SARS-CoV-2 in an autopsy case of an asymptomatic carrier of COVID-19

Momoka Tanabe', Kazuho Maeda', Hikaru Kuninaka', Moe Mukai', Ayako Nasu' ', Yosuke Usumoto' ', Chiaki Fuke', Yoko Ihama', Yutaro Yamaoka², Kei Miyakawa², Akihide Ryo²

'Department of Legal Medicine, Yokohama City University Graduate School of Medicine, Yokohama, Japan; ²Department of Microbiology, Yokohama City University Graduate School of Medicine, Yokohama, Japan

Objective: We investigated the distribution and infectivity of severe acute respiratory syndrome coronavirus 2 (SARS-CoV-2) in body fluids and organs in an autopsy case of an asymptomatic carrier of coronavirus disease 2019 (COVID-19).

Case: A man in his fifties suffered a cardiopulmonary arrest. He was declared dead at a hospital. Although he did not present any symptoms of COVID-19, the antigen test for SARS-CoV-2 was positive. He was stored at $4{ }^{\circ} \mathrm{C}$ from $15 \mathrm{~h}$ after death. An autopsy was then performed $105 \mathrm{~h}$ after death. To prevent infection, $70 \%$ ethanol was injected into his nose and 
mouth just before the autopsy. The cause of death was traumatic hemorrhagic shock.

Material and methods: RNA was extracted from nasopharyngeal swabs collected before the autopsy ( $15 \mathrm{~h}$ postmortem) and during autopsy (105 h postmortem), serum, cerebrospinal fluid, gastric contents, urine, tonsil, lung, heart, liver, spleen, kidney, stomach, small intestine, and large intestine. RNA copy numbers of SARS-CoV-2 were quantified by real-time reverse transcription polymerase chain reaction. Virus isolation was performed in the nasopharyngeal swabs, serum, and gastric contents.

Results. The nasopharyngeal swab had the highest viral load, followed by gastric contents, tonsil, stomach, serum, large intestine, small intestine, heart, and left lung. Infectious viruses were isolated from nasopharyngeal swabs and gastric contents.

Discussion: In this case of an asymptomatic carrier of COVID-19, SARS-CoV-2 was distributed in various body fluids and organs, and infectious viruses were isolated from nasopharyngeal swabs and gastric contents. Notably, gastric contents had a high viral load and infectious viruses. Therefore, gastric contents may be a specimen as well as a nasopharyngeal swab for virological examination of respiratory tract infections.

Conclusion: Appropriate infection prevention measures should be observed when handling corpses and specimens of those suspected with COVID-19.

\section{P-RM-40 \\ Causes of Discrepancies Between Clinical and Medico- legal Diagnosis}

\author{
Anatolii Bondarev, Andrei Pădure \\ State University of Medicine and Pharmacy, Chisinau, Republic of Moldova
}

Introduction: Assessment of the deficiencies in the process of diagnosing and treatment, analysis of discrepancies between clinical and medicolegal diagnosis, discussing obtained results with physicians are important objectives in cases of medico-legal intrahospital death investigation.

Method: Discrepancy between clinical and medico-legal diagnosis is defined as hypodiagnosis or hyperdiagnosis, also it includes situations of incorrectly formulated and late clinical diagnosis. We analyzed 160 cases of discrepancies detected during period of five years (2014-2018) in patients with mechanic traumas died in hospitals and investigated by the Center of Legal Medicine from the Republic of Moldova. The aim of this study was to establish causes of detected discrepancies.

Results and discussion: During analysis of medico-legal investigations we compared all three compartments of the diagnosis (main disease, complications and concomitant ones). Discrepancy was confirmed in following situations: another disease (trauma) was found at autopsy-hypodiagnosis; pathology included in clinical diagnosis is not confirmed at autopsyhyperdiagnosis; not the same location or etiology of the disease; a syndrome (cardiac arrest, etc.) appears instead of the main disease; clinical diagnosis is not made correctly or is established late. Incorrect formulation of the diagnosis included: etiologic or pathogenetic principles are not respected, lack of compartmentalizing or replacement of the main disease with its complication or concomitant disease.

Our study found both subjective and objective causes of discrepancies. Objective causes were generated by: short duration of patient stay in hospital; severe state of patient; lack of technical conditions for diagnosing; atypical manifestation or short expressions of disease; masked or rare pathologies; patient's refusal of investigation. Subjective ones included: insufficient clinical examination; overestimation or underestimation of personal/disease history, of laboratory tests or instrumental investigations, of conclusions by consultants; incorrect formulation of diagnosis.

Conclusion: Discrepancies between clinical and medico-legal diagnosis were mostly determined by combination of several different causes. Usually a complex of unfavorable factors and circumstances resulted in fatal hypodiagnosis. Major discrepancies with a decisive role in patient's death occurred when several objective and subjective causes were associated.
P-RM-41

\section{Ethische Aspekte gerichtlicher Leichenöffnungen}

Clara-Sophie Schwarz, Tanja Germerott

Institut für Rechtsmedizin der Johannes Gutenberg-Universität Mainz

Fragestellung: Ein würdevoller Umgang mit Leichen erscheint intuitiv angezeigt und wird vom Gesetzgeber und der Bevölkerung gefordert. Doch weder der rechtliche noch der ontologische Status der Leiche ist unumstritten. Der Anspruch Verstorbener auf einen würdevollen Umgang mit ihren sterblichen Überresten ist nicht leicht zu begründen. Unklar ist auch, worin ein würdevoller Umgang mit Leichen konkret besteht.

In der gegenständlichen Studie wurde der Frage nachgegangen, ob die Würde der innen anvertrauten Leichen für RechtsmedizinerInnen ein relevantes Thema ist und wie sich ihre Vorstellungen in der täglichen Praxis niederschlagen.

Methode: Zur Anwendung gelangte ein Online-Fragebogen. Die Antworten auf Single- und Multiple-Choice-Fragen wurden deskriptiv analysiert. Ergänzend zu den bereits publizierten Ergebnissen sollen nun besonders die als Freitext eingegebenen Kommentare berücksichtigt werden.

Ergebnisse: Insgesamt haben 109 Personen den Fragebogen vollständig beantwortet. Es handelt sich um 97 ÄrztInnen $(88,99 \%)$ und 12 ObduktionsassistentInnen (11,01\%). Die Mehrheit der Befragten hält den würdevollen Umgang mit Leichen für ein rechtsmedizinisch relevantes Thema. Dabei wurde eine lege artis durchgeführte Obduktion von vielen Befragten als nicht per se problematisch erachtet. Allerdings wurden Begleitumstände benannt, die einen würdevollen Umgang mit Leichen beeinträchtigen können, z. B. bezüglich Leichentransport und -aufbewahrung, Anwesende im Obduktionssaal usw.

Diskussion: Das ärztliche Selbstverständnis erfordert die kritische Auseinandersetzung mit dem eigenen Tun, so auch in der Rechtsmedizin. Rechtsmedizinerlnnen genießen einen Vertrauensvorschuss, einerseits als ÄrztInnen, andererseits als Personen, die mithilfe ihrer Ausbildung einer staatsbürgerlichen Pflicht nachkommen, und zugleich als Vertreter der Gruppe von Menschen, innerhalb derer sie tätig sind. Die in der Umfrage ermittelten Antworten tragen diesen Überlegungen Rechnung. Die Ergebnisse helfen, den Bogen in die tägliche Obduktionspraxis zu spannen und bieten weitere interessante Forschungsansätze zu ethischen Aspekten der Rechtsmedizin.

Fazit: Für die meisten RechtsmedizinerInnen ist die würdevolle Behandlung von Leichen ein praxisrelevantes Thema, wobei vor allem äußere Bedingungen als problematisch wahrgenommen werden. Die Beschäftigung mit dem Thema erscheint auch mit Blick auf die Repräsentation unseres Faches z. B. in den Medien essentiell.

\section{P-RM-42}

The medical specialty program in Forensic and Legal Medicine at the University of Guadalajara, Jalisco, Mexico

\section{Carrillo-Núñez $\mathrm{G}^{1}$, Bonilla-Virgen $\mathrm{R}^{1}$, Holz F², Birngruber $\mathrm{CG}^{2}$}

'Morphology Department, University Center of Health Science, University of Guadalajara, Guadalajara/Mexico; ${ }^{2}$ Institute of Legal Medicine, University Hospital Frankfurt, Goethe University, Frankfurt am Main/Germany

Introduction: Mexico, a country with a population of 127 million, recorded 27 homicides for every 100,000 inhabitants in 2019. More than 73,000 persons are currently said to be missing, and the remains of more than 37,000 people haven't been identified yet.

Current situation: The country has an urgent need for specialized forensic doctors to assist the rule of law in dealing with these problems. Currently, there are various master's degree programs in the area of forensic sciences, or related to criminalistics, criminology, criminal investigation or criminal law that are offered in various states of the country. But only three 
universities offer specialization in Legal Medicine or Forensic Medicine to graduates of Medical School.

Plan. Therefore: the University of Guadalajara (UdG) decided to implement the medical specialty program in Forensic Medicine. The study plan is considered to be carried out in three years with training in areas of criminology, criminalistics, and forensic medicine. A cooperation with the Jalisco Institute of Forensic Sciences (IJCF) is intended to ensure practical education and training.

Project: The German Academic Exchange Service (DAAD) is supporting a joint project of the UdG in Mexico and the Institute of Legal Medicine of the Goethe-University in Frankfurt, Germany, to support the development and the implementation of the new curriculum. It is intended that this specialization can help to strengthen the rule of law in Mexico by educating new medical doctors, recently graduated from Medical School, as well as training forensic doctors working in the IJCF.

\section{P-RM-43 \\ Morphological changes in nerve cells under hypoxia and with the addition of drugs}

Kei Murakami ${ }^{1 *}$, Tomoya Ikeda ${ }^{1,2}$, Naoto Tani ${ }^{1,2}$, Miho Watanabe ${ }^{1,3}$ Tatsuya Hirokawa', Fumiya Morioka', Alissa Shida', Yayoi Aoki', Takaki Ishikawa ${ }^{1,2}$

'Department of Legal Medicine, Osaka City University Medical School, 1-4-3 Asahi-machi, Abeno, Osaka 545-8585, Japan; ${ }^{2}$ Forensic Autopsy Section, Medico-legal Consultation and Postmortem Investigation Support Center, c/o Department of Legal Medicine, Osaka City University Medical School, 1-4-3 Asahi-machi, Abeno, Osaka 545-8585, Japan; ${ }^{3}$ Laboratory of Clinical Regenerative Medicine Department of Neurosurgery, Faculty of Medicine, University of Tsukuba, Health and Medical Science Innovation laboratory 403, Tsukuba City, Ibaraki 305-8575, Japan

Background: Central nervous system stimulants (CNS stimulants) cause nerve cell death due to hypoxia and cerebral edema. We examined the morphological changes in nerve cells to which were added various drugs and under hypoxic conditions. We compared the severity of cerebral edema among autopsy cases, and resultant changes in cultured nerve cells using transmission electron microscopy (TEM).

Methods: We classified autopsy cases into 5 groups (Group A: stimulants detected; Group B: stimulants and psychiatric drug detected; Group C: caffeine detected; Group D: psychiatric drug detected; Group E: drugs not detected). We compared macropathological findings, brain weight, brain computed tomography (CT) images and histopathological findings in the parietal and frontal lobes among the groups. In the culture experiment, we cultured human nerve cells under six conditions based on $\mathrm{O}_{2}$ concentration and addition of drugs, and examined the resulting morphological changes using TEM.

Results: In the autopsy experiments, cerebral edema was more severe in Groups A and B than the other groups. TEM of cultured nerve cells revealed that morphological changes and collapse of organelles were more severe with hypoxia and in cases with prolonged drug exposure. Loss of organelles, collapse of the nuclear form and release of cytoplasmic contents due to bursting of the cell membrane were observed in severe cases. Discussion: In this study, not only did cerebral edema and nerve cell edema worsen, but morphological changes and collapse of organelles were also caused by the addition of CNS stimulants and with hypoxia, until finally the cell membrane burst and the nerve cells died.
Klinische Rechtsmedizin

$\mathrm{P}-\mathrm{Kl}-1$ bis $\mathrm{P}-\mathrm{Kl}-6$

P-KI-1

Onlinesurvey GUIDE4YOU - Auswertung eines

Erhebungsinstrumentes zur Erfassung häuslicher Gewalt in der Kommune Heidelberg

Svenja Gimbel ${ }^{1}$, Nadia Sosnowsky-Waschek ${ }^{1}$ Kristina Wojtanowski², Marie-Luise Löffler ${ }^{3}$ Kathrin Yen²,

${ }^{1}$ SRH Hochschule Heidelberg, Fakultät für Angewandte Psychologie; ${ }^{2}$ Insttitut für Rechtsmedizin und Verkehrsmedizin, Universitätsklinikum Heidelberg; ${ }^{3} \mathrm{Amt}$ für Chancengleichheit, Stadt Heidelberg

Hintergrund und Zielsetzung: Trotz eines zunehmend besser ausgebauten Hilfesystems finden viele Frauen* noch keinen Zugang zu den Hilfsangeboten. Angelehnt an frühere Studien (BMFSFJ, 2009; FRA, 2014) und im Rahmen eines durch die EU finanzierten Modellprojektes GUIDE4YOU wurde ein Fragebogen konzipiert, der die Situation der Betroffenen und die Nutzung von Unterstützungsangeboten systematisch erhebt. Der Fragebogen erfasst die Gewalterfahrungen, deren Zeitpunkt/Intensität, das Inanspruchnahmeverhalten der Strukturen der Stadt Heidelberg, individuelle Bedürfnisse und Entscheidungsprozesse.

Methode: Die Testbatterie umfasst 44 Items mit offenem und geschlossenem Antwortformat. Mittels explorativer Datenanalyse sowie logistischer Regression konnten wesentliche Komponenten des Hilfesuchverhaltens, die Bedarfe der Betroffenen sowie das tatsächliche Inanspruchnahmeverhalten professioneller Hilfsangeboten in Abhängigkeit von erlebter Gewalt identifiziert werden.

Ergebnisse: Für den Erhebungszeitraum vom 11.03.2020 bis 15.04 .2021 wurden $\mathrm{N}=226$ vollständige Datensätze ausgewertet. Hierbei geben $73,0 \%(n=165)$ der Frauen an, körperliche Gewalterfahrungen erfahren zu haben, $49,6 \%(n=114)$ berichten erzwungene sexuelle Gewalthandlungen und $81,0 \%(n=183)$ psychische Gewalt in einmaliger oder kumulierter Form. Die Bereitschaft, die Tat zur Anzeige zu bringen, beträgt lediglich 13,7\%, was auf eine hohe Dunkelziffer hinweist. Professionelle Unterstützungsangebote werden unabhängig vom Schweregrad der Gewalt lediglich von knapp einem Fünftel $(19,0 \%, n=43)$ genutzt. Eine Inanspruchnahme von Hilfe im sozialen Umfeld der Betroffenen (z. B. durch Freunde/Bekannte) wird in 18,1\% $(n=41)$ der Fälle angegeben. Rund drei Viertel der Frauen $(76,1 \%, n=172)$ geben an, sich nach der schlimmsten Gewalttat nicht beim Arzt vorgestellt zu haben. Von den $N=42$ Nutzerinnen professioneller Hilfsangebote, werten $48 \%$ der Befragten, die Hilfestellungen als gar nicht oder nur wenig hilfreich. Als Gründe der Nichtnutzung werden Scham $(52,7 \%, n=97)$, fehlende Intentionsbildung sich „Von außen“ zu Hilfe holen (35,3\%, $n=65)$, Unkenntnis der Hilfestrukturen $(33,7 \%, n=62)$ sowie fehlende Beweise der Tat $(32,6 \%, n=60)$ angeführt. Eine Analyse der offenen Antwortformate ergibt ferner, dass Angst und Schuld $(n=26)$, geringe Erfolgsaussichten $(n=22)$, Nicht-Erkennen der Ernsthaftigkeit $(n=14)$, persönliche Beziehungen zum Täter $(n=13)$ sowie Schutzverhalten ggü. den Kindern $(n=7)$ zu beachten sind.

Diskussion: Erste Datenalysen geben Aufschluss über die Betroffenenperspektive und zeigen auf, dass individuelle Bewertungsprozesse sowie das Wissen über das Hilfesystem wesentliche Einflussgrößen auf das Inanspruchnahmeverhalten der Betroffenen bei der Nutzung professioneller Angebote in Heidelberg darstellen. Deutlich wird jedoch auch, dass ein tieferes Verständnis der psychischen Situation der Frauen in Zusammenhang mit der Intentionsbildung bei der Nutzung des Hilfesystems weiter systematisch erforscht werden muss.

\section{Literatur}

1. BMFSFJ (2009). Gewalt gegen Frauen in Paarbeziehungen. Eine sekundäranalytische Auswertung zur Differenzierung von Schweregraden, Mustern, Risikofaktoren und Unterstützung nach erlebter Gewalt. Berlin: BMFSFJ.

2. FRA-European Union Agency for Fundamental Rights (2014), Violence against women: An EU-wide survey: Main results, Publications Office of the European 
Union. In Luxembourg: Publications Office of the European Union. https:// doi.org/10.2811/67959 (http://fra.europa.eu/sites/default/files/fra-2014-vawsurvey-main-results-apr14_en.pdf).

\section{P-KI-2 \\ Vaginale Verletzungen nach einvernehmlichem Geschlechtsverkehr}

\author{
L. Lohner ${ }^{1}$, L. Nigbur ${ }^{1}$, C. Klasen ${ }^{2}$, S. Anders ${ }^{1}$ \\ 'Institut für Rechtsmedizin, Universitätsklinikum Hamburg-Eppendorf, Hamburg, \\ Deutschland; ${ }^{2}$ Klinik und Poliklinik für Gynäkologie, Universitätsklinikum Hamburg- \\ Eppendorf, Hamburg, Deutschland
}

Einleitung:Vaginale Verletzungen nach ungewolltem Geschlechtsverkehr (GV) sind mehrfach in der Literatur beschrieben. Studien über vergleichbare Verletzungen nach einvernehmlichem Geschlechtsverkehr sind rar und begrenzen sich hauptsächlich auf die Lokalisation und die Inzidenz. Ziele der vorgestellten Studie waren die Relevanz vaginaler Verletzungen nach einvernehmlichem GV in der gynäkologischen Praxis und die Evaluation von Risikofaktoren.

Methode: Alle niedergelassenen Gynäkolog:innen in Hamburg wurden anhand eines einseitigen Fragebogens per Faxumfrage kontaktiert. Zusätzlich erfolgte im Jahr 2018 anhand eines detaillierteren Fragebogens eine prospektive Datenerhebung in der Klinik und Poliklinik für Gynäkologie im Universitätsklinikum Hamburg-Eppendorf (UKE). Beide Fragebögen erfassten verschiedene Aspekte wie Risikofaktoren, Klassifikation und Lokalisation der Verletzungen, aktive Blutungen, Notwendigkeit der Versorgung und Krankenhauseinweisung.

Ergebnisse: Insgesamt gaben 83,5\% der niedergelassenen Gynäkolog:innen an, vaginale Verletzungen nach einvernehmlichem GV in der Praxis mindestens einmal gesehen zu haben. Hinsichtlich der Verletzungsart und maximalen Verletzungsschwere gaben 52,1 \% der Ärzt:innen Schleimhauterosionen, 32,3\% mucosadurchgreifende Verletzungen und $14,6 \%$ penetrierende Verletzungen an. Aktive Blutungen wurden bereits von $56,3 \%$ der Ärzt:innen befundet, $28,1 \%$ haben eine Nahtversorgung vornehmen müssen. Als risikoerhöhende Faktoren wurden die Menopause $(37,5 \%)$, eine Verwendung von Gegenständen $(19,8 \%)$ sowie Alkoholund/oder Drogenkonsum (16,7\%) berichtet. In 2018 stellten sich lediglich drei Patientinnen mit Vaginalverletzungen nach einvernehmlichem GV im UKE vor, diese Fälle werden deskriptiv vorgestellt.

Diskussion und Fazit: Limitationen waren die fehlende Zuordnung zwischen einer bestimmten Verletzung und bestehenden Risikofaktoren sowie das Vertrauen auf anamnestischen Angaben. Die Ergebnisse weisen auf die Relevanz vaginaler Verletzungen auch nach einvernehmlichem GV hin und sollten im Rahmen der rechtsmedizinischen Gutachtertätigkeit beim unfreiwilligen GV Berücksichtigung finden.

\section{P-KI-3 \\ Dynamics of torture in the Republic of Moldova}

Toporet Natalia, Padure Andrei

State University of Medicine and Pharmacy; Chisinau, Republic of Moldova

Introduction: Torture and other ill-treatment are crimes prohibited by international laws. The Republic of Moldova ratified the UN Convention against Torture and Other Cruel, Inhuman or Degrading Treatment or Punishment in 1995, but the pacta sunt servanda principle is not still fully implemented.

Purpose: The study aimed to establish the dynamics of torture phenomenon in the Republic of Moldova during 2009-2019 years.

Material and methods: The present research is based on a retrospective analysis of the annual statistical reports of the Center of Forensic Medicine.

Results and discussion: 3361 people subjected to medico-legal investigations alleged torture or other ill-treatments committed especially by po- lice officers and other official persons. Mostly, citizens were subjected to torture in 2009 (513) and 2019 (458). Compared to other years, the number of people alleging torture in 2009 and 2019 was twice higher. In general, a positive annual trend of torture cases was noticed.

The highest rate of torture was generated by massive protests in April 2009. Police used brutal force during protests and against detained young people. Afterwards, specific actions aiming to prevent torture and prosecute torturers were taken by governmental institutions. Thus, a new department dedicated to the investigation of torture within the General Prosecutor's office was created. A standard operational procedure for prosecutors was developed and approved. Another standard operational procedure for the use of force and special restrictive measures for police officers was developed and approved as well. Prosecutors were trained in terms of investigating the torture cases and applying the SOP. Medico-legal experts, professionals working in penitentiary system and police stations were trained to recognize torture and avoid being involved in it. Torture was incriminated by including it as a crime in Criminal Code. This led to the decreasing of torture allegations. Despite the fact that following years the number of cases decreased, a positive trend of this crime was observed. This proves the torture is still present in our society and needs further detailed research in order to determine its causes, conditions and consequences.

Conclusion: Despite the Republic of Moldova has ratified the UN Convention against Torture and Other Cruel, Inhuman or Degrading Treatment or Punishment, this violation of Human Rights is still present and requires measures to be undertaken.

\section{P-KI-4}

Pflege-, Ernährungs- und Gesundheitszustand Verstorbener: Einfluss auf die Qualität gespendeter Augenhornhäute (unter besonderer Berücksichtigung des Endothels).

Mara Vorwieger, Larissa Lohner, Benjamin Ondruschka, Olaf J.C. Hellwinkel

Institut für Rechtsmedizin, Transplantatgewebebank, Lions-Augenhornhautbank am UKE, Universitätsklinikum Hamburg-Eppendorf, Hamburg, Deutschland

Fragestellung: Retrospektive Auswertung zum Einfluss von Alter, Pflegezustand, Body-Mass-Index und Suchtstatus älterer (im Alter von mindestens 70 Jahren verstorbener) Augenhornhaut-Spender auf die Qualität der cornealen Endotheldichte.

Methode: Serielle Kompilation eines Kollektivs $(n=599)$ aus der Datenbank der Lions-Augenhornhautbank am UKE (Sterbealter zwischen 70 und 90 Jahren mit kompletten Entnahme- und Endothel-Kulturdatensätzen zwischen 2008 und 2019) mit den korrespondierenden Leichenschauberichten der Hornhautspender aus dem Hamburger Institut für Rechtsmedizin $(n=386)$ mittels MS-Excel. Die o. g. Parameter wurden auf einen Einfluss auf das Endothel nach Explantation der Cornea bzw. dessen Verhalten in Organkultur statistisch (per R Core Team 2020) in lokal-linearen Regressionsanalysen (Signifikanzgrenzwert $p \leq 0,05$ ) und in Modellschätzungen untersucht.

Ergebnisse: Sterbealter (stärkster Effektor, negativ) und Suchtstatus (positiv), aber auch BMI und Pflegezustand (variabel) bilden sich in der Endotheldichte nach Explantation ab. Zudem korrelieren Lagerungsdauer (negativ), Endotheldichte nach Explantation (positiv), das Geschlecht (männlich; positiv) und der BMI (negativ) mit der Stabilität des Endothels in Organkultur. Die Modellschätzungen legen nahe, dass der Suchtstatus und der Pflegezustand kombinierte Prädikatoren für die Endothelqualität bei Explantation darstellen könnten. Der BMI könnte sich als ein bislang unbeachteter Prädiktor für die Endothelstabilität in Organkultur darstellen.

Diskussion: Sollten sich die gefundenen Prädikatoren (nach prospektiver Prüfung an unabhängigen Kollektiven) als robust erweisen, weisen sie auf statistische (ggf. auch kausale) Einflüsse von Pflege und Ernährungszustand auf die Zellbiologie und -alterung bislang unbeachteter Zelltypen 
wie das Augenhornhautendothel hin. Da die Cornea nicht aktiv durchblutet wird, stellt sich dann auch die Frage nach einer Übertragbarkeit dieser Beobachtungen auf andere transplantationsrelevante Gewebe, in denen die Metabolitver- und -entsorgung ebenfalls indirekt erfolgt (Knorpelgewebe).

Fazit: Der Ernährungs- und Pflegezustand potenzieller Hornhautspender könnten für die Beurteilung einer Eignung zur Gewebespende (und perspektivisch ggf. auch osteo-chondraler Gewebe) bedeutsam sein. Praktisch könnten entsprechende Nomogramme in Zukunft das Auswahlverfahren für ältere Hornhautspender i. S. einer Ökonomisierung ergänzen.

\section{P-KI-5 \\ Gewaltopferversorgung im klinischen Alltag}

\section{Walz, C.-S. Schwarz, M. Jannermann, T. Germerott}

Universitätsmedizin der Johannes Gutenberg-Universität Mainz, Institut für Rechtsmedizin, Am Pulverturm 3, 55131 Mainz

Einleitung: Aktuellen politischen Bestrebungen zufolge soll Personen nach einer Gewalterfahrung vor dem Hintergrund der Istanbul-Konvention eine Beweissicherung auch ohne Strafanzeige flächendeckend in Deutschland ermöglicht werden. Ärzt*Innen in Kliniken und Arztpraxen sind häufig die ersten Kontaktpersonen. Die Untersuchung von Gewaltopfern erfordert einen gerichtsverwertbaren Standard, da die Behandlungsunterlagen in Strafverfahren zur Beweissicherung herangezogen werden. Methode: Um Schwierigkeiten bei der Versorgung von Gewaltopfern zu erfassen, wurde eine onlinebasierte Umfrage unter Ärzt*Innen in Kliniken und niedergelassenen Praxen in Rheinland-Pfalz durchgeführt. Es wurden Angaben zur ärztlichen Tätigkeit, Häufigkeit durchgeführter Untersuchungen, Untersuchungstechnik und -ausstattung sowie zu Unsicherheiten und Unterstützungsbedarfen hinsichtlich forensischer Aspekte erfasst. Zudem wurden die Teilnahme an Fortbildungen und Kooperationen zur Untersuchung von Gewaltopfern abgefragt.

Ergebnisse: Wir erhielten Rückmeldungen von 94 Ärzt*Innen aus Kliniken und Praxen unterschiedlicher Fachgebiete. $79 \%$ der Befragten gaben an, keine oder nur einzelne Untersuchungen von Gewaltbetroffenen durchgeführt zu haben. Während ein Großteil der Ärzt*Innen schriftliche Dokumentationen und Fotografien anfertigt, entnehmen weniger als die Hälfte fallabhängig Blut- und Urinproben und lediglich acht Befragte führen eine Spurensicherung durch. Materialien zur Spurensicherung stehen $27 \%$ der Befragten zur Verfügung. Unsicherheiten bestehen im Erkennen und Ansprechen von Gewaltfolgen, in der gerichtsverwertbaren Beweissicherung und in rechtlichen Aspekten. Die Ärzt*Innen fordern Unterstützung, überwiegend in Form von Fortbildungen, (rechtsmedizinischer) Beratung und Dokumentationshilfen.

Diskussion: Die Versorgung von Gewaltopfern stellt Ärzt*Innen im klinischen Alltag vor unterschiedliche Herausforderungen. Die vorliegenden Ergebnisse unterstreichen, dass die Ärzt*Innen vor allem Unterstützungsbedarf hinsichtlich der gerichtverwertbaren Standards angaben und weniger hinsichtlich der medizinischen Versorgung bzw. ärztlichen Betreuung. Somit handelt es sich vor allem um Aspekte, betreffend derer das Fachgebiet Rechtsmedizin über die notwendige Expertise verfügt. Um die politischen Bestrebungen nach einer flächendeckenden Versorgung unter Einhaltung geforderter Standards umzusetzen, ist daher unbedingt eine intensive Einbindung der Expertise der Rechtsmedizin zu fordern.

\section{P-KI-6}

New developments in forensic pathological diagnosis of long-term adult abuse

Hiromi Yamashita' ${ }^{1}$, Takehiko Murase ${ }^{2}$, Yuki Abe ${ }^{2}$, Keita Shingu², Yoriko Shinba², Masahide Mitsuma², Takumi Osaki ${ }^{2}$, Takahiro Umehara ${ }^{2}$, Kazuya Ikematsu ${ }^{2}$

'Department of Forensic Dental Science, Unit of Social Medicine, Medical and Dental Sciences, Graduate School of Biomedical Sciences, Nagasaki University, Nagasaki, Japan; ${ }^{2}$ Department of Forensic Pathology and Science, Unit of Social Medicine, Medical and Dental Sciences, Graduate School of Biomedical Sciences, Nagasaki University, Nagasaki, Japan

Objective: In recent years, adult abuse such as elder abuse and domestic violence has become new social problem, and sometimes results in death. These cases were exposed to long-term stress. In child abuse case, forensic pathologists check atrophy of thymus, but there was no useful finding in adult abuse. We focused on the anterior cingulate cortex (ACCX), which showed electrophysiological changes in stress loading experiments in rats. In this study, we elucidated stress response genes in rat ACCX after long term stress with microarray analysis and quantitative PCR (qPCR). Method: Rats were exposed to restraining stress for six hours per day during 3 or 7 days. We investigated the modulation of nociceptive responses in the ACCX neurons following restraint stress in rats. After purification of total RNA of ACCX, microarray analysis employed, and quantitative realtime PCR ( $q-P C R)$ was performed about genes whose expressional level changed with the analysis.

Result: The microarray analysis elucidated many genes including $\mathrm{Fmo2}$, $C \mathrm{Cr} 1$ and $\mathrm{Actg} 2$ as stress responded genes. With q-PCR, the expression level of $F m o 2$ was significantly increased $(p<0.05)$. In addition, the expression levels of $C c r 1$ and Actg2 increased significantly in the 3 days $(p<0.05)$ and decreased in the 7 days.

Discussion and Conclusion: In this study, we identified the three stress response genes including Actg2. In previous electrophysiological experiments, a significant increase in the number of spikes in ACCX was observed in the 7 days. Babu reported that Actins maintains neurotransmission. Actg2 belongs Actin family. The changing level of Actg2 mRNA in ACCX might involved in electrophysiological changes after stress. We will check protein level of Actg2 after chronic stress in Actg2 to clarify the relation between Actg2 and electrophysiological changes.

Toxikologie:

P-TX-1 bis P-TX-20

\section{P-TX-1}

An autopsy case of a multiple drug ingestion

Hiroshi Kinoshita, Mitsuru Kumihashi, Mostofa Jamal, Tadayoshi Yamashita, Etsuko Tanaka, Shoji Kimura

Department of Forensic Medicine Faculty of Medicine, Kagawa University, Kagawa, Japan

Case Report: We present a multiple drug ingestion case. A female in her thirties was found dead in her house. She had been receiving therapy for mental disorder and was receiving prescribed drugs.

Autopsy findings: The deceased was $153 \mathrm{~cm}$ in height and $40 \mathrm{~kg}$ in weight. Autopsy showed no evidence of external injury. The heart weighed $179 \mathrm{~g}$ and contained $90 \mathrm{ml}$ of blood without coagulum. The left and right lungs weighed $684 \mathrm{~g}$ and $759 \mathrm{~g}$, respectively, and were congested. The brain weighed $1332 \mathrm{~g}$ and was slight edematous. The stomach contained 160 $\mathrm{mL}$ of brownish liquid containing food residue. No ethanol was detected in blood sample, and drug screening using a Triage ${ }^{\mathrm{TM}}$ test panel (Biosite Diagnostic Inc, San Diego, CA) yielded negative results.

Results and Discussion: Quantitative toxicological analysis showed that the concentrations of fluvoxamine, levomepromazine, trihexyphenidyl, bromazepam, haloperidol, sulpiride and 7-aminoflunitrazepam (metabolite of flunitrazepam) in a femoral venous blood sample were $0.947 \mu \mathrm{g} /$ 
$\mathrm{mL}, 0.238 \mu \mathrm{g} / \mathrm{mL}, 0.225 \mu \mathrm{g} / \mathrm{mL}, 0.024 \mu \mathrm{g} / \mathrm{mL}, 0.010 \mu \mathrm{g} / \mathrm{mL}, 0.045 \mu \mathrm{g} / \mathrm{mL}$ and $0.037 \mu \mathrm{g} / \mathrm{mL}$, respectively. From the autopsy findings, results of the toxicological examination and investigation by the authorities, we concluded that the cause of her death was due to interaction of multiple psychotropic drugs.

\section{P-TX-2}

\section{Unterkühlung unter dem Einfluss von „Purple Drank“}

Maximilian Methling, Nadine Theofel, Sabrina Wangerin, Elke Vejmelka, Frank Rosenbaum, Stefan Scholtis, Michael Tsokos

Landesinstitut für gerichtliche und soziale Medizin Berlin

Einleitung: Eine Mischung aus in einigen Staaten freiverkäuflichen codeinhaltigen Hustensäften und Promethazin wird in einigen Subkulturen als Modedroge „Purple drank", „Dirty Sprite" oder "Lean“ (mit "Sprite” gemischt ergibt sich eine leuchtend purpurne Farbe) konsumiert. Wir stellen den Fall eines 20-jährigen Mannes vor, der im Winter mit Anzeichen einer Unterkühlung auf einem Firmengelände aufgefunden wird und $2 \mathrm{~h}$ nach Einlieferung in ein Krankenhaus (Körperkerntemperatur 29,9 ${ }^{\circ} \mathrm{C}$ ) verstirbt. Bei dem Betroffenen wurden eine Sprite-Flasche mit purpurnem Inhalt, sowie Codein, Promethazin und Benzodiazepine aufgefunden. Folgende Asservate wurden der Abteilung übergeben: Tropfflasche Promethazin $20 \mathrm{mg} / \mathrm{ml}$ neuraxpharm ${ }^{\circledR}$, „Euphon Sirup ${ }^{\circledR}$ (Codein $100 \mathrm{mg} / \mathrm{ml}$ ), Alprazolam $1 \mathrm{mg}$ 1A Pharma ${ }^{\circledR}$ und Tranxilium ${ }^{\circledast}$ Tabs (Dikaliumchlorazepat).

Methode: Es erfolgte eine systematische toxikologische Analyse mittels GC-MS, eine Blutalkoholuntersuchung mittels HS-GC sowie eine anschlieBende Quantifizierung mittels LC-MS/MS und HPLC-DAD.

Ergebnisse: Die Obduktion ergab lediglich die unspezifischen Zeichen eines plötzlichen Todes, typische Unterkühlungsbefunde (Wischnewski-Flecken) waren nicht nachweisbar.

Die chemisch-toxikologischen Untersuchungen führten zu folgenden Befunden:

Urin: Morphin, Codein, Tilidin, Alprazolam, Promethazin, Lidocain, Ethanol n. n. $(<0,1 \%)$, Nicotin, Coffein

Schenkelvenenblut: Ethanol n. $\mathrm{n} .(<0,1 \% 0)$, Morphin $0,02 \mu \mathrm{g} / \mathrm{ml}$, Morphin-3-glucuronid 0,05 $\mu \mathrm{g} / \mathrm{ml}$, Morphin-6-glucuronid 0,006 $\mu \mathrm{g} / \mathrm{ml}$, Codein $0,5 \mu \mathrm{g} / \mathrm{ml}$, Codeinglucuronid $0,19 \mu \mathrm{g} / \mathrm{ml}$, Tilidin $0,03 \mu \mathrm{g} / \mathrm{ml}$, Nortilidin $0,08 \mu \mathrm{g} / \mathrm{ml}$, Bisnortilidin $0,07 \mu \mathrm{g} / \mathrm{ml}$, Alprazolam $0,4 \mu \mathrm{g} / \mathrm{ml}$, Promethazin $2,5 \mu \mathrm{g} / \mathrm{ml}$, Lidocain $0,6 \mu \mathrm{g} / \mathrm{ml}$

Diskussion: Der Fall zeigt, dass vom Konsum solcher Medikamentenzubereitungen (hier eigenständig dosiert) eine ernste Gefahr ausgehen kann. Der Betroffene ist infolge des Mischkonsums von Codein, Promethazin, Tilidin und Alprazolam massiv bewusstseinsgetrübt und nicht mehr handlungsfähig. Infolge dessen ist er bei sehr kalten Außentemperaturen an einer Unterkühlung verstorben. Die nachgewiesenen Substanzkonzentrationen sind insbesondere unter Berücksichtigung der wechselseitigen Wirkverstärkung für sich genommen bereits als toxisch und potenziell lebensbedrohlich anzusehen.

\section{P-TX-3}

\section{Todesursache Kohlenstoffmonoxid-Intoxikation? (Überraschendes Ergebnis einer "Routine"-Sektion)}

K. Metzler ${ }^{1}$, M. Meinhardt ${ }^{2}$, S. Heide ${ }^{1}$, J. Seibt ${ }^{1}$

${ }^{1}$ Technische Universität Dresden, Institut für Rechtsmedizin, Dresden; ${ }^{2}$ Universitätsklinikum Dresden, Institut für Pathologie, Dresden

Fragestellung: Ein 26-jähriger, alleinlebender Mann wurde nach Wohnungsöffnung durch die Feuerwehr leblos auf einer Couch in seinem mit Klebeband von innen abgedichteten Badezimmer aufgefunden. In dem relativ großen Raum befanden sich zudem zwei Feuerschalen mit abgebrannter Holzkohle. Am Morgen des selbigen Tages hatten sich Freunde des Verstorbenen an die Polizei gewandt, nachdem der Geschädigte innen am Abend zuvor Abschiedsvideos zukommen ließ. Durch den lei- chenschauhaltenden Arzt wurde als Todesursache „Asphyxie durch Kohlenstoffmonoxid" angegeben.

In einem Abschiedsbrief, der in der Wohnung des Verstorbenen aufgefunden wurde, und in den Videos, die er Familie und Bekannten zukommen ließ, begründet der Verstorbene seinen Suizid mit schweren unheilbaren Erkrankungen (It. eigenen Angaben Autoimmunerkrankung, Gendefekt, akute Polyneuropathie und Rückenmarkskrebs).

Methode/Ergebnisse: Eine Sektion wurde veranlasst, um die Diagnose der Leichenschau zu bestätigen und fremdes Verschulden am Tod des Geschädigten auszuschließen.

Im Rahmen der Sektion konnten jedoch keine morphologischen Hinweiszeichen einer akuten Kohlenstoffmonoxid-Vergiftung festgestellt werden. Die klinisch-chemische Untersuchung des Herzbluts ergaben eine Kohlenstoffmonoxid-Konzentration von weniger als $2 \%$. Dafür fand sich eine massive Aspirationspneumonie mit reichlich eitrigem Schleim in den Atemwegen und massiver Brüchigkeit des Lungengewebes sowie auffällig symmetrische Läsionen im Stammkerngebiet des Großhirns. Hinweis für schwerwiegende Vorerkrankungen fanden sich autoptisch nicht.

Zur Todesursachenfeststellung erfolgten weiterhin chemisch-toxikologische und histologische Untersuchungen. Eine Einwirkung von Alkohol, stark wirksamen Medikamenten und Betäubungsmitteln konnte zum Zeitpunkt des Versterbens ausgeschlossen werden.

Die histologische Untersuchung des Lungengewebes bestätigte eine Aspirationspneumonie mit ausgeprägten Granulozytenansammlungen und amorphem Fremdmaterial in den Alveolen. Bei der neuropathologischen Aufarbeitung des Hirngewebes zeigten sich beidseits multiple frische Parenchymblutungen und -nekrosen, wie sie bei überlebten Kohlenmonoxid-Intoxikationen gelegentlich gesehen werden.

Diskussion/Fazit: Durch die interdisziplinären Untersuchungen konnte festgestellt werden, dass der Tod entgegen der ursprünglichen Annahme letztlich durch eine Aspirationspneumonie a.e. infolge einer erheblichen Bewusstseinstrübung durch eine primär nicht-letale Kohlenmonoxid-Intoxikation eintrat.

\section{P-TX-4}

\section{Lieber tot als lebendig von Würmern zerfressen - der} EXIT aus dem Leben

N. Walle*, A. Dörr, B. Peters, M.-C. Feix-Berscheid, S. Potente, P.H. Schmidt und N. Schäfer

Universität des Saarlandes, Institut für Rechtsmedizin, Homburg (Saar)

Fallbeschreibung: Eine 54 Jahre alte Frau sei von ihrem Ehemann tot aufgefunden worden. Bereits seit mehreren Jahren habe die Verstorbene unter einer Schizophrenie sowie Wahnvorstellungen gelitten und geglaubt, sie werde von Würmern zerfressen. Sie habe Todessehnsucht geäußert und versucht, Kontakt zu einer schweizerischen Sterbehilfeorganisation aufzunehmen. In der Wohnung seien eine Vielzahl an Medikamenten aufgefunden worden, jedoch keine Anhaltspunkte für einen Suizid.

Ergebnisse: Bei der Obduktion fand sich als wesentlicher Befund im Magen reichlich rötlich-bräunliche Flüssigkeit mit weißlich-griesartigen Konkrementen. Zudem konnten flächenhafte kristalline Ablagerungen der Magenschleimhaut festgestellt werden. Hinweise für eine konkurrierende innere Todesursache ergaben sich nicht.

Bei den chemisch-toxikologischen Untersuchungen wurden Pentobarbital und Metoclopramid in allen untersuchten Körperflüssigkeiten (Herzblut, Venenblut, Mageninhalt, Urin) nachgewiesen. Die Quantifizierung mittels GC-MS erbrachte nach flüssig-flüssig Extraktion im Venen- respektive Herzblut ca. 31 mg/l bzw. ca. 135 mg/l Pentobarbital. Die Konzentration im Venenblut liegt hierbei in einem Bereich, für den Pentobarbitalbedingte Todesfälle nach der Einnahme von $10 \mathrm{~g}$ Pentobarbital berichtet wurden. Ergänzende Daten zur Quantifizierung von Pentobarbital und Metoclopramid in den entnommenen Organproben werden im Rahmen der Tagung vorgestellt.

Diskussion: Während für Pentobarbital in Deutschland heutzutage keine zugelassenen Fertigarzneimittel mehr verfügbar sind, wird der Arzneistoff 
von einigen Sterbehilfeorganisationen, z. B. in der Schweiz (EXIT), im Rahmen von Freitodbegleitungen verwendet. Pentobarbital lässt sich auch ohne entsprechende Verordnung unter dem amerikanischen Markennamen "Nembutal" in einschlägigen „Internet-Shops" in Kombination mit einem Antiemetikum als Möglichkeit "des letzten Weges" bestellen.

Fazit: Im vorliegenden Fall ist das Todesgeschehen in Analogie zu den Protokollen von Freitodbegleitungen mit einer Intoxikation durch Pentobarbital in Kombination mit Metoclopramid als Prokinetikum in suizidaler Absicht vereinbar.

Die Falldarstellung verdeutlicht, dass auch „historische“ Wirkstoffe bei der postmortalen toxikologischen Analytik nicht in Vergessenheit geraten sollten.

\section{P-TX-5 \\ Ein ungewöhnlicher Suizid mit Natriumnitrit und Paracetamol}

Theofel N, Janke J, Vejmelka E, Wangerin S, Tsokos M, Scholtis S

Landesinstitut für gerichtliche und soziale Medizin, Berlin

Fragestellung: In der Wohnung eines 26-jährigen Mannes (174 cm, 76 kg) wurde ein Abschiedsbrief mit einer genauen Gebrauchsanleitung zum Suizid vorgefunden. Demnach soll im ersten Schritt Paracetamol eingenommen werden, eine Stunde gewartet und im Anschluss eine Lösung eines nicht näher beschriebenen weißen Pulvers konsumiert werden. Danach wäre man im Himmel. Darüber hinaus wurden in der Wohnung des Verstorbenen $250 \mathrm{~g}$ eines gelblichen Pulvers in einer Plastiktüte mit der Aufschrift „NaNO ${ }_{2}$ " sichergestellt. Die Systematische Toxikologische Analyse brachte kein Toxin hervor, sondern nur das erwartete Paracetamol und Coffein. Daher wurden im Folgenden weitere massenspektrometrische und photometrische Untersuchungen durchgeführt.

Methode: Es wurden Schenkelvenenblut, Mageninhalt und verschiedene nicht-biologische Asservate (leicht gelbliche Flüssigkeit aus einem Weinglas, weiße Anhaftungen eines zerbrochenen Weinglases und ein Silberlöffel mit weißen Anhaftungen) mittels HPLC/DAD und HPLC/ESI(-)QTOFMS untersucht.

Ergebnisse: Während der Obduktion wurden kräftig ausgeprägte, rötlichbraune Totenflecke, ein rot-bräunlich verfärbtes Gesicht und eine ebenso rot-bräunlich veränderte Schleimhaut der Luftröhre und des Magens festgestellt. Im Rahmen der toxikologischen Analyse wurden $10 \mu \mathrm{g} / \mathrm{mL}$ Paracetamol und $81 \mu \mathrm{g} / \mathrm{mL}$ Nitrat im Schenkelvenenblut sowie $410 \mu \mathrm{g} / \mathrm{mL} \mathrm{Ni}$ trat im Mageninhalt nachgewiesen. In den nicht-biologischen Asservaten wurden Nitrit und Nitrat nachgewiesen.

Diskussion: Nitritverbindungen sind sehr toxisch, wenn sie in den menschlichen Verdauungstrakt gelangen. Todesfälle sind nach Einnahme von 4-6 $\mathrm{g}$ beschrieben. Dabei kommt es zu einer Erweiterung der Blutgefäße, einem Abfall des Blutdrucks, Herzrasen und schließlich zum Kreislaufkollaps. Bei schweren Intoxikationen steht das Krankheitsbild einer Methämoglobinämie im Vordergrund. Hierbei wird Hämoglobin zu Methämoglobin und Nitrit zu Nitrat umgesetzt. Optisch lässt sich dies an einer Braunfärbung des Blutes feststellen. Hohe Methämoglobingehalte (>60\%) führen schließlich zum Tod, da Methämoglobin keinen Sauerstoff transportieren kann.

Fazit: Die bestimmte Konzentration von Paracetamol liegt im therapeutischen Bereich $(5-25 \mu \mathrm{g} / \mathrm{mL})$. Nitrit wurde in diesem Fall vollständig zu Nitrat oxidiert.

\section{P-TX-6 \\ A fatality involving ocfentanil and clonazepam}

Theofel N, Rosenbaum F, Vejmelka E, Tsokos M, Scholtis S

Governmental Institute of Legal Medicine and Forensic Sciences, Berlin

Background: The consumption of new psychoactive substances has rapidly increased in the recreational drug scene. Besides cannabinoids and designer cathinones, new synthetic opioids have recently emerged. Postmortem blood concentrations after intravenous $(3.7-36 \mathrm{ng} / \mathrm{mL}$ ) or intranasal $(9.1-15 \mathrm{ng} / \mathrm{mL})$ overdosage have so far been reported in literature.

We report on a 32 -year-old man $(187 \mathrm{~cm}, 80 \mathrm{~kg})$ who was found lifeless in a hotel. Several suicide notes and a sealed plastic bottle with two used syringes were secured by the police. During autopsy a fresh injection site at the left elbow, acute blood congestion, a pulmonary edema, and a brain swelling were observed.

Methods: The content of the two syringes was analyzed by means of LCHRMS. Ocfentanil, clonazepam, and 7-aminoclonazepam were quantitated in all specimens taken during autopsy using a targeted LC-MS/MS approach.

Results: Ocfentanil was highest in gastric content $(68 \mathrm{ng} / \mathrm{mL})$, followed by liver $(57 \mathrm{ng} / \mathrm{g})$, bile fluid $(45 \mathrm{ng} / \mathrm{mL})$, heart blood $(40 \mathrm{ng} / \mathrm{mL})$, femoral blood/cerebrospinal fluid $(20 \mathrm{ng} / \mathrm{ml})$, urine $(7 \mathrm{ng} / \mathrm{ml})$, and lowest in hair (qualitative detection). Clonazepam was only detected in bile fluid $(129 \mathrm{ng} / \mathrm{ml})$ and hair $(0.25 \mathrm{ng} / \mathrm{mg})$. 7-Aminoclonazepam was found in liver $(387 \mathrm{ng} / \mathrm{g})$, urine $(239 \mathrm{ng} / \mathrm{ml})$, femoral blood $(227 \mathrm{ng} / \mathrm{ml})$, heart blood $(134 \mathrm{ng} / \mathrm{ml})$, cerebrospinal fluid $(92 \mathrm{ng} / \mathrm{ml})$, and hair $(0.43 \mathrm{ng} / \mathrm{mg})$. Caffeine, acetaminophen, benzoic acid, and ocfentanil were found in both syringes.

Discussion: The deceased had taken a high dose of clonazepam and an overdosage of ocfentanil prior to death. The concentration of ocfentanil found in blood and the other specimens exceeds the concentration for fentanyl-related deaths, although ocfentanil exhibits a higher analgesic activity. In addition, ocfentanil undergoes postmortem redistribution (heart blood/femoral blood: 2, liver/femoral blood: $2.9 \mathrm{~L} / \mathrm{kg}$ ). The substances found in the two syringes are typical cutting agents for street heroin.

Conclusion: If ocfentanil had not been identified in the syringe, the presence of ocfentanil would have been overlooked in this case due to the low concentration. We updated our quantitation method by this synthetic opioid, because ocfentanil carries a high risk of overdose.

\section{P-TX-7}

\section{Synthetische Cocain-Derivate - Neue psychoaktive Substanzen}

\section{T. R. Sundermann ${ }^{1,2}$}

'Institut für Rechts- und Verkehrsmedizin, Universitätsklinikum Heidelberg; ${ }^{2}$ Institut für Pharmazie und Molekulare Biotechnologie, Universität Heidelberg

Fragestellung: Cocain ist das in der Europäischen Union derzeit am häufigsten konsumierte illegale Stimulans. Obwohl viele halb- und vollsynthetische Cocain-Derivate bekannt sind, steht eine systematische forensisch-chemische Untersuchung dieser Substanzen noch aus. Der Handel und Konsum dieser als "Research Chemicals" angebotenen psychoaktiven Substanzen (z. B. Troparil, Dichloropan, RTI-55), die sich strukturell oder funktionell an der Leitstruktur Cocain orientieren, ist legal möglich, da eine Aufnahme in das Neue-psychoaktive-Stoffe-Gesetz (NpSG) bisher noch nicht erfolgt ist. Synthetische Cocain-Derivate und deren Metaboliten werden im Rahmen der üblichen forensisch-toxikologischen Untersuchungen nicht zuverlässig erfasst.

Methode: Zur Beurteilung der aktuellen Verbreitung und Verfügbarkeit von synthetischen Cocain-Derivaten (Phenyltropane, 1,4-Dialkylpiperazine, Phenylpiperidine und Benztropine) sollten einschlägige Seiten des öffentlichen Internets, die „Research Chemicals" anbieten, identifiziert werden. Anschließend sollte das Auftauchen und Verschwinden derartiger Substanzen auf diesen Seiten beobachtet und wenn möglich Substanzproben erworben werden. Zudem sollte eine initiale Überprüfung der immunchemischen Kreuzreaktivität in gängigen Immunoassays erfolgen.

Ergebnisse: Im Rahmen dieses Projektes wurden etablierte "Research Chemical"-Webseiten herausgesucht und das Angebot monatlich beobachtet. Eine ergänzende Suche nach neuen Webseiten wurde alle drei Monate durchgeführt. Substanzen wie Troparil und Dichloropan waren vielfach bei verschiedenen Internethändlern vertreten und kommerziell 
verfügbar. Auch strukturähnliche, als „neuartige“ Cocain-Analoga vertriebene Substanzen konnten identifiziert und erworben werden. Die Untersuchung in immunchemischen Tests zeigte eine nur als gering einzustufende Kreuzreaktivität.

Diskussion/Fazit: Die legale Verfügbarkeit von psychoaktiven Stimulanzien nimmt durch das NpSG kontinuierlich ab. Daher soll die systematische Beobachtung von synthetischen Cocain-Derivaten fortgesetzt werden. Zudem sollen die im Rahmen der Untersuchung erworbenen Proben und beschlagnahmte Substanzen der Landeskriminalämter (Projekt ADEBARplus) einem „Drug Profiling“ unterzogen werden, um Rückschlüsse auf die Herstellungspraxis in den illegalen Laboren treffen zu können. Eine weitergehende forensisch-chemische sowie pharmakologische Charakterisierung dieser Substanzen ist vorgesehen. Diese Daten könnten zukünftig zu einer Aufnahme der Cocain-Analoga in das NpSG beitragen.

\section{P-TX-8 \\ The first case of suicide bag with helium in Bulgaria-a slow modern influence in South-Eastern Europe}

Yanko G. Kolev

Department of Forensic medicine, Medical University of Pleven, Bulgaria

Introduction: Over the last two decades, more and more so-called "suicide bag" cases with use of helium (He) were reported from many countries. The use of a plastic bag with helium inhalation is a method of committing suicide that became popular due to the peaceful death that results, as described by the various advocacy groups that support legalized suicide and based on filmed cases. Helium-induced death has been described as rapid and painless. The influence of this popularity in South-Eastern Europe is slow, as there are still no reported cases from the region.

Case report: The first local documented case is from Gabrovo, Bulgaria, in 2018. A young man, single and web-addicted introvert, was found dead in his home, with typical set of two helium disposable gas tanks, tubing and a plastic bag over the head/face. After the deathscene examination, autopsy was performed, revealing no more than minimal signs of asphyxiation.

Discussion: It is important to combine a detailed crime scene investigation with modern methods of detection of the gas in the body, when possible, to confirm the diagnosis. First responders should be cautious and aware that variants of the suicide bag method may have been used that may include the mixing of household chemicals to create a poisonous gas such as hydrogen sulfide or other gases may be used as nitrogen, propane, butane, argon etc., so oxygen $\left(0_{2}\right)$ deficient atmosphere or ignition risks may exist.

\section{P-TX-9}

Neurochemical effects of diphenidine derivatives, a new psychoactive substance, on the dopaminergic reward system using rat brain microdialysis

Katsuhiro Okuda, Yuta Takahashi, Masaru Asari, Kanae Mori, Ryo Namba, Keiko Shimizu

Dept. Leg. Med., Asahikawa Medical Univ., Asahikawa, Japan

Background: Diphenidine (DPD), which is one of the new psychoactive substances, is also colloquially known as 'legal highs'. Both DPD and phencyclidine (PCP) are NMDA receptor antagonists, which share the same chemical structure, and drug mechanisms. Previously we have reported that locomotor activity and brain dopamine and norepinephrine contents are increased after DPD injection in rats. In this study we evaluated the neurochemical effects of intraperitoneal DPD derivatives (4-hydroxy-DPD and 4-methoxy-DPD) on the dopaminergic reward system using rat brain microdialysis.
Methods: Male Slc:Wistar/ST rats were anesthetized and stereotaxically implanted with a microdialysis probe in the right nucleus accumbens (NAc). Perfusion was performed on the following day, and the dialysates were automatically injected into an HPLC-ECD apparatus at 15-min intervals before and after intraperitoneal DPD derivative administration. The norepinephrine, dopamine and serotonin contents were determined using HPLC-ECD, and the locomotor activity was measured by an infrared sensor system. In another group of rats, dialysates were collected and then analyzed by LC-MS/MS. DPD derivatives were detected by ESI-positive mode. The product ion $\mathrm{m} / \mathrm{z} 197.1$ from m/z 282.2 and $\mathrm{m} / \mathrm{z} 211.0$ from $\mathrm{m} / \mathrm{z} 296.5$ were selected for monitoring 4-hydroxy-DPD and 4-methoxyDPD, respectively.

Results and discussion: Increases in the locomotor activity and dopamine and norepinephrine contents were observed and DPD derivatives were concomitantly detected in the rat-brain dialysate after treatment with DPD derivatives. Peak concentrations observed at 30 to 45 min gradually decreased in a time-dependent manner in the brain. This demonstrates that the DPD derivatives penetrated the blood-brain barrier well. Intriguingly, 4-Hydoxy-DPD was detected even when 4-methoxy-DPD was administered, implying that demethylation could have occurred in the body/ brain. Although 4-hydroxy-DPD is a polar compound compared to DPD and 4-methoxy-DPD, it was found in the brain not only as a metabolite but also remained as the injected compound per se. A transporter might be involved in the blood-brain barrier penetration of DPD derivatives.

\section{P-TX-10}

Ist das Synthetische Cannabinoid 5F-MDMB-P7AICA anfällig für eine postmortale Umverteilung? - Eine systematische Studie im Schweinemodell nach inhalativer Applikation

Adrian A. Dörr', Frederike Nordmeier', Nadja Walle' ${ }^{1}$, Matthias W. Laschke', Michael D. Menger ${ }^{2}$, Peter H. Schmidt ${ }^{1}$, Markus R. Meyer ${ }^{3}$ und Nadine Schäfer ${ }^{1}$

${ }^{1}$ Universität des Saarlandes, Institut für Rechtsmedizin, Homburg (Saar); ${ }^{2}$ Universität des Saarlandes, Institut für Klinisch-Experimentelle Chirurgie, Homburg (Saar), ${ }^{3}$ Universität des Saarlandes, Abteilung für Experimentelle und Klinische Toxikologie, Center for Molecular Signaling (PZMS), Homburg (Saar)

Fragestellung: Gerade im Zusammenhang mit dem Konsum neuerer hochpotenter synthetischer Cannabinoide (SC) wird über Vergiftungen und Todesfälle berichtet. In der postmortalen toxikologischen Analytik muss bei der Beurteilung von zum Todeszeitpunkt vorliegenden Konzentrationen die postmortale Umverteilung (PMR) berücksichtigt werden. Das Schweinemodell hat sich für die systematische Untersuchung des Phänomens bereits als geeignet erwiesen. Ziel dieser Studie war die Untersuchung der PMR des SC 5F-MDMB-P7AICA sowie seines Hauptmetaboliten 5F-MDMB-P7AICA-Dimethylbutansäure (DBA).

Methode: 5F-MDMB-P7AICA ( $200 \mu \mathrm{g} / \mathrm{kg}$ Körpergewicht) wurde narkotisierten und beatmeten Schweinen $(n=6)$ inhalativ verabreicht. Nach $8 \mathrm{~h}$ wurden die Tiere eingeschläfert und nach Probennahme von Geweben und Körperflüssigkeiten (u.a. Blut, Muskel, Leber, Galle und Duodenalinhalt) über 3 Tage bei Raumtemperatur gelagert. Das Probenspektrum wurde täglich erneut entnommen. Die Analyse erfolgte nach Festphasenextraktion mittels Standardadditionsverfahren und LC-MS/MS, Blut wurde nach Proteinfällung mittels Kalibrationsgerade quantifiziert.

Ergebnisse: 5F-MDMB-P7AICA fand sich perimortal vor allem im Duodenalinhalt. Die Konzentration fiel postmortal im Verlauf der Lagerung ab, während sie im Muskelgewebe im Median um den Faktor 3 anstieg. Hohe Konzentrationen an DBA fanden sich perimortal vor allem in Duodenalinhalt, Urin und Nierengewebe. Im Duodenalinhalt fielen die Konzentrationen im Verlauf der Lagerung im Median etwa um den Faktor $10 \mathrm{ab}$, wohingegen in der Niere keine starken Veränderungen beobachtet wurden. Des Weiteren fand sich in der Leber im Median ein Anstieg von DBA um etwas mehr als den Faktor 2. In Femoral- und Herzblut fanden sich bei Todeseintritt Analytenkonzentrationen von unter $0,5 \mathrm{ng} / \mathrm{ml}$, die im Verlauf der Lagerung relativ konstant blieben. 
Diskussion: 5F-MDMB-P7AICA und DBA wurden in den meisten Proben über 3 Tage nachgewiesen. Ein Anstieg an 5F-MDMB-P7AICA fand sich im Muskelgewebe, wobei eine Umverteilung aus dem subkutanen Fettgewebe ursächlich sein könnte. DBA stieg in der Leber an, wofür eine Umverteilung aus der Galle in Frage kommen könnte.

Fazit: Für den postmortalen Nachweis von 5F-MDMB-P7AICA und DBA bieten sich Muskel, Niere und Duodenalinhalt als alternative Matrices an. Die Konzentrationen im Blut scheinen auch postmortem auf niedrigem Niveau relativ stabil zu bleiben. Lediglich in Duodenalinhalt, Leber und Muskulatur fanden sich geringe PMR-Prozesse.

\section{P-TX-11 \\ Biodistribution of insulin following massive subcutaneous insulin injection}

Tomoya Ikeda ${ }^{1,2}$, Naoto Tani ${ }^{1,2}$, Tatsuya Hirokawa' ${ }^{1}$, Kei Ikeda ${ }^{1}$, Fumiya Morioka', Alissa Shida', Yayoi Aoki', Takaki Ishikawa ${ }^{1,2}$

${ }^{1}$ Department of Legal Medicine, Osaka City University Medical School, Osaka, Japan.; ${ }^{2}$ Medico-legal Consultation and Postmortem Investigation Support Center, c/o Osaka City University Medical School, Osaka, Japan.

Objective: Insulin is the only hormone in the body that decreases blood glucose levels. Severe hypoglycemia is a potentially fatal condition that requires immediate medical intervention. In forensic medicine, postmortem diagnosis of subcutaneous insulin injection is often difficult. The pathophysiology of a massive insulin injection case was examined, and the biodistribution of insulin was investigated.

Method: A man in his thirties committed suicide by injecting insulin many times into his abdomen and was found dead in his bedroom several hours later. An autopsy was performed a day later.

Result: Ten injection marks were observed in the lower abdomen, with hemorrhage in the subcutaneous fatty tissue. The lungs were heavy with edema, and all other organs, especially the brain, were edematous. Micropathological findings showed alveolar injury with alveolar hemorrhage, as well as cerebral parietal lobe nerve cell edema. Biochemical examination showed that the blood insulin level was higher (left heart blood: $163.0 \mu \mathrm{lU} /$ $\mathrm{mL}$; right heart blood: $374.0 \mu \mathrm{lU} / \mathrm{mL}$; iliac vein blood: $5640.0 \mu \mathrm{lU} / \mathrm{mL}$ ) than the clinical reference range $(1.84-12.2 \mu \mathrm{lU} / \mathrm{mL})$ and significantly higher in the insulin injection sites $(200,000 \mu \mathrm{lU} / \mathrm{mL})$. The blood glucose and Cpeptide levels were low. Although insulin is metabolized mainly by the kidneys, the insulin level in the kidneys was low (left: $17.9 \mu \mathrm{lU} / \mathrm{mL}$; right: $20.2 \mu \mathrm{IU} / \mathrm{mL}$ ).

Discussion and Conclusion: Measuring insulin levels in body fluids and tissues can help determine the pathophysiology of insulin injection cases. When insulin injection into fatty tissues is suspected, high insulin levels can be expected at the insulin injection sites rather than in the blood.

\section{P-TX-12}

\section{Tissue distribution of morphine and levetiracetam used for pain management in a terminal cancer patient}

Brian Waters, Kenji Hara, Masayuki Kashiwagi, Aya Matsusue, Shin-ichi Kubo Fukuoka University, Faculty of Medicine, Department of Forensic Medicine, Fukuoka, Japan

Objective: The WHO-recommended method of cancer pain treatment includes opioid and/or non-opioid analgesics, supplementary analgesics, side effect countermeasures, etc. We report on an autopsy case of a terminal cancer patient who had been receiving morphine and levetiracetam for pain treatment

Case history: A Mexican male in his 40 s was visiting Japan for treatment of terminal cancer. He was found lying unresponsive on a futon in a facility where he was receiving care. Two years prior he had an operation on an adenoid cystic carcinoma of the left parotid gland, after which his can- cer was diagnosed as terminal. Morphine and levetiracetam were discovered in his room.

Autopsy findings: Tumors were observed in the left parotid gland, left submandibular gland, and in the lungs. His lymph nodes were swollen and a grayish-brown sputum was found in his airway. His lungs were heavy and the cut surface of the lungs was spotted with light and dark brown areas.

Method: Toxicological screening was performed on blood and urine samples by deproteinization with acetonitrile, phospholipid removal with filter cartridges, and reverse phase weak anion exchange SPE. The extracted sample was analyzed by GC-MS and LC-MS/MS. Quantitative analysis was performed by LC-MS/MS. Autopsy samples were extracted with acetonitrile and phospholipid removal cartridges. Detection was by multiple reaction monitoring (MRM) mode, with transitions for morphine and levetiracetum of $m / z 286>165$ and $m / z 171>126$, respectively.

Results/discussion: Toxicological screening revealed morphine, its metabolites morphine-3- and morphine-6-glucuronide, and levetiracetam. Morphine concentrations in left femoral blood and urine were 122 and $7813 \mathrm{ng} / \mathrm{g}$, respectively. The levetiracetam concentration in the left femoral blood was $17.3 \mu \mathrm{g} / \mathrm{g}$. A full tissue distribution of all body fluids and tissues collected at autopsy will be reported.

Morphine is used to treat moderate to severe pain, however it is often abused for its euphoric effects. Levetiracetam, originally an epilepsy treatment, can be used to treat the neuropathic pain that occurs when cancer invades the nerves. The blood morphine concentration in this case was consistent with other cases where morphine was used for cancer pain. The levetiracetam concentration was in the therapeutic range.

Conclusion: To our knowledge a full tissue distribution of this combination of cancer treating drugs has not been reported. The distribution of these drugs in the body fluids and tissues could provide important information to the medical and toxicology communities.

\section{P-TX-13}

Kinetics and distribution of benzalkonium compounds with different alkyl chain length following intravenous administration in rats.

Hitomi Kera, Chiaki Fuke, Yosuke Usumoto, Ayako Nasu, Kazuho Maeda, Moe Mukai, Wakana Sato, Momoka Tanabe, Hikaru Kuninaka, Yoko Ihama

Department of Legal Medicine, Yokohama City University Graduate School of Medicine, Yokohama, Japan.

Objective: Benzalkonium chloride is widely used in disinfectants. Several toxicological and fatal cases have been reported; however, little is known about its kinetics and distribution. We investigated the kinetic characteristics and distribution of benzalkonium cation (BZK) based on the length of the alkyl chains $\mathrm{C} 12, \mathrm{C} 14$, and C16.

Material and Methods: Male Wistar/ST rats were treated intravenously with BZK solution (dose, $13.9 \mathrm{mg} / \mathrm{kg}$ ) containing equal amounts of the three homologues. Kinetic parameters in the blood were assessed, and BZK distribution in the blood and tissues was examined both in rapid intravenous (IV) and drip intravenous (DIV) administrations. BZK concentrations were analysed by liquid chromatography-tandem mass spectrometry (LC-MS/MS).

Results: BZK with longer alkyl chains showed lower elimination tendencies and remained in the blood for a longer duration. Concentrations of BZK were higher in the heart, lung, spleen, and kidney than those in the blood, and lower in the brain and fat. In both the IV and DIV groups, the lung, liver, spleen, and fat samples showed higher concentrations of the longer alkyl chains (BZK-C12<-C14<-C16), and the opposite trend was observed in the kidney (BZK-C16<-C14<-C12). Only the heart and muscle samples exhibited the homologues in ratios comparable to the original administered solutions. Differences between IV and DIV groups could be identified by comparing concentrations of BZK homologues in the heart, lung, spleen, and kidney samples. 
Discussion: We administered a mixture containing three BZK homologues, and found that the kinetics differed depending on the alkyl chain length. Moreover, BZK concentrations varied in blood and tissue samples, and the distribution was also characterised by the length of alkyl chain, which had the potential to differentiate between IV and DIV administration. We concluded that collecting blood and various tissues, such as heart, lung, liver, spleen, kidney, and muscle, and analysing each homologue, provided useful information in the case of suspected BZK poisoning.

\section{P-TX-14}

Untersuchungen zu Stabilität und Abbauverhalten von Zopiclon in Blut- und Urinproben mittels LC-MS/MS

Sven Baumann', Christina Müller², Heiner Trauer ${ }^{1}$, Lars Wünsch², Jens Meiler², Jan Dreßler

'Institut für Rechtsmedizin; ${ }^{2}$ Institut für Wirkstoffentwicklung, Medizinische Fakultät der Universität Leipzig, Deutschland

Fragestellung: Das Sedativum Zopiclon zählt neben Zolpidem und ZalepIon zu den sogenannten Benzodiazepin-ähnlichen Z-Substanzen. In einer Reihe von forensisch-toxikologischen Untersuchungen ist zur vollständigen Bewertung die quantitative Bestimmung von Zopiclon notwendig. Allerdings ist seit längerem bekannt, dass vor allem hydrolytische Prozesse zur Degradation von Zopiclon in Blut- und Urinproben beitragen und somit die Ergebnisse maßgeblich verändern können.

Methode: Ziel war daher die systematische Untersuchung zur Stabilität von Zopiclon in verschiedenen Lösungsmitteln sowie Blut- und Urinproben mittels geeigneter LC-MS/MS Verfahren. Neben dem Abbau des eigentlichen Wirkstoffes sollten dabei außerdem bekannte und ggf. neue Abbauprodukte identifiziert und deren quantitative Veränderungen beobachtet werden. Hierzu wurden Screening-Verfahren mittels hochauflösender Massenspektrometrie sowie zielgerichtete LC-MS/MS Methoden für die Untersuchung der identifizierten Substanzen etabliert und angewendet.

Ergebnisse: Neben den endogenen Metaboliten N-Desmethylzopiclon sowie Zopiclon-N-oxid konnten weitere durch Hydrolyse gebildete Degradationsprodukte analytisch erfasst werden. Zu den bereits beschriebenen Verbindungen 2-Amino-5-Chlorpyridin (ACP) und ein durch Desacetylierung entstandenes 7-OH-pyrrolopyrazin-5-on Derivat (Eszopiclone Impurity B) konnte ein bis dato nicht beschriebenes potenzielles Methoxy-Derivat auf Basis der erhaltenen Spektren identifiziert werden. Die forcierte Degradation für eine vollständige Umsetzung von Zopiclon unter basischen Bedingungen und erhöhter Temperatur zu ACP lieferte dagegen keine einheitlichen Ergebnisse.

Diskussion: Im forensisch-toxikologischen Routinebetrieb ist die quantitative Analyse von Zopiclon unerlässlich. Aufgrund verschiedener Prozesse, die zum Abbau der Substanz beitragen, wird diese deutlich erschwert. Die Analyse von Degradationsprodukten neben endogenen Metaboliten kann bei der Beurteilung der Probenalterung und der Bewertung initialer Zopiclonkonzentrationen helfen. Eine quantitative Bestimmung von ACP anstelle von Zopiclon ist auf Basis unserer Ergebnisse dagegen nicht praktikabel.

Fazit: Eine präzise und richtige quantitative Bestimmung von Zopiclon ist hinsichtlich präanalytischer und analytischer Gesichtspunkte eine Herausforderung. Die vorgestellten Daten zeigen einerseits neue Erkenntnisse zur Stabilität von Zopiclon und anderseits die Notwendigkeit für weitere Untersuchungen.
P-TX-15

Determination of aminoglycoside antibiotics in human plasma using UPLC-Q-ToF-MS

Masaya Fujishiro', Sawa Minohara ${ }^{1,2}$, Akihiro Nakauchi ${ }^{1,3}$, Mari Hashimoto', Chika Hasegawa ${ }^{1,4}$, Takeshi Kumazawa ${ }^{5}$ and Takaaki Matsuyama ${ }^{1}$

${ }^{1}$ Department of Legal Medicine, Showa University School of Medicine, Tokyo, Japan; ${ }^{2}$ Department of Plastic and Reconstructive Surgery, Showa University School of Medicine, Tokyo, Japan; ${ }^{3}$ Faculty of Numazu Human Care, Tohto University, Shizuoka, Japan; ${ }^{4}$ Department of Legal Medicine, Toho University School of Medicine, Tokyo, Japan; ${ }^{5}$ Seirei Christopher University School of Nursing, Shizuoka, Japan

Objective: Aminoglycosides are a class of broad-spectrum antibiotics with several clinical uses. Owing to their ototoxic and nephrotoxic side effects, therapeutic drug monitoring is required. This study aimed to devise a high-throughput method for identification and quantitative determination of aminoglycoside antibiotics in human plasma using ultra-performance liquid chromatography-quadrupole time-of-flight-mass spectrometry (UPLC-Q-ToF-MS).

Method: Plasma samples spiked with five aminoglycosides (streptomycin, spectinomycin, amikacin, kanamycin, and gentamycin) and an internal standard (ribostamycin) were diluted and centrifuged in aqueous formic acid and acetonitrile. The clear supernatant extract was evaporated and reconstituted in the mobile phase, of which $4 \mu \mathrm{L}$ was injected to UPLC-Q-ToF-MS.

Result: Prominent drug peaks were observed within $3 \mathrm{~min}$. The regression equations showed excellent linearity within the range of $1.0-100 \mathrm{mg} / \mathrm{mL}$. To demonstrate the applicability of UPLC-Q-ToF-MS for clinical practice, the concentrations of streptomycin and gentamycin in plasma samples were quantitated from three healthy volunteers after injecting streptomycin and gentamycin, respectively. The observed concentrations were within the normal therapeutic levels.

Discussion: In contrast to LC-MS/MS analysis, Q-ToF-MS has a greater advantage as it can provide high resolution and accurate mass information. Use of UPLC-Q-ToF-MS is recommended for Therapeutic Drug Monitoring of aminoglycosides in clinical and toxicological settings. Under optimized conditions, satisfactory extraction efficiency, linearity, and reproducibility were achieved using our established method. UPLC-Q-ToF-MS analysis enabled the identification and sensitive quantitation of aminoglycosides that exceeded the performance of ELISA and HPLC-MS/MS. Additionally, it proved useful as a high-throughput method for screening, identification, and quantitative determination of aminoglycosides in clinical and toxicological analyses.

Conclusion: To the best of our knowledge, this is the first report addressing the use of a small-volume LLE method and UPLC-Q-ToF-MS analysis for the identification and quantification of aminoglycosides in biological samples.

\section{P-TX-16}

Verification of a database library of drugs and metabolites detected in formalin tissues and fixatives constructed utilizing in silico analysis

Kyoko UEKUSA ${ }^{1}$, Masahiko TAKINO ${ }^{2}$, Kousuke ISHINO², Yoshimasa KANAWAKU ${ }^{1}$

'Department of Legal Medicine, Nippon Medical School, Chiba, Japan; ${ }^{2}$ Agilent Technologies Japan, Ltd., Tokyo, Japan; ${ }^{3}$ Department of Integrated Diagnostic Pathology, Nippon Medical School, Tokyo, Japan

Objective: To improve the evaluation of drugs in tissues following formalin fixation, we built a database library of drugs, metabolites, and other compounds detected in formalin tissues and fixatives, utilizing Q-TOF analysis software. Unidentifiable compounds registered as estimations in the database library were verified against standard metabolites.

Method: Existing Q-TOF data were analyzed in silico with ACD/Meta Sense software for predicting metabolites, using some predicted metabolites as standards. A new liver homogenate and fixatives of drug-negative cases 
were spiked with standards including the above metabolites, cartridge filtered to remove protein and phospholipids after extraction with QuEChERS, and newly analyzed with an Agilent 6546 LC/Q-TOF system. The updated monoisotopic mass, retention time, and product ion spectrum data were registered in the Personal Compound Database Library (PCDL). Recovery and matrix effects of compounds in the liver homogenate and fixatives were calculated. The study was approved by the Ethics Review Board of Nippon Medical School, Japan.

Results: Using the updated PCDL, a drug and metabolite search performed with the previous Q-TOF data returned good library search scores. Regarding the predicted metabolites, three types of quetiapine could be identified by the product ion spectrum. The product ion spectra of two types of chlorpromazine metabolite were similar. Recovery was higher in metabolites than parent compounds. Matrix effect was low for the parent compound in fixatives.

Discussion: Compound identification in formalin was advanced by analysis with metabolite prediction software. Differences in the product ion spectrum did not significantly affect the library search score in the PCDL, depending on the equipment used. The low matrix effect in the fixatives was considered due to ion inhibition caused by formalin.

Conclusion: Construction of a database library to search for drugs and metabolites in formalin tissues by utilizing in silico analysis and updated Q-TOF data of metabolites is possible.

\section{P-TX-17 \\ Potenzielle Biomarker der gamma-Hydroxybuttersäure - Ein neuer Ansatz}

\section{J.S. Thimm' ', V. Hofmann'1, M. Bartel' ${ }^{1}$, T. R. Sundermann ${ }^{1,2}$}

${ }^{1}$ Institut für Rechts- und Verkehrsmedizin, Universitätsklinikum Heidelberg; ${ }^{2}$ Institut für Pharmazie und Molekulare Biotechnologie, Universität Heidelberg

Fragestellung: Gamma-Hydroxybuttersäure (GHB) wird in den öffentlichen Medien sowohl als Partydroge („Liquid Ecstasy“) als auch als Vergewaltigungsdroge („Date Rape Drug“) dargestellt. Aufgrund der raschen Elimination im Körper, ist das Nachweisfenster für GHB begrenzt und ein eindeutiger Nachweis nicht immer gegeben. Obwohl in den letzten Jahren intensiv nach neuen GHB-Biomarkern gesucht wurde, konnte bisher das Nachweisfenster nicht nachhaltig vergrößert werden. Beim Alkohol umfasst das Spektrum der in der Forensischen Toxikologie genutzten Alkoholbiomarker sowohl hydrophile Metaboliten, wie das Ethylglucuronid und -sulfat, als auch lipophile Vertreter, wie Fettsäureethylester und Phosphatidylethanole. Für GHB wurden lipophile Metaboliten bisher praktisch nicht berücksichtigt.

Methode: In Analogie zu den Alkoholbiomarkern sollten verschiedene Fettsäureester, Triglyceride und Phospholipide als potenzielle lipophile Metabolite des GHB hergestellt und untersucht werden. Um eine Verwechselung mit der endogen vorhandenen beta-Hydroxybuttersäure (BHB) und deren Metaboliten zu verhindern, sollten diese Substanzen ebenfalls hergestellt und in die nachfolgenden Untersuchungen miteinbezogen werden.

Ergebnisse: In Kooperation mit dem Institut für Pharmazie und Molekulare Biotechnologie wurden verschiedenen GHB-Derivate wie Fettsäureester (16:0 und 18:1), Triglycerid (16:0/18:1), Phospholipid (16:0/18:1) und die entsprechenden BHB-Derivate erfolgreich synthetisiert und analytisch charakterisiert. Die Entwicklung einer HPLC-MS/MS-Methode wurde etabliert, um eine eindeutige Identifizierung dieser Substanzen zu ermöglichen.

Diskussion/Fazit: Mit der HPLC-Methode können zukünftig Untersuchungen zur endogenen Bildung, in-vitro Untersuchungen und weiterer Analysen von authentischem Probenmaterial (Vollblut und Haare) durchgeführt werden, um die Eignung als Biomarker abschließend beurteilen zu können.

\section{P-TX-18}

\section{Magnetresonanzspektroskopische Darstellung der Ethanolkonzentration im Gehirn}

Dominik Schuldis ${ }^{1}$, Annette Thierauf-Emberger ${ }^{1}$, Michael Dacko², Thomas Lange ${ }^{2}$

'Institut für Rechtsmedizin, Universitätsklinikum Freiburg; ${ }^{2}$ Medizinphysik, Radiologische Universitätsklinik, Universitätsklinikum Freiburg

Fragestellung: Für forensische Fragestellungen wird in der Regel die Blutalkoholkonzentration bestimmt; gut untersucht ist der Verlauf der Blutalkoholkurve. Wesentlicher Wirkungsort des Ethanols ist jedoch das Gehirn. Zum Verlauf der Ethanolkurve in diesem Organ liegen noch keine vollständigen Kenntnisse vor. Dazu wurde eine magnetresonanzspektroskopische Studie durchgeführt.

Methode: Bei insgesamt 10 Probandlnnen wurde die Ethanolkonzentration im Gehirn (okzipitaler Kortex) mittels Protonenmagnetresonanzspektroskopie (PMRS, Single-Voxel-PMRS) direkt gemessen. Die Versuchsteilnehmer tranken nach mindestens 2-tägiger Alkoholabstinenz innerhalb von 30 min Wodka in einer Menge, die zu einer anhand der Widmark-Formel errechneten maximalen Blutalkoholkonzentration in Höhe von $0,7 \%$ führen sollte. Mit dem Ende der Trinkzeit begannen die magnetresonanzspektroskopischen Untersuchungen in wiederholten Zyklen. Zum Vergleich wurden in regelmäßigen Abständen Blutentnahmen durchgeführt. Über eine Wasserreferenzmessung und eine Schätzung des Wassergehalts anhand von MRT-Bilddaten konnte die Alkoholkonzentration im Hirn absolut quantifiziert werden.

Ergebnisse: Der zeitliche Verlauf der Hirnethanolkonzentrationen spiegelte den Verlauf der Blut- bzw. Serumkonzentrationen annähernd wider, wies jedoch über das kleine Kollektiv einige Heterogenitäten auf. Quantitativ waren die gemessenen Hirn- und Blutkonzentrationen nicht vergleichbar. Aus der Art der praktischen Durchführung ergaben sich Schwierigkeiten bei der Darstellung des ansteigenden Kurvenabschnitts.

Diskussion: Dargestellt wird ein Vergleich zwischen den Blut- und Hirnethanolkurven und diskutiert werden mögliche Einflussfaktoren auf die verschiedenen Kurvenverläufe.

Fazit: Es gelang eine (nahezu) durchgängige Darstellung des absteigenden Kurvenanteils der Hirnethanolkurve. Für Anschlussstudien ist eine Lösung des Problems der schweren Darstellbarkeit des ansteigenden Kurvenabschnitts zu suchen.

\section{P-TX-19}

\section{Study on selected alcohol-drinking markers in urine by GC-MS analysis}

Kenji Hara, Brian Waters, Ryoko Nakano, Masayuki Kashiwagi, Aya Matsusue, and Shin-ichi Kubo

Department of Forensic Medicine, Faculty of Medicine, Fukuoka University

Objective: Ethanol analysis is often used to prove alcohol consumption and the degree of drinking. However, after a short time ethanol becomes undetectable in the body. We have used GC-MS to search for ethanolcomplementary drinking markers that may be useful for prolonging detectability of alcohol consumption and detecting, which beverage was consumed. In this study, we will report on the selection of the compounds. Materials and method: Urine from volunteers was collected $2 \mathrm{~h}$ after drinking an alcoholic beverage. The beverages included beer, red and white wine, whiskey, sake, etc. Sample preparation: $0.1 \mathrm{ml}$ of urine, $0.3 \mathrm{ml}$ of deionized water, and $0.05 \mathrm{ml}$ of a urease solution were mixed and kept at room temperature for $30 \mathrm{~min}$. The sample was then mixed with $2 \mathrm{ml}$ of acetonitrile and $0.1 \mathrm{ml}$ of acetic acid and poured through a weak cation exchange cartridge (ISOLUTE CBA, $500 \mathrm{mg} / 3 \mathrm{~mL}$, Biotage), followed by a mixture of $2 \mathrm{ml}$ of acetonitrile and $0.1 \mathrm{ml}$ of ammonia water. The eluent was collected in a glass tube containing $0.5 \mathrm{ml}$ of acetic acid. The mixture was evaporated under a nitrogen stream at $42^{\circ} \mathrm{C}$ (Biotage TurboVap). 
GC-MS conditions: Apparatus: Shimadzu QP-2010Ultra; column: a tandem column with a ZB-SemiVolatiles $(3 \mathrm{~m} \times 0.18 \mathrm{~mm}$ i. d., $0.36 \mu \mathrm{m}$ film thickness) connected to a BPX5 ( $4 \mathrm{~m} \times 0.15 \mathrm{~mm}$ i.d., $0.25 \mu \mathrm{m}$ film thickness). Column oven temperature program: $110^{\circ} \mathrm{C}$ for $0.5 \mathrm{~min}$, ramped to $200^{\circ} \mathrm{C}$ at $70{ }^{\circ} \mathrm{C} / \mathrm{min}$, and raised to $320^{\circ} \mathrm{C}$ at $50^{\circ} \mathrm{C} / \mathrm{min}$. Injection port temperature: $280^{\circ} \mathrm{C}$. Beverages were investigated using the same method for determination of target compounds.

Results and discussion: By this GC-MS method, the detection of a wide range of acidic and basic compounds was achieved. In almost all the beverages, 2-phenethyl alcohol was detected. Tyrosol and ethyl glucoside were found in all the brewed beverages. Syringaldehyde was found in all whiskey beverages. Hydroxy-methylacetophenones and methoxybenzenediols were often detected in beer. Malic acid-like peaks were prominently detected in white wine. Many other flavors contained in alcoholic beverages and foods were detected. Volunteer urine was analyzed by targeting compounds commonly detected from the alcoholic beverages. Many of the compounds were also detectable in the urine samples. By this method, multiple alcoholic beverage components can be simultaneously detected, suggesting that GC-MS analysis is a useful means to prove the consumption of alcoholic beverages.

Conclusion: By this analysis method, various types of drinking marker candidates can simultaneously be detected. We think that meaningful information can be obtained in the study of alcoholic beverage markers.

\section{P-TX-20 \\ A drunk-driving case of an individual with alcohol use disorder and ultra-rapid alcohol metabolism}

Himemiya-Hakucho Ayako', Tatsuya Fujimiya²

'Department of Legal Medicine, Yamaguchi University Graduate School of Medicine, Yamaguchi, Japan; ${ }^{2}$ Saikyo Institute of Legal Medicine, Shiga, Japan

Objective: A 40-year-old man caused a traffic accident while driving one afternoon. His measured breath alcohol concentration $(\mathrm{BrAC})$ was $1.08 \mathrm{mg} / \mathrm{L}$; however, he insisted that he was unaware of the alcohol remaining in his body during the traffic accident. He claimed to have been continuously drinking alcoholic beverages, except while sleeping, at his home for 2 days before the accident.

Method:Widmark's formula was used for estimation of blood alcohol concentrations (BACs) from the measured BrAC. The time course of BACs was estimated from the amounts of alcohol he stated he had consumed or from the actual $\mathrm{BrAC}$ measurement.

Results: An expert witness confirmed the consistency and rationality of his statement. The measured $\mathrm{BrAC}$ was consistent with his statement when the $\beta_{60}$ value was $0.36 \mathrm{mg} / \mathrm{mL} / \mathrm{h}$, which indicates an ultra-rapid elimination rate in alcohol metabolism. We found his statement to be irrational because the calculated blood alcohol level was high, showing signs of alcohol intoxication. Most people are aware of alcohol remaining in the body at this level, but such awareness is subjective and cannot be confirmed objectively. Incidentally, the suspect died not long afterwards and the case was not prosecuted.

Discussion: and Conclusion: Drunk-driving must be committed intentionally for it to be viewed as a criminal act in Japan; in other words, a person must be aware of the presence of alcohol. In this case, the patient was a hazardous drinker and was suspected to have alcoholism. A person with an alcohol use disorder may find this judgment to be more difficult due to factors such as simple factual error, alcohol tolerance, mendaciousness, and denial of alcoholism as a disease. Thus, interventions by the judiciary in resolving a criminal act and by health professionals are both important. Promotion of the social system of medical intervention for drunk-drivers would be beneficial to both individuals and society. Development of this system is underway in Japan, but greater progress is urgently needed.

\section{References}

1. Nihon Arukoru Yakubutsu lgakkai Zasshi 55, 112-122, 2020
P-TX-21

\section{Urinary phenylacetylglutamine as a possible biomarker for central nervous system disorders}

Natsuki Ikematsu' ${ }^{1}$ Kenji Hara², Brian Waters², Aya Matsusue², Mio Takayama³, Masayuki Kashiwagi², Shin-ichi Kubo²

' Department of Legal Medicine, University of the Ryukyus, Okinawa, Japan; ${ }^{2}$ Department of Forensic Medicine, Fukuoka University, Fukuoka, Japan; ${ }^{3}$ Tokyo Medical Examiner's Office, Tokyo, Japan

Objective: Phenylacetylglutamine (PAG) is a metabolite excreted in human urine. Phenylalanine is metabolized to phenylacetic acid, which is amide bonded to glutamine to form PAG. It is known that the intestinal microbiota extensively catabolizes proteins and rich amino acids, including phenylalanine and tyrosine, to form PAG and $p$-cresol sulfate. We have reported on the significance of blood $p$-cresol in forensic autopsy cases. We are currently studying PAG as a new urinary biomarker.

Materials and method: Urine samples were collected from 145 forensic autopsy cases. Urinary PAG concentration was analyzed quantitatively by GC-MS, according to our previously reported methods. Urinary creatinine (Cr) concentration was also analyzed by GC-MS. For statistical analysis, the JMP Pro 15.0.0 software program was used. The relationship between urine PAG/Cr (ratio of each concentration), $\mathrm{Cr}$ concentration, age, sex, cause of death, postmortem interval, and duration from failure to death was statistically analyzed.

Results and discussion: The median (range) of $\mathrm{Cr}$ was 0.74 (0.03-3.51) $\mathrm{mg} / \mathrm{ml}$ and PAG/Cr was $0.13(0.01-1.45)$. PAG/Cr showed a weak positive correlation with age $(\rho=0.4122)$. PAG/Cr was significantly lower in the group with PMI within 24 hours than in the group within 10 days $(p=0.0258)$. There were no other significant differences. Urinary $\mathrm{Cr}$ concentrations were not significantly different for any of the analyses.

The distribution of PAG/Cr was observed by box-and-whisker plot. The third quartile (PAG/Cr 0.245) or higher was defined as abnormally high levels. PAG/Cr was abnormally high in 36 of 145 cases (25\%). So, we examined the causes of death in which the percentage of cases with abnormally high PAG/Cr was much greater than $25 \%$.

The PAG/Cr levels in central nervous system (CNS) disorder deaths (50\%), freezing deaths (55\%), and traumatic encephalopathy deaths (63\%), were frequently abnormally high. The PAG/Cr levels were high due to internal and external CNS disorders, and it was considered that the delay in intestinal peristalsis due to CNS disorders led to high levels of urinary PAG/Cr. Past studies of $p$-cresol in blood have also found high levels of $p$ cresol in cases of brain damage and deaths affecting gastrointestinal function. In freezing cases, it is possible that the high value was due to central nervous system damage caused by hypoxemia.

Conclusion: Urinary PAG/Cr may be a biomarker for CNS disorders.

Forensische Molekularbiologie P-FM-1 bis P-FM-7

\section{P-FM-1}

Forensic identification from mixed and dried blood spots using single-cell genomic technique

Yukiko Dozen, Yohei Miyake, Arisa Hayashi, Atsushi Nagai, Tomomi Michiue

Department of Legal Medicine, Graduate School of Medicine, Gifu University, Gifu, Japan

Objective: Forensic identification from mixed samples is one of the most important issues in the forensic science. We analyzed DNA types of a single leukocyte isolated from mixed and dried blood spots using single-cell genomic technique.

Materials and methods: We obtained peripheral blood from three Japanese volunteers, and made mixtures of the blood from two people in equal amounts, which was done similarly for three people. The blood spots of the mixtures were made on Petri-dishes and the blood spots were 
rehydrated with distilled water after been crushed by beads. Flow cytometry was used for isolating leukocytes from the rehydrated blood spots. The lymphocyte was fluorescently labeled using an anti-CD3 antibody and isolated using a Cell Sorter SH800 (Sony). DNA from every single isolated cell was amplified using the REPLI-g Single Cell Kit (Qiagen). After amplified DNA purification, 15 autosomal STRs and an amelogenin were amplified using the AmpFISTR Identifiler Plus PCR Amplification Kit (ABI), electrophoresed using the ABI PRISM 310 Genetic Analyzer (ABI), and the genotype was determined using GeneMapper ID v.3.2 (ABI).

Results and discussion: There were no lymphocyte samples in which all 16 loci were correctly detected. However, The DNA types of one of the two people were detected in 44 of 48 lymphocyte samples obtained from mixed blood spots of two people. The average percentages of correctly detected loci among all 16 loci were approximately $30 \%$, the maximum was approximately $75 \%$, and the minimum was approximately $6.3 \%$. The DNA types of one of the three people were also detected in 37 of $40 \mathrm{lym}$ phocyte samples obtained from mixed blood spots of three people. The average percentages of correctly detected loci among all 16 loci were approximately $26 \%$, the maximum was approximately $56 \%$, and the minimum was approximately $13 \%$. Even if the amount of blood is very small, the number of lymphocytes contained in it is huge, so we believe that it is possible to obtain samples with the nearly complete DNA profile using this technique.

Conclusion: These results suggest that single-cell genomic technique is an effective method for forensic identification from mixed blood spots.

\section{P-FM-2 \\ Geschickt kombiniert zum Ziel}

\section{Katja Anslinger, Birgit Bayer, Marta Diepenbroek}

Institut für Rechtsmedizin der Ludwig-Maximilians-Universität, München, Deutschland

Fragestellung: Die Gesetzesänderung des §81e der StPO ermöglicht den Strafverfolgungsbehörden in Deutschland seit Ende 2019 molekulargenetische Untersuchungen zur Vorhersage äußerlich sichtbarer Merkmale (konkret Augen-, Haar- und Hautfarbe) sowie des biologischen Alters eines Spurenverursachers zu beauftragen. In speziellen Fällen ist es im Freistaat Bayern darüber hinaus möglich, auch Untersuchungen zur biogeographischen Herkunft eines Spurenverursachers durchzuführen (Polizeiaufgabengesetz, Art. 32, Abs. 1, Ziffer 4). Erfahrungsgemäß existieren jedoch in einigen Fällen, in denen diese Analysen angefordert werden, nur Mischspuren. Mischspuren, aus denen das autosomale oder Y-chromosomale DNA-Profil einer fremden Person abgeleitet werden konnte, die aufgrund ihrer Komplexität bzw. Mischungsverhältnisse jedoch für die Phänotypisierung nicht geeignet sind. Was tun, wenn für eine erweiterte DNA-Analyse, die idealer Weise zum Erreichen einer größtmöglichen Vorhersagegenauigkeit an 1-Personen-Spuren durchgeführt wird, kein geeignetes Spurenmaterial zur Verfügung steht? Ein Weg aus der Misere wird an zwei Fallbeispielen aufgezeigt (Fall 1 - Altfall aus 1997: nur Vorhersagen von Augen-, Haar- und Hautfarbe; Fall 2 - aktuelles versuchtes Tötungsdelikt, incl. Vorhersage der biogeographischen Herkunft).

Methode: In beiden Fällen wurde die Präparation von Einzelpartikeln gezielt eingesetzt, um Reinspuren mit ausreichender DNA-Menge sowohl zur Durchführung einer individualisierenden STR-Analyse als auch für eine erweiterte DNA-Analyse zu erhalten. Die Vorhersagen erfolgten mithilfe des von uns entwickelten Customer Panels Ion AmpliSeq ${ }^{\text {TM }}$ PhenoTrivium und unter Verwendung der Converge ${ }^{\mathrm{Tm}}$ Software (beides ThermoFisher Scientific) bzw. des HIrisPlex-S-DNA-Phänotypisierungs-Webtool (jeweils in Doppelbestimmung).

Ergebnisse und Diskussion: Geeignete Einzelpartikel der jeweils gesuchten fremden Person konnten präpariert und daraus fast vollständige Konsensusprofile generiert werden (Fall 1: 39 der 41 HIrisPlex-S Marker; Fall 2: 39 der 41 HlrisPlex-S Marker und 161 der 163 autosomalen Abstammungsmarker bzw. 115 der 120 Y-chromosomaler Marker). Obwohl der erste Fall nur die Vorhersage des Phänotyps umfasste, waren die erhaltenen Ergebnisse sehr informativ, da die daraus resultierende Vorhersage (braune Au- gen, schwarze Haare und dunkle Haut) für Europäer unüblich ist. Der zweite Fall zeigte, dass der vorhergesagte Phänotyp (blaue Augen, hellbraunes Haar, blasse bis mittlere Haut) mit der vorhergesagten Abstammung (europäisch und Y-chromosomale Haplogruppe R-M269) übereinstimmt.

Fazit: Einmal mehr erweist die Technik der Einzelpartikelpräparation ihr enormes Potenzial zur Lösung fast unlösbarer Fälle.

\section{P-FM-3}

\section{Analysis of haplotype in mitochondrial DNA mixtures using LNA-mediated PCR clamping}

Masaru Asari', Yuta Takahashi', Chisato Hoshina', Katsuhiro Okuda', Kanae Mori', Ryo Namba², Keiko Shimizu'

'Department of Legal Medicine, Asahikawa Medical University, Asahikawa, Japan; ${ }^{2}$ Sapporo Higashi Tokushukai Hospital, Sapporo, Japan

Objective: Locked nucleic acid (LNA) has been widely used for various genetic analyses, and has many benefits, in terms of the specificity or sensitivity of amplification, because LNA-containing primers/probes form more stable duplexes with template DNA than probes lacking LNA. Here, we developed a new method for discriminating HV1 haplotypes from mitochondrial DNA (mtDNA) mixtures by applying PCR clamping using LNA. $P C R$ clamping is based on the selective inhibition of amplification using LNA-containing probes, which can discriminate single-nucleotide differences.

Method: We selected 171 sequences with single-nucleotide variations from the HV1 region, and evaluated the specificity of LNA-containing probes for them by predicting $\mathrm{Tm}$ values. Each probe targeted one or two variations (16209C, 16217C, 16257A/16261T, 16297C/16298C, 16304C, $16362 C$, or $16362 T$ ) that are particularly common in the Japanese population, and the specificity of each probe was analyzed using exactly matched and mismatched templates. We prepared mixed samples by mixing DNA from two individuals at a ratio of 1:9, 1:4, 1:1, 4:1, or 9:1, and then performed Sanger sequencing analysis after PCR clamping with each probe. This study was approved by the ethical committee of Asahikawa Medical University.

Results and discussion: The differences of Tm between mismatched and exactly matched probe-template duplexes depended on the type of LNA nucleotides for discriminating single-nucleotide differences, and the cytosine LNA nucleotide at the site of variations in the probes was most effective to discriminate these differences. Seven designed probes completely inhibited the amplification of exactly matched templates. Our method distinguished each haplotype at lower ratios from two-person mixtures. Moreover, we analyzed three-person mixtures with representative sequences, and detected the minor haplotype of one individual present at a rate of $10 \%$ by adding two selected probes.

Conclusion: The ability to discriminate haplotypes in mixed samples by using LNA-mediated PCR clamping indicates the potential value of $\mathrm{mtD}$ NA analysis.

\section{P-FM-4}

Quantitative Analyse von miRNA in Myokardinfarkten und plötzlichen Herztodesfällen in Blut und Gewebe

Mildeberger, Luise; Wilmes, Verena; Scheiper, Stefanie; Verhoff, Marcel A.; Kauferstein, Silke

Institut für Rechtsmedizin, Universitätsklinikum Frankfurt, Goethe-Universität, Frankfurt am Main, Deutschland

Fragestellung: MikroRNAs (miRNAs) sind kurze, nicht kodierende RNAs, die regulierend in viele biologische Prozesse eingreifen. Sie binden im Bereich des 3'UTR ihrer Ziel mRNA und können so entweder deren Translation inhibieren oder zu deren Abbau führen. MiRNAs stellen zurzeit einen der vielversprechendsten potenziellen Biomarker bei kardiovaskulären Erkrankungen dar. Im Fokus unserer Studie stand hierbei der Vergleich der 
Expressionsmuster in Myokardinfarkten (MI) und plötzlichen Herztodesfällen (sudden cardiac death =SCD), sowie zwischen Gewebe und zirkulierenden miRNAs.

Methode: Im Rahmen dieser Studie wurden die Expressionen von verschiedenen miRNAs in Herzgewebe und in Vollblut von MI und SCD relativ mittels q-RT-PCR unter Berücksichtigung der MIQE Richtlinien bestimmt. Ergebnisse: Erste Ergebnisse unserer Studie zeigten im Gewebe der SCD Fälle drei Gruppen mit jeweils niedrigen, mittleren und hohen Fold Change Werten der miRNA Expressionen. Darüber hinaus wurde eine signifikant erhöhte Expression von miR-1 und miR-133a im Blut von MI Proben im Vergleich zu den SCD Proben und zur Kontrollgruppe detektiert. Diskussion und Fazit: Vor allem die muskelspezifischen miRNAs miR-1 und miR-133a zeigten bereits Unterschiede in ihren Expressionen im Herzgewebe von MI und SCD. Unser Ergebnis deutet zum ersten Mal darauf hin, dass miRNAs auch im Blut zur Unterscheidung dieser beiden Krankheitsbilder geeignet sind. Die erhöhte Expression zirkulierender miRNAs bei MI könnte darüber hinaus ein weiterer Hinweis im Hinblick auf einen Mechanismus der interzellulären Kommunikation und Signaltransduktion bei miRNAs darstellen.

\section{P-FM-5}

\section{Robustness of Lactobacillus crispatus DNA-based vaginal fluid identification}

\author{
M. Ohmura', J. Ohta ${ }^{1,2}$ \\ ${ }^{1}$ Forensic Biology Unit, Scientific Crime Laboratory, Kanagawa Prefectural Police, Kana- \\ gawa, Japan,${ }^{2}$ Department of Forensic Dentistry, Graduate School of Medical and Dental \\ Sciences, Tokyo Medical and Dental University, Tokyo, Japan
}

Objective: Lactobacillus crispatus DNA-based vaginal fluid identification (VFID) is a useful approach for investigating sexual assaults. However, it has two main limitations: 1) The constituent bacteria of vaginal flora are affected due to the menstrual cycle, and vaginal fluid samples of various menstrual phases are collected for studying a case and 2) Semen-mixed vaginal fluid samples are handled using differential extraction protocols for human identification (HID) in a case, thereby increasing sample consumption. This study aimed to evaluate the robustness of $L$. crispatus DNAbased VFID using various menstrual phase samples and semen-mixed vaginal fluid samples.

Methods: Vaginal fluid samples were collected from a healthy female donor from two sites and four sampling periods of the menstrual cycle. $L$. crispatus DNA and total bacterial DNA were quantified by quantitative PCR. To normalize the analyzed samples, relative 165 rRNA copies were calculated by dividing the number of $L$. crispatus DNA copies to the total number of bacterial DNA copies. Semen-mixed vaginal fluid samples were treated using the differential extraction process. Both the DNA extracts of sperm and epithelial cell fractions were amplified using the GlobalFiler ${ }^{\mathrm{TM}}$ Kit and examined using L. crispatus DNA-based VFID.

Results: Relative $16 \mathrm{~S}$ rRNA copies of $L$. crispatus DNA were not significantly different between the vaginal fluid samples collected from two different sites (Student' $t$-test, $P=0.756$ ) as well as among samples collected in all phases of the menstrual cycle (Tukey HSD test, $P>0.05$ ). L. crispatus DNA was quantified from epithelial cell fraction, and male donor-derived DNA profiles were obtained from sperm fractions.

Discussion: Since the detection performance of $L$. crispatus DNA was found to be constant regardless of the sampling sites and menstrual phase, we consider that $L$. crispatus DNA is a robust VFID marker. Moreover, L. crispatus DNA-based VFID approach could be combined with HID approach for the analysis of semen-mixed vaginal fluid samples. These results suggest that $L$. crispatus DNA-based VFID is practical, as it can minimize sample utilization.
P-FM-6

\section{Characterization of nonfunctional alleles of FUT2 in a database}

Mikiko Soejima and Yoshiro Koda

Department of Forensic Medicine, Kurume University School of Medicine, Kurume, Japan

Objective: $\mathrm{ABO}$ blood typing has been used for personal identification in forensic medicine and criminal investigations since $A B O$ antigens are present not only on the surface of red blood cells but in body fluids in human. The FUT2 encodes the secretor type $a(1,2)$ fucosyltransferase that participates in synthesis of the $\mathrm{H}$ antigen, which is a precursor of $A$ and $B$ antigens, on the surface of mucosa or in secretions. Secretors express $A B O$ substrates in saliva and non-secretors do not. Many single nucleotide polymorphisms (SNPs) and copy number variations have been reported to show unique distributions among different populations.

Method: We selected 18 uncharacterized FUT2 alleles listed in the Erythrogene database and obtained genomic DNA having these alleles. Haplotyping was performed by subcloning into a plasmid. The activity of the encoded $a(1,2)$ fucosyltransferase was examined by flow cytometry of $\mathrm{H}$ antigen expressed. The impact of each nonsynonymous SNP on the enzyme was also estimated by software.

Result: We experimentally confirmed the haplotypes and 10 of 18 alleles disagreed with those in the database, while the existences of listed SNPs were completely confirmed in the indicated samples. We then examined the activity of the encoded enzyme for 13 alleles by $\mathrm{H}$ antigen expression and finally identified two non-secretor alleles $\left(s e^{610}\right.$ and $\left.s e^{357,856,863}\right)$ and one weak secretor allele $\left(s e^{262,357}\right)$, while in silico analysis predicted that many alleles impair the function.

Discussion: The observed discrepancy of haplotypes against database may be attributed to their low frequency. Although the software for prediction of the functional impacts of amino acid substitutions are valuable tools, these seemed to overestimate the effects of nonsynonymous SNPs in the FUT2. It is easy to clone the coding sequence or determine the haplotype of the coding polymorphisms because the sequence of the FUT2 is coded solely in exon 2.

Conclusion: The present results suggest that correct haplotyping and functional assays are desirable for analysis of the FUT2.

\section{P-FM-7}

\section{DNA methylation-based age prediction in the Japanese population by pyrosequencing analysis}

Yuta Takahashi' ${ }^{1}$, Masaru Asari ${ }^{1}$, Katsuhiro Okuda' ${ }^{1}$ Kanae Mori' ${ }^{1}$ Ryo Namba², Keiko Shimizu ${ }^{1}$

${ }^{1}$ Department of Legal Medicine, Asahikawa Medical University, Asahikawa, Japan; ${ }^{2}$ Sapporo Higashi Tokushukai Hospital, Sapporo, Japan

Objective: Age prediction based on DNA methylation levels has been reported as an informative method for forensic science because of the association of methylation levels with chronological age. However, large amounts of DNA (10-20 ng) are recommended for methylation analysis because of its low sensitivity. In this study, we investigated the correlation between age and methylation levels in the Japanese population. Additionally, the effects of multiplex PCR on the sensitivity and accuracy were analyzed.

Method: Buccal cells were collected from 75 healthy Japanese individuals. Genomic DNA was extracted and subjected to bisulfite conversion. Then, $10 \mathrm{ng}$ of the bisulfite-converted DNA was used for PCR amplification of 35 cycles for eight selected genomic regions as previously described for East Asian populations. The amplification reactions for the eight regions were performed independently. DNA methylation levels were measured by pyrosequencing analysis. The age predicted by multiple liner regression analysis was compared with the chronological age. For the multiplex $\mathrm{PCR}$, the same eight genomic regions were amplified simultaneously, and 
10 ng of DNA was used for multiplex PCR amplification of 10 cycles. Subsequent amplification and methylation detection were performed as described above. This study was approved by the ethics committee of Asahikawa Medical University.

Result: discussion and conclusion: A model composed of seven of the eight selected regions exhibited strong correlation between predicted and chronological age, with mean absolute deviation from chronological age of 3.54 years. Our results indicate that these seven regions can be used to predict chronological age in the Japanese population. Multiplex PCR affected the sensitivity and accuracy, and improved the sensitivity in many regions. However, the accuracy differed among the eight regions, probably because the sizes of their amplification products ranged 112-296 bp. Therefore, to correctly analyze methylation levels by multiplex PCR, it may be necessary to optimize the primers and sequences to be analyzed.

\section{Bildgebung/Identifikation}

$\mathrm{P}-\mathrm{Bl}-1$ bis P-BI-5

\section{P-Bl-1}

Analysis of cervical spine injury in autopsy cases, comparing before and after the installation of postmortem computed tomography

Yoriko Shinba ${ }^{1}$, Masahide Mitsuma ${ }^{1}$, Keita Shingu ${ }^{1}$, Yuki Abe ${ }^{1}$, Takehiko Murase ${ }^{1}$, Hiromi Yamashita ${ }^{2}$, Takahiro Umehara ${ }^{1}$, Kazuya Ikematsu ${ }^{1}$

'Department of Forensic Pathology and Science; 'Department of Forensic Dental Science, Graduate School of Biomedical Sciences, Nagasaki University, Nagasaki, Japan

Objective: Cervical spine injuries (CSI) are almost fatal in forensic cases, but difficult to diagnose only with external findings. Overlooking a cervical spine injury can lead to misdiagnose the cause of death with trauma. We started postmortem computed tomography (PMCT) in 2011. Since then, we have applied it to almost all corpses. With PMCT, some of CSI were diagnosed, but others were unable to detected and found only after autopsy. Therefore, we analyzed autopsy cases to clarify current status and problem to diagnose as CSI with PMCT.

Method: All autopsy cases of 2005 to 2010, and 2014 to 2019 were examined, and divided to 2 groups; before (2005 to 2010) and after (2014 to 2019) the installation of PMCT. Then, we compared the data of CSI. Additionally, we selected the cases of CSI after the installation, and analyzed whether the CSI could be pointed out with PMCT, a difference of CT scan method, the findings in forensic autopsy and so on.

Result \& Discussion: There were 389 autopsies in 6 years before and 932 in 6 years after the installation of PMCT. The rate of CSI increased; $1.03 \%$ (4 cases) before installation to $3.86 \%$ (36 cases) after it $(p<0.05)$. In 6 years after the installation, only 20 of 36 cases $(55.6 \%)$ were diagnosed as CSI with PMCT. We showed that PMCT was not sufficient to diagnose as CSI. We were able to point out CSI in 16 of 23 cases (69.6\%) with CT scan in the cervical extension position in addition to the usual PMCT scan method. Among the autopsy cases of all CSI, anterior dissection of cervical spine with injury of face or forehead was the most common, which was 24 of 36 cases $(66.7 \%)$. We had impression that cervical hyperextension might be the most common type of CSI.

Conclusion: In the cases with injury of face or forehead, it is necessary to perform PMCT with the cervical extension position.
P-BI-2

Eine Überprüfung der dentalen Methode von Roberts et al. aus dem Jahr 2016 zum Nachweis der Vollendung des 18. Lebensjahres

Maximilian Timme', Jens Borkert ${ }^{1}$, Laurin Steffens ${ }^{1}$, Denys Shay ${ }^{2}$, Andreas Schmeling ${ }^{1}$

'Institut für Rechtsmedizin, Universitätsklinikum Münster, Röntgenstraße 23, 48149 Münster, Deutschland; ${ }^{2}$ Institut für Epidemiologie und Sozialmedizin, Westfälische Wilhelms-Universität Münster, Domagkstraße 3, 48149 Münster, Deutschland

Einleitung: Im Jahr 2016 haben Roberts et al. eine neue zahnmedizinische Methode zum Nachweis der Vollendung des 18. Lebensjahres vorgestellt. Bei dieser Methode werden die Weiten der distalen Wurzelkanäle der Zähne 36, 37 und 38 [FDI] im Sinne einer Mustererkennung im Orthopantomogramm (OPG) visuell miteinander verglichen.

Methode: Für die gegenständliche Studie wurden 603 OPG von 300 Frauen und 303 Männern im Alter von 16 bis 25 Jahren untersucht. Die OPG stammten aus unterschiedlichen Abteilungen einer Universitätszahnklinik. Die OPG wurden von 3 Untersuchern ausgewertet, wobei ein Untersucher alle OPG in zwei unabhängigen Durchläufen ausgewertet hat. Abschließend wurde durch die 3 Untersucher eine konsensuale Bestimmung vorgenommen.

Ergebnisse: Insgesamt konnte konsensuell in nur 31 Fällen (11 Frauen, 20 Männer) überhaupt ein Stadium nach Roberts et al. zugeordnet werden. Zusätzlich war eine Auswertung in 38 weiteren Fällen grundsätzlich möglich, jedoch war der Befund nicht mit den Stadien nach Roberts et al. in Deckung zu bringen. Nichtauswertbarkeit war außerdem gegeben, wenn Zähne fehlten, die Zähne nicht vollständig entwickelt waren, oder die Zähne von Pathologien betroffen waren. Das Stadium RCW-C, welches nach Roberts et al. bei Frauen zum Nachweis der Vollendung des 18. Lebensjahres geeignet ist, konnte in der untersuchten Kohorte bei den Frauen konsensuell nicht nachgewiesen werden. Die Stadien RCW-B und RCW-C waren von Roberts et al. zum Nachweis der Vollendung des 18. Lebensjahres bei Männern beschrieben worden. Diese Stadien konnten bei den Männern insgesamt nur 4-mal $(3 \times \mathrm{RCW}-\mathrm{C}, 1 \times \mathrm{RCW}-\mathrm{B})$ nachgewiesen werden, wobei diese Personen deutlich über 18 Jahre alt waren. Der Cohens-Kappa für die Binnenbeobachterübereinstimmung lag im guten bzw. sehr guten Bereich (Frauen: 0,78; Männer: 0,88). Der Fleiss-Kappa für die Zwischenbeobachterübereinstimmung der 3 Untersucher lag im moderaten Bereich (Frauen: 0,49; Männer: 0,48).

Diskussion: Die grundsätzliche Eignung der Methode zum Nachweis der Volljährigkeit für Männer und Frauen wurde nicht widerlegt. Jedoch kann die Anwendung der Methode aktuell wegen der geringen Häufigkeit der tatsächlichen Anwendbarkeit nicht empfohlen werden. Außerdem scheint der Stadieneinteilung keine allgemeingültige Entwicklungsabfolge zu Grunde zu liegen, da sie oftmals nicht zu den vorliegenden Befunden passt. Zukünftig ist zu prüfen, ob die Herkunft der OPG aus einer Zahnklinik die Häufigkeit der Auswertbarkeit negativ beeinflusst hat.

\section{P-BI-3}

Die Bedeutung des Einflusses von sozioökonomischem Status und Ernährungsstatus auf die Skelett- und Zahnentwicklung im Rahmen der forensischen Altersschätzung

Maximilian Timme ${ }^{1}$, André Karch², Denys Shay ${ }^{2}$, Christian Ottow ${ }^{3}$, Andreas Schmeling ${ }^{1}$

'Institut für Rechtsmedizin, Universitätsklinikum Münster, Röntgenstraße 23, 48149Münster, Deutschland; '2Institut für Epidemiologie und Sozialmedizin, Westfälische Wilhelms-Universität Münster, Domagkstraße 3, 48149 Münster, Deutschland; ${ }^{3}$ Klinik für Radiologie, Universitätsklinikum Münster, Albert-Schweitzer-Campus 1, 48149 Münster, Deutschland 
Einleitung: Die forensische Altersschätzung kann ein wichtiges Hilfsmittel zur Durchführung rechtstaatlicher Verfahren sein. Bei der Altersschätzung wird die Entwicklung von Skelett- und Zahnmerkmalen einer Person mit Referenzdaten verglichen. Als mögliche Einflussfaktoren auf die Entwicklung sind der Ernährungsstatus und der sozioökonomische Status (SES) der zu begutachtenden Person von Bedeutung. Als Indikator für den Ernährungsstatus kann der Body-Mass-Index (BMI) herangezogen werden. Methode: Prospektiv wurde der Einfluss von BMI und SES auf die Skelettund Zahnentwicklung in einer deutschen Studienpopulation ermittelt. Dazu wurde die Entwicklung der medialen Epiphyse des Schlüsselbeins, der distalen Epiphyse des Radius, der distalen Epiphyse des Femur, der proximalen Epiphyse der Tibia und des linken unteren dritten Molaren bei 294 Frauen und 287 Männern im Alter von 12 bis 24 Jahren mittels 3-Tesla Magnetresonanztomographie (MRT) untersucht. Zusätzlich wurden der BMI und der SES der Studienteilnehmer erfasst.

Ergebnisse: Für alle untersuchten Merkmale und Kombinationen konnte keine Evidenz für einen Einfluss des SES festgestellt werden. Für den BMI waren die Ergebnisse differenzierter: in der univariablen Analyse war der BMI mit allen Merkmalen assoziiert (Beta zwischen 0,10 und $0,44 ; p<0,001)$. Bei Berücksichtigung des physiologischen Anstiegs des $\mathrm{BMI}$ mit zunehmendem Alter war der Effekt des BMI geringer und in der Mehrzahl der Modelle nicht mehr relevant - die Betas lagen bei Werten zwischen 0,00 und 0,05. Für einen gesamt Skelett-Status, welcher alle ossären Merkmale kombiniert, betrug das altersbereinigte Beta für Frauen $0,11(p=0,021)$ und für Männer $0,08(p=0,23)$. Niedrige Beta- und $r^{2}$-Werte $(0,00$ (adjustiert)- 0,16 (nicht-adjustiert)) waren in beiden Modellen für die Entwicklung der dritten Molaren zu ermitteln.

Für den SES kann davon ausgegangen werden, dass sich die Lebensumstände der Studienteilnehmer nicht ausreichend stark unterschieden, um einen Einfluss des SES auf die Skelett- und Zahnentwicklung darzustellen.

Für den BMI konnte kein bzw. nur geringer Einfluss auf die Entwicklung der untersuchten Systeme gefunden werden. Die Zahnentwicklung war bei beiden Geschlechtern völlig unabhängig vom BMI. Zahnmedizinische Methoden sollten daher Bestandteil jeder Altersschätzung sein.

\section{$\mathrm{P}-\mathrm{Bl}-4$}

\section{Die Bestimmung des Volumens der Zahnpulpa zur forensischen Altersschätzung: eine in-vitro Vergleichsstudie zwischen 9,4T-UTE-MRT und DVT:}

Maximilian Timme ${ }^{1}$, Jens Borkert ${ }^{1}$, Nina Nagelmann ${ }^{2}$, Adam Streeter $^{3}$, André Karch ${ }^{3}$, Andreas Schmeling ${ }^{1}$

'Institut für Rechtsmedizin, Universitätsklinikum Münster, Röntgenstraße 23, 48149 Münster, Deutschland; ${ }^{2}$ Experimentelle Magnetische Kernresonanz, Klinik für Radiologie, Universitätsklinikum Münster, Albert-Schweitzer-Campus 1, 48149 Münster, Deutschland; ${ }^{3}$ Institut für Epidemiologie und Sozialmedizin, Westfälische Wilhelms-Universität Münster, Domagkstraße 3, 48149 Münster, Deutschland

Einleitung: Die Fähigkeit eines Rechtsstaates das Alter von Personen nachzuweisen kann für die Durchführung rechtsstaatlicher Verfahren entscheidend sein. Zahnärztliche Merkmale können grundsätzlich zur Bestimmung des chronologischen Alters einer Person herangezogen werden. Die altersassoziierte Verkleinerung der Zahnpulpa ist ein entsprechendes Merkmal.

Methode: Wir evaluierten das Potenzial moderner Magnetresonanztomographie (MRT) zur dreidimensionalen Darstellung der Zahnpulpa im direkten Vergleich zur digitalen Volumentomographie (DVT). Wir untersuchten 32 extrahierte menschliche Zähne (Zahn 11-48 [FDI]) mittels 9,4-Tesla-UTE (ultrashort echo time) -MRT und DVT (Methoden). Die 3DRekonstruktion wurde sowohl durch manuelle als auch halbautomatische Segmentierung (Verfahren) für beide Methoden in zwei Durchläufen von einem Untersucher durchgeführt. Neun zufällig ausgewählte Zähne wurden außerdem von einem zweiten Untersucher mit beiden Methoden und Verfahren erneut untersucht. Statistisch wurde die Übereinstimmung zwischen den Untersuchern, den Methoden (MRT vs. DVT) und den Verfahren (manuell vs. halbautomatisch) ermittelt.
Ergebnisse: Mittels DVT konnte das Pulpavolumen aller Zähne bestimmt werden. Aufgrund von MRT-Artefakten war dies mittels MRT bei 2 Zähnen nicht möglich. Das mittels DVT bestimmte mittlere Pulpavolumen war bei größerer Streuungsbreite durchweg größer ( 43\%). Die Messungen mittels MRT zeigten eine größere Sensitivität für Unterschiede zwischen den Verfahren $(p=0,016)$ und zwischen den Untersuchern $(p=0,009)$. Es konnte kein signifikanter Unterschied zwischen ein- und mehrwurzeligen Zähnen festgestellt werden. Mit Blick auf die Zwischenbeobachterübereinstimmungen waren die ermittelten Pulpenvolumen gleich (ICC $>0,995$ ).

Diskussion: 9,4T-UTE-MRT eignet sich für den Einsatz zur Altersbestimmung mit guter Zuverlässigkeit und geringerer Schwankungsbreite im Vergleich zum DVT. Beim MRT ist aufgrund der detaillierteren Darstellung des Inneren der Pulpahöhle eine manuelle Segmentierung notwendig. Da mittels DVT eine vergleichsweise größere Darstellung des Pulpavolumens zu erwarten ist, sind methodenspezifische Referenzwerte für die praktische Altersbestimmung unerlässlich. Die Ergebnisse sollten in Zukunft unter in-vivo Bedingungen verifiziert werden.

\section{P-BI-5}

\section{Forensische Zahnmedizin: was ist das? Einblicke in eine interdisziplinäre Wissenschaft:}

Dr. med. Dr. med. dent. Claus Grundmann, Moers ${ }^{1,2}$

'Gesundheitsamt und Institut für Rechtsmedizin Duisburg; ${ }^{2}$ Arbeitskreis für Forensische Odontostomatologie (AKFOS)

Fragestellung: Die forensische Zahnmedizin betrifft die Grenzbereiche zwischen den Rechtswissenschaften, der Medizin und der Zahnmedizin. Aus diesem Grund wurde im Jahre 1976 anlässlich der 102. Jahrestagung der Deutschen Gesellschaft für Zahn-, Mund- und Kieferheilkunde (DGZMK) in Stuttgart der gemeinsame „Arbeitskreis Forensische OdontoStomatologie" der DGZMK und der Deutschen Gesellschaft für Rechtsmedizin (DGRM) gegründet.

Methode: In diesem Arbeitskreis sind Sachverständige vereint, die den Staatsanwaltschaften und Gerichten zahnmedizinische Sachverhalte interpretieren: sowohl im Zivil- als auch im Strafrecht.

Ergebnisse: Zu den Schwerpunkten der Tätigkeiten gehört die zahnärztliche Identifizierung: neben den DNA- und Fingerabdruckvergleichsuntersuchungen ist die dentale Identifizierung eine der drei anerkannten wissenschaftlichen Identifizierungsmethoden.

Zahnärztinnen und Zahnärzte sind unverzichtbar, wenn es um die forensische Altersbestimmung von Lebenden und Toten geht: neben den körperlichen und radiologischen Untersuchungen sind auch die dentalen Befunde von großer Bedeutung.: Die Zunahme häuslicher Gewalt in den letzten Jahren bzw. Jahrzehnten hat dazu geführt, dass auch Zahnärzte in der Lage sein sollten Verletzungen im Mund-, Kiefer- und Gesichtsbereich "gerichtsfest" zu dokumentieren.

Zusätzlich sollen sie auch in der Lage sein, Bissverletzungen (menschlicher oder tierischer Genese) sicher zu beurteilen, um im Extremfall dem Gericht die Möglichkeit zur Verurteilung des Verursachers zu geben.

Im Kontext von (Verkehrs-) Unfällen kann zahnärztliche Expertise ebenfalls erforderlich sein: um zu beurteilen, welche Zahnschäden unfallbedingt sind oder bereits vor dem traumatischen Ereignis existierten.

Diskussion: Wie in dieser kurzen Übersicht dargestellt, gibt es eine große Schnittmenge im Bereich Justiz, Medizin und Zahnmedizin. Selbstverständlich gehören hierzu auch das zahnärztliche Vertragsrecht und mögliche zahnärztliche Behandlungsfehler, worauf in einem gesonderten Vortrag einzugehen wäre.

Fazit: Es muss als bedauerlich angesehen werden, dass an den meisten Deutschen Zahnkliniken bisher nur geringe oder gar keine Grundlagen der forensischen Zahnmedizin gelehrt werden. 
Traumatologie Verkehr

P-TR-1 bis P-TR-7

\section{P-TR-1 \\ Bulbusruptur mit Orbitabodenfraktur - Sturz oder Stoß?}

\author{
L. Malolepszy, J. N. Wilk, R. Dettmeyer \\ Institut für Rechtsmedizin, Justus-Liebig-Universität Gießen
}

Einleitung: Eine Ruptur des Bulbus oculi nach penetrierender Gewalt von vorne, z. B. mittels Faustschlag, kommt gelegentlich vor, auch mit einer Orbitawandfraktur. Differentialdiagnostisch kann sich die Frage einer sturzbedingten Verletzung stellen. Die Rekonstruktion des Unfallmechanismus steht hierbei im Vordergrund.

Vorgeschichte: Eine Frau berichtete ihrer Freundin, ihr Partner habe beim Streit ihren Kopf gepackt und diesen mit dem linken Auge heftig gegen die Eckkante einer Küchenzeile gestoßen. Im Krankenhaus gab die Frau (BAK 1,53\%) ein Sturzgeschehen an. Zum Zeitpunkt der Verhandlung war die Geschädigte bereits verstorben, der Lebensgefährte gab an, seine Partnerin sei alkoholisiert gestürzt.

Befunde: Bei Einweisung in die Klinik zeigte sich ein Oberlidhämatom links, radiologisch eine Bulbusruptur sowie eine Fraktur des Orbitabodens links mit Blutung in den Sinus maxillaris. Keine anderweitigen Verletzungen.

Rechtsmedizinische Beurteilung: Rekonstruktiv lag ein Abstand zwischen Augenhöhe und Küchenzeile von ca. $60 \mathrm{~cm}$ vor, wenn die $175 \mathrm{~cm}$ große Frau auf die in $92,5 \mathrm{~cm}$ Höhe befindliche Eckkante gestürzt sein sollte. Das Verletzungsmuster setzt zudem einen nach vorn gebeugten Oberkörper voraus. Die geringe Sturzhöhe bei dynamischer Oberkörperbewegung müsste zu einer solchen Aufprallenergie führen, dass eine Bulbusruptur und eine Orbitabodenfraktur entstehen könnten. Die Eckkante bedeutet eine stumpf-punktuelle, in die Augenhöhle penetrierende Gewalt. Daher wäre hier eine Bulbusruptur eher zu erwarten, als bei einer flächenhaften stumpfen Gewalteinwirkung. Der auf den Bulbus oculi ausgeübte Druck von frontal mit einem Vektor nach okzipital muss derart intensiv gewesen sein, dass es zu einer Fraktur des papierdünnen Orbitabodens kommen konnte. Eine solche heftige Gewalt ist unproblematisch gegeben, wenn der Kopf der Frau mit dem linken Auge aktiv auf die Eckkante gestoßen wurde.

Fazit: Beide Varianten ließen sich nicht ausschließen. Die Abgrenzung eines Sturz- oder Schlaggeschehens gegenüber einem Stoßen nach unten erwies sich als schwierig. Die Umstände des Geschehens und das Verletzungsmuster sprachen mit überwiegender Wahrscheinlichkeit für ein gewaltsames Stoßen.

\section{P-TR-2 \\ Deaths caused by Single Stab Injuries to the Trunk - Homicide or Suicide?}

\footnotetext{
Maria Berg von Linde, MD 1,2, Carl Johan Wingren, MD, PhD 1,2

'Department of Forensic Medicine in Lund, Swedish National Board of Forensic Medicine, Sweden; ${ }^{2}$ The research group for forensic medicine, Department of clinical sciences Malmoe, Faculty of medicine, Lund university, Sweden
}

Question: Which variables differentiate between

Method: Using the Swedish forensic autopsy register we identified 75 homicides and 38 suicides that died between 2010 and 2019 following a single stab injury to the trunk. In these cases we extracted characteristics of the deceased/scene of death and findings during the autopsy. We applied logistic regression models to analyze associations between the characteristics and the manner of death (homicide/suicide) as estimated by the forensic pathologist.

Results: We identified a median age of 34 years respectively 51 years in victims of homicides and suicides, and both groups were dominated by males. We observed that an outdoor death scene was associated with homicides (OR 15.74, $95 \% \mathrm{Cl}$ 5.09-48.72). Furthermore, homicidal stab injuries to the thorax often engaged bone/cartilage (OR 4.34, $95 \% \mathrm{Cl} 1.71-$ 10.99). Homicide victims were to a larger extent influenced by alcohol compared to victims of suicide (OR $8.14,95 \% \mathrm{Cl} 2.85-23.7)$.

Discussion and conclusion: We report that a death scene located outdoors, injuries to bone/cartilage of the ribcage as well as findings of alcohol in the postmortem analysis were associated with homicides. From our findings we speculate that deaths caused by a single stab to the trunk are less common in homicides in a domestic setting. Our study covers information of all homicidal and suicidal single stab deaths in Sweden between 2010 and 2019, but still the study in some aspects suffers from low statistical power. We conclude that further research is needed based on larger case series, meta-analyses but also research that includes other approaches such as convictions in assessing the manner of death to reduce potential circular reasoning.

\section{P-TR-3}

\section{0-fache scharfe Gewalteinwirkung im Rahmen einer Suizidhandlung}

Janssen K, Zindler K, Grellner W

Abteilung Rechtsmedizin, Universitätsmedizin Göttingen, Robert-Koch-Str. 40, 37075 Göttingen, Deutschland

Einleitung: Suizide durch scharfe Gewalt stellen an sich keine Seltenheit dar. Ungewöhnlich ist indes eine hohe Zahl von Einzelverletzungen im dreistelligen Bereich, die den Verdacht einer Fremdeinwirkung wecken kann. Falldarstellung und Vorgeschichte: Eine 57-jährige Frau wurde von ihrem Ehemann beobachtet, wie sie aus einem Fenster im ersten Stock fiel. Am Vorfallsort wurde ein Brotmesser mit einschneidiger, gezahnter Klinge (Länge ca. $14 \mathrm{~cm}$, Breite bis $2 \mathrm{~cm}$ ) aufgefunden.

Obduktionsbefunde: Es fand sich eine multiple scharfe Gewalteinwirkung mit mindestens 250 abgrenzbaren Einzelbefunden (Hautdurchtrennungen, Anritzungen, Anstiche) in folgender Verteilung: Hals (mindestens 41), Brust- und Bauchregion (120, hier auch zahlreiche Textildurchtrennungen), rechter Unterarm (89). Die maximale Länge der Verletzungen betrug $6 \mathrm{~cm}$, die maximale Tiefe 7,5 cm, es kam zur dreifachen Bauchhöhleneröffnung mit Leberbeteiligung. Zahlreiche Einzelverletzungen wiesen die Merkmale Oberflächlichkeit, Parallelität und Gruppierung auf. Ferner zeigte sich als todesursächlicher Hauptbefund ein sturzbedingtes massives Schädelhirntrauma mit Impressionsbruch, Schädelbasisfraktur sowie Subdural- und Subarachnoidalblutungen. Zeichen eines wesentlichen Blutverlustes ergaben sich nicht.

Diskussion: Die mindestens 250-fache scharfe Gewalteinwirkung in suizidaler Absicht kann als Ausnahme angesehen werden, unseres Wissens wurde bislang über maximal 187 Einzelverletzungen berichtet. Die zugängliche Lokalisation bei Linkshändigkeit und die typischen morphologischen Zeichen einer Eigenbeibringung belegten eine suizidale Handlung, wobei das vorgefundene Tatwerkzeug geeignet erschien. Die Betroffene wurde bei der Tatbegehung durch ihren Ehemann gestört und wählte mit dem Fenstersprung offenbar spontan einen Wechsel der Suizidmethode im Sinne eines sekundär kombinierten Suizids. Dadurch kam es zu einer überholenden todesursächlichen Wirksamkeit der Schädel-Hirn-Verletzungen im Vergleich zu den potenziell ebenfalls tödlichen Stichwunden. Fazit: Eine durch Selbstbeibringung verursachte 250 -fache scharfe Gewalteinwirkung stellt eine rechtsmedizinische Rarität dar. Auch wenn diese im vorliegenden Fall nicht todesursächlich war, so wäre hierdurch dennoch die Möglichkeit eines letalen Ausgangs gegeben gewesen. 
P-TR-4

\section{Zur Größe der Schusslücke in Abhängigkeit von der Einschusslokalisation}

\section{Geisenberger' ${ }^{1}$, V. Thoma' ${ }^{1}$, S. Pollak', R. Braunwarth²,M. Große Perdekamp ${ }^{1}$}

'Institut für Rechtsmedizin des Universitätsklinikums Freiburg, Freiburg, Deutschland; ${ }^{2}$ Landeskriminalamt Baden-Württemberg, Kriminaltechnisches Institut, Stuttgart, Deutschland

Fragestellung: Neben dem Abstreifring, dem Kontusionsring und etwaigen Nahschusszeichen zählt der Hautsubstanzdefekt zu den typischen Merkmalen einer Einschusswunde. Bei der Untersuchung realer Schussverletzungen wurde wiederholt beobachtet, dass die Schusslücken an der Vorder- und Rückseite des Rumpfes auch bei Verwendung gleichartiger Munition unterschiedlich groß waren. Um dieser Frage nachzugehen, wurde Schweinehaut aus der Nacken- und Bauchregion beschossen.

Methode: Mit Vollmantel-Rundkopfgeschossen im Pistolen-Kaliber $9 \mathrm{~mm}$ wurden Testschüsse unter standardisierten Bedingungen abgegeben. Die Hautstücke aus Nacken- und Bauchregion wurden an der Oberfläche mit Hämalaun eingefärbt und hängend (Zugkraft ca. $10 \mathrm{~N}$ ) jeweils 10-mal beschossen. Die Einschüsse wurden mit Maßstab fotografisch dokumentiert und mit Hilfe eines Bildbearbeitungsprogramms vermessen.

Ergebnisse und Diskussion: Anhand der Testschüsse konnte gezeigt werden, dass in den vergleichend untersuchten Regionen auffällige Unterschiede der Durchmesser und damit auch der Flächen der Einschlusslücken bestanden. An der Nackenhaut mit der dort größeren Dicke des Coriums fanden sich durchweg kleinere Einschusslücken als an der Bauchhaut, die eine geringere Dicke der Lederhaut aufweist. Als Erklärung bietet sich die unterschiedliche Elastizität der Haut an der ventralen und dorsalen Oberfläche des Rumpfes an.

Fazit: Bei der Befundinterpretation sollte daher berücksichtigt werden, ob sich eine Einschusswunde an der Vorder- oder Rückseite des Rumpfes befindet.

\section{P-TR-5}

\section{Suicide by two gunshots in vital body parts}

\section{Alexey Maltsev, Anastasiya Mordanova}

Kirov State Medical University, Department of Forensic Medicine, Kirov State Institute of Forensic Medicine

Introduction: Identifying of the possibility of causing injuries by own self may be difficult in some situations. In our practice, there was a case of two gunshot wounds caused by own hand of person.

Materials. The dead body of man, 57 years old, was found in the woods. The hunting smooth-bore rifle was near the corpse. A note confirming the desire for suicide was found near the corpse. This case was witnessed by a taxi driver. The man with the rifle in his hands drove to the woods by taxi. Results: In an external examination of the body the entrance and exit gunshot wounds on the left part of thorax were found. Significant destruction of the left part of the head and an entrance gunshot wound in the region of the lower jaw were found. The following injuries to the chest organs were found in the autopsy: the ribs fractures, hemorrhage of the heart, hemorrhage and damage of the left lung. These damages in the area of one wound canal were located. The following head injuries were found: multiple fractures of skull bones, traumatic destruction and extraction of the left frontal, parietal and temporal lobes of brain substance. In a histological study of chest damages reactive changes indicating the formation within a few minutes before death were detected. In a study of head damage such changes were not detected.

Conclusion:. This case indicates the possibility of active action after the formation of gunshot wound to the chest with damages of the ribs, lung and heart. The man, after forming the severe chest injuries, was able to make a second shot to the head.
P-TR-6

\section{Kombinierte Suizide durch Schuss und Erhängen}

P Wolf' ${ }^{1}$, RB Dettmeyer ${ }^{1}$, CG Birngruber ${ }^{2}$

'Institut für Rechtsmedizin, Justus-Liebig-Universität, Universitätsklinikum Gießen und Marburg, Gießen/Deutschland; ' 2 Institut für Rechtsmedizin, Klinikum der Goethe-Universität, Frankfurt am Main/Deutschland

Einleitung.: Suizide sind nach Unfällen die in Deutschland zweithäufigste Ursache eines nicht-natürlichen Todes. Am häufigsten ist dabei der Tod durch Erhängen, gefolgt vom Schusswaffengebrauch. In der rechtsmedizinischen Literatur werden „einfache" von „kombinierten“ Suiziden unterschieden.

Material und Methoden.: Eine retrospektive Auswertung von am Institut für Rechtsmedizin Gießen untersuchten Schusstodesfällen erbrachte dre Suizide, bei denen Schuss und Strangulation als geplante kombinierte Suizidmethode angewandt wurden.

Falldarstellungen.: Fall 1:

Der Leichnam eines 66-Jährigen Karzinompatienten wurde mit einem Kopfdurchschuss in kniender Position an einem Baum hängend gefunden. Die Obduktion erbrachte einen Kopfdurchschuss, unverletzte Halsweichteile, keine Verletzungen des Zungenbeins oder Kehlkopfs und keine Stauungszeichen. Todesursächlich war ein Kopfdurchschuss.

Fall 2:

Ein 82-jähriger Unternehmer wurde mit zwei Einschüssen in der Brust, in freier Suspension hängend, in seiner Fabrikhalle gefunden. Die Obduktion ergab zwei Brustdurchschüsse mit Verletzungen von Herz und Lunge sowie eine unterblutete Strangmarke und Frakturen von Zungenbein und Kehlkopf ohne Stauungszeichen. Todesursächlich war eine Kombination aus Erhängen und den Schussverletzungen.

Fall 3:

Der Leichnam eines 88-jährigen Schmerzpatienten wurde in seinem Domizil neben einer Kleinkaliber-Langwaffe, mit einer Schlinge um den Hals, befestigt an einer aus der Wand gerissenen Aufhängung gefunden. Die Obduktion erbrachte einen tangentialen Schädeldurchschuss mit oberflächlicher Verletzung des Stirnhirns und eine unterblutete Strangmarke am Hals mit Frakturen von Zungenbein und Kehlkopf ohne Stauungszeichen. Todesursächlich war ein Erhängen.

Diskussion/Fazit.: Kombinierte Suizide stellen eine Seltenheit bei den rechtsmedizinisch untersuchten Suiziden dar, wobei die Kombination aus Schuss und Strangulation am häufigsten vorkommt. Obgleich derartige Fälle als kombinierte Suizide bezeichnet werden, liegt nicht immer auch eine kombinierte Todesursache vor.

\section{P-TR-7}

\section{Ophthalmologische und Forensische Tatsachen über Sehstärke}

Kazim Hilmi Or

Facharzt für Augenkrankheiten, Islandstraße 30. 22145 Hamburg. Deutschland

Fragestellung: Die Sehstärke als Sehleistung wird im alltäglichen Leben sowie forensisch als Schwellenwert angesehen, bei denen gewisse Spannweiten nach unten hin erlaubt werden. Die wissenschaftlichen augenärztlichen Erkenntnisse der letzten Jahrzehnte haben aber u. a. wissenschaftlich andere Messmethoden sowie höhere Schwellenwerte bei Sehstärke messen und feststellen lassen. Deshalb können Probleme entstehen.

Methode: Die Messmethode der Sehstärke und die verschiedenen sogenannten normalen Sehstärkenschwellen werden revidiert. Sie werden u. a. mit verschiedenen gesetzlichen Vorgaben verglichen.

Ergebnisse: Die Messung der Sehstärke ist in der Gesetzgebung mit Snellen Tafeln. Sie sind nicht logarithmisch. Das heißt wissenschaftlich, dass zwischen den gemessenen Zeilenwerten keine gleichmäßigen Abstände sind. Deshalb ist in allen internationalen wissenschaftlichen Arbeiten die Sehstärke mit logarithmischen ETDRS Tafeln zu messen und anzugeben. 


\section{Abstracts}

Da sind zwischen den einzelnen Mehrstufen der Sehstärke gleichmäßige Abstände. Klinisch wird aber weiter mit Snellen-Messtafeln Sehstärkenmessungen gemacht. Die Sehstärkenerkenntnisse der letzten Jahrzehnte sollten mit Gegebenheiten verglichen werden. Eine „normale Sehstärke" beträgt klinisch in Snellen Tafeln 1,0. Eine „ausreichende Sehstärke“ auf jedem Auge ist Straßenverkehrsordnung 0,7. Ein normaler Mensch hat aber eine durchschnittliche Sehstärke von 1,4. Manche Menschen mit bestimmten Augenaberrationen bzw. mit deren Korrektur durch Operationen („Adleraugen“) können sogar eine Sehstärke von 2,0 haben. Es gibt auf der Welt sogar Menschen die ohne Korrektur 2,2 sehen können. Physiologisch sieht ein normalsichtiger Mensch bei Sonnenlicht sogar 3,0. Diese Werte zeigen, daß z. B. viele Menschen, die Sehstärkeneinbußen haben hinnehmen müssen, forensisch als "normal" eingestuft werden können.

Diskussion: Die routinemäßige klinische Messmethode der Sehstärke ist wissenschaftlich nicht die optimale. Für prozentuale Angaben des Verlustes sollten Messungen mit ETDRS Tafeln gemacht oder entsprechend umgerechnet werden. Normale Menschen können besser sehen, als die routinemäßig gemessenen Schwellenhöchstwerte. Deshalb kann bei Sehverlusten das Ausmaß des Sehstärkenverlustes nicht richtig genug bestimmt werden.

Fazit: Es gibt eine Diskrepanz zwischen messbarer Höchstwerte in Sehstärke und forensischer Sehverlustbestimmung. Diese Diskrepanz soll evaluiert und gegebenenfalls verändert werden. 


\section{Autorenregister}

$\begin{array}{ll}\text { A } & \\ \text { Abe Y } & \text { P-Bl-1, P-KI-6, P-RM-15, } \\ & \text { P-RM-17, P-RM-22 } \\ \text { Aboutara N } & \text { V-TX-10, V-TX-6 } \\ \text { Abriani A } & \text { V-Bl-6 } \\ \text { Adamec J } & \text { V-TR-3, V-TR-4, V-TR-5 } \\ \text { Albers A } & \text { P-RM-25, V-BI-4 } \\ \text { Albrecht K } & \text { V-H-1 } \\ \text { Alissa S } & \text { P-RM-21 } \\ \text { Anders S } & \text { P-KI-2, V-KI-6, V-RM-7, V-TR- } \\ & 10 \\ \text { Andresen-Streichert H V-TX-2, V-TX-6 } \\ \text { Anslinger K } & \text { P-FM-2, V-FM-1, V-FM-4 } \\ \text { Aoki Y } & \text { P-RM-21, P-RM-24, P-RM- } \\ & \text { 26, P-RM-30, P-RM-37, } \\ & \text { P-RM-43 } \\ \text { Arora N } & \text { V-FM-5 } \\ \text { Arsenyan K A } & \text { P-RM-10 } \\ \text { Asari M } & \text { P-FM-3, P-FM-7, P-TX-9 } \\ \text { Ayako H H } & \text { P-TX-20 }\end{array}$

\section{B}

Bachynskyi V

Banaschak S

BärW

Bartel M

Baumann S

Baumgartner D

Bayer B

Bayer $R$

Becker J

Beckmann B M

Beike J

Berg von Linde $M$

Berger C

Berger $F$

Betz W

Birngruber C B

Bisharyan M S

Blum J

Bockholdt B

Bockholdt $P$

Bodammer $\mathrm{L}$

Böge B

Böhme $P$

Bojkova D

Bolliger $S$

Bondarev A

Bonilla-Virgen $\mathrm{R}$

Borkert J

Bormann C

Braunwarth $\mathrm{R}$

Brockmann C

Bruch G M

Büttner $A$

C

Cappel S

Carrillo-Núñez G

$\begin{array}{ll}\text { CHaas } & \text { V-FM-5 } \\ \text { Chizuko Sasaki } & \text { P-RM-14 } \\ \text { Ciesek S } & \text { V-RM-8 } \\ \text { Cinatl J } & \text { V-RM-8 }\end{array}$

\section{D}

$\begin{array}{ll}\text { Dacko M } & \text { P-TX-18 } \\ \text { Dahm P } & \text { V-TX-2 } \\ \text { Daldrup T } & \text { V-TX-12 } \\ \text { Davceva N } & \text { P-RM-38 } \\ \text { Debertin A S } & \text { V-KI-2 } \\ \text { Deigendesch N } & \text { P-RM-8 } \\ \text { Derani H } & \text { P-RM-18 } \\ \text { Dettmeyer R } & \text { P-RM-13, P-RM-27, P-TR-1, } \\ & \text { V-KI-5 } \\ \text { Dettmeyer R B } & \text { P-TR-6 } \\ \text { Diaconescu I } & \text { P-RM-5 } \\ \text { Diepenbroek M } & \text { P-FM-2, V-FM-4 } \\ \text { Dokter M } & \text { P-RM-28, V-FM-10, V-KI-3 } \\ \text { Dörr A A } & \text { P-TX-4, P-TX-10 } \\ \text { Dozen Y } & \text { P-FM-1 } \\ \text { Dreßler J } & \text { P-TX-14, V-TR-7, V-TX-5 } \\ \text { Dzengis J } & \text { P-RM-38 }\end{array}$

E

EShimada

Edler C

Ehrenfellner B P-RM-29

Eickhoff S V-FM-3

Eisenmenger W P-RM-16

Elsner K V-FM-9, V-TR-11

Engel $\mathrm{K} \quad \mathrm{V}-\mathrm{BI}-3$

Engelmann T A P-RM-25, P-RM-36, V-BI-4,

V-KI-2

Eppler M V-RM-5

Erath-Honold J V-RM-2

\section{$\mathrm{F}$}

Fangerau $\mathrm{H} \quad \mathrm{V}-\mathrm{RM}-13$

Feix-Berscheid M C P-TX-4

Feld D V-KI-7

Feld K V-KI-7, V-TX-2

Fels $\mathrm{H} \quad \mathrm{V}-\mathrm{TX}-7$

Fieguth A P-RM-25, P-RM-36

Fischer S V-BI-8

Fitzek A V-BI-5

Franz T V-TX-4

Freislederer A V-TR-8

Fujimiya T P-TX-20

Fujishiro M P-TX-15

Fujita $S \quad P-R M-30$

Fuke C P-RM-39, P-TX-13

Fukunaga $T \quad P-R M-2$

Furukawa F P-RM-11, P-RM-16, P-RM-

19, P-RM-23, P-RM-3, V-RM-

11

\section{G}

Garazdiuk M P-RM-7, V-RM-3

Garazdiuk O P-RM-7, V-RM-3

Gascho D V-BI-1

Geisenberger D P-TR-4
Germerott T

Gimbel S

Glemser P

Göbel J

Gonzalez M

Gotsmy W

Grabherr S

Gradhand E

Graw M

Grellner W

GroßTE

Große Perdekamp M P-TR-4

Groth $0 \quad$ V-TX-8

Gruber H V-TR-9

Grundmann C P-BI-5

Gündüz T V-FM-3

\begin{tabular}{|c|c|}
\hline $\mathrm{H}$ & \\
\hline Hagen D & P-RM-33 \\
\hline Hahnemann M & V-KI-7 \\
\hline Hara K & $\begin{array}{l}\text { P-RM-9, P-TX-12, P-TX-19, } \\
\text { P-TX-21 }\end{array}$ \\
\hline Hartmann C & P-RM-36 \\
\hline Hartung B & V-TX-12 \\
\hline Hartwig S & $\mathrm{V}-\mathrm{H}-1, \mathrm{~V}-\mathrm{H}-3$ \\
\hline Hasegawa C & P-TX-15 \\
\hline Hashimoto $\mathrm{M}$ & P-TX-15 \\
\hline Hashizume Y & P-RM-19, P-RM-23, P-RM-3 \\
\hline Hauck S M & V-RM-6 \\
\hline Hayashi A & P-FM-1 \\
\hline Heger A & V-FM-8 \\
\hline Heide S & P-TX-3 \\
\hline Heinemann A & V-BI-5 \\
\hline Heinrich F & V-TX-10 \\
\hline Heinze S & V-BI-4 \\
\hline Hellwinkel O J C & $\mathrm{P}-\mathrm{KI}-4$ \\
\hline Helmreich C & P-RM-1 \\
\hline Helmus J & V-KI-7 \\
\hline Hillebrand D & V-RM-2 \\
\hline Hirokawa T & $\begin{array}{l}\text { P-RM-21, P-RM-24, P-RM- } \\
\text { 26, P-RM-37, P-RM-43, } \\
\text { P-TX-11 }\end{array}$ \\
\hline Hitosugi M & P-RM-20, V-TR-12 \\
\hline Hochscheid C & V-KI-5 \\
\hline Hofer $P$ & V-TR-4, V-TR-5, \\
\hline Hoffmann E & V-KI-5 \\
\hline Hoffmann EHA & P-RM-27 \\
\hline Hofmann V & P-TX-17, V-TX-9 \\
\hline Hollenbach D & V-FM-7 \\
\hline Holz F & $\begin{array}{l}\text { P-RM-42, P-RM-6, V-BI-8, } \\
\text { V-RM-1, V-RM-4, V-RM-8, } \\
\text { V-TX-1 }\end{array}$ \\
\hline Hoshina C & P-FM-3 \\
\hline Hostiuc S & P-RM-5 \\
\hline Hurzlmeier C & V-TR-3 \\
\hline I & \\
\hline Ihama Y & P-TX-13, P-RM-39 \\
\hline Ikeda K & $\begin{array}{l}\text { P-RM-21, P-RM-24, P-RM- } \\
\text { 26, P-RM-37, P-TX-11 }\end{array}$ \\
\hline Ikeda T & $\begin{array}{l}\text { P-RM-21, P-RM-24, P-RM- } \\
\text { 26, P-RM-37, P-RM-43, } \\
\text { P-TX-11 }\end{array}$ \\
\hline
\end{tabular}

P-KI-5, P-RM-32, P-RM-41, V-FM-9, V-TR-11

P-RM-12

V-RM-1

P-RM-29, P-RM-33

V-BI-3 V-TR-4, V-TR-5, V-TX-8

P-RM-31, P-TR-3

P-RM-12

H

Hahnemann

Hartmann C P-RM-36

Hartung B V-TX-12

Hartwig S V-H-1, V-H-3

P-RM-19, P-RM-23, P-RM-3

Heinemann A

Helmus J V-KI-7

Hillebrand D $\quad$ V-RM-2

26, P-RM-37, P-RM-43,

P-TX-11

V-KI-5

, V-TR-5,

X-17, V-TX-9

P-RM-42, P-RM-6, V-BI-8,

V-RM-1, V-RM-4, V-RM-8, 


\begin{tabular}{|c|c|c|c|c|c|}
\hline Ikematsu K & $\begin{array}{l}\text { P-BI-1, P-KI-6, P-RM-15, } \\
\text { P-RM-17, P-RM-22 }\end{array}$ & Kondo T & $\begin{array}{l}\text { P-RM-11, P-RM-16, P-RM- } \\
\text { 19, P-RM-23, P-RM-3, V-RM- }\end{array}$ & Mitsuma M & $\begin{array}{l}\text { P-BI-1, P-KI-6, P-RM-15, } \\
\text { P-RM-17, P-RM-22 }\end{array}$ \\
\hline Ikematsu N & P-TX-21 & & 11 & Miura M & V-TX-13 \\
\hline Immel U D & V-FM-9 & König L & V-RM-13 & Miyaishi S & V-TX-13 \\
\hline Inoue $\mathrm{H}$ & P-RM-14 & Koop B E & V-FM-3 & Miyakawa K & P-RM-39 \\
\hline Inoue $\mathrm{K}$ & P-RM-2 & Kopetschke R & V-RM-2 & Miyake Y & P-FM-1 \\
\hline Irie W & P-RM-14 & Kottner S & V-BI-1 & Möbius D & V-BI-5 \\
\hline \multirow[t]{3}{*}{ Ishida Y } & P-RM-11, P-RM-16, P-RM- & Kozlowski J & V-BI-8 & Monticelli F & P-RM-29, P-RM-33, V-TR-4, \\
\hline & 19, P-RM-23, P-RM-3, V-RM- & Krämer T & V-FM-5 & & V-TR-5 \\
\hline & 11 & Krause V & V-BI-8 & Mordanova A & P-TR-5 \\
\hline \multirow[t]{2}{*}{ Ishigami A } & P-RM-11, P-RM-16, P-RM- & Krutzek A & V-TR-9 & Mori K & P-FM-3, P-FM-7, P-TX-9 \\
\hline & 19, P-RM-23, P-RM-3 & Kubo S & P-RM-9, P-TX-12, P-TX-19, & Morioka F & P-RM-21, P-RM-24, P-RM- \\
\hline \multirow[t]{3}{*}{ Ishikawa T } & P-RM-21, P-RM-24, P-RM- & & P-TX-21 & & 26, P-RM-43, P-TX-11 \\
\hline & 26, P-RM-37, P-RM-43, & Kumazawa T & P-TX-15 & Moriya F & V-TX-13 \\
\hline & P-TX-11 & Kumihashi M & P-TX-1 & Mückenberger K & V-BI-8 \\
\hline Ishino $\mathrm{K}$ & P-TX-16 & Kümmerli R & V-FM-5 & Muggenthaler $\mathrm{H}$ & $\mathrm{V}-\mathrm{KI}-7$ \\
\hline Ismaili Z & P-RM-4 & Kuninaka $\mathrm{H}$ & P-RM-39, P-TX-13 & Mukai M & P-RM-39, P-TX-13 \\
\hline Ivaskevich I & P-RM-34 & Kuninaka Y & P-RM-11, P-RM-16, P-RM- & Mukaida N & P-RM-19, V-RM-11 \\
\hline Ivceva A & P-RM-38 & & 19, P-RM-23, P-RM-3, V-RM- & Müller A & V-TX-10, V-TX-6 \\
\hline \multirow[t]{2}{*}{ Iwersen-Bergmann S } & V-TX-10, V-TX-6 & & 11 & Müller C & P-TX-14 \\
\hline & & Kunz S N & V-BI-6, V-TR-3 & Murakami K & P-RM-43 \\
\hline$J$ & & Küster M & V-TX-11 & Murase T & $\begin{array}{l}\text { P-BI-1, P-KI-6, P-RM-15, } \\
\text { P-RM-17, P-RM-2 }\end{array}$ \\
\hline Jamal M & P-TX-1 & & & Murck M & V-RM-4 \\
\hline Janke J & P-TX-5 & $\mathrm{L}$ & & Mußhoff F & P-RM-1, V-TX-3, V-TX-4, \\
\hline Jannermann M & P-KI-5 & Landmann A & V-KI-4 & & V-TX-7, V-TX-8 \\
\hline Janssen K & P-TR-3 & Lange T & P-TX-18 & & \\
\hline Jenewein T & P-RM-12, V-RM-2 & Lanzl F & V-TR-6 & & \\
\hline Jung $\mathrm{H}$ & V-BI-7 & Laschke M W & P-TX-10 & $\mathbf{N}$ & \\
\hline Jungen $\mathrm{H}$ & V-TX-10 & Lau M & V-TX-12 & Nagai A & P-FM-1 \\
\hline \multirow[t]{3}{*}{ Jungen $\mathrm{H}$} & V-TX-6 & Lenz C & P-RM-8,V-BI-2 & Nagato J & P-RM-14 \\
\hline & & Lessig R & V-TX-11 & Nagelmann $\mathrm{N}$ & P-BI-4 \\
\hline & & Lickert A & V-TR-2 & Nakamaru N & P-RM-14 \\
\hline K & & Lodwig A & V-RM-7 & Nakamura M & P-RM-20 \\
\hline Kanawaku Y & P-TX-16 & Löffler M L & P-KI-1 & Nakano R & P-TX-19 \\
\hline Kántor F & V-BI-8 & Lohner L & P-KI-2, P-KI-4 & Nakauchi A & P-TX-15 \\
\hline Karch A & P-BI-3, P-BI-4 & Löwisch G & V-TR-6 & Namba R & P-FM-3, P-FM-7, P-TX-9 \\
\hline Karger B & V-KI-7 & Lux C & V-TR-9 & Nasu A & P-RM-39, P-TX-13 \\
\hline \multirow[t]{2}{*}{ Kashiwagi M } & P-RM-9, P-TX-12, P-TX-19, & & & Naue J & V-FM-2 \\
\hline & P-TX-21 & & & Nentwig C & V-TR-3 \\
\hline \multirow[t]{2}{*}{ Kauferstein S } & P-FM-4, P-RM-12, V-FM-6, & M & & Niess C & P-RM-12, V-FM-6, V-RM-1 \\
\hline & V-RM-2 & Maatz R & V-TX-12 & Nigbur L & $\mathrm{P}-\mathrm{KI}-2$ \\
\hline \multirow[t]{2}{*}{ Kawaguchi M } & P-RM-11, P-RM-16, P-RM-3, & Madea B & $\mathrm{V}-\mathrm{H}-2$ & Nordmeier F & P-TX-10 \\
\hline & V-RM-11 & Maeda K & P-RM-39, P-TX-13 & Nosaka M & P-RM-11, P-RM-16, P-RM- \\
\hline Kera H & P-TX-13 & Mahlke NS & P-RM-35 & & 19, P-RM-23, P-RM-3, V-RM- \\
\hline Kern N & V-TR-9 & Makuch D & V-FM-7 & & 11 \\
\hline Kettering $\mathrm{K}$ & V-RM-2 & Malolepszy L & P-TR-1, V-KI-5, P-RM-27 & & \\
\hline \multirow[t]{2}{*}{ Kettner M } & P-RM-6, V-RM-2, V-RM-8, & Maltsev A & P-TR-5 & & \\
\hline & V-TR-9 & Manhart J & P-RM-18 & 0 & \\
\hline Khachatryan PS & P-RM-10 & Mann N & V-TR-11 & Obermayer A & P-RM-33 \\
\hline Kieliba T & V-TX-2 & Matsuki J & P-RM-11, P-RM-16, P-RM- & Ochiai E & P-RM-14 \\
\hline \multirow[t]{3}{*}{ Kimura A } & P-RM-11, P-RM-16, P-RM- & & 23, P-RM-3 & Ohlwärther T & $\mathrm{V}-\mathrm{KI}-5$ \\
\hline & 19, P-RM-23, P-RM-3, V-RM- & Matsusue A & P-RM-9, P-TX-12, P-TX-19, & Ohmura M & P-FM-5 \\
\hline & 11 & & P-TX-21 & Ohta J & P-FM-5 \\
\hline Kimura S & P-TX-1 & Matsuyama T & P-TX-15 & Okuda K & P-FM-3, P-FM-7, P-TX-9 \\
\hline Kinoshita $\mathrm{H}$ & P-TX-1 & Mayer F & V-FM-3 & Ondruschka B & P-KI-4, V-BI-5, V-RM-7, V-TR- \\
\hline Klasen C & P-KI-2 & Meiler J & P-TX-14, V-TX-5 & & $10, \mathrm{~V}-\mathrm{TR}-7$ \\
\hline Klee A & V-TX-2 & Meinhardt M & P-TX-3 & Operhalski F & V-RM-2 \\
\hline Klintschar M & P-RM-25, P-RM-36, V-BI-4 & Menger M D & P-TX-10 & Or KH & P-TR-7 \\
\hline Kniep I & V-BI-5 & Methling M & P-TX-2 & Osaki T & P-KI-6 \\
\hline Koçibelli M & P-RM-4 & Metzler K & P-TX-3 & Ott J & P-RM-28 \\
\hline Koda Y & P-FM-6 & Meyer M R & P-TX-10 & Ottow C & P-BI-3 \\
\hline Koelzer S C & P-RM-6, V-TX-1 & Michiue T & P-FM-1 & Ozaki M & P-RM-11, P-RM-16 \\
\hline Kolev Y G & P-TX-8 & Mikuláš L' & V-RM-12 & & \\
\hline \multirow[t]{2}{*}{ Kondo $\mathrm{M}$} & P-RM-14 & Mildeberger L & P-FM-4 & & \\
\hline & & Minohara S & P-TX-15 & & \\
\hline
\end{tabular}




\begin{tabular}{|c|c|c|c|c|c|}
\hline P & & SchulzI & V-TR-11 & Thali M J & V-BI-1, V-BI-9 \\
\hline Pădure A & P-KI-3, P-RM-40 & Schulz M M & V-BI-1 & Theofel N & P-TX-2, P-TX-5, P-TX-6 \\
\hline Pankratz H & V-RM-5 & Schulz S & P-RM-25 & Thierauf-Emberger A & P-TX-18, V-TR-2 \\
\hline Pavliukovych N & P-RM-7 & Schwarz C S & P-KI-5, P-RM-32, P-RM-41 & Thimm J & V-TX-9 \\
\hline Pavliukovych 0 & V-RM-3 & Schwarz M & V-TR-7 & Thimm J S & P-TX-17 \\
\hline Peldschus S & V-TR-6, V-TR-1 & Schweitzer W & V-BI-9 & Thoma V & P-TR-4, V-TR-2 \\
\hline Peters B & P-TX-4 & Schwender H & V-TX-12 & Timme M & P-BI-2, P-BI-3, P-BI-4 \\
\hline Petzel-Witt S & V-TX-1 & Seibt J & P-TX-3 & Toennes S W & P-RM-6, V-TX-1 \\
\hline Pfeiffer $\mathrm{H}$ & V-KI-7 & Seidl $M$ & P-RM-35 & Tojo M & P-RM-20 \\
\hline Philipp K P & V-FM-10, P-RM-28, V-KI-3 & Seifert $D$ & V-KI-6 & Tonoyan A A & P-RM-10 \\
\hline Philipp M & P-RM-18 & Serani E & P-RM-4 & Toporet N & $\mathrm{P}-\mathrm{KI}-3$ \\
\hline \multirow[t]{2}{*}{ Pittner S } & P-RM-29, P-RM-33, V-TR-4, & Seßler M & P-RM-1 & Tosevska-Trajkovska K & P-RM-38 \\
\hline & V-TR-5 & Shay D & P-BI-2, P-BI-3 & Trauer $\mathrm{H}$ & P-TX-14, V-TX-5 \\
\hline Plenzig S & V-RM-8 & Shida A & P-RM-24, P-RM-26, P-RM- & Trübner K & V-BI-7, V-TR-8 \\
\hline Pollak S & P-TR-4 & & 43, P-TX-11 & Tsiatsiuyeu A M & V-RM-10, V-RM-9 \\
\hline Popsor S & V-BI-7 & Shimada E & P-RM-11, P-RM-19, P-RM- & Tsokos M & P-TX-2, P-TX-5, P-TX-6 \\
\hline Potente S & P-TX-4 & & 23, P-RM-3, V-RM-11 & & \\
\hline Preuß-Wössner J & V-H-3, V-RM-6 & Shimizu K & P-FM-3, P-FM-7, P-TX-9 & & \\
\hline Prinz L & V-RM-5 & Shinba Y & P-KI-6, P-RM-15, P-RM-17, & U & \\
\hline \multirow[t]{2}{*}{ Püschel K } & \multirow[t]{2}{*}{ V-RM-7, V-TR-10, V-TX-13 } & & P-RM-22 & Uekusa K & P-TX-16 \\
\hline & & Shingu K & $\begin{array}{l}\text { P-RM-15,3 P-BI-1, P-KI-6, } \\
\text { P-RM-17, P-RM-22 }\end{array}$ & Umehara T & $\begin{array}{l}\text { P-BI-1, P-KI-6, P-RM-15, } \\
\text { P-RM-17, P-RM-22 }\end{array}$ \\
\hline $\mathbf{R}$ & & Siamionau V V & V-RM-10, V-RM-9 & Usumoto Y & P-RM-39, P-TX-13 \\
\hline Rabenau H F & V-RM-8 & Šidlo J & V-RM-12 & & \\
\hline Rahaus S & V-TX-8 & Šidlová H & V-RM-12 & & \\
\hline Reckert A & V-RM-13 & Šikuta J & V-RM-12 & V & \\
\hline Reich T & V-TR-9 & Simion S P & V-BI-7 & van Rüth V & V-TX-10 \\
\hline Reichenbach K & P-RM-18 & Sinamati A & P-RM-4 & Vanchuliak 0 & P-RM-34 \\
\hline Ricken T & $\mathrm{V}-\mathrm{KI}-7$ & Skopp G & V-TX-3, V-TX-4, V-TX-7 & Vejmelka E & P-TX-2, P-TX-5, P-TX-6 \\
\hline Riepert T & P-RM-32 & Soejima M & P-FM-6 & Verhoff M A & V-TR-9, P-RM-12, P-RM-6, \\
\hline \multirow[t]{2}{*}{ Ritz-Timme S } & P-RM-35, V-FM-3, V-FM-8, & \multicolumn{2}{|c|}{ Sosnowsky-Waschek N P-KI-1 } & & V-BI-8, V-FM-6, V-RM-2, \\
\hline & V-RM-13 & Sperhake J P & V-RM-6 & & V-RM-8 \\
\hline Roeber I & P-RM-31 & Steffens L & $\mathrm{P}-\mathrm{BI}-2$ & VerhoffS & P-FM-4 \\
\hline Roidou M & $\mathrm{V}-\mathrm{BI}-9$ & Steinbacher $P$ & P-RM-29 & Vorwieger M & $\mathrm{P}-\mathrm{KI}-4$ \\
\hline Ron A & V-BI-5, V-TR-10 & Steiner I & V-TX-12 & Vyshka G & P-RM-4 \\
\hline Rosenbaum F & P-TX-2, P-TX-6 & Steuer A & V-FM-5 & & \\
\hline \multirow[t]{3}{*}{ Rothschild M A } & \multirow[t]{3}{*}{ V-KI-1, P-RM-12, V-TX-2 } & Steurer S & V-BI-5 & & \\
\hline & & Stiller D & V-TX-11 & W & \\
\hline & & Stoiber W & P-RM-33 & Wagner W & V-FM-3 \\
\hline S & & Storf $\mathrm{H}$ & P-RM-12 & Walle $\mathrm{N}$ & P-TX-10, P-TX-4 \\
\hline Saigusa K & P-RM-30 & Stöttner B & V-TR-13 & Walz C & $\mathrm{P}-\mathrm{KI}-5$ \\
\hline Saito J & P-RM-14 & Streeter A & P-BI-4 & Walz F & V-TR-1 \\
\hline Sakamoto M & P-RM-14 & Stroh A & P-RM-12 & Wangerin S & P-TX-2, P-TX-5 \\
\hline Sarkisova Y & P-RM-34 & Strohbeck-Kühner $\mathrm{P}$ & V-TR-13 & Watanabe M & P-RM-43 \\
\hline Sato W & P-TX-13 & Sundermann T R & P-TX-17, P-TX-7, V-TX-9 & Waters B & P-RM-9, P-TX-12, P-TX-19, \\
\hline Satoh F & P-RM-14 & Swayambhu M & V-FM-5 & & P-TX-21 \\
\hline Sauer $P$ & V-TR-9 & Szewczyk A & V-TX-10, V-TX-6 & Weber A & V-KI-5 \\
\hline Schädler J & V-BI-5 & & & Weber M & V-TX-11 \\
\hline Schäfer N & P-TX-10, P-TX-4 & & & Welkerling S & V-TR-9 \\
\hline Schafmayer C & P-RM-18 & $\mathrm{T}$ & & Wiedfeld C & V-TX-3, V-TX-4 \\
\hline Scheiper V & P-FM-4 & Tabunscik M & P-RM-12 & Wieser M & V-BI-6 \\
\hline Scheiper-Welling S & P-RM-12, V-RM-1 & Takahashi Y & P-FM-3, P-FM-7, P-TX-9 & Wilk J N & P-TR-1 \\
\hline Schenkl S & $\mathrm{V}-\mathrm{KI}-7$ & Takamiya M & P-RM-30 & Wilmes L & P-FM-4 \\
\hline Scheurer E & P-RM-8, V-BI-2 & Takashima K & P-RM-20 & Wilmes S & V-KI-6 \\
\hline Schmeling A & $\mathrm{P}-\mathrm{BI}-2, \mathrm{P}-\mathrm{BI}-3, \mathrm{P}-\mathrm{BI}-4$ & Takaso M & V-TR-12 & Wilmes V & V-FM-6 \\
\hline Schmidt P & V-FM-7 & Takayama M & P-TX-21 & Windgassen $M$ & $\mathrm{~V}-\mathrm{H}-1$ \\
\hline Schmidt P H & P-TX-10, P-TX-4 & Takeda A & V-TR-12 & Wingren $C \mathrm{~J}$ & P-TR-2 \\
\hline Schmitt G & V-TX-9 & Takino M & P-TX-16 & Wittig $\mathrm{H}$ & P-RM-8 \\
\hline Schneider P M & P-RM-12 & Tanabe M & P-RM-39, P-TX-13 & Wittschieber D & V-KI-7 \\
\hline Schneider T & V-FM-5 & Tanaka E & P-TX-1 & Wojtanowski K & P-KI-1, V-Kl-4 \\
\hline Scholtis S & P-TX-2, P-TX-5, P-TX-6 & Tanaka M & P-RM-3 & Wolf $\mathrm{P}$ & P-TR-6 \\
\hline Schöpfer J & V-TR-4, V-TR-5 & Tani N & P-RM-21, P-RM-24, P-RM- & Wolter T & P-RM-13, V-KI-5 \\
\hline Schröder A S & V-RM-6, V-RM-7 & & 26, P-RM-37, P-RM-43, & Wörmann X & V-KI-6 \\
\hline Schröder M & V-RM-13 & & P-TX-11 & Wunder C & P-RM-6, V-BI-8, V-RM-2, \\
\hline Schrüfer A & P-RM-29 & Taniguchi K & V-TX-13 & & V-TX-1 \\
\hline Schuldis D & P-TX-18, V-TR-2 & Tank A & P-RM-35, V-TX-12 & Wünsch L & P-TX-14, V-TX-5 \\
\hline Schulte JE & $\mathrm{V}-\mathrm{BI}-8$ & Taruya A & P-RM-11 & & \\
\hline
\end{tabular}


Abstracts

$X$

Xhemali B P-RM-4

Y

Yamamoto $\mathrm{H} \quad$ P-RM-11, P-RM-16, P-RM-

19, P-RM-23, P-RM-3, V-RM-

11

Yamamoto T P-RM-15

YamaokaY P-RM-39

YamasakiY V-TX-13

Yamashita H P-BI-1, P-KI-6, P-RM-15,

P-RM-17, P-RM-22

Yamashita T P-TX-1

YAoki P-TX-11

Yen K P-KI-1, V-KI-4

Z

Zack F V-H-3

Zehner R V-BI-8

Zindler K P-RM-31, P-TR-3

Zinka B V-TX-8

Zissler A P-RM-29

Zosel C V-TX-5

Zube K V-TX-12 